Cochrane Database of Systematic Reviews

\title{
Acupuncture for stroke rehabilitation (Review)
}

Yang A, Wu HM, Tang JL, Xu L, Yang M, Liu GJ

Yang A, Wu HM, Tang JL, Xu L, Yang M, Liu GJ.

Acupuncture for stroke rehabilitation.

Cochrane Database of Systematic Reviews 2016, Issue 8. Art. No.: CD004131.

DOI: 10.1002/14651858.CD004131.pub3.

www.cochranelibrary.com 
TABLE OF CONTENTS

ABSTRACT

PLAIN LANGUAGE SUMMARY

SUMMARY OF FINDINGS

BACKGROUND

OBJECTIVES

METHODS

RESULTS

Figure 1.

Figure 2.

Figure 3.

Figure 4.

DISCUSSION

AUTHORS' CONCLUSIONS

ACKNOWLEDGEMENTS

REFERENCES

CHARACTERISTICS OF STUDIES

DATA AND ANALYSES

Analysis 1.1. Comparison 1 Acupuncture plus baseline treatment versus sham acupuncture plus baseline treatment, Outcome 1 Improvement of motor function.

Analysis 1.2. Comparison 1 Acupuncture plus baseline treatment versus sham acupuncture plus baseline treatment, Outcome 2 Improvement of cognitive function.

Analysis 1.3. Comparison 1 Acupuncture plus baseline treatment versus sham acupuncture plus baseline treatment, Outcome 3 Improvement of Health-Related Quality of Life (MOS SF-36).

Analysis 1.4. Comparison 1 Acupuncture plus baseline treatment versus sham acupuncture plus baseline treatment, Outcome 4 Improvement of Stroke-Specific Quality of Life(SS QOL).

Analysis 2.1. Comparison 2 Acupuncture plus baseline treatment versus baseline treatment alone, Outcome 1 Improvement of dependency at the end of treatment.

Analysis 2.2. Comparison 2 Acupuncture plus baseline treatment versus baseline treatment alone, Outcome 2 Improvement of dependency at the end of follow-up.

Analysis 2.3. Comparison 2 Acupuncture plus baseline treatment versus baseline treatment alone, Outcome 3 Improvement of global neurological deficit at the end of treatment.

Analysis 2.4. Comparison 2 Acupuncture plus baseline treatment versus baseline treatment alone, Outcome 4 Improvement of global neurological deficit at the end of follow-up.

Analysis 2.5. Comparison 2 Acupuncture plus baseline treatment versus baseline treatment alone, Outcome 5 Improvement of global neurological deficit at the end of treatment.

Analysis 2.6. Comparison 2 Acupuncture plus baseline treatment versus baseline treatment alone, Outcome 6 Improvement of motor function at the end of treatment.

Analysis 2.7. Comparison 2 Acupuncture plus baseline treatment versus baseline treatment alone, Outcome 7 Improvment of general motor function at the end of follow-up (Fugl-Meyer Assessment).

Analysis 2.8. Comparison 2 Acupuncture plus baseline treatment versus baseline treatment alone, Outcome 8 Improvement of motor function at the end of treatment (Fugl-Meyer Assessment).

Analysis 2.9. Comparison 2 Acupuncture plus baseline treatment versus baseline treatment alone, Outcome 9 Improvement of cognitive function at the end of treatment.

Analysis 2.10. Comparison 2 Acupuncture plus baseline treatment versus baseline treatment alone, Outcome 10 Improvment of cognitive function at the end of follow-up (MMSE).

Analysis 2.11. Comparison 2 Acupuncture plus baseline treatment versus baseline treatment alone, Outcome 11 Improvement of cognitive function at the end of treatment.

Analysis 2.12. Comparison 2 Acupuncture plus baseline treatment versus baseline treatment alone, Outcome 12 Improvement of depression at the end of treatment.

Analysis 2.13. Comparison 2 Acupuncture plus baseline treatment versus baseline treatment alone, Outcome 13 Improvement of depression at the end of treatment (HAMD).

Analysis 2.14. Comparison 2 Acupuncture plus baseline treatment versus baseline treatment alone, Outcome 14 Improvement of swallowing function at the end of treatment (Water drinking test). 
Analysis 2.15. Comparison 2 Acupuncture plus baseline treatment versus baseline treatment alone, Outcome 15 Improvement of swallowing function at the end of treatment (Water drinking test).

Analysis 2.16. Comparison 2 Acupuncture plus baseline treatment versus baseline treatment alone, Outcome 16 Improvement of pain at the end of treatment (Visual Analogue Scale).

Analysis 2.17. Comparison 2 Acupuncture plus baseline treatment versus baseline treatment alone, Outcome 17 Improvement of sleep quality at the end of treatment (Rhone Planck Sleepiness Scale).

Analysis 2.18. Comparison 2 Acupuncture plus baseline treatment versus baseline treatment alone, Outcome 18 Improvement of spasticity at the end of treatment (Modified Ashworth Spasticity Rating Scale).

Analysis 2.19. Comparison 2 Acupuncture plus baseline treatment versus baseline treatment alone, Outcome 19 Improvement of quality of life at the end of treatment (MOS SF-36).

APPENDICES

WHAT'S NEW

HISTORY

CONTRIBUTIONS OF AUTHORS

DECLARATIONS OF INTEREST

SOURCES OF SUPPORT

INDEX TERMS 
[Intervention Review]

\section{Acupuncture for stroke rehabilitation}

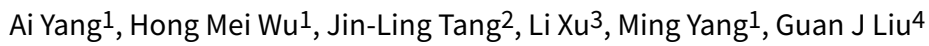

${ }^{1}$ Center of Geriatrics and Gerontology, West China Hospital, Sichuan University, Chengdu, China. 2Division of Epidemiology, The Jockey Club School of Public Health and Primary Care, The Chinese University of Hong Kong, Hong Kong SAR, China. ${ }^{3}$ Center of Health Care and Management, Hospital of Chengdu Office of People's Government of Tibetan Autonomous Region, Chengdu, China. ${ }^{4} \mathrm{Chinese}$ Cochrane Centre, Chinese Evidence-Based Medicine Centre, West China Hospital, Sichuan University, Chengdu, China

Contact: Hong Mei Wu, Center of Geriatrics and Gerontology, West China Hospital, Sichuan University, 37 Guo Xue street, Chengdu, China.drwhm@163.com,drwhm@126.com.

Editorial group: Cochrane Stroke Group.

Publication status and date: New search for studies and content updated (no change to conclusions), published in Issue 8, 2016.

Citation: Yang A, Wu HM, Tang JL, Xu L, Yang M, Liu GJ. Acupuncture for stroke rehabilitation. Cochrane Database of Systematic Reviews 2016, Issue 8. Art. No.: CD004131. DOI: 10.1002/14651858.CD004131.pub3.

Copyright @ 2016 The Cochrane Collaboration. Published by John Wiley \& Sons, Ltd.

\section{A B S T R A C T}

\section{Background}

Stroke is the second most common cause of death in the world and in China it has now become the main cause of death. It is also a main cause of adult disability and dependency. Acupuncture for stroke has been used in China for hundreds of years and is increasingly practiced in some Western countries. This is an update of the Cochrane review originally published in 2006 .

\section{Objectives}

To determine the efficacy and safety of acupuncture therapy in people with subacute and chronic stroke. We intended to test the following hypotheses: 1) acupuncture can reduce the risk of death or dependency in people with subacute and chronic stroke at the end of treatment and at follow-up; 2) acupuncture can improve neurological deficit and quality of life after treatment and at the end of follow-up; 3 ) acupuncture can reduce the number of people requiring institutional care; and 4) acupuncture is not associated with any intolerable adverse effects.

\section{Search methods}

We searched the Cochrane Stroke Group Trials Register (June 2015), the Cochrane Central Register of Controlled Trials (CENTRAL; Cochrane Library 2015, Issue 7), MEDLINE (1966 to July 2015, Ovid), EMBASE (1980 to July 2015, Ovid), CINAHL (1982 to July 2015, EBSCO), and AMED (1985 to July 2015, Ovid). We also searched the following four Chinese medical databases: China Biological Medicine Database (July 2015); Chinese Science and Technique Journals Database (July 2015); China National Infrastructure (July 2015), and Wan Fang database (July 2015).

\section{Selection criteria}

Truly randomised unconfounded clinical trials among people with ischaemic or haemorrhagic stroke, in the subacute or chronic stage, comparing acupuncture involving needling with placebo acupuncture, sham acupuncture, or no acupuncture.

\section{Data collection and analysis}

Two review authors independently selected trials for inclusion, assessed quality, extracted and cross-checked the data.

\section{Main results}

We included 31 trials with a total of 2257 participants in the subacute or chronic stages of stroke. The methodological quality of most of the included trials was not high. The quality of evidence for the main outcomes was low or very low based on the assessment by the system of Grades of Recommendation, Assessment, Development and Evaluation (GRADE). 
Two trials compared real acupuncture plus baseline treatment with sham acupuncture plus baseline treatment. There was no evidence of differences in the changes of motor function and quality of life between real acupuncture and sham acupuncture for people with stroke in the convalescent stage.

Twenty-nine trials compared acupuncture plus baseline treatment versus baseline treatment alone. Compared with no acupuncture, for people with stroke in the convalescent phase, acupuncture had beneficial effects on the improvement of dependency (activity of daily living) measured by Barthel Index (nine trials, 616 participants; mean difference (MD) 9.19, 95\% confidence interval (CI) 4.34 to 14.05; GRADE very low), global neurological deficiency (seven trials, 543 participants; odds ratio (OR) 3.89, 95\% $\mathrm{Cl} 1.78$ to 8.49 ; GRADE low), and specific neurological impairments including motor function measured by Fugl-Meyer Assessment (four trials, 245 participants; MD 6.16, 95\% Cl 4.20 to 8.11 ; GRADE low), cognitive function measured by the Mini-Mental State Examination (five trials, 278 participants; MD $2.54,95 \% \mathrm{Cl} 0.03$ to 5.05; GRADE very low), depression measured by the Hamilton Depression Scale (six trials, 552 participants; $\mathrm{MD}-2.58,95 \% \mathrm{Cl}-3.28$ to -1.87 ; GRADE very low), swallowing function measured by drinking test (two trials, 200 participants; MD $-1.11,95 \% \mathrm{Cl}-2.08$ to -0.14 ; GRADE very low), and pain measured by the Visual Analogue Scale (two trials, 118 participants; MD $-2.88,95 \% \mathrm{Cl}-3.68$ to -2.09 ; GRADE low). Sickness caused by acupuncture and intolerance of pain at acupoints were reported in a few participants with stroke in the acupuncture groups. No data on death, the proportion of people requiring institutional care or requiring extensive family support, and all-cause mortality were available in all included trials.

\section{Authors' conclusions}

From the available evidence, acupuncture may have beneficial effects on improving dependency, global neurological deficiency, and some specific neurological impairments for people with stroke in the convalescent stage, with no obvious serious adverse events. However, most included trials were of inadequate quality and size. There is, therefore, inadequate evidence to draw any conclusions about its routine use. Rigorously designed, randomised, multi-centre, large sample trials of acupuncture for stroke are needed to further assess its effects.

\section{PLAIN LANGUAGE SUMMARY}

\section{Acupuncture for stroke rehabilitation}

\section{Review question}

Acupuncture is a treatment based on ancient Chinese medicine in which fine needles or pressure is applied at certain sites in the body for therapeutic purposes. We wanted to know whether acupuncture is effective in improving the recovery of daily activities, movement, and quality of life in people who had experienced a stroke more than one month previously.

\section{Background}

Stroke is a major cause of death in the world and can also cause severe disability. Acupuncture is a relatively simple, inexpensive and safe treatment that has been used in China for hundreds of years and is increasingly practiced in some Western countries. However, it remains uncertain whether the existing evidence is sufficiently reliable to recommend the routine use of acupuncture.

\section{Study characteristics}

We identified 31 studies to July 2015 for inclusion in the review. These included a total of 2257 participants who had had a stroke more than one month previously. They all investigated acupuncture aimed at promoting recovery compared with no acupuncture or sham acupuncture. Outcomes included measures of daily activities (activities of daily living), neurological function, movement, cognition, depression, swallowing, pain, and quality of life. Most of the studies (29/31) were conducted in China; the studies varied considerably with respect to the time of stroke, specific techniques used, and the frequency of acupuncture.

\section{Key results}

We found some evidence that acupuncture improved activities of daily living and a number of aspects of neurological function. However, these conclusions were based on studies with low quality evidence. No serious side effects were reported and there was no information on the effects of acupuncture on death or the need for institutional care.

\section{Quality of the evidence}

It proved difficult to reliably determine the quality of the evidence because of poor reporting of study characteristics. Therefore, we have described most conclusions as having low or very low quality evidence. 


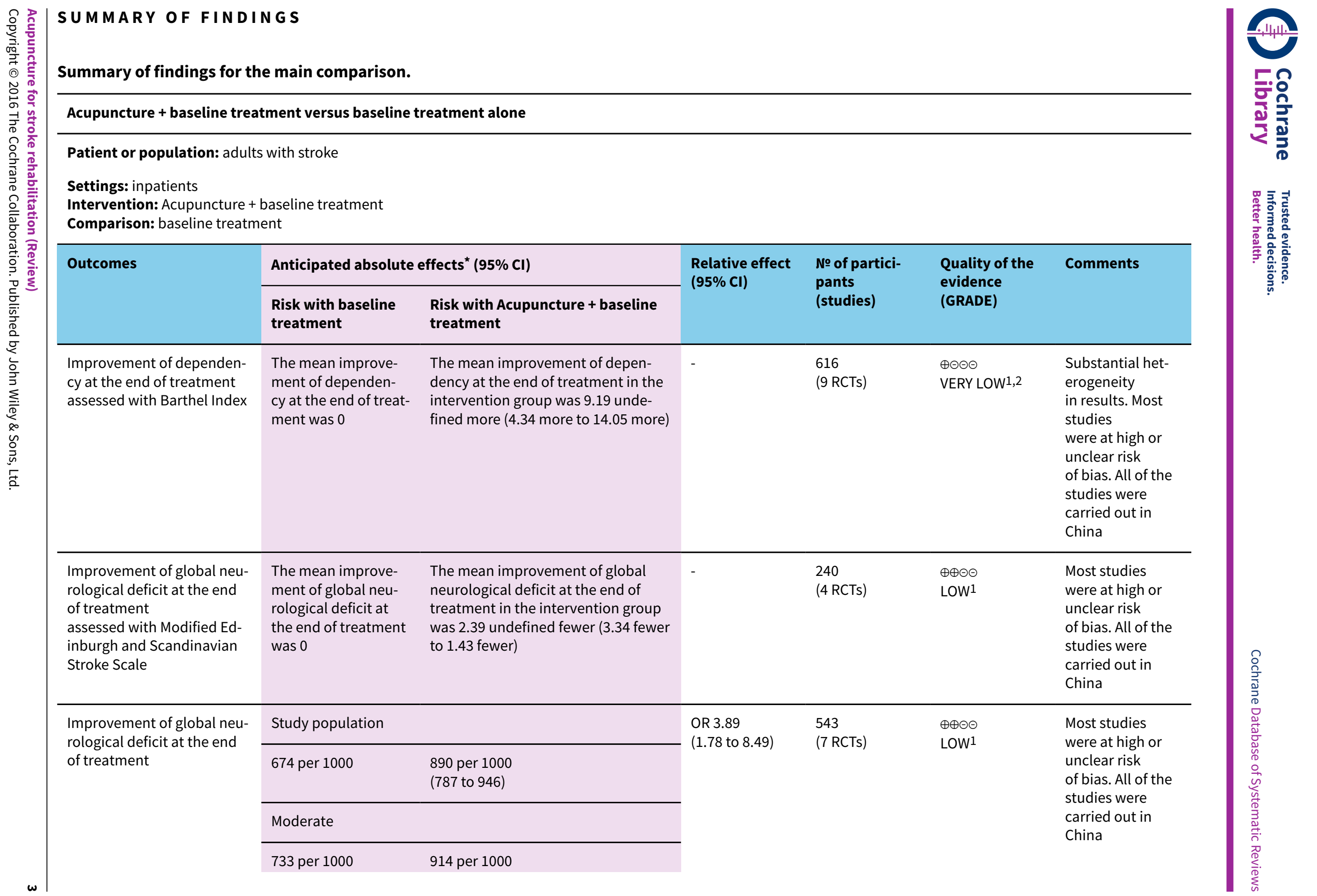




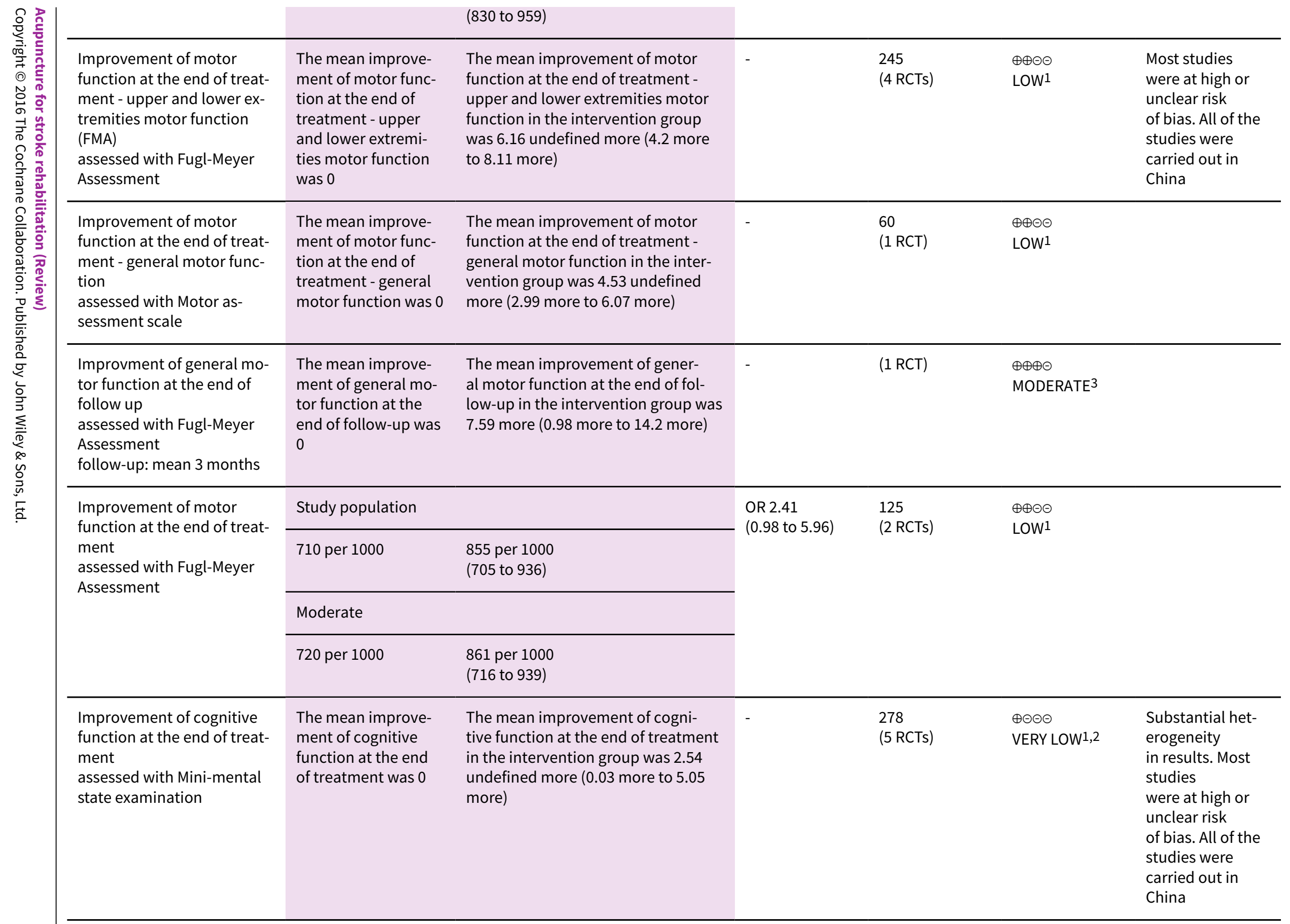




\begin{tabular}{|c|c|c|c|c|c|c|}
\hline 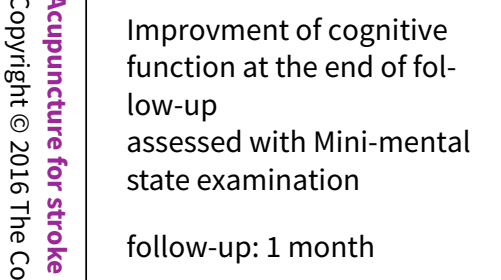 & $\begin{array}{l}\text { The mean improve- } \\
\text { ment of cognitive } \\
\text { function at the end } \\
\text { of follow up was } 0\end{array}$ & $\begin{array}{l}\text { The mean improvement of cogni- } \\
\text { tive function at the end of follow-up } \\
\text { in the intervention group was } 3.47 \\
\text { undefined more ( } 2.43 \text { more to } 4.51 \\
\text { more) }\end{array}$ & - & $\begin{array}{l}71 \\
(1 \mathrm{RCT})\end{array}$ & $\begin{array}{l}\oplus \oplus \ominus \ominus \\
\text { LOW1 }\end{array}$ & \\
\hline \multirow{4}{*}{$\begin{array}{l}\text { Improvement of cognitive } \\
\text { function at the end of treat- } \\
\text { ment } \\
\text { assessed with: Mini-mental } \\
\text { state examination }\end{array}$} & Study population & & \multirow{4}{*}{$\begin{array}{l}\text { OR } 3.82 \\
\text { (1.89 to } 7.72)\end{array}$} & \multirow{4}{*}{$\begin{array}{l}166 \\
\text { (3 RCTs) }\end{array}$} & \multirow{4}{*}{$\begin{array}{l}\oplus \oplus \odot \odot \\
\text { LOW1 }\end{array}$} & \\
\hline & 512 per 1000 & $\begin{array}{l}800 \text { per } 1000 \\
\text { (665 to } 890)\end{array}$ & & & & \\
\hline & \multicolumn{2}{|l|}{ Moderate } & & & & \\
\hline & 533 per 1000 & $\begin{array}{l}814 \text { per } 1000 \\
\text { (684 to } 898)\end{array}$ & & & & \\
\hline $\begin{array}{l}\text { Improvement of depression } \\
\text { at the end of treatment } \\
\text { assessed with Hamilton De- } \\
\text { pression Scale }\end{array}$ & $\begin{array}{l}\text { The mean improve- } \\
\text { ment of depression } \\
\text { at the end of treat- } \\
\text { ment was } 0\end{array}$ & $\begin{array}{l}\text { The mean improvement of depres- } \\
\text { sion at the end of treatment in the } \\
\text { intervention group was } 2.58 \text { unde- } \\
\text { fined fewer ( } 3.28 \text { fewer to } 1.87 \text { fewer) }\end{array}$ & - & $\begin{array}{l}552 \\
\text { (6 RCTs) }\end{array}$ & $\begin{array}{l}\oplus \odot \Theta \Theta \\
\text { VERY LOW } 1,2\end{array}$ & $\begin{array}{l}\text { Substantial het- } \\
\text { erogeneity } \\
\text { in results. Most } \\
\text { studies } \\
\text { were at high or } \\
\text { unclear risk } \\
\text { of bias. All of the } \\
\text { studies were } \\
\text { carried out in } \\
\text { China }\end{array}$ \\
\hline \multirow{4}{*}{$\begin{array}{l}\text { Improvement of depression } \\
\text { at the end of treatment } \\
\text { assessed with Hamilton De- } \\
\text { pression Scale }\end{array}$} & Study population & & \multirow{4}{*}{$\begin{array}{l}\text { OR } 2.03 \\
\text { (1.10 to } 3.72 \text { ) }\end{array}$} & \multirow{4}{*}{$\begin{array}{l}342 \\
\text { (4 RCTs) }\end{array}$} & \multirow{4}{*}{$\begin{array}{l}\oplus \oplus \ominus \ominus \\
\text { LOW1 }\end{array}$} & \multirow{4}{*}{$\begin{array}{l}\text { Most studies } \\
\text { were at high or } \\
\text { unclear risk } \\
\text { of bias. All of the } \\
\text { studies were } \\
\text { carried out in } \\
\text { China }\end{array}$} \\
\hline & 784 per 1000 & $\begin{array}{l}880 \text { per } 1000 \\
\text { (799 to } 931 \text { ) }\end{array}$ & & & & \\
\hline & Moderate & & & & & \\
\hline & 807 per 1000 & $\begin{array}{l}894 \text { per } 1000 \\
\text { (821 to } 939)\end{array}$ & & & & \\
\hline $\begin{array}{l}\text { Improvement of swallowing } \\
\text { function at the end of treat- } \\
\text { ment }\end{array}$ & $\begin{array}{l}\text { The mean improve- } \\
\text { ment of swallowing } \\
\text { function at the end } \\
\text { of treatment was } 0\end{array}$ & $\begin{array}{l}\text { The mean improvement of swallow- } \\
\text { ing function at the end of treatment } \\
\text { in the intervention group was } 1.11 \\
\text { undefined fewer ( } 2.08 \text { fewer to } 0.14 \\
\text { fewer) }\end{array}$ & - & $\begin{array}{l}200 \\
\text { (2 RCTs) }\end{array}$ & $\begin{array}{l}\oplus \ominus \ominus \ominus \\
\text { VERY LOW } 1,2\end{array}$ & \\
\hline
\end{tabular}




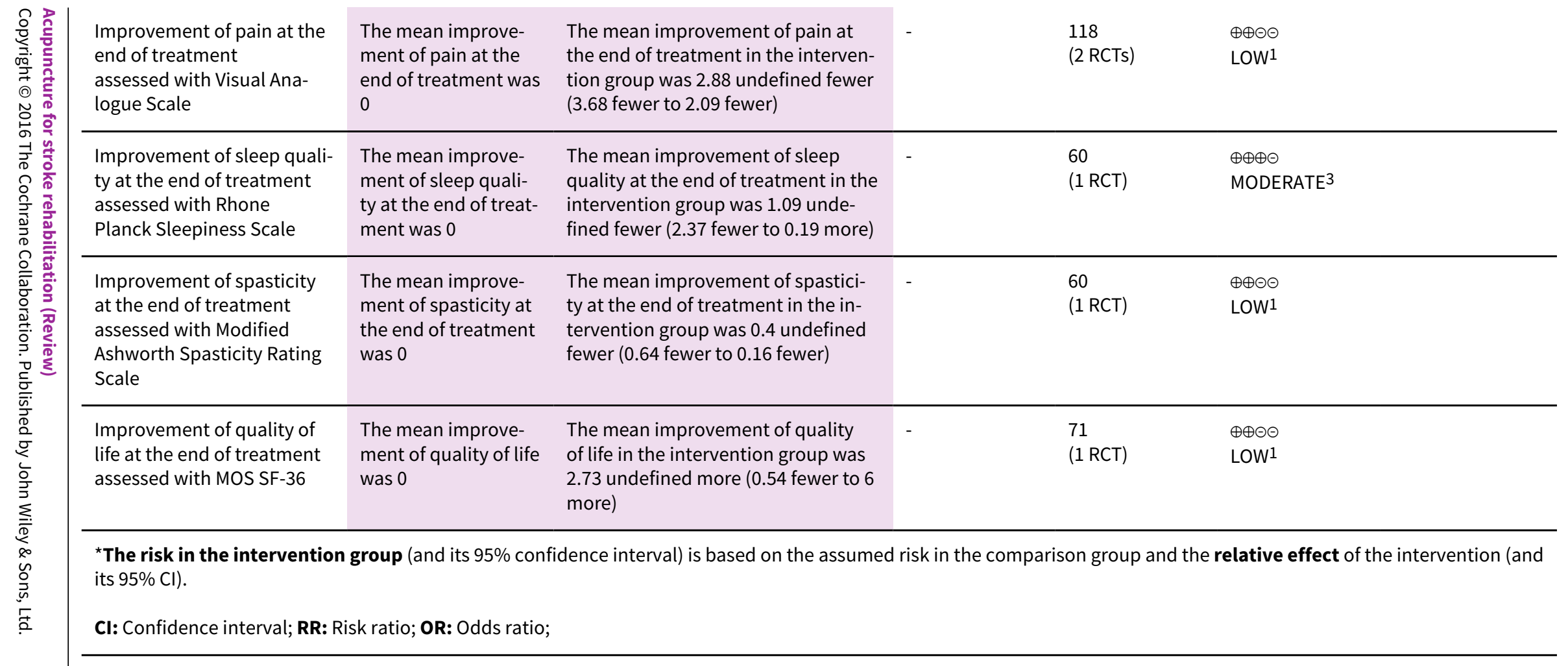

\section{GRADE Working Group grades of evidence}

High quality: We are very confident that the true effect lies close to that of the estimate of the effect

Moderate quality: We are moderately confident in the effect estimate: The true effect is likely to be close to the estimate of the effect, but there is a possibility that it is substantially different

Low quality: Our confidence in the effect estimate is limited: The true effect may be substantially different from the estimate of the effect

Very low quality: We have very little confidence in the effect estimate: The true effect is likely to be substantially different from the estimate of effect

1 Downgraded by two levels for very serious risk of bias (none of the trials used adequate allocation concealment, nor blinding of participants or researchers. Also, most of them were at risk of attrition bias).

2 Downgraded by one level for serious inconsistency (due to substantial heterogeneity, $\left.\right|^{2}=57 \%$ ).

3 Downgraded by one level for this trial did not use blinding of participants or researchers. 


\section{B A C K G R O U N D}

\section{Description of the condition}

Stroke is the second leading cause of death in the world (GBD2013 2015). In the USA, stroke accounted for about one of every 19 deaths in 2010. On average, someone dies of stroke every four minutes (Go 2014). In 2013, stroke has become the leading cause of death in cities and rural areas in China (GBD2013 2015). Although age-standardised rates of stroke mortality have decreased worldwide in the past two decades, the absolute numbers of people with first stroke (16.9 million), stroke survivors (33 million), stroke-related deaths (5.9 million), and disabilityadjusted life-years (DALYs) lost (102 million) in 2010 were still high and had significantly increased since 1990 (68\%, 84\%, $26 \%$, and $12 \%$ increase, respectively), imposing a great burden on families and communities in low-income and middle-income countries (Feigin 2014). Despite considerable research efforts on multiple treatment modalities, there is still no single rehabilitation intervention demonstrated unequivocally to aid recovery. This reality drives people to search for other modalities of treatment in an attempt to further improve the outcome of stroke rehabilitation, such as acupuncture and Chinese herbal medicine.

\section{Description of the intervention}

Acupuncture is one of the main modalities of treatment in traditional Chinese medicine and can be traced back more than 3000 years in China (Wu 1996). Being a relatively simple, inexpensive, and safe treatment compared with other conventional interventions, acupuncture has been well accepted by Chinese patients and is widely used to improve motor, sensation, speech, and other neurological functions in people with stroke. As a therapeutic intervention, acupuncture is also increasingly practiced in some Western countries (Hegyi 2012; Johansson 1993; NIH 1998; Salom-Moreno 2014; Schaechter 2007; Wayne 2005).

\section{How the intervention might work}

Many studies in animals and humans have demonstrated that acupuncture can cause multiple biological responses, including circulatory and biochemical effects. These responses can occur locally or close to the site of application, or at a distance. They are mediated mainly by sensory neurons to many structures within the central nervous system. This can lead to activation of pathways affecting various physiological systems in the brain as well as in the periphery (Jansen 1989; Johansson 1993; Magnusson 1994; Sun 2001; Wang 2001 ). In summary, possible mechanisms of the effects of acupuncture on neurological conditions include stimulation of neuronal cell proliferation (Cheng 2008), facilitation of neural plasticity (Ren 2008), reduction of the post-ischaemic inflammatory reaction (Liu 2009a), and prevention of neuronal apoptosis (Zhang 2008a).

\section{Why it is important to do this review}

There are a large number of studies of the clinical efficacy of acupuncture in stroke rehabilitation published in the world, especially in China, but not all demonstrate a beneficial effect on stroke rehabilitation (Hu 1993; Johansson 2001; Sun 2001; Sze 2002; Zhan 2014; Zhang 1996; Zhang 2015). Many systematic reviews of trials of acupuncture in stroke rehabilitation have been conducted (Ernst 1996; Hopwood 1996; Kong 2010; Li 2014; Park 2001; Smith 2002; Sze 2002; Wu 2010a). These reviews, however, included mainly trials with stroke patients in either the acute, or subacute, and chronic stages. Some reviews only focused on specific types of stroke (Liu 2005; Wang 2012a; Zheng 2011a), or needling (Dong 2013; Kim 2010; Zhou 2013), or neurologic deficits (Lim 2015; Long 2012; Liu 2014a; Park 2014; Qi 2009; Wong 2012; Zhang 2009a; Zhang 2012a; Zhang 2014a; Zhu 2011a). Knowing that a large number of clinical studies had been completed since this review was originally published in 2006 (Wu 2006), we aimed to conduct an up-to-date systematic review of publications regardless of subtype of stroke, or needling, or neurologic deficits.

The aim of this review was to systematically analyse all the randomised controlled trials of acupuncture for subacute and chronic stroke to provide the best available evidence to inform clinical practice and further research planning on stroke treatment.

\section{O B JECT IVES}

To determine the efficacy and safety of acupuncture therapy in people with subacute and chronic stroke. We intended to test the following hypotheses: 1) acupuncture can reduce the risk of death or dependency in people with subacute and chronic stroke at the end of treatment and at follow-up; 2) acupuncture can improve neurological deficit and quality of life after treatment and at the end of follow-up; 3) acupuncture can reduce the number of people requiring institutional care; and 4) acupuncture is not associated with any intolerable adverse effects.

\section{METHODS}

\section{Criteria for considering studies for this review}

\section{Types of studies}

In the review, we included randomised controlled clinical trials (RCTs) comparing acupuncture with at least one control group that used placebo, sham treatment, or conventional treatment in people with subacute (one to three months since onset) or chronic stroke (over three months since onset). We excluded trials using quasi-randomisation or the allocation of participants using alternation, case record numbers, dates of birth, day of the week, or controlled trials using any other non-random allocation methods.

\section{Types of participants}

Trials involving participants of any age or sex with ischaemic or haemorrhagic stroke in the subacute (one to three months since onset) or chronic phases (over three months since onset) were eligible. Stroke must have been diagnosed according to the World Health Organization definition (rapidly developed clinical signs of focal (or global) disturbances of cerebral function, lasting more than 24 hours or leading to death, with no other apparent cause than of vascular origin (Asplund 1988)), or confirmed by computerised tomography (CT), or magnetic resonance imaging (MRI). We did not include trials of participants with subarachnoid haemorrhage or subdural haematoma. We also excluded trials that included people in the acute phase of stroke (within one month since onset).

\section{Types of interventions}

We included trials evaluating acupuncture therapy that involved needling after stroke onset at the subacute or chronic phases, regardless of times of treatment or length of treatment period. We included either traditional acupuncture, in which the needles 
were inserted in classical meridian points, or contemporary acupuncture, in which the needles were inserted in non-meridian or trigger points, regardless of the source of stimulation (for example, hand or electrical stimulation). We excluded trials in which the acupuncture treatment did not involve needling, such as acupressure or laser acupuncture.

The control interventions were placebo acupuncture, sham acupuncture, or other conventional treatment. Placebo acupuncture refers to a needle attached to the skin surface (not penetrating the skin but at the same acupoints) (Van Tulder 2000). Sham acupuncture refers to:

1. a needle placed in an area close to but not in the acupuncture points (Van Tulder 2000);

2. subliminal skin electrostimulation via electrodes attached to the skin (SCSSS 1999).

The comparisons we investigated were:

1. acupuncture only compared with placebo or sham treatment;

2. acupuncture in addition to baseline medication or treatment compared with placebo or sham treatment in addition to baseline medication or treatment;

3. acupuncture in addition to baseline medication or treatment compared with baseline medication or treatment alone.

We excluded trials that compared different forms of acupuncture only and we also excluded trials reporting only physiological or laboratory parameters.

\section{Types of outcome measures}

We included trials that used at least one of the following outcome measures.

\section{Primary outcomes}

Death or dependency at the end of follow-up (at least three months or longer after stroke onset). We defined dependency as dependent on others in activities of daily living, based on the correlated definition of the Barthel scores (Activities of Daily Living, ADL) as a score of less than 60 or an Oxford handicap grade 3 to 6 (Sulter 1999), or the trialists' own definition.

\section{Secondary outcomes}

1. The proportion of people requiring institutional care or requiring extensive family support at the end of follow-up (at three months or longer after stroke onset). Family care is the main form of care for severely dependent people in developing countries.

2. Changes of neurological deficit after acupuncture treatment and at the end of follow-up (at three months or longer after stroke onset). The measures could focus on specific impairment (for example, Motricity Index, or Motor Assessment Scale, which assess only motor function), or global neurological deficit (for example, the National Institute of Health Stroke Scale, European Stroke Scale, the Scandinavian Stroke Scale) or two kinds of Chinese Stroke Recovery Scales, which involve motor, sensory and other impaired neurological functions. The Chinese Stroke Recovery Scale 1 (CSRS 1) refers to "the Revised Diagnostic Criteria of Acute Cerebral Infarction" formulated by the second National Academic Symposium on Cerebrovascular Diseases of the Chinese Medical Association in 1986, which is similar to the Revised Scandinavian Stroke Scale (RSSS). The Chinese Stroke Recovery Scale 2 (CSRS 2) refers to "the Chinese Stroke Recovery Scale based on principles of traditional Chinese medicine".

3. Death from any causes during the entire treatment and followup period.

4. Quality of life (QOL) at the end of follow-up (at three months or longer after stroke onset). This could be measured by the Nottingham Health Profiles or Spiter Quality of Life Index.

5. Possible adverse events including dizziness, difficulty in tolerating electrostimulation, infection, puncture of a lung, heart tamponades, spinal cord injury, disrupted pacemaker function; and presumed to be caused by acupuncture or electrostimulation. We evaluated the number of participants developing at least one severe adverse event listed above.

\section{Search methods for identification of studies}

See the 'Specialized register' section in the Cochrane Stroke Group module. We searched for all trials in all languages and arranged translation of relevant papers where necessary.

\section{Electronic searches}

\section{Original searches (2005)}

We initially obtained relevant trials from the following sources with no language restriction.

1. Cochrane Stroke Group Trials Register (November 2005).

2. Cochrane Central Register of Controlled Trials (CENTRAL) (Cochrane Library 2005, Issue 3).

3. MEDLINE (1966 to November 2005) combined with the Cochrane highly sensitive search strategy for identifying RCTs in MEDLINE (Dickersin 1994).

4. EMBASE (1980 to November 2005). Modified MEDLINE search and combined with the Cochrane highly sensitive search strategy for identifying RCTs in EMBASE (Lefebvre 1996).

5. Chinese Stroke Trials Register (November 2005).

6. Chinese Acupuncture Trials Register (November 2005).

7. Trials Register of the Cochrane Complementary Medicine Field (November 2005).

8. CINAHL (1982 to November 2005).

9. AMED (the Allied and Complementary Medicine Database, 1985 to November 2005).

10.Chinese Biological Medicine Database (CBM-disc, 1979 to November 2005).

11.National Center for Complementary and Alternative Medicine Register (http://nccam.nih.gov/clinical trials/) and National Institute of Health Clinical Trials Database (http:// clinicaltrials.gov) (searched November 2005).

\section{Review update (2015)}

We searched CENTRAL and the Cochrane Stroke Group Trials Register as above for new trials. We obtained relevant new trials from the following sources with no language restriction in the updated review.

1. Cochrane Stroke Group Trials Register (June 2015; Appendix 1).

2. Cochrane Central Register of Controlled Trials (CENTRAL; 2015, Issue 7) (Appendix 2). 
3. MEDLINE (July 2015; Ovid; Appendix 3).

4. EMBASE (July 2015; Ovid; Appendix 4).

5. CINAHL (July 2015; EBSCO;Appendix 5).

6. AMED (the Allied and Complementary Medicine Database, July 2015; Ovid; Appendix 6).

7. Chinese Biological Medicine Database (July 2015; Appendix 7).

8. Chinese Science and Technique Journals Database (to July 2015; Appendix 8).

9. China National Infrastructure (to July 2015; Appendix 9).

10.WanFang database (to July 2015; Appendix 10).

\section{Searching other resources}

\section{Original searches (2005)}

1. We handsearched four Chinese journals relevant to acupuncture (from 1980 to November 2005):

a. Acupuncture Research;

b. Chinese Acupuncture and Moxibustion;

c. Journal of Clinical Acupuncture and Moxibustion;

d. Shanghai Journal of Acupuncture and Moxibustion.

2. We checked the reference lists of all relevant papers identified, including two systematic reviews (Park 2001; Sze 2002), for further published and unpublished trials.

\section{Review update (2015)}

We searched the reference lists of all relevant papers identified.

\section{Data collection and analysis}

\section{Selection of studies}

Two review authors (AY, LX) independently checked the titles and abstracts of trials for inclusion based on the selection criteria outlined above. We retrieved the full text of the article if there was any doubt whether the article should be excluded or not. In cases of disagreement between the two review authors, a third member of the stroke research group (JLT or HMW) reviewed the information to decide on inclusion or exclusion of an article.

\section{Data extraction and management}

Two review authors (AY, L) independently extracted information on participants, methods, interventions, outcomes, and results by using a self-developed data extraction form. We translated studies not in English or Chinese before assessment. Where more than one publication for a study existed, we grouped reports together and we used the publication with the most complete data. Where relevant outcomes were only published in earlier versions, we used these data. We resolved disagreements by involving a third review author (JLT or HMW) or through discussion.

\section{Assessment of risk of bias in included studies}

We assessed the following items using the Cochrane risk of bias assessment tool (Higgins 2011a; Appendix 11).

1. Was there adequate sequence generation?

2. Was allocation adequately concealed?

3. Was knowledge of the allocated interventions adequately prevented during the study?

4. Were incomplete outcome data adequately addressed?
5. Are reports of the study free of suggestion of selective outcome reporting?

6. Was the study apparently free of other problems that could put it at a risk of bias?

Two review authors (AY, LX) independently assessed risk of bias; any disagreements were resolved by a third review author (JLT or HMW).

\section{Measures of treatment effect}

For dichotomous outcomes (e.g. death or dependency, adverse effects), we expressed the results as odds ratios (ORs) with 95\% confidence intervals (Cls). For continuous outcomes (e.g. quality of life), we used the mean difference (MD), or the standardised mean difference (SMD) if different scales were used.

\section{Assessment of heterogeneity}

We tested heterogeneity between trial results using a standard $\mathrm{Chi}^{2}$ test on $\mathrm{N}-1$ degrees of freedom, with a threshold value of $\mathrm{P}<0.1$, and with the $\mathrm{I}^{2}$ test (Higgins 2003). $\mathrm{I}^{2}$ values of $25 \%, 50 \%$ and $75 \%$ correspond to low, medium and high levels of heterogeneity.

\section{Assessment of reporting biases}

If we identified a sufficient number of studies, we planned to examine for potential publication bias using a funnel plot (Sterne 2011).

\section{Data synthesis}

We pooled data using the random-effects model but we also used the fixed-effect model to ensure robustness of the model chosen and susceptibility to outliers.

\section{Subgroup analysis and investigation of heterogeneity}

We planned to undertake subgroup analyses to explore possible sources of heterogeneity (e.g. participants, interventions, and study quality). Heterogeneity among participants could be related to the type and severity of stroke. Post-stroke neurological recovery is known to be obvious within three months, especially poststroke motor recovery, and is unlikely beyond six months, so heterogeneity in treatments could be related to times to start of treatment. Mixing patients with interval from stroke onset of less than three months, three to six months, and more than six months in one sample would make the assessment of the efficacy of an intervention methodologically unsound. If appropriate data were available, we planned a subgroup analysis to compare participants with different times to start of treatment (within three months, three to six months, and after six months) using the method outlined by Deeks 2001.

\section{Sensitivity analysis}

If appropriate data were available, we planned a sensitivity analysis to assess the effects of including only those trials:
1. that were double blind;
2. with adequate concealment of randomisation;
3. published in a language other than Chinese. 


\section{RES U LTS}

\section{Description of studies}

\section{Results of the search}

\section{6 version}

For the 2006 version of this review, we identified 6402 potentially relevant articles, retrieved 50 full-text articles, and included five trials with 368 participants (Dai 1997; Li 1997a; Lun 1999; Naeser 1992; Wang 2001).

\section{5 update}

For the update of this review, we identified 5874 potentially relevant articles from January 2005 to July 2015. Of these, we retrieved 371 full-text articles for further assessment and included 26 trials with 1889 participants (Bao 2012; Chou 2009; Gao 2014a; Guo 2011; Guo 2012; Huang 2008a; Ke 2015; Li 2010a; Li 2011a; Li 2013a; Liu 2013a; Sun 2013a; Sun 2015; Wang 2011a; Wang 2012; Wu 2008; Wu 2011a; Wu 2013a; Xu 2013; Yao 2014; Zhan 2014; Zhang 2013a; Zhang 2015; Zheng 2014; Zhou 2014; Zhu 2007). There are four relevant ongoing studies (Fu 2011; Liu 2013b; Xie 2006; Zhong 2010; Characteristics of ongoing studies). In total, we have included 31 trials in this updated review. Results of the search are displayed in Figure 1. 
Figure 1. Study flow diagram.

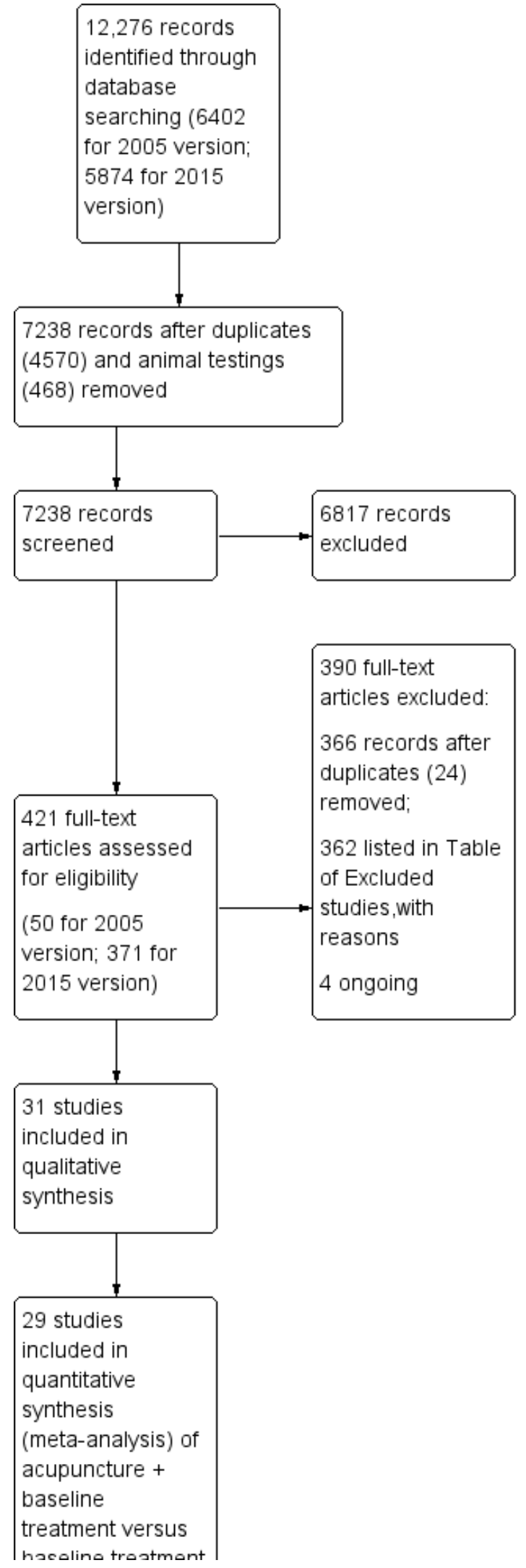


Figure 1. (Continued)

treatment versus baseline treatment

\section{Included studies}

A total of 31 trials were eligible for inclusion in this systematic review. For details of each included trial please see the Characteristics of included studies table.

\section{Participants}

Of the 31 included trials, 29 were conducted in China, one in the UK, and one in the USA.

The age of participants ranged from 24 to 95 years. More men than women were included in 23 trials (between $47 \%$ and $75 \%$ men) (Bao 2012; Dai 1997; Guo 2011; Guo 2012; Huang 2008a; Ke 2015; Li 2010a; Li 2011a; Liu 2013a; Lun 1999; Sun 2013a; Wang 2001; Wang 2011a; Wang 2012; Wu 2008; Wu 2011a; Yao 2014; Zhan 2014; Zhang 2013a; Zhang 2015; Zheng 2014; Zhou 2014; Zhu 2007). Three trials did not describe the gender of the participants (Li 1997a; Li 2013a Naeser 1992). The range of time from stroke onset was from one month to 8.5 years.

There were five trials involving participants with interval from stroke onset between one to three months (Huang 2008a; Li 2013a; Naeser 1992; Wu 2013a; Zhou 2014), 10 trials more than three months (Dai 1997; Bao 2012; Chou 2009; Gao 2014a; Guo 2012; Li 2011a; Liu 2013a; Sun 2013a; Sun 2015; Zhang 2013a), and 16 trials including participants with interval from stroke onset of either less than three months or more than three months (Guo 2011; Ke 2015; Li 1997a; Li 2010a; Lun 1999; Wang 2001; Wang 2011a; Wang 2012; Wu 2008; Wu 2011a; Xu 2013; Yao 2014; Zhan 2014; Zhang 2015; Zheng 2014; Zhu 2007).

Seven trials included participants with ischaemic stroke only (Dai 1997; Bao 2012; Huang 2008a; Naeser 1992; Wu 2011a; Zhang 2015; Zhou 2014). Five trials did not describe the type of stroke (Guo 2012; Li 2011a; Sun 2015; Xu 2013; Zhan 2014). All other trials included participants with ischaemic and haemorrhagic stroke (Chou 2009; Gao 2014a; Guo 2011; Ke 2015; Li 1997a; Li 2010a; Li 2013a; Liu 2013a; Lun 1999; Sun 2013a; Wang 2001; Wang 2011a; Wang 2012; Wu 2008; Wu 2013a; Yao 2014; Zhang 2013a; Zheng 2014; Zhu 2007). All of the included trials used CT or MRI to confirm the diagnosis of stroke. The severity on entry was mild to severe in two trials (Dai 1997; Naeser 1992), without a definition of severity or not stated in the remaining 29 trials (Bao 2012; Chou 2009; Gao 2014a; Guo 2011; Guo 2012; Huang 2008a; Ke 2015; Li 1997a; Li 2010a; Li 2011a; Li 2013a; Liu 2013a; Lun 1999; Sun 2013a; Sun 2015; Wang 2001; Wang 2011a; Wang 2012; Wu 2008; Wu 2011a; Wu 2013a; Xu 2013; Yao 2014; Zhan 2014; Zhang 2013a; Zhang 2015; Zheng 2014; Zhou 2014; Zhu 2007).

\section{Interventions}

Two trials compared real acupuncture plus baseline treatment with sham acupuncture plus baseline treatment (Chou 2009; Naeser 1992); the remaining 29 trials compared acupuncture plus baseline medication or treatment with baseline medication or treatment alone. None of the trials compared acupuncture only with placebo or sham treatment.
Among the included trials there were 10 three-armed trials (Dai 1997; Guo 2011; Huang 2008a; Li 1997a; Li 2013a; Sun 2015; Wang 2001; Wu 2013a; Zhang 2013a; Zhang 2015) and one four-armed trial (Wu 2008) comparing acupuncture plus baseline medication or treatment with baseline medication treatment alone, one kind of acupuncture with another kind of acupuncture, or acupuncture only with other treatment. In this review, the baseline medication or treatment included Western medicine (WM), traditional Chinese medicine (TCM), non-pharmacological therapy, or a combination. WM included aspirin and other conventional drug therapies.

With one exception (Chou 2009), none of the other 30 included trials reported the acupuncture rationale or acupuncturists' background, including duration of relevant training, length of clinical experience and expertise in the specific condition. The acupuncture interventions used varied considerably across trials. Nineteen trials used only manual stimulation (Bao 2012; Dai 1997; Gao 2014a; Guo 2012; Huang 2008a; Ke 2015; Li 1997a; Li 2011a; Li 2013a; Lun 1999; Wang 2001; Wang 2011a; Wang 2012; Wu 2008; Wu 2013a; Xu 2013; Zhan 2014; Zhang 2015; Zheng 2014), four used only electrical stimulation (Chou 2009; Naeser 1992; Sun 2015; Wu 2011a), and eight used the combination of manual and electrical stimulation (Guo 2011; Li 2010a; Liu 2013a; Sun 2013a; Yao 2014; Zhang 2013a; Zhou 2014; Zhu 2007). Acupuncture point prescriptions were not consistent, with 15 trials involving either scalp or body acupoints (Chou 2009; Guo 2012; Huang 2008a; Ke 2015; Li 2011a; Li 2013a; Liu 2013a; Lun 1999; Wang 2001; Wang 2011a; Wang 2012; Wu 2013a; Zhan 2014; Zhang 2013a; Zhang 2015), and 16 trials using both body and scalp acupoints (Bao 2012; Dai 1997; Gao 2014a; Guo 2011; Li 1997a; Li 2010a; Naeser 1992; Sun 2013a; Sun 2015; Wu 2008; Wu 2011a; Xu 2013; Yao 2014; Zheng 2014; Zhou 2014; Zhu 2007). Numbers of points used ranged from one to 27 points in all included trials. The needle retention time was 15 to 40 minutes in all included trials. Thirteen trials reported the achievement of 'deqi', an irradiating feeling said to indicate effective needling (Bao 2012; Chou 2009; Dai 1997; Li 2010a; Li 2011a; Liu 2013a; Lun 1999; Sun 2013a; Sun 2015; Wang 2001; Yao 2014; Zheng 2014; Zhu 2007). Information on needle type was available in 13 trials (Bao 2012; Chou 2009; Dai 1997; Li 2010a; Lun 1999; Liu 2013a; Naeser 1992; Sun 2013a; Sun 2015; Wu 2011a; Yao 2014; Zheng 2014; Zhu 2007). The length of treatment period ranged from one to 24 weeks with the number of treatment sessions varying from six to 120 sessions and the frequency of treatment from five sessions per week to two sessions per day.

\section{Outcomes}

The most commonly reported outcomes were dependency, global neurological deficit, and specific neurological impairment after acupuncture treatment. Thirteen trials evaluated the effect of acupuncture on dependency (activities of daily living) at the end of acupuncture treatment. The measures employed included the Barthel Index (BI) or modified Barthel Index (MBI) in 11 trials (Bao 2012; Huang 2008a; Ke 2015; Li 2010a; Wang 2012; Wu 2011a; Yao 2014; Zhan 2014; Zhang 2015; Zheng 2014; Zhou 2014) and the Physical Self-maintenance Scale (PSMS) combined with 
Instrumental Activities of Daily Living Scale (IADL) in two trials (Li 2011a; Sun 2013a). Twelve trials measured the global neurological deficit score or the proportion of participants with an improvement of global neurological deficit at the end of acupuncture treatment (Dai 1997; Gao 2014a; Guo 2011; Huang 2008a; Li 1997a; Lun 1999; Sun 2013a; Wang 2001; Yao 2014; Zhang 2015; Zhou 2014; Zhu 2007). The measures employed included NIHSS, CSRS1 (e.g. MESSS ) and CSRS2 (TCM). Six trials evaluated the effect of acupuncture on motor function measured with Fugl-Meyer scale (FMA) and Motor assessment scale after treatment (Li 2013a; Wang 2011a; Wang 2012; Wu 2011a; Yao 2014; Zhou 2014). Eighteen trials evaluated the effect of acupuncture on specific neurological impairments (e.g. cognitive function; swallowing function; depression) at the end of treatment (Bao 2012; Gao 2014a; Guo 2011; Guo 2012; Li 2010a; Li 2011a; Liu 2013a; Sun 2013a ;Sun 2015; Wang 2011a; Wu 2008; Wu 2011a; Wu 2013a; Xu 2013; Yao 2014; Zhang 2013a; Zheng 2014; Zhou 2014). Two trials reported quality of life measured with the Medical Outcomes Study 36-Item Short-Form Health Survey (MOS SF-36) (Chou 2009; Sun 2013a). Only five trials reported information on adverse events (Li 2010a; Sun 2013a; Sun 2015; Zhang 2013a; Zhou 2014). None of the 31 included trials provided any information on death, proportion of participants requiring institutional care or extensive family support after acupuncture treatment or at the end of follow-up.

\section{Excluded studies}

Of the 12,276 citations identified from English and Chinese databases, we excluded 11,855 citations during the initial screening of titles and abstracts. The main reasons for these exclusions were as follows.
1. Not stroke.

2. Studies not RCT.

3. Stroke duration since onset less than 30 days.

4. Acupuncture not involving needling: such as acupressure; laser acupuncture.

5. Studies comparing different kinds of acupuncture therapies.

6. Review articles.

We retrieved a total of 421 potentially eligible studies for screening of the full-text papers.

Of the 421 potentially eligible studies, we excluded 390 studies for the following reasons.

1. Questionable randomisation.

2. Comparing two different methods of acupuncture.

3. Stroke duration since onset less than 30 days.

4. Duplicates.

5. Others: abstract, review.

For details please see the Characteristics of excluded studies table.

\section{Risk of bias in included studies}

Please see Characteristics of included studies for details of the methodological quality, and Figure 2 and Figure 3 for summaries of the risk of bias findings in all included trials.

\section{Figure 2. Risk of bias graph: review authors' judgements about each risk of bias item presented as percentages across all included studies.}

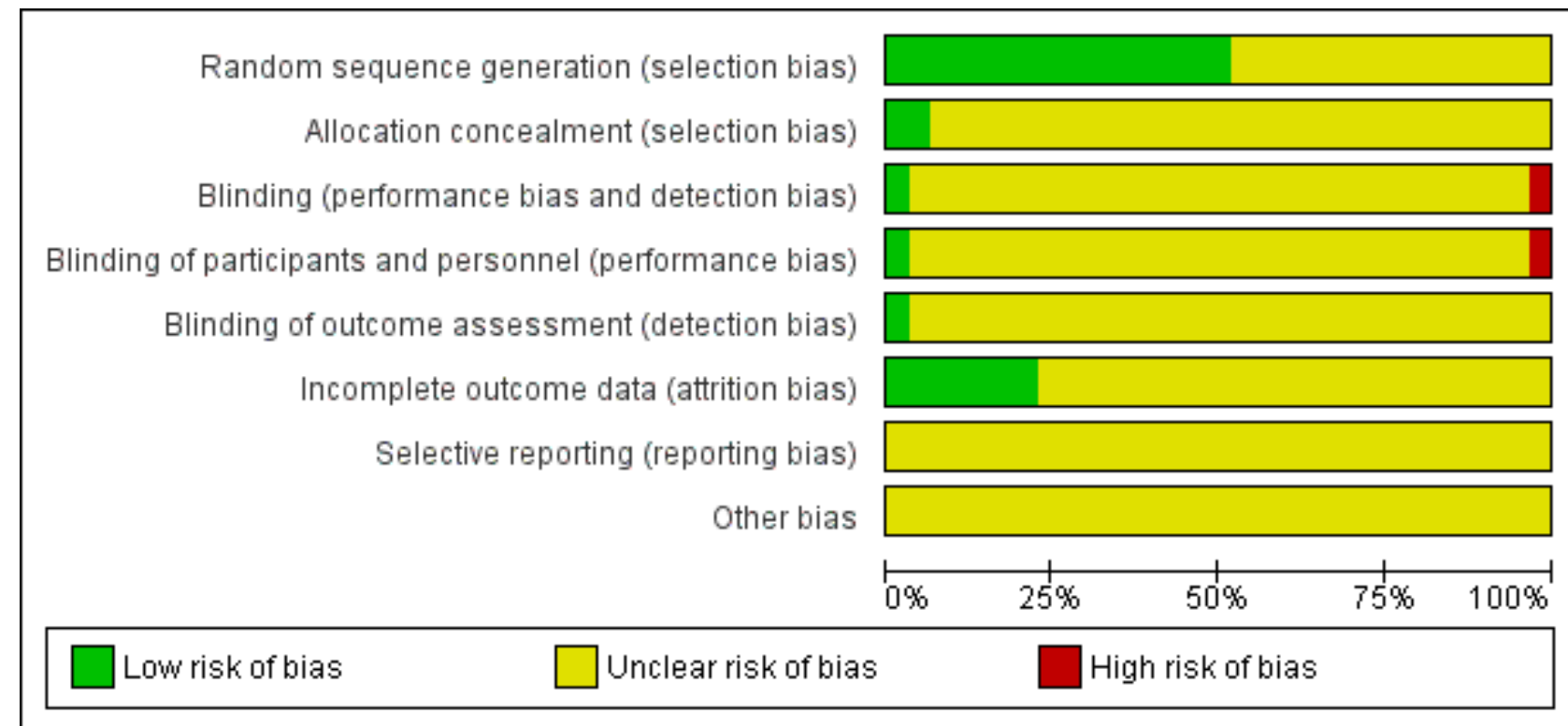


Figure 3. Risk of bias summary: review authors' judgements about each risk of bias item for each included study.

\begin{tabular}{|c|c|c|c|c|c|c|c|c|}
\hline & 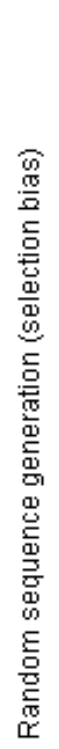 & 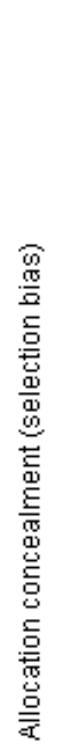 & 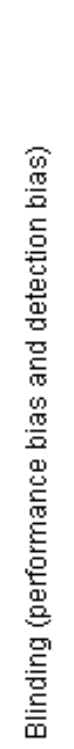 & 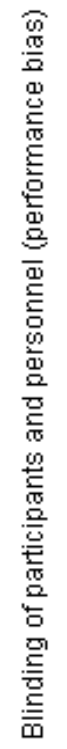 & 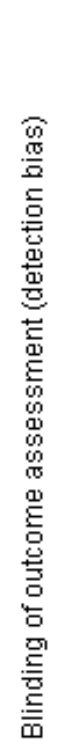 & 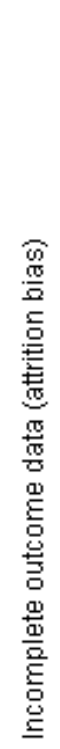 & 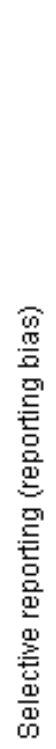 & 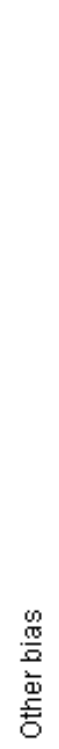 \\
\hline Bao 2012 & + & $?$ & $?$ & $?$ & $?$ & $?$ & $?$ & $?$ \\
\hline Chou 2009 & $?$ & $?$ & $?$ & $?$ & $?$ & + & $?$ & $?$ \\
\hline Dai 1997 & $?$ & $?$ & $?$ & $?$ & $?$ & $?$ & $?$ & $?$ \\
\hline Gao 2014a & + & $?$ & $?$ & $?$ & $?$ & + & $?$ & $?$ \\
\hline Guo 2011 & $?$ & $?$ & $?$ & $?$ & $?$ & $?$ & $?$ & $?$ \\
\hline Guo 2012 & ? & $?$ & $?$ & $?$ & $?$ & $?$ & $?$ & $?$ \\
\hline Huang 2008a & + & $?$ & $?$ & $?$ & $?$ & $?$ & $?$ & $?$ \\
\hline Ke 2015 & $?$ & $?$ & $?$ & $?$ & $?$ & $?$ & $?$ & $?$ \\
\hline Li 1997a & $?$ & $?$ & $?$ & ? & $?$ & $?$ & $?$ & ? \\
\hline Li 2010a & + & ? & $?$ & $?$ & $?$ & + & ? & $?$ \\
\hline Li 2011a & ? & $?$ & $?$ & $?$ & $?$ & $?$ & ? & $?$ \\
\hline Li 2013a & $?$ & $?$ & $?$ & $?$ & $?$ & $?$ & ? & $?$ \\
\hline Liu 2013a & $?$ & ? & ? & ? & $?$ & ? & $?$ & ? \\
\hline Lun 1999 & $?$ & $?$ & $?$ & $?$ & ? & $?$ & $?$ & $?$ \\
\hline Naeser 1992 & ? & ? & $?$ & + & $?$ & $?$ & ? & $?$ \\
\hline Sun 2013a & + & ? & $?$ & ? & ? & + & ? & ? \\
\hline Sun 2015 & + & $?$ & $?$ & $?$ & $?$ & $?$ & $?$ & $?$ \\
\hline Wang 2001 & $?$ & $?$ & $?$ & $?$ & ? & $?$ & ? & ? \\
\hline Wang 2011a & + & $?$ & ? & ? & ? & ? & $?$ & ? \\
\hline Wang 2012 & + & $?$ & $?$ & $?$ & ? & $?$ & ? & $?$ \\
\hline
\end{tabular}


Figure 3. (Continued)

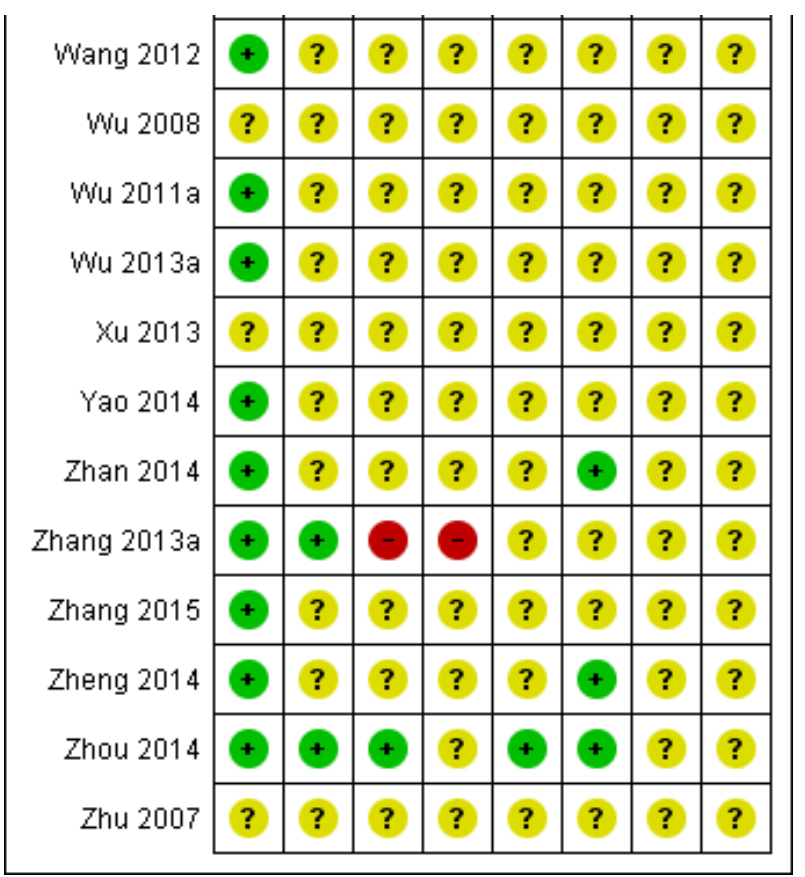

\section{Allocation}

\section{Random sequence generation}

Thirteen trials randomly assigned participants to groups by using random number tables (Bao 2012; Huang 2008a; Gao 2014a; Li 2010a; Sun 2013a; Wang 2011a; Wang 2012; Wu 2013a; Yao 2014; Wu 2011a; Zhan 2014; Zhang 2015; Zheng 2014). The remaining 18 trials did not report their methods of random sequence generation.

\section{Allocation concealment}

Of the 31 included trials, only three trials reported adequate allocation concealment by using sealed envelopes (Sun 2015; Zhang 2013a; Zhou 2014).

\section{Blinding}

Zhang 2013a reported that participants, their physicians, and outcome assessors were not blinded. Zhou 2014 reported that the investigators were blinded but the participants were not. Naeser 1992 reported that the participants were blinded without describing the method in detail. No information on blinding was available in the remaining 28 trials.

\section{Incomplete outcome data}

Seven trials reported withdrawals, but the results were not analysed on an intention-to-treat basis (Chou 2009; Gao 2014a; Li 2010a; Sun 2013a; Zhan 2014; Zheng 2014; Zhou 2014). There was no statement on dropouts or withdrawals in any of the remaining 24 trials. For each of these 24 trials, the number of participants randomised was the same as participants analysed, so it appears that there were no exclusions from the trials after randomisation. We concluded that, although the results appeared to be analysed by intention-to-treat, we cannot be certain about this.

\section{Selective reporting}

The included trials in this review did not report some clinically important outcomes, such as death, requiring Institutional care, and all-cause mortality. Of the 31 included studies, only five studies reported adverse events (Li 2010a; Sun 2013a; Sun 2015; Zhang 2013a; Zhou 2014), therefore we assumed that this may have constituted some degree of reporting bias.

\section{Other potential sources of bias}

There was insufficient information reported to determine if there were any other potential sources of bias.

\section{Effects of interventions}

See: Summary of findings for the main comparison

\section{Acupuncture plus baseline treatment versus sham acupuncture plus baseline treatment}

Two trials compared real acupuncture plus baseline treatment with sham acupuncture plus baseline treatment (Chou 2009; Naeser 1992).

\section{Changes of specific neurological impairments after acupuncture treatment and at the end of follow-up}

One trial with 16 participants evaluated the effect of acupuncture on the improvement of motor function after treatment by using a categorical approach rather than continuous scales (Naeser 1992). It showed that real acupuncture was not superior to sham acupuncture in the improvement of motor function for participants with stroke in the convalescent stage (OR $9.00,95 \% \mathrm{Cl} 0.40$ to 203.30; Analysis 1.1), but the confidence interval was very wide and included clinically significant effects in both directions.

Another trial with 33 participants evaluated the effect of acupuncture on the change of cognitive function after treatment 
(Chou 2009 ).There were significant improvements in orientation (MD 4.21, 95\% Cl 1.78 to 6.64), perception (MD 5.32, 95\% Cl 0.93 to 9.71 ), and praxis (MD $3.80,95 \% \mathrm{Cl} 2.12$ to 5.48 ) among participants in the real acupuncture group compared with the sham acupuncture group, but acupuncture was not superior to control in the improvement of visuomotor organisation (MD 2.76, 95\% Cl -0.58 to 6.10 ), thinking operation (MD $0.1295 \% \mathrm{Cl}-0.64$ to 0.88 ), and memory (MD $0.35,95 \% \mathrm{Cl}-0.43$ to 1.13 ) (Analysis 1.2).

\section{Quality of life at the end of follow-up}

One trial with 33 participants evaluated health-related quality of life measured by means of self-report using the Medical Outcomes Study 36-Item Short-Form Health Survey (SF-36) and StrokeSpecific Quality of Life Scale (SS-QOL) (Chou 2009). It showed that real acupuncture was not superior to sham acupuncture in the improvement of health-related quality of life measured by the SF-36 (physical component summary: MD $-2.66,95 \% \mathrm{Cl}-10.57$ to 5.25; mental component summary: MD $11.52,95 \% \mathrm{Cl}-1.76$ to 24.80 ; Analysis 1.3), and the SS-QOL (language: MD 13.34, 95\% Cl -3.02 to 29.70; personality: MD $3.10,95 \% \mathrm{Cl}-11.73$ to 17.93 ; Analysis 1.4 ) from baseline to week eight among participants with stroke in the convalescent stage.

No data on death or dependency, the proportion of people requiring institutional care or requiring extensive family support, death from any cause and possible adverse events were available in these two trials (Chou 2009; Naeser 1992).

\section{Acupuncture plus baseline treatment versus baseline treatment alone}

Twenty-nine trials compared acupuncture plus baseline treatment with baseline treatment alone (Bao 2012; Dai 1997; Gao 2014a; Guo 2011; Guo 2012; Huang 2008a; Ke 2015; Li 1997a; Li 2010a; Li 2011a; Li 2013a; Liu 2013a; Lun 1999; Sun 2013a; Sun 2015; Wang 2001; Wang 2011a; Wang 2012; Wu 2008; Wu 2011a; Wu 2013a; Xu 2013; Yao 2014; Zhan 2014; Zhang 2013a; Zhang 2015; Zheng 2014; Zhou 2014; Zhu 2007).

\section{Death or dependency at the end of treatment and follow-up}

No data on death at the end of treatment or follow-up were available in any of the included trials.

Eleven trials with a total of 956 participants measured improvement of dependency after acupuncture treatment by using continuous scales only (Barthel Index (BI), Modified Barthel Index (MBI) and Activity of Daily Living Scale (ADL)) (Bao 2012; Huang 2008a; Ke 2015; Li 2010a; Li 2011a; Wang 2012; Wu 2011a; Yao 2014; Zhan 2014; Zhang 2015; Zheng 2014). There was significant improvement in dependency measured by the $\mathrm{BI}$, the MBI, and the ADL Scale among participants in the acupuncture group compared with the control group (BI: MD 9.19, 95\% Cl 4.34 to 14.05; participants $=616$; studies $=9 ; I^{2}=95 \%$; MBI: MD 3.44, 95\% Cl 0.30 to 6.58 ; participants $=60$; studies $=1 ;$ ADL: MD 7.80, 95\% Cl 6.04 to 9.56; participants $=62$; studies $=1$; Analysis 2.1). Heterogeneity was significant and may be attributable to differences in severity of stroke, times of evaluation from stroke onset, and types of stroke.

One trial with 147 participants evaluated the effect of acupuncture on the improvement of dependency measured by the $\mathrm{BI}$ at the end of three months' follow-up (Zhou 2014). There was a beneficial effect of acupuncture on the improvement of dependency for participants with stroke in the convalescent stage (MD 7.49, 95\% Cl 1.79 to 13.19; Analysis 2.2). One trial with 71 participants evaluated the effect of acupuncture on the improvement of dependency measured by the ADL scale at the end of one month's follow-up (Sun 2013a). It also showed a beneficial effect of acupuncture on the improvement of dependency (MD 3.83, 95\% Cl 2.67 to 4.99; Analysis 2.2).

\section{Proportion requiring institutional care or requiring extensive family support at the end of follow-up}

No data on the proportion of participants requiring institutional care or extensive family support at the end of follow-up were available in these 29 trials.

\section{Changes of global neurological deficit after acupuncture treatment and at the end of follow-up}

Eight trials measured global neurological deficit at the end of treatment and follow-up by using continuous scales. Of these, four trials evaluated the effect of acupuncture on global neurological function measured by the Modified Edinburgh and Scandinavian Stroke Scale (Gao 2014a; Huang 2008a; Zhang 2015; Zhu 2007). There was a significant decrease in the neurological deficit score among participants in the acupuncture group compared with the control group (MD $-2.39,95 \% \mathrm{Cl}-3.34$ to -1.43 ; participants = 240; studies $=4 ; I^{2}=23 \%$; Analysis 2.3). Two trials evaluated the effect of acupuncture on global neurological function measured by the Neurological Function Deficit Scale (NFDS) (Guo 2011; Yao 2014). There was no significant improvement in global neurological function among participants in acupuncture group compared with control group (MD $-1.02,95 \% \mathrm{Cl}-5.80$ to 3.76 ; participants = 123; studies $=2 ; I^{2}=19 \%$; Analysis 2.3). One trial evaluated the effect of acupuncture on the improvement of global neurological function measured by the NFDS at the end of one month followup (Sun 2013a). It showed a beneficial effect of acupuncture on the improvement of global neurological function (MD -6.15, 95\% $\mathrm{Cl}-7.09$ to -5.21 ; Analysis 2.4). One trial evaluated the effect of acupuncture on the improvement of global neurological function by using the National Institue of Health Stroke Scale (NIHSS) at the end of three months' follow-up (Zhou 2014). There was no significant improvement in global neurological function among participants in acupuncture group compared with control group (MD $-0.83,95 \% \mathrm{Cl}-1.94$ to 0.28 ; Analysis 2.4 ).

Seven trials with a total of 543 participants measured improvement of global neurological deficit after acupuncture treatment by using categorical approaches only (CSRS 1 and CSRS 2) rather than continuous scales, for example changes of global neurological deficit score (Dai 1997; Huang 2008a; Li 1997a; Lun 1999; Wang 2001; Yao 2014; Zhang 2015). There was significant heterogeneity among the seven trials $\left(1^{2}=55 \%\right)$, which was possibly due to differences in outcome measurements used, times of evaluation from stroke onset, and types of stroke. This means that the overall estimate of treatment effect is not reliable. Hence, the apparent improvement of global neurological deficit in the acupuncture group compared with the control group should be interpreted with caution (OR 3.89, $95 \% \mathrm{Cl} 1.78$ to 8.49; participants = 543; studies = $7 ;\left.\right|^{2}=55 \%$; Analysis 2.5). 
Changes of specific neurological impairments after acupuncture treatment and at the end of follow-up

Of the 31 included trials, 20 measured specific neurological impairment at the end of treatment and follow-up, mainly including motor function, cognitive function, speech function, depression, swallowing function, pain, sleep, and spasticity.

\section{Motor function}

Four trials used the Fugl-Meyer Assessment (FMA) to measure motor function in the upper and lower extremities at the end of treatment (Li 2013a; Wang 2011a; Wu 2011a; Yao 2014). Acupuncture was superior to no acupuncture in the improvement of motor function in the upper and lower extremities (MD 6.16, 95\% $\mathrm{Cl} 4.20$ to 8.11; participants $=245$; studies $=4 ;\left.\right|^{2}=28 \%$; Analysis 2.6) . One trial with 60 participants evaluated the effect of acupuncture on the improvement of general motor function measured by the Motor Assessment Scale at the end of treatment (Wang 2012). There was a significant difference between the two groups (MD 4.53, $95 \% \mathrm{Cl} 2.99$ to 6.07 ; Analysis 2.6). One trial with 147 participants evaluated the effect of acupuncture on the improvement of general motor function measured by the FMA at the end of three months' follow-up (Zhou 2014). There was a beneficial effect of acupuncture on the improvement of general motor function for participants with stroke in the convalescent stage (MD $7.59,95 \% \mathrm{Cl} 0.98$ to 14.20 ; Analysis 2.7).

Two trials measured improvement of motor function after acupuncture treatment by using categorical approaches (FMA) (Li 2013a; Wang 2011a). There was no significant improvement in motor function among participants in the acupuncture group compared with the control group (OR 2.41, 95\% Cl 0.98 to 5.96; Analysis 2.8).

\section{Cognitive function}

Five trials evaluated the effect of acupuncture on the improvement of cognitive function measured by the Mini-Mental State Examination (MMSE) at the end of treatment (Bao 2012; Li 2010a; Li 2011a; Liu 2013a; Zheng 2014). Acupuncture was superior to no acupuncture in the improvement of cognitive function for participants with stroke in the convalescent stage (MD 2.54, 95\% $\mathrm{Cl} 0.03$ to 5.05 ; participants $=278$; studies $=5 ; 1^{2}=98 \%$; Analysis 2.9). The significant heterogeneity between the trials was possibly due to differences in times of evaluation from stroke onset, severity on entry, needling details, and outcome measurements used. Two trials measured this outcome by using the Montreal Cognitive Assessment Scale (MoCA) at the end of treatment (Bao 2012; Zheng 2014). There was also a beneficial effect of acupuncture on the improvement of cognitive function for participants with stroke in the convalescent stage (MD 1.34, 95\% $\mathrm{Cl} 0.76$ to 1.92; participants = 120 ; studies $=2 ; I^{2}=0 \%$; Analysis 2.9). The difference in one trial in which cognitive function was evaluated by the Revised Hasegawa Dementia Scale (HDS-R) was significant too (Li 2010a) (MD 1.26, $95 \% \mathrm{Cl} 0.29$ to 2.23; participants $=46$; studies $=1$; Analysis 2.9). One trial evaluated the effect of acupuncture on the improvement of cognitive function measured by MMSE at the end of one month's follow-up (Sun 2013a). There was a significant difference between the two groups (MD 3.47, 95\% Cl 2.43 to 4.51; Analysis 2.10).

Three trials measured improvement of cognitive function after acupuncture treatment by using categorical approaches (MMSE) (Bao 2012; Li 2010a; Zheng 2014). There was no significant heterogeneity among them. It showed that acupuncture was beneficial for the improvement of cognitive function in participants with stroke in the convalescent stage (OR $3.82,95 \% \mathrm{Cl} 1.89$ to 7.72; participants $=166$; studies $=3 ; I^{2}=0 \%$; Analysis 2.11$)$. One trial with 46 participants evaluated this outcome measured by categorical approaches (HDS-R). It also showed that acupuncture was beneficial for the improvement of cognitive function in participants with stroke in the convalescent stage (OR 4.02, 95\% Cl 1.12 to 14.46 ; Analysis 2.11).

\section{Depression}

Six trials evaluated the effect of acupuncture on the improvement of depression measured by the Hamilton Depression Scale (HAMD) at the end of treatment (Guo 2011; Gao 2014a; Sun 2015; Wu 2008; Zhang 2013a; Zhou 2014). There was a beneficial effect of acupuncture on the improvement of depression for participants with stroke in the convalescent stage (MD $-2.58,95 \% \mathrm{Cl}-3.28$ to -1.87 ; participants $=552$; studies $=6 ; I^{2}=71 \%$; Analysis 2.12). One trial measured this outcome by using the Symtoms of Traditional Chinese Medicine (TCM) depression scale (Gao 2014a). There was also a beneficial effect of acupuncture on the improvement of depression for participants with stroke in the convalescent stage (MD -1.57, 95\% Cl-2.96 to -0.18; Analysis 2.12).

Four trials measured improvement of depression after acupuncture treatment by using categorical approaches (HAMD) (Gao 2014a; Sun 2015; Wu 2008; Zhang 2013a). There was no significant heterogeneity among them. It also showed that acupuncture was beneficial for the improvement of depression in participants with stroke in the convalescent stage (OR $2.03,95 \% \mathrm{Cl} 1.10$ to 3.72 ; participants $=342$; studies $=4 ; I^{2}=0 \%$; Analysis 2.13).

\section{Swallowing function}

Three trials evaluated the effect of acupuncture on the improvement of swallowing function at the end of treatment (Guo 2012; Wu 2013a; Xu 2013). Acupuncture was superior to no acupuncture in the improvement of dysphagia measured by a drinking test in two trials (Wu 2013a; Xu 2013) (MD -1.11, 95\% Cl -2.08 to -0.14 ; participants $=200$; studies $=2 ; \mathrm{I}^{2}=96 \%$; Analysis 2.14). The difference was also significant in another trial in which dysphagia was evaluated categorically by a drinking test (Guo 2012) (OR 95.29, 95\% Cl 10.93 to 830.86; Analysis 2.15).

\section{Pain}

Two trials evaluated the effect of acupuncture on the improvement of pain measured by the Visual Analogue Scale (VAS) (Wang 2011a; Yao 2014). There was a significant decrease in scores among participants in the acupuncture group compared with the control group (MD $-2.88,95 \% \mathrm{Cl}-3.68$ to -2.09 ; participants = 118; studies = $2 ; I^{2}=0 \%$; Analysis 2.16). It showed that acupuncture was superior to no acupuncture in the improvement of pain.

\section{Sleep}

One trial evaluated the effect of acupuncture on the improvement of sleep quality measured by the Rhone Planck Sleepiness Scale (Zhang 2013a). There was no significant improvement in sleep quality among participants in the acupuncture group compared with the control group (MD $-1.09,95 \% \mathrm{Cl}-2.37$ to 0.19 ; Analysis 2.17). 


\section{Spasticity}

One trial evaluated the effect of acupuncture on the improvement of spasticity measured by the Modified Ashworth Spasticity Rating Scale (Wu 2011a). There was a beneficial effect of acupuncture on the improvement of spasticity for participants with convalescent stroke (MD $-0.40,95 \% \mathrm{Cl}-0.64$ to -0.16 ; participants $=60$; studies $=$ 1 ; Analysis 2.18).

\section{Death from any cause during the whole treatment and follow-up period}

No data on death from any cause during the period of treatment and follow-up were available in these 29 trials.

\section{Quality of life at the end of follow-up}

One trial reported no significant change in health-related quality of life measured by means of self-report using the Medical Outcomes Study 36-Item Short-Form Health Survey (SF- 36) from baseline to one month after treatment among participants in the acupuncture group compared with the control group (Sun 2013a) (MD 2.73, 95\% $\mathrm{Cl}-0.54$ to 6.00; participants $=71$; studies $=1$; Analysis 2.19$)$.

\section{Possible adverse events}

Adverse events were reported in five trials (Li 2010a; Sun 2013a; Sun 2015; Zhang 2013a; Zhou 2014). Of these, three trials reported no obvious adverse events related to acupuncture (Li 2010a; Sun 2015; Zhang 2013a). Zhou 2014 reported bleeding, haematoma, and pain at the acupoint in the acupuncture group and Sun 2013a found itchiness of the skin at the acupoint in one participant in the acupuncture group. No other serious adverse events were reported.

\section{Subgroup analysis}

We were unable to perform pre-determined subgroup analyses based on time of starting acupuncture and stroke severity because most trials did not provide information for the specified outcomes.

\section{Sensitivity analysis}

We were unable to perform the predetermined sensitivity analyses for trials with adequate concealment of randomisation and blinding, and that were published in languages other than Chinese because most trials did not provide the necessary data.

\section{Publication bias}

Nine trials comparing acupuncture plus baseline treatment with baseline treatment alone evaluated the effect of acupuncture on the improvement of dependency measured by the Barthel Index. Based on these nine trials, we produced a funnel plot to check for publication bias in this systematic review. We found that the funnel plot was asymmetric (Figure 4).

Figure 4. Funnel plot of comparison 2, Acupuncture + baseline treatment versus baseline treatment alone, outcome: 2.1 Improvement of dependency at the end of treatment.

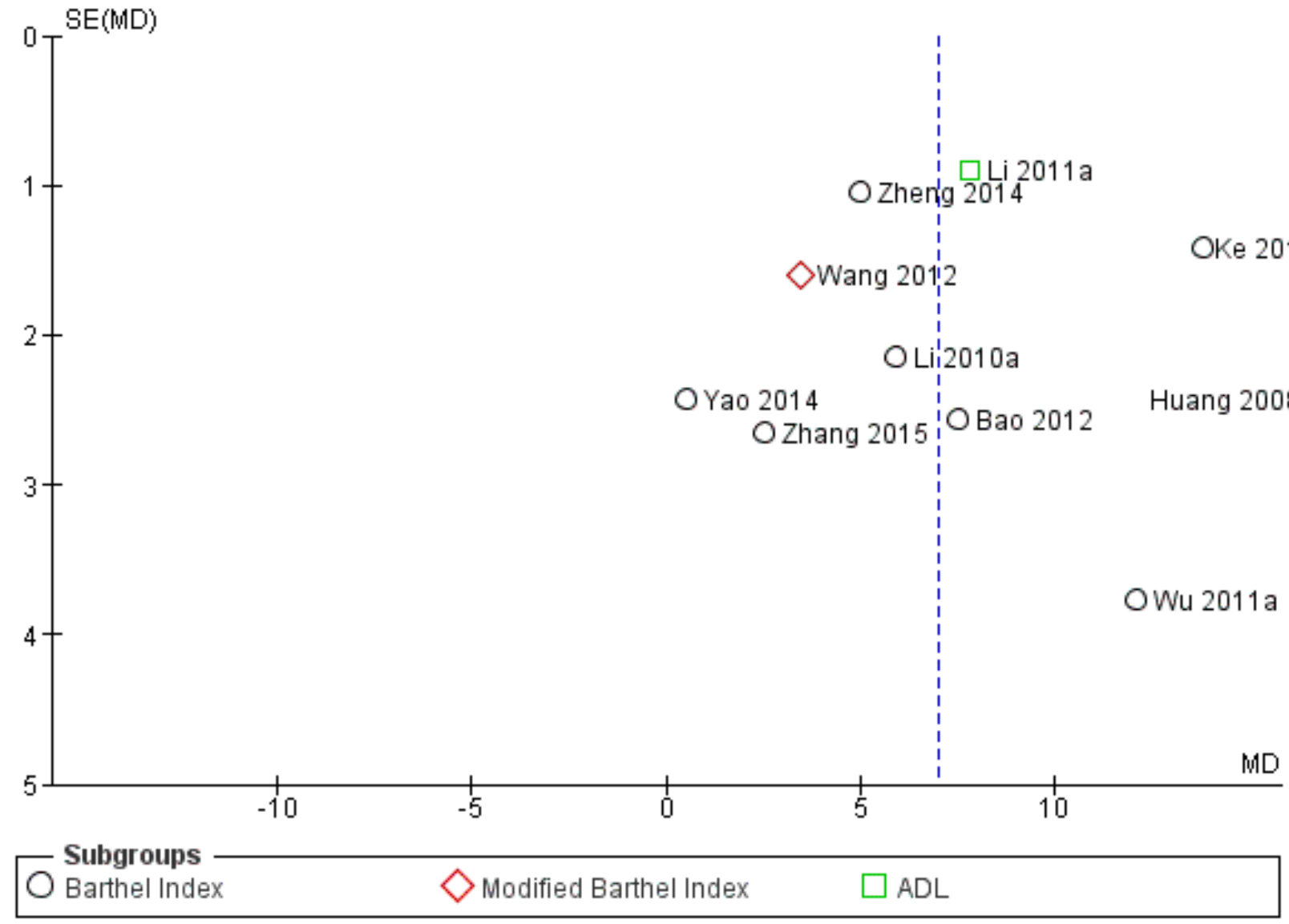


Although funnel plot asymmetry has long been equated with publication bias, the funnel plot should be seen as a generic means of displaying small-study effects. Small-study effects may be due to factors other than publication bias, such as poor methodological quality leading to spuriously inflated effects in smaller studies, true heterogeneity, artefactual, and chance (Sterne 2011).

\section{DISCUSSION}

\section{Summary of main results}

We included 31 trials in this review, with a total of 2257 participants in the subacute or chronic stage of stroke. Two trials were conducted outside China (Chou 2009; Naeser 1992) and the remaining 29 trials were conducted in China. The present review on acupuncture for stroke is also not representative of different racial groups.

\section{The results revealed the following.}

1. Compared with no acupuncture, for people with stroke in the subacute or chronic stage, acupuncture may have a beneficial effect on improving dependency (activities of daily living); global neurological deficiency; and specific neurological impairments including motor function, cognitive function, depression, swallowing function, pain, and spasticity.

2. Acupuncture was not superior to sham acupuncture or no acupuncture on improving the quality of life in people with stroke in the subacute or chronic stage.

3. There were no serious adverse events reported in people with stroke in the convalescent stage using acupuncture.

4. Currently there is no evidence from the included RCTs for the effect of acupuncture on death, requiring institutional care, and all-cause mortality in people with stroke in the subacute or chronic stage.

\section{Overall completeness and applicability of evidence}

In this systematic review, a substantial number of the included studies were conducted in China and were published in Chinese. Our electronic searching successfully identified studies for which an abstract was available in Chinese, as well as a number of studies based on English titles. However, we believe it is likely that we will not have identified all relevant Chinese trials, in particular those for which only English titles were available and those not published in journals included in the electronic databases that we searched. The asymmetric funnel plot further proved that there was existing publication bias in this systematic review (Figure 4).

Many of the relevant trials that we included were published only as brief reports. This was frequently the case for studies published in Chinese, for which published versions were often less than two pages long. Although we contacted study authors, when possible, to confirm study eligibility, we did not have the time or resources to contact all study authors for further information on trial design or study results. Thus, in general the completeness of study information is low, resulting in a high number of studies for which risk of bias is classed as 'unclear'.

\section{Characteristics of participants}

The studies included In this review were predominantly conducted in China, so the review is not representative of different racial groups. The type and severity of stroke may alter the effects of acupuncture on people with stroke. From the available information, it was not possible to perform pre-specified subgroup analyses comparing people with different severities of stroke, and different times to start of treatment after stroke. This was due firstly, to the limited number studies for the specified outcomes, secondly, to only some of the included trials reporting data on severity, and thirdly, to most trials not clearly defining the interval between stroke onset and the start of the intervention treatment, and including participants with a mix of different intervals from stroke onset to start of intervention treatment.

\section{Properties of interventions}

The quality of acupuncture treatment is closely related to its effectiveness. Misleading results may have occurred if the treatment schedules were inadequate or administered by unskilled practitioners. However, information on the experience and training of the acupuncturists who gave the treatments was available in only one trial (Chou 2009). Furthermore, the acupuncture techniques, the number of acupoints, the number and duration of sessions, and the duration of the intervention period varied across trials. Some trials reported that the acupuncture points, the number of sessions, and the duration of treatment were individualised according to the practical conditions in each stroke patient. From the scarce description of treatment in all trials, it is difficult to evaluate if the acupuncture treatment was valid or not. The consensus of an international group of experienced acupuncturists and researchers was that clinical trials of acupuncture must use an optimal form of treatment, defined by examining standard texts and by surveying and consulting experts, and must be reported by using Revised Standards for Reporting Interventions in ClinicalTrials of Acupuncture (STRICTA) (Hugh 2010).

\section{Outcomes measures}

\section{Efficacy}

Because post-stroke neurological recovery is known to be obvious within three months, especially post-stroke motor recovery, and unlikely beyond six months, mixing people with interval from stroke onset of less than three months, three to six months, and more than six months in one sample would make the assessment of the efficacy of an intervention methodologically unsound. From the available information, it was not possible to perform pre-specified subgroup analyses comparing people with different times to start of treatment (within three months, three to six months, and after six months) for each outcome. This was due to the limited amount of data, the varied outcome measurements, or both, in this systematic review.

The long-term goal of treatment for stroke is to reduce mortality and disability, and ultimately to prolong survival and improve quality of life. Data available from the included trials were mainly secondary outcomes. There was a lack of data from RCTs on clinically relevant outcomes at long-term follow up, such as mortality and quality of life. The lack of reliable evidence on primary outcomes meant that we were unable to draw conclusions about the influence of acupuncture on stroke.

\section{Adverse events}

Of the 31 included trials with a total of 2257 participants in the convalescent phase of stroke, only one participant was reported to have suffered from bleeding and three participants were reported 
to have suffered from intolerance to pain at acupoints. There were no serious adverse events reported. From the available evidence, it appears that acupuncture is a safe treatment when used for people with stroke. However, it should be noted that this result was based on insufficient information from five trials with a small number of participants (Li 2010a; Sun 2013a; Sun 2015; Zhang 2013a; Zhou 2014). Most trials in this systematic review did not report whether any adverse events relevant to acupuncture were apparent in their participants. The reasons for insufficient reporting of adverse events were possibly as follows. Firstly, Chinese practitioners perceive acupuncture as free of side effects, secondly, because these are rare events, data from RCTs will almost never be sufficient to prove or disprove a causal relationship between a complementary and alternative medicine (CAM) therapy and a rare adverse event, and thirdly, study authors reported positive effects without reporting adverse events as well. However, some studies demonstrated that serious adverse events have been associated with acupuncture, such as infections (HIV, hepatitis, subacute bacterial endocarditis) caused by non-sterile needles, or complications (pneumothorax, cardiac tamponade) caused by tissue trauma, but the incidence of adverse events was unknown (Ernst 1997).

\section{Quality of the evidence}

The current available evidence shows that acupuncture may have beneficial effects on the improvement of dependency, global neurological deficiency, and specific neurological deficiency in some dimensions. Unfortunately due to low methodological quality with regard to methods of randomisation, allocation concealment and blinding of assessment of most included trials, and probable publication bias, there is currently insufficient evidence to support the routine use of acupuncture for people with stroke in the convalescent stage. The general low methodological quality of the included trials of acupuncture for stroke prohibited meaningful sensitivity analyses to illuminate the robustness of the results of the review to the exclusion of those trials with inadequate methodology. It was also not possible to perform sensitivity analysis to confirm the robustness of the results of the review to the exclusion of Chinese trials, because only two non-Chinese trials were included. However, this systematic review provides comprehensive and updated information on the effects of acupuncture for stroke in the convalescent stage for clinical practice. Therefore, further research on acupuncture for stroke is worthwhile in future.

\section{Potential biases in the review process}

The major limitations of this review are related to the weakness inherent in the available published literature on acupuncture for stroke. While most studies reported global and specific neurological deficit results, the measurement of the outcomes varied considerably across trials. The combined results from studies with such wide variation were unreliable. Furthermore, many studies did not provide detailed information on the severity of the disease, the exact time of starting the acupuncture treatment, the modalities of acupuncture technique and acupuncturist's background, and possible adverse effects relevant to acupuncture treatment. This brings the generalisability of the results into question.

Another limitation of this systematic review is that publication bias might be present, as indicated by the asymmetric funnel plot for the effect of acupuncture on the improvement of dependency measured by the Barthel Index. Although we undertook extensive literature searches, we still could not exclude the possibility that studies with negative findings remain unpublished.

\section{AUTHORS' CONCLUSIONS}

\section{Implications for practice}

Although acupuncture may have positive effects in stroke rehabilitation and there were no reported serious adverse events, the small number of low quality studies and the probability of publication bias means that there was insufficient evidence to support the routine use of acupuncture for people with subacute or chronic stroke.

\section{Implications for research}

The widespread use of acupuncture, the promising results with less severe side effects, lower cost, and the insufficient quality of the available trials warrant further research. Large sham or placebocontrolled trials are needed to confirm or refute the available evidence. The following features should be addressed in further studies.

1. Detailed reporting of the generation of the allocation sequence and allocation concealment.

2. Application and clear description of blinding.

3. Use of placebo or sham acupuncture as the control.

4. Clear definition of the modality of acupuncture, and acupuncture technique based on evidence or a consensus of experts (STRICTA).

5. Use of standard validated outcome measures.

6. Reporting of clinically important outcome measures at longterm follow-up, such as mortality and quality of life.

7. Adverse events critically assessed by standardised monitoring or an effective self-report system. Attention should be paid to rare, severe adverse events relevant to acupuncture.

8. The study should be reported according to the STRICTA criteria (Hugh 2010) in conjunction with the CONSORT statement (Schulz 2010).

\section{ACKNOWLEDGEMENTS}

We thank Mrs Hazel Fraser for providing us with relevant trials and systematic reviews from the Cochrane Stroke Group Trials Register and Mrs Brenda Thomas for her help with developing the search strategy and helpful comments. We express our gratitude to Dr Valentina Assi, Dr Bo Wu, lead editor Prof Peter Langhorne, Julie Gildie, and Tam Watson for their very helpful comments. 


\section{R E F E R E N C E S}

\section{References to studies included in this review}

Bao 2012 \{published data only\}

Bao Y. Clinical study on mild cognitive impairment after stroke treated with cord-supplementing and brain strengthening acupuncture [益髓健脑针刺法治疗脑梗死后轻度认知功能障 碍的临床研究] . Available at: http://cdmd.cnki.com.cn/Article/ CDMD-10228-1012467639.htm (accessed 8 August 2015) 2012.

Chou 2009 \{published data only (unpublished sought but not used)\}

Chou P, Chu H, Lin J. Effects of electroacupuncture treatment on impaired cognition and quality of life in Taiwanese stroke patients. Journal of Alternative \& Complementary Medicine 2009;15(10):1067-73.

\section{Dai 1997 \{published data only\}}

Dai CY, Lu F. Efficacy observation on the treatment of sequelae of cerebral infarction in 46 patients by integrating Chinese with modern medicine. Practical Journal of Integrating Chinese with Modern Medicine 1997;10(1):438.

\section{Gao 2014a \{published data only\}}

Gao X. Clinical observation on treating poststroke depression by scalp acupuncture and back shu points [ 针刺头穴结合五 脏背俞穴治疗中风后抑郁的临床疗效观察]. Available at: http://cdmd.cnki.com.cn/Article/CDMD-10228-1014250907.htm (accessed 8 August 2015) 2014.

Guo 2011 \{published data only\}

Guo AS, Li AH, Chen X, Cai JY, Wu QF. Effects of electricacupuncture and fluoxetine on depression and neurological function of post-stroke depression patients [电针联合氟西汀 对卒中后抑有症患者抑郁状态及神经功能的影响]. Shandong Medical Journal 2011;51(25):9-11.

\section{Guo 2012 \{published data only\}}

Guo LJ, Yang GF. Clinical research of acupuncture treatment combined with popsicle stimulus in the treatment of dysphagia after apoplexy [针刺配合冰棒刺激治疗中风后吞咽困难的临 床研究]. China Journal of Chinese Medicine 2012;27(7):918-9.

\section{Huang 2008a \{published data only\}}

Huang GF, Zhang HX, Zhang TF. Effects of scalp acupuncture combined with rehabilitation therapy on motor function in the hemiplegic patient of cerebral thrombosis at convalescent period [头针结合康复治疗对脑血栓形成恢复期偏瘫患 者运动功能的影响]. Chinese Acupuncture \& Moxibustion 2008;28(8):573-5.

\section{Ke 2015 \{published data only\}}

Ke J, Wang JH, Li CE. Acupuncture by linguiba method combined with rehabilitation for 40 patients after stroke [ 针 刺灵龟八法配合康复锻炼治疗中风40例]. Henan Traditional Chinese Medicine 2015;35(1):153-5.

\section{Li 1997a \{published data only\}}

Li X. Efficacy analysis of rehabilitation in the treatment of hemiplegia in 112 stroke patients [112例中风偏㿈患者分组治
疗的康复疗效分析]. Chinese Journal of Rehabitative Theory and Practice 1997;3(1):22-4.

\section{Li 2010a \{published data only\}}

Li W. Efficacy observation on the effects of acupuncture in the treatment of mild cognitive impairment after stroke [针刺 对脑卒中后轻度认知功能障碍的疗效观察]. Available at: http://cdmd.cnki.com.cn/Article/CDMD-10026-2010145185.htm (accessed 8 August 2015) 2010.

\section{Li 2011a \{published data only\}}

Li M. Clinical research on the treatment of cognitive impairment after stroke by pericardium acupuncture [针刺手厥阴心包经特 定穴治疗脑卒中后认知障碍的临床研究]. Available at:http:// cdmd.cnki.com.cn/article/cdmd-10228-1011222586.htm (accessed 8 August 2015) 2011.

\section{Li 2013a \{published data only\}}

Li XZ, Liu YX. Observation on the effects of acupuncture and rehabilitation in the treatment of shoulder-hand syndrome due to stroke [针刺结合康复训练分期治疗肩手综合征的观察] . Chinese Journal of Gerontology 2013;33(21):5247-8.

\section{Liu 2013a \{published data only\}}

Liu J, Feng XD. Clinical observation of treating cognitive impairment after stroke by electroacupuncture at Baihui and Shenting with cognitive rehabilitation training [电针百会、神 庭穴配合康复训练治疗脑卒中后认知障碍临床研究]. China Journal of Chinese Medicine 2013;28(4):608-10.

Lun 1999 \{published data only\}

Lun X, Peng ZF, Peng SZ. Clinical observation on the treatment of sequelae of stroke by needling temporal three points [颞 三针为主治疗中风后遗症的临床观察]. Journal of Clinical Acupuncture and Moxibustion 1999;15(4):8-9.

\section{Naeser 1992 \{published data only\}}

Naeser MA, Alexander MP, Stiassny-Eder D, Galler V, Hobbs J, Bachman D. Real versus sham acupuncture in the treatment of paralysis in acute stroke patients: a CT scan lesion site study. Journal of Neurorehabilitation 1992;6(4):163-73.

Sun 2013a \{published data only\}

Sun YT. Clinical study of post-stroke vascular cognitive impairment treatment with galvano-acupuncture and cognitive training [电针结合认知训练治疗梗死后血管性认知障碍的 临床研究] . Available at: http://cdmd.cnki.com.cn/Article/ CDMD-10572-1013226538.htm (accessed 8 August 2015) 2013.

\section{Sun 2015 \{published data only\}}

Sun YT, Bao YH, Wang SL, Chu JM, Li LP. Efficacy observation on the treatment of post-stroke depression by acupuncture at the acupoints based on ziwuliuzhu and Prozac [子午流注 取穴针刺配合百忧解治疗脑卒中后抑有疗效观察]. Chinese Acupuncture \& Moxibustion 2015;355(2):119-22.

\section{Wang 2001 \{published data only\}}

Wang ZY. Compared analyses among Chinese medicinal herbs, acupuncture and combination of them in the treatment of 
hemiplegia in stroke patients [中药、针刺、针药并举对 脑卒中偏瘫康复的疗效对比分析]. Modern Rehabilitation 2001;5(6):130.

\section{Wang 2011a \{published data only\}}

Wang X, Wang WQ. Observation on the treatment of fire needle therapy in 43 patients with shoulder-hand syndrome after stroke [火针疗法治疗肩手综合征43例]. Guangming Journal of Chinese Medicine 2011;26(4):754-6.

Wang 2012 \{published data only\}

Wang J, Cui X, Ni HH, Huang CS, Zhou CX, Wu Y, et al. Observation on the effects of interactive scalp acupuncture on motor function in patients with stroke [互动式头针治疗对脑 卒中患者运动功能的影响]. Chinese Journal of Rehabilitation Medicine 2012;27(10):941-3.

\section{Wu 2008 \{published data only\}}

Wu XM, Wang B. Efficacy observation on the treatment of depression caused by stroke in 40 patients by acupuncture and fluoxetine [针刺配合百忧解口服治疗脑卒中后抑郁障碍 40 例 疗效观察] . Chinese Journal of Difficult and Complicated Cases 2008;7(6):357-8

\section{Wu 2011a $\{$ published data only\}}

Wu W. Efficacy observation on the treatment of post-stroke strephenopodia by acupuncture and rehabilitation training [ 针 刺配合康复训练治疗中风偏痽侧足内翻疗效观察]. Shanghai Journal of Acupuncture - Moxibustion 2011;30(5):321-3.

\section{Wu 2013a $\{$ published data only\}}

Wu YL, Wang L, Tuo S, Yu X, Wang Q. Clinical study on the effects of acupuncture kinesitherapy for dysphagia caused by pseudobulbar paralysis after stroke [互动式针刺法对卒 中后假性延髓麻㾇吞咽困难的疗效]. Chinese Journal of Rehabilitation Medicine 2013;28(8):739-42,757.

\section{Xu 2013 \{published data only\}}

Xu JY, Zhou ZL, Wu J. Clinical observation on the treatment of post-stroke dysphagia by Tiaoshen Tongluo Acupuncture combined with Tongue 3-needle and acupuncturing Double Yifeng Acupoints [调神通络针法结合舌三针及针刺双侧毉 风穴治疗脑卒中后吞咽困难临床观察]. Journal of Zhejiang University of Traditional Chinese Medicine 2013;37(9):1117-8, 1132.

\section{Yao 2014 \{published data only\}}

Yao WJ. Clinical research on the effects of huici acupuncture combined with rehabilitation in the treatment of upper extremity dysfunction due to stroke [恢刺法结合康复训练 对脑卒中后上肢功能障碍影响的临床研究]. Available at: http://cdmd.cnki.com.cn/Article/CDMD-10315-1014409892.htm (accessed 8 August 2015) 2014.

\section{Zhan 2014 \{published data only\}}

Zhan LX. Acupuncture and moxibustion in combination with rehabilitation in the treatment of senile cerebral apoplexy hemiplegia: random parallel control study [针炎联合康复训练 治疗老年脑卒中偏瘫随机平行对照研究]. Journal of Practical Traditional Chinese Internal Medicine 2014;28(1):134-6.

\section{Zhang 2013a \{published data only\}}

Zhang ZR. Clinical research on treating post-stroke depression by electric acupuncture shenwuxing [电针神五星治疗中风 后抑郁的临床研究] . Available at: http://cdmd.cnki.com.cn/ Article/CDMD-10633-1014171987.htm (accessed 8 August 2015) 2013.

\section{Zhang 2015 \{published data only\}}

Zhan WY. Clinical research on the effects of scalp acupuncture combined with rehabilitation in the treatment of hemiplegia due to cerebral thrombosis [头针联合康复治疗脑血栓形成 偏瘫患者的临床研究] . Journal of Yanan University (Medical Sciences) 2015;13(1):35-7.

\section{Zheng 2014 \{published data only\}}

Zheng Q. Clinical study on the treatment of mild cognitive impairment after stroke by yishentiaodu acupuncture [益肾调督针法治疗脑卒中后轻度认知功能障碍的临 床研究] . Available at: http://cdmd.cnki.com.cn/Article/ CDMD-10228-1014250904.htm (accessed 8 August 2015) 2014.

\section{Zhou 2014 \{published data only\}}

Zhou YF. Acupuncture for poststroke depression: a single-center randomized controlled trial [针刺治疗缺血性脑卒中后抑郁的 随机对照试验]. Available at: http://cdmd.cnki.com.cn/Article/ CDMD-10344-1015546952.htm (accessed 8 August 2015) 2014.

\section{Zhu 2007 \{published data only\}}

Zhu XJ, Gao WB, Yang XY. Clinical observation on the effects of acupuncture combined with rehabilitative exercises in the treatment of shoulder subluxation after stroke [针刺结合康复 训练治疗中风后肩关节半脱位的临床观察]. Journal of Beijing University of Traditional Chinese Medicine 2007;14(3):23-5.

\section{References to studies excluded from this review}

Bai 2007 \{published data only\}

Bai L, Jin GY. Observation on the effects of acupuncture combined with rehabilitation on the neurologic function after stroke [针刺联合现代康复治疗脑梗死神经功能缺损的临 床研究] . Chinese Archives of Traditional Chinese Medicine 2007;25(4):838-9.

Bai 2011 \{published data only\}

Bai ZQ. Observation on the effects of acupuncture on aphasia following ischemic stroke [针刺治疗脑梗塞失语症疗效的观 察] . Chinese Journal of Ethnomedicine and Ethnopharmacy 2011;20(3):125.

\section{Bai 2013 \{published data only\}}

Bai YL, Li L, Hu YS. Prospective, randomized controlled trial of physiotherapy and acupuncture on motor function and daily activities in patients with ischemic stroke. Journal of Alternative and Complementary Medicine 2013;19:684-9.

\section{Bao 2008 \{published data only\}}

Bao J, Pan XH. Clinical observation of acupuncture combined with rehabilitation in the treatment of dysphagia after stroke [针刺加康复训练对脑卒中吞咽障碍的疗效观察]. Journal of Hebei Medical University 2008;29(6):876-7. 
Bao 2010 \{published data only\}

Bao ZY, Kang P, Zhu HQ, Yang CY. Efficacy observation on the treatment of pseudobulbar palsy due to stroke by auditory evoked potential acupuncture [听觉诱发电位对针刺治疗中 风后假性球麻痹疗效评定]. Chinese Journal of Misdiagnosis 2010;10(36):8857-8.

\section{Bao 2012a \{published data only\}}

Bao YH, Wang YW, Chu JM, Zhu GX, Wang CM, Hou HM. Observation of the curative effect of electrical acupuncture combined with rehabilitation on shoulder pain following hemiplegia [电针结合康复对中风后偏瘫肩痛患者疼痛及上肢 运动功能改善作用的临床观察]. Chinese Archives of Traditional Chinese Medicine 2012;19(1):59-60.

\section{Cai 2010 \{published data only\}}

Cai SH, Yan LH, Nie B. Clinical observation on the treatment of apoplexy hemiplegia by electrical acupuncture at the back shu points and the front mu points [俞募穴电针治疗中风偏 瘫临床观察]. Clinical Journal of Traditional Chinese Medicine 2010;22(2):124-6.

\section{Calabro 2011 \{published data only\}}

Calabro S. Scalp acupuncture for stroke. Acupuncture Today 2011; Vol. 12:37.

\section{Cao 2010a \{published data only\}}

Cao RL, Yang GQ, Huang LP, Zhang ZC. Acupuncture at tongue tri-point and ren ying point for swallowing dysfunction after stroke [舌三针及人迎穴为主治疗脑卒中后吞咽功能障碍] Shanxi Journal of Traditional Chinese Medicine 2010;31(1):89.

\section{Cao 2010b \{published data only\}}

Cao XQ. Acupuncture combined with dialectical treatment for 54 cases with pseudobulbar palsy after stroke [辨证论治配 合针刺治疗假性球麻痹54例]. Chinese Journal of Traditional Chinese Medicine 2010;22(8):718.

\section{Chang 2010 \{published data only\}}

Chang JL, Gao Y, Li SL, Wang J, Cao KG, Ma B. Effect of acupuncture and speech rehabilitation on motor aphasia after stroke [针刺配合语言康复治疗脑卒中后运动性失 语]. Chinese Journal of Rehabilitation Theory and Practice 2010;16(1):58-9.

\section{Chao 2009 \{published data only\}}

Chao WB. Clinical study on treatment of aphasia due to apoplexy by acupuncture [针炎治疗中风失语症临床研究] . Chinese Journal of Basic Medicine in Traditional Chinese Medicine 2009;15(8):619,625.

\section{Chau 2009 \{published data only\}}

Chau AC, Cheung RT, Jiang X. Acupuncture of motor-implicated acupoints on subacute stroke patients: an fMRI evaluation study. Medical acupuncture 2009;21(4):233-41.

\section{Che 2002 \{published data only\}}

Che JL. Clinical observation on the treatment of sequelae of stroke in 40 patients with relatively long duration by needling abdominal points. Jiangshu Traditional Chinese Medicine 2002:23(1):31-2.

\section{Chen 2000 \{published data only\}}

Chen ZF, Jiang GH, Lai XS. Clinical observation on the effects of electronic acupuncture treating vascular dementia [电针治 疗血管性痴呆临床疗效观察] . Journal of Clinical Acupuncture and Moxibustion 2000;16(12):18-20.

\section{Chen 2007 \{published data only\}}

Chen W, Gu HW, Liu XQ, Yu Q, Liu SH, Liu HL. Observation on the effects of neurological function in patients with ischemic stroke by needing Zusanli and Xuanzhong points [针刺足三里、悬 钟对缺血性脑卒中神经功能的影响及其临床意义]. Chinese Journal of Rehabilitation Medicine 2007;22(12):1110-1.

\section{Chen 2008a \{published data only\}}

Chen AL, Li XP, Yu JL, Shi WH, Zhou J, Wang W. Effect of nerve trunk acupuncture combined with rehabilitation on hand function of stroke patients [针刺神经干及康复训练对脑卒中 患者手功能的影响]. Chinese Journal of Rehabilitation Medicine 2008;23(6):416.

\section{Chen 2008b \{published data only\}}

Chen M. Results of acupuncture on the dysphagia due to cerebral stroke [针刺治疗对脑卒中吞咽障碍康复的效果]. China Tropical Medicine 2008;8(12):2177, 2194.

\section{Chen 2009 \{published data only\}}

Chen YQ. Clinical study with SEMG on efficacy of acupuncture in combination with rehabilitation in relieving the foot drop of the patients with stroke [针炎配合康复治疗对中风偏痽后足下垂 疗效的表面肌电研究] . Available at: http://cdmd.cnki.com.cn/ Article/CDMD-10315-2009252155.htm (accessed 8 August 2015) 2009.

\section{Chen 2010a \{published data only\}}

Chen X, Chen YF, Mao M, Mou X, Rao P, Bai Y. Clinical research on the effects of acupuncture therapy combined with contemporary rehabilitation techniques for hemiplegia and spasticity caused by apoplexy [针刺结合现代康复技术治疗中 风偏瘫痉挛状态的临床研究]. Journal of Chengdu University of TCM 2010;33(1):27-9.

\section{Chen 2010b \{published data only\}}

Chen YY. Clinical observation on the effects of acupuncture combined with rehabilitation for patients with limb spasticity after stroke [针刺配合康复疗法对中风病肢体痉挛患者的 临床观察] . Available at: http://cdmd.cnki.com.cn/Article/ CDMD-10572-2010126355.htm (accessed 8 August 2015) 2010.

\section{Chen 2012a \{published data only\}}

Chen HY. Clinical observation on Quanjing acupuncture therapy combined with rehabilitation training for treatment of hemiplegia and spasticity caused by apoplexy [全经针 刺法结合康复训练治疗恢复期中风偏瘫痉挛状态的临 床观察]. Available at: http://cdmd.cnki.com.cn/Article/ CDMD-10541-1012401427.htm (accessed 8 August 2015) 2012.

Chen 2012b \{published data only\}

Chen YH, Jiang TZ, Zhang B, Huang W, Liu N, Cao SJ. Clinical study on acupuncture in the treatment of swallowing dysfunction from apoplexy [针刺治疗脑梗死后吞咽障碍 
临床研究] . Clinical Journal of Traditional Chinese Medicine 2012;24(11):1067-9.

\section{Chen 2013 \{published data only\}}

Chen LF. Acupuncture for young ischemic stroke: a controlled randomized trial. ChiCTR Chinese Clinical Trial Register (http:// www.chictr.org/) (ChiCTR-TRC-13003317) (accessed 8 August 2015) 2013.

\section{Chen 2014 \{published data only\}}

Chen CY, Ge LB, Xu MS. Clinical study on the evaluation of acupuncture in treating ischemic stroke of recovery stage mostly based on static equilibrium [以静态平衡为主评估针 刺治疗缺血性中风恢复期临床疗效]. Shanghai Journal of Acupuncture and Moxibustion 2014;33(4):291-5.

\section{Cheng 2006 \{published data only\}}

Cheng Y, Tang QS. Clinical random control study of acupuncture on treating stagnation of liver-qi with deficiency of the spleen syndrome of gerontic depressive disorder after stroke [针刺 治疗老年期中风后郁证肝郁脾虚候的随机对照临床研究]. Journal of TCM Brain Diseases 2006;2(2):129-32.

\section{Cheng 2007 \{published data only\}}

Cheng Y, Tang QS. Abdominal acupuncture in treating liverqi stagnation and spleen deficiency in the elderly with poststroke depression: A randomized and controlled observation [腹针治疗老年期脑卒中后郁证肝郁脾虚候的随机对照观察]. Journal of Clinical Rehabilitative Tissue Engineering Research 2007;11(39):7791-4.

\section{Cheng 2011 \{published data only\}}

Cheng XK, Wang ZM, Sun L. Post-stroke hand dysfunction treated with acupuncture at Zhongzhu (TE 3) and Waiguan (TE 5) [针刺中渚、外关治疗脑卒中后手功能障碍]. Chinese Acupuncture \& Moxibustion 2011;31(2):117-20.

Chow 2006 \{published data only\}

Chow ESL, Lau PMY, Chau RMW. Effectiveness of acupuncture treatment in stroke rehabilitation. Neurorehabilitation and Neural Repair 2006;20:209.

\section{Chu 2007 \{published data only\}}

Chu YJ, Wang CY, Zhang Y. Clinical observation of acupuncture for 72 cases with depression after stroke [针刺治疗脑卒中 后抑郁症72例临床观察]. Chinese Journal of Gerontology 2007;27(9):1720-1.

\section{Chu 2009 \{published data only\}}

Chu GX, Yi XQ. Clinical observation on the treatment of spastic paralysis by electrical acupuncture combined with rehabilitation [电针结合康复疗法治疗中风痉㨻性㿈疾的 临床观察]. Hubei Journal of Traditional Chinese Medicine 2009;31(8):13-4.

\section{Cui 1992 \{published data only\}}

Cui YY, Zhao JH, Huang WC, Wang AP. Observation on the effects of acupuncture in the treatment of compulsive crying and laughing due to multiple cerebral infarction [针刺治疗多发性 脑梗塞性强哭强笑症的疗效观察]. Journal of Acupuncture and Moxibustion 1992;1:19-20.
Ding 2000 \{published data only\}

Ding BY, Cui YJ. Observation on the effects of acupuncture and cupping in the treatment of arthritic spasm in 52 stroke patients. Shanghai Journal of Acupuncture and Moxibustion 2000;19(3):28.

\section{Dong 2007a \{published data only\}}

Dong G. The optimized scheme of acupuncture treatment on symptom based stroke sequelae and clinical assessment on generic technology. ChiCTR Chinese Clinical Trial Register (http://www.chictr.org/Site/English/Index.htm) ( ChiCTRTRC-08000209) (accessed 8 August 2015) 2007.

\section{Dong 2007b \{published data only\}}

Dong JP, Sun WY, Wang S, Wu ZQ, Liu F. Clinical observation on the effects of head point-through-point electroacupuncture for treatment of poststroke depression [头部电针透穴治疗脑 卒中后抑郁症临床观察]. Chinese Acupuncture \& Moxibustion 2007;27(4):241-4.

Dong 2008a \{published data only\}

Dong G. Clinical curative effect and safe research on treatment of haemorrhagic stroke with stage acupuncture. ChiCTR Chinese Clinical Trial Register (http://www.chictr.org/) (ChiCTRTRC-08000225) (accessed 8 August 2015) 2008.

Dong 2008b \{published data only\}

Dong JL, Xi GM, Zhou SH. Study of acupuncture Lianquan point combined with Fengchi point for 32 patients with pseudobulbar palsy after stroke [风池配合廉泉穴针炎治疗脑卒中后假性延 髓性麻㿔32 例] . Chinese Journal of Practical Nervous Diseases 2008;11(1):38-9.

Dong 2009 \{published data only\}

Dong Y, Liu G, Wang T. Tongdu Kaiyin acupuncture for 30 patients with aphasia after stroke [通督开喑针法治疗脑卒中失 语症30例]. Journal of Anhui Traditional Chinese Medical College 2009;28(1):34-6.

\section{Du 2013 \{published data only\}}

Du GY. Observation on the effects of acupuncture for 100 cases with postapoplectic pseudobulbar palsy [针炎治疗中风后 假性球麻痹100例] . Journal of Medical Theory and Practice 2013;25(1):40-1.

\section{Duan 2010 \{published data only\}}

Duan YW, Sun XJ, Feng X, Xu JX. Observation of 40 patients with postapoplectic pseudobulbar palsy treated by acupuncture [针刺治疗脑卒中后假性球麻痹40 例]. Yunnan Journal of Traditional Chinese Medicine and Materia Medica 2010;31(10):45-6.

Duan 2014 \{published data only\}

Duan JY, Ding BY, Zong L. Clinical observation of acupuncture at the thirteen ghost Aacupoints for post-stroke anxiety and depression [针刺十三鬼穴为主治疗脑卒中焦虑抑郁共病临 床观察]. Shanghai Journal of Acupuncture and Moxibustion 2014;33(6):536-8. 
Fang 2009 \{published data only\}

Fang GF, Liu JD. Effect of acupuncture combined with function training for post-stoke dysphagia [针刺配合功能训练治疗脑 卒中后吞咽障碍疗效分析]. Modern Medicine Journal of China 2009;11(11):54-7.

\section{Feng 1996a \{published data only\}}

Feng SL, Guo ZQ, Xie GR. Observation on the clinical effects of hemiplegia from apoplexy treated by needling Feng Fu, Ya Men points. Journal of Hunan College of Traditional Chinese Medicine 1996;16(3):61-4.

\section{Feng 1996b \{published data only\}}

Feng SL, Guo ZQ, Xie GR. Clinical observation and experimental studies on the treatment of cerebral thrombus by needling "Feng Fu, Ya Men" points. Journal of Guangzhou University of Traditional Chinese Medicine 1996;13(2):20-3.

Feng 2011 \{published data only\}

Feng X. Acupuncture for 68 cases with supranuclear paralysis caused by stroke [针刺鷖风穴配合咽后壁点刺治疗假性延髓 麻痹68 例]. Guangming Journal of Traditional Chinese Medicine 2011;26(5):1007.

Fink 2004 \{published data only\}

Fink M, Rollnik JD, Bijak M, Borstädt C, Däuper J, Guergueltcheva V, et al. Needle acupuncture in chronic poststroke leg spasticity. Archives of Physical Medicine and Rehabilitation 2004;85(4):667-72.

Fu 2010 \{published data only\}

Fu WB, Guo Y, Chen XK. Comprehensive therapeutic protocol of electroacupuncture combined with Chinese herbs and rehabilitation training for treatment of cerebral infarction: a multi-center randomized controlled trial [ 电针联合中药、康 复训练综合方案治疗脑梗死: 多中心随机对照研究]. Chinese acupuncture \& moxibustion 2010;30(1):6-9.

\section{Fu 2013 \{published data only\}}

Fu LX. Acupuncture treatment of ischemic stroke basal ganglia aphasia clinical curative effect evaluation: a randomized controlled study. ChiCTR Chinese Clinical Trial Register (http:// www.chictr.org/) ( ChiCTR-TRC-12003168) (accessed 8 August 2015) 2013

\section{Fu 2014 \{published data only\}}

Fu ZY, Li XR, Wu QM, Li DD, Liu WA. Clinical observation on acupuncture and Chinese medicine combined with stroke unit for treatment of ischemic stroke at convalescence stage [针 刺和中药结合卒中单元治疗缺血性脑卒中恢复期患者的临 床研究] . Chinese Journal of Integrative Medicine on Cardio/ Cerebrovascular Disease 2014;12(1):48-51.

Gao 2001 \{published data only\}

Gao HY, Yan LF, Liu BB. Clinical study on treatment of senile vascular dementia by acupuncture. Journal of Traditional Chinese Medicine 2001;21(2):103-9.

\section{Gao 2008 \{published data only\}}

Gao CY. Clinical observation on the effects of rehabilitation combined with acupuncture in the treatment of dysphagia after stroke [脑卒中后吞咽困难康复训练加针刺治疗疗效观察] . Chinese Journal of Gerontology 2008;28(12):2486-7.

Gao 2011 \{published data only\}

Gao GY. Clinical research on the treatment of hemiplegia after stroke by scalp acupuncture and Brunnstrom technique [头 针配合Brunnstrom促通技术治疗缺血性脑卒中后偏瘫患者 的临床研究] . Available at: http://cdmd.cnki.com.cn/Article/ CDMD-10507-1012253202.htm (accessed 8 August 2015) 2011.

Gao 2014b \{published data only\}

Gao ZQ. Research on the treatment of hemiplegia after stroke by optimized techniques of acupuncture and moxibustion [针炎康复优化技术治疗中风后偏痽的研究]. Available at: http://cdmd.cnki.com.cn/Article/CDMD-10369-1014334635.htm (accessed 8 August 2015) 2014.

Gong 2008 \{published data only\}

Gong $\mathrm{H}$. The clinical investigation of ultrasound, laser therapy and acupuncture for patients with cerebral infarction [超声、 激光加针炎治疗脑梗塞的临床研究]. Available at: http:// cdmd.cnki.com.cn/article/cdmd-10422-2008189373.htm (accessed 8 August 2015) 2008.

\section{Gu 2007 \{published data only\}}

Gu HW, Ma WP, Chen W, Li QS, Liu XQ, Liu SH. Treatment of ischemic stroke by acupuncture at Zusanli and Xuanzhong [针刺足三里和悬钟治疗缺血性脑卒中]. Journal of Clinical Rehabilitation Tissue Engineering Research 2007;11(25):4931-3.

\section{Gu 2009 \{published data only\}}

Gu YC. Clinical research on the effects of acupuncture at Jinjinyuye point combined with speech therapy for broca aphasia after stroke [针刺金津玉液结合语言康复训练治 疗中风后运动性失语的临床研究]. Available at: http:// cdmd.cnki.com.cn/Article/CDMD-10393-2009201641.htm (accessed 8 August 2015) 2009.

\section{Guan 2009a \{published data only\}}

Guan CX, Guo GH, Yu L. Observation on the effects of acupuncture plus deglutition training in the treatment of dysphagia caused by stroke [针刺配合吞咽训练治疗脑 卒中后吞咽障碍的疗效观察]. Journal of Medical Forum 2009;30(4):19-23.

\section{Guan 2009b \{published data only\}}

Guan CY. Observation on therapeutic effect of Youxuan acupuncture and rehabilitation exercise in the treatment of hemiplegia after apoplexy [针刺优选法结合现代康复 治疗脑卒中后偏㿈临床疗效观察]. Available at: http:// cdmd.cnki.com.cn/article/cdmd-10760-2009119611.htm (accessed 8 August 2015) 2009.

\section{Guan 2013 \{published data only\}}

Guan C. Clinical research on the effects of acupuncture at heel vessel points and rehabilitation training in the treatment of strephenopodia after cerebral infarction [针刺跷脉穴结合 康复训练治疗脑梗死后足内翻的临床研究]. Available at: http://cdmd.cnki.com.cn/Article/CDMD-10541-1013183193.htm (accessed 8 August 2015) 2013. 
Guo 1999 \{published data only\}

Guo XY, Wei YF. Clinical observation on the effects of acupuncture in the treatment of muscular spasm in 124 stroke patients. Chinese Acupuncture and Moxibustion 1999;9:553.

\section{Guo 2006a \{published data only\}}

Guo XL. Effects of scalp acupuncture combined with function training on the gait of stroke patients [头针结合康复训练 对脑卒中后患者偏瘫步态的影响] . Available at: http:// cdmd.cnki.com.cn/Article/CDMD-10393-2006162983.htm (accessed 8 August 2015) 2006.

Guo 2006b \{published data only\}

Guo Y. Therapeutic effect observation of acupoint blocking on shoulder joint subluxation of post-apoplexy [穴位封闭治疗中 风后肩关节半脱位疗效观察]. Shanxi Journal of Traditional Chinese Medicine 2006;22(3):39-40.

Guo 2013 \{published data only\}

Guo QS. Clinical observation on the treatment of stroke hemiplegia by acupuncture combined with Chinese medicine [针刺联合中药治疗中风偏瘫临床观察]. Journal of Liaoning University of TCM 2013;15(1):187-9.

Han 2008 \{published data only\}

Han P. Effects of scalp acupuncture and occupation therapy on motor functions of the upper limb in patients with stroke [头 针结合作业疗法对脑卒中患者上肢运动功能及生活自理能力 影响的临床对照研究] . Available at: http://cdmd.cnki.com.cn/ Article/CDMD-10393-2008207891.htm (accessed 8 August 2015) 2008.

\section{Han 2010 \{published data only\}}

Han XY, Liu Y. Clinical observation of acupuncture combined with rehabilitation in the treatment of dysphagia after stroke [针刺结合康复护理治疗脑卒中后吞咽困难的临床研究]. China New Technologies and Products. 2010;4:15.

\section{Han 2011 \{published data only\}}

Han DX, Zhuang LX, Zhang Y. Evaluation on efficacy of Jin's "Sanzhen" therapy combined with rehabilitation training for hemiplegia of stroke patients by Fugl-Meyer scale [用FuglMeyer 量表评价靳三针结合康复训练对脑梗死偏瘫的疗效] . Acupuncture research 2011;36(3):209-14.

\section{Han 2012 \{published data only\}}

Han N. Acupuncture combined with rehabilitation training for swallowing dysfunction following stroke [针刺配合康复训练 治疗中风后吞咽功能障碍]. Journal of Community Medicine 2012;10(9):32-3

\section{Han 2014 \{published data only\}}

Han J, Wu Y. Post-stroke patients with dysarthria treated by acupuncture at neck points, tongue acupuncture plus speech rehabilitation training: a randomized parallel controlled study [项针、舌针联合言语康复训练治疗脑卒中后构音障碍随机平 行对照研究] . Journal of Practical Traditional Chinese Internal Medicine 2014;28(5):135-7.
Hang 2014 \{published data only\}

Hang FJ, Fu XY, Wang TT, Dai DC, Tang CL, He XG. Effects of oral placement therapy combined with acupuncture of specific points on dysphagia after stroke [口腔定位疗法联合特定 穴位针刺对脑卒中后吞咽障碍的影响]. Chinese Journal of Rehabilitation Medicine 2014;29(12):1129-33.

He 2008 \{published data only\}

He YJ. Clinical study on treating urinary incontinence after stroke by acupuncture [针炎治疗脑卒中后尿失禁的临 床研究] . Available at: http://cdmd.cnki.com.cn/Article/ CDMD-10572-2008100424.htm (accessed 8 August 2015) 2008.

Hegyi 2012 \{published data only\}

Hegyi G, Szigeti G. Rehabilitation of stroke patients using Yamamoto New Scalp Acupuncture: a pilot study. Journal of Alternative \& Complementary Medicine 2012;18(10):971-7.

\section{Hong 2013 \{published data only\}}

Hong YB, Cheng HY, Wang GL, Xia SW, Liu H, Liu HL. Clinical research of special acupuncture therapy by TCM differentiation on improving quality of life in patients of ischemic stroke [辨 证应用特色针刺疗法对缺血性脑卒中患者生活质量的改善] Journal of Medical Research 2013;42(2):41-5.

Hou 1998 \{published data only\}

Hou AL, Wang L, Pu Y. Clinical observation of treatment of multi-infarctional dementia by herbs, oxygen and acupuncture. Shanghai Journal of Acupuncture and Moxibustion 1998;17(2):12-3.

\section{Hsing 2012 \{published data only\}}

Hsing W, Imamura M, Weaver K, Fregni F, Azevedo Neto RS. Clinical effects of scalp electrical acupuncture in stroke: a shamcontrolled randomized clinical trial. Journal of Alternative \& Complementary Medicine 2012;18(4):341-6.

\section{Hu 2011 \{published data only\}}

$\mathrm{Hu}$ JK, Hu KM, Hu T. Clinical research of acupuncture combined with speech training for spasmodic dysphonia after apoplexy [针刺结合语言训练治疗脑卒中痉挛型构音障碍的临床 研究]. Journal of Sichuan of Traditional Chinese Medicine 2011;29(2):117-9.

\section{Hu 2012 \{published data only\}}

Hu SL. Balanced muscular tension needling method with Shenqifutan capsule treatment of cerebral infarction recovering from clinical observation [张力平衡针法配合参芪复瘫胶 囊治疗脑梗塞恢复期的临床观察]. Available at: http:// cdmd.cnki.com.cn/article/cdmd-10541-1012401619.htm (accessed 8 August 2015) 2012.

Huang 2002 \{published data only\}

Huang HS, Huang X. Effects of "Chuan Xiong Qin and Huang Qi" on the treatment of upper and lower limbs pain due to stroke in 50 patients. Research of Traditional Chinese Medicine 2002;18(1):9-10. 
Huang 2008b \{published data only\}

Huang F, Liu Y, Zhou FX. Effects of acupuncture on vascular cognitive impairment after stroke [针刺对脑梗死后血管性认知 障碍的影响] . Guangdong Medical Journal 2008;29(11):1918-20.

\section{Huang 2008c \{published data only\}}

Huang F. Clinical observation on puncturing mainly back-shu points for treating blood-stasis blocking collateral type of ischemic apoplexy [针刺背俞穴为主治疗气虚血瘀型缺血性中 风的临床观察]. Available at: http://cdmd.cnki.com.cn/Article/ CDMD-10572-2008100417.htm (accessed 8 August 2015) 2008.

\section{Huang 2011 \{published data only\}}

Huang ZJ, Chen JX, Chang ZY. Clinic analysis of half-lengthflabbiness after hemiplegia stroke treated by acupuncture combined with rehabilitation training [针炎配合康复训练治 疗脑卒中后半身不遂的临床研究]. China Journal of Chinese Medicine 2011;26(9):1149-50.

\section{Huang 2012 \{published data only\}}

Huang GW. Clinical study of acupuncture treatment for fecal and urine incontinence after stroke [针刺治疗中风后大小便失 禁的临床研究]. Available at: http://cdmd.cnki.com.cn/Article/ CDMD-10315-1012402005.htm (accessed 8 August 2015) 2012.

\section{Huang 2014 \{published data only\}}

Huang LL. Randomized controlled clinical study on Shenque Fuxi Bagua acupuncture therapy in treating constipation after stroke [神阙伏羲八卦针刺疗法治疗中风后便秘的随机对 照临床研究] . Available at: http://cdmd.cnki.com.cn/Article/ CDMD-10633-1015543271.htm (accessed 8 August 2015) 2014.

\section{Jia 2012 \{published data only\}}

Jia CJ, Ni GX, Tan H, Zhang X. Clinical observation on the effects of acupuncture combined with rehabilitation in the treatment of stage-IV shoulder-hand syndrome from apoplexy [康复训 练结合针炎治疗脑卒中后肩手综合征IV期临床疗效观察]. Journal of Changchun University of Traditional Chinese Medicine 2012;28(4):711-2.

\section{Jiang 1998 \{published data only\}}

Jiang GH, Li YH, Yang WH. Clinical observation on treatment of sequelae of stroke with CT localization acupuncture. Shanghai Journal of Acupuncture and Moxibustion 1998;17(2):6-7.

\section{Jiang 2000 \{published data only\}}

Jiang ZY, Li CD. Needling paravertebral points in treatment of post-stroke thalamic pain. International Journal of Clinical Acupuncture 2000;11(1):7-10.

\section{Jiang 2006 \{published data only\}}

Jiang $\mathrm{H}$, Wen XY, Shi TH, Zhang SM. Efficacy observation on the treatment of depression due to lacunar infarction by electroacupuncture [电针刺激治疗腔隙性脑梗死后抑有 状态的疗效观察]. Chinese Journal of Physical Medicine and Rehabilitation 2006;28(12):807-10.

\section{Jiang 2009 \{published data only\}}

Jiang D, Zhang L, Li B. Acupuncture for 27 cases with dysphagia after stroke [针刺治疗假性延髓麻痹吞咽障碍27例]. Chinese Journal of Clinical Healthcare 2009;12(5):518-9.

\section{Jiang 2010 \{published data only\}}

Jiang Y, Zhu JG, Xiong J. Clinical observation of consciousness restoring obstruction clearing needling technique in the treatment of subacute cerebral hemorrhage [醒脑开空针 刺法治疗亚急性期脑出血的临床观察]. Chinese Journal of Ethnomedicine and Ethnopharmacy 2010;19(18):89-90.

Jiang 2011a \{published data only\}

Jiang L, Zhao J. Acupuncture combined with drugs in the treatment of post-stroke depression [针炎结合药物治疗脑卒 中后抑有的临床研究]. Journal of Clinical Acupuncture and Moxibustion 2011;27(11):15-7.

Jiang 2011b \{published data only\}

Jiang YJ. Electroacupuncture DU20 and DU24 treatment on cognitive impairment after stroke [电针百会、神庭对脑卒中后 认知功能障碍的影响] . Available at: http://cdmd.cnki.com.cn/ article/cdmd-10393-1011220783.htm (accessed 8 August 2015) 2011.

\section{Jiang 2012 \{published data only\}}

Jiang L. Clinical research on acupuncture treatment for pseudobulbar paralysis after stroke [针刺治疗脑卒中后假性 延髓麻㿎的临床研究] . Available at: http://cdmd.cnki.com.cn/ Article/CDMD-10228-1012468023.htm (accessed 8 August 2015) 2012.

\section{Jiang 2013 \{published data only\}}

Jiang P, Zheng ZY. Clinical observation on the treatment of hemiplegia spasticity by acupuncture antagonist muscle corresponding acupoints and Bobath therapy [针刺拮抗肌相应 穴位结合Bobath 疗法治疗偏瘫疼挛状态的临床观察]. Journal of Clinical Acupuncture and Moxibustion 2013;29(1):18-20.

\section{Jin 1993 \{published data only\}}

Jin R, Lai XS, Li YH, Liang RA. Clinical observation on the treatment of sequelae of stroke with three temporal needling. Chinese Acupuncture and Moxibustion. 1993;2:11-2.

\section{Jin 2010a \{published data only\}}

Jin CX. Clinical research of acupuncture combined with rehabilittion for upper limber spasticity induced by stroke [针刺结合康复治疗中风偏瘫上肢痉挛状态的临床 研究] . Available at: http://cdmd.cnki.com.cn/Article/ CDMD-87801-2010263051.htm (accessed 8 August 2015) 2010.

\section{Jin 2010b \{published data only\}}

Jin RJ, Zhu TM, Wang Q. Effects of electric acupuncture at acupoint of antagonistic muscles combined with facilitation techniques on motor function and activity of daily living in patients with hemiplegia caused by cerebral infarction [电针拮 抗肌腧穴复合易化技术对脑梗塞后偏瘫患者运动功能及日常 生活能力的影响]. Journal of Chengdu University of Traditional Chinese Medicine 2010;33(3):9-12.

Kang 2011 \{published data only\}

Kang JJ. Clinical study on the effects of electroacupuncture on GV20 and EX-HN1 on stroke patients with cognitive impairment [电针百会及四神聪治疗脑卒中认知障碍患者的临床疗 效观察] . Available at: http://cdmd.cnki.com.cn/Article/ CDMD-10393-1011220779.htm (accessed 8 August 2015) 2011. 
Kang 2013 \{published data only\}

Kang GF, Chen JH, Li TL, Wu QM, Yang RF. Efficacy of Shen-qi Fu-tan capsule and tension balance acupuncture on cerebral infarction at convalescence: a clinical observation of 30 cases [参芪复瘫胶囊联合张力平衡针法治疗脑梗死恢复期 30 例临 床观察] . Guiding Journal of Traditional Chinese Medicine and Pharmacy 2013;19(12):14-6.

\section{Kjendahl 1997 \{published data only\}}

Kjendahl A, Sallstrom S, Osten PE, Stanghelle JK. A one year follow-up study on the effects of acupuncture in the treatment of stroke patients in the subacute stage: a randomized, controlled study. Clinical Rehabilitation 1997;11:192-200.

\section{Lai 1997a \{published data only\}}

Lai XS. Observation on the effects of acupuncture in the treatment of senile vascular dementia. Chinese Acupuncture and Moxibustion. 1997;4:201-2.

\section{Lai 1997b \{published data only\}}

Lain XS, Zhang JW, Muo FZ, Jiang GH, Li JQ, Zheng ZC. Clinical observation on the effects of acupuncture in the treatment of vascular dementia. Chinese Acupuncture and Moxibustion. 1997;12:713-6.

\section{Lai 1998 \{published data only\}}

Lai XS, Muo FZ, Jiang GH, Li JQ, Chen JL, Kuang ZY. Observation of clinical effect of acupuncture on vascular dementia and its influence on superoxide dismutase, lipid peroxide and nitric oxide. Chinese Journal of Integrated Traditional and Western Medicine 1998;18(11):648-51.

\section{Lai 2004 \{published data only\}}

Lai XS, Liu JY, Jiang GM. Effect of combination of acupuncture treatment at Liench' tian and plum blossom needle treatment at the tip of tongue on aphasia after stroke and its significance on hemorheology. Chinese Journal of Clinical Rehabilitation 2004;8(19):3818-20.

\section{Lai 2011 \{published data only\}}

Lai J. Clinical research of acupuncture combined with rehabilitation therapy for dysarthria after stroke [针刺结 合康复治疗脑卒中后构音障碍的临床研究]. Available at: http://cdmd.cnki.com.cn/article/cdmd-10633-1011155206.htm (accessed 8 August 2015) 2011.

\section{Lang 2013 \{published data only\}}

Lang JY, Zhuang LX, He J, Jia C, Zhou SH, Ke LP. Randomized controlled study on Jin's three needle therapy on spastic hemiplegia after ischemic stroke ["靳三针"疗法治疗缺血 性中风后痉挛性偏瘫随机对照研究]. Shanghai Journal of Acupuncture and Moxibustion 2013;32(6):440-3.

\section{Lao 2013 \{published data only\}}

Lao LZ. Clinical research on motility dysarthria after stroke treated with acupuncture combining with rehabilitation training [针刺结合康复训练治疗脑卒中后运动性构音障碍 的临床研究] . Available at: http://cdmd.cnki.com.cn/Article/ CDMD-10572-1013229348.htm (accessed 8 August 2015) 2013.

\section{Lee 2007 \{published data only\}}

Lee SW, Yun JM, Son JW, Kang BG, Park SM, Yun H J. The effect of electroacupuncture on upper-extremity spasticity of stroke patients. Journal of Korean Oriental Medicine 2007;28:492-501.

\section{Lee 2009 \{published data only\}}

Lee SY, Baek YH, Park SU. Intradermal acupuncture on ShenMen and Nei-Kuan acupoints improves insomnia in stroke patients by reducing the sympathetic nervous activity: a randomized clinical trial. American Journal of Chinese Medicine 2009;37(6):1013-21.

\section{Lei 2013 \{published data only\}} Lei YQ, Li RL, Lin QF, Han ZY, Wu CH, Huang XH. Zengshi Taichi acupuncture for 65 patients with pseudobulbar palsy after stroke [曾氏太极针法治疗脑卒中后假性球麻 㾇65例] . Liaoning Journal of Traditional Chinese Medicine 2013;40(4):780-1.

\section{Li 1993 \{published data only\}}

$\mathrm{Li} \mathrm{YH,} \mathrm{Jin} \mathrm{R.} \mathrm{Three} \mathrm{forms} \mathrm{of} \mathrm{acupuncture} \mathrm{in} \mathrm{the} \mathrm{treatment} \mathrm{of}$ sequelae of cerebrovascular accident. Chinese Acupuncture and Moxibustion 1993;4:35-8.

\section{Li 1994a \{published data only\}}

Li CD, Huang Y, LI YK, Hu KM, Jiang ZY. Treating post-stroke depression with "mind-refreshing antidepressive" acupuncture therapy: a clinical study of 21 cases. International Journal of Clinical Acupuncture 1994;5(4):389-93.

Li 1994b \{published data only\}

$\mathrm{Li} \mathrm{YH}$, Jin R. Clinical study in the treatment of sequelae of cerebrovascular accident with needling temporal points. Acupuncture Research 1994;19(2):4-6.

\section{Li 1997b \{published data only\}}

Li YH, Yang WH, Zhuang LX, Zheng L. Clinical study of acupuncture in the treatment of vascular dementia. Acupuncture Research 1997;3(1):22-4.

\section{Li 2006a \{published data only\}}

Li CY, Fan YZ, Xue WH, Tian Y, Yan L, Ni AH. Clinical study on Baihui(GV 20) acupuncture in treating cerebral infarction [针 刺百会穴治疗脑梗塞的临床研究]. Shanghai Journal of Traditional Chinese Medicine 2006;40(6):19-20.

\section{Li 2006b \{published data only\}}

Li GC, Zhao X. Clinical observation on treatment of apoplectic aphasia by acupuncture plus rehabilitation [针刺配合康复治疗 脑卒中失语的临床观察]. Shanghai Journal of Acupuncture and Moxibustion 2006;25(9):13-4.

\section{Li 2006c \{published data only\}}

Li J, Wang Y, Liu B. Observation on the curative effects of acupuncture combined with rehabilitation on postapoplectic shoulder pain [针炎结合康复手法治疗脑卒中后肩痛的疗 效观察]. Chinese Journal of Trauma and Disability Medicine 2006;14(1):37-8. 


\section{Li 2006d \{published data only\}}

Li T, Tian GJ, Zhang L, Wei GW, Ma Q, Han JX. Clinical study of acupuncture on the neurological function in postoperative patients with extensive cerebral infarction [针刺对大面积 脑梗塞术后病人神经功能的影响]. Shanghai Journal of Acupuncture and Moxibustion 2006;25(9):3-5.

\section{Li 2006e \{published data only\}}

Li T, Zhao JG, Tian GJ, Zhang L, Liu SJ. Clinical observation on the effects of acupuncture on neurological function in patient after operation of hypertensive cerebral hemorrhage [针刺对高 血压脑出血术后病人神经功能的影响]. Chinese Acupuncture \& Moxibustion 2006;26(4):247-9.

\section{Li 2008a \{published data only\}}

Li JA, Li JL. Clinical observation on the effects of acupuncture in the treatment of dysphagia induced by ischemic stroke [ 针 刺治疗缺血性中风后吞咽困难的临床观察] . Journal of Beijing University of Traditional Chinese Medicine 2008;15(4):17-9.

\section{Li 2008b \{published data only\}}

Li P, Sun GF, Yao GM, Yan RY, Xia MH, Zhang WJ. Clinical observations on the treatment of dysphagia induced by pseudobulbar palsy by acupuncture plus rehabilitation therapy [针刺联合康复治疗脑卒中后吞咽障碍的临床观察]. Shanghai Journal of Acupuncture and Moxibustion 2008;27(5):10-1.

\section{Li 2008c \{published data only\}}

Li SW, Zhang ZX. Efficacy observation on the rehabilitation of stroke by acupuncture [针刺在脑梗死康复治疗中的应用价 值观察] . Journal of Zhejiang University of Traditional Chinese Medicine 2008;32(4):514-5.

\section{Li 2008d \{published data only\}}

Li T. Clinical observation of acupuncture combined with language recovery training for 32 patients with motor aphasia after apoplexy [针刺配合语言训练治疗中风后运动性失语32 例临床观察] . Available at: http://cdmd.cnki.com.cn/Article/ CDMD-10199-2009021115.htm (accessed 8 August 2015) 2008.

\section{Li 2009a \{published data only\}}

Li F. Clinical study on the treatment of post-stroke depression by acupuncture combined with fluoxetine [针刺结合百忧 解治疗中风后抑郁症的临床观察] . Available at: http:// cdmd.cnki.com.cn/Article/CDMD-10507-2009158081.htm (accessed 8 August 2015) 2009.

\section{Li 2009b \{published data only\}}

Li Y, Zhang J, Chen YJ, Pan FQ, Xiao ZX, Tian JY. Research on the effects of neuro-facilitation technique combined with acupuncture on activities of daily living in stroke patients [神经促通技术联合针刺对脑卒中偏瘫患者日常生活活动 能力的影响]. Chinese Journal of Rehabilitation Medicine 2009;24(12):1106-8

\section{Li 2010b \{published data only\}}

Li CW. Effects of acupuncture on swallowing function in patients with stroke [针刺对脑卒中患者吞咽功能的影响]. Journal of Emergency Traditional Chinese Medicine 2010;19(9):1609.

\section{Li 2010c \{published data only\}}

Li HY, Li LF, Li Y. Clinical research on the effects of acupuncture combined with rehabilitation in the treatment of dysphagia after stroke [针刺联合康复训练对脑卒中后假性球麻痹吞咽 困难干预作用的临床研究]. Guangming Journal of Chinese Medicine 2010;25(5):830-1.

\section{Li 2011b \{published data only\}}

Li PF, Pan YX, Wang Y, Sun PY, Pu F, Zhang YL. Clinical research on the effects of acupuncture combined with rehabilitation training in the treatment of dysphagia after stroke [针刺配合 吞咽康复训练治疗脑卒中后吞咽障碍的临床研究] . Journal of Clinical Acupuncture and Moxibustion 2011;27(9):1-5

\section{Li 2011c \{published data only\}}

Li WL. Clinical study on the effects of electroacupuncture combined with rehabilitation therapy for hemiplegia after ischemic stroke [电针结合康复训练治疗缺血性中风后偏瘫 的临床研究] . Jiangsu Journal of Traditional Chinese Medicine 2011;43(9):68-9.

\section{Li 2011d \{published data only\}}

Li Y. Acupuncture treatment for motor aphasia after stroke [针刺治疗中风后运动性失语症]. Available at: http:// cdmd.cnki.com.cn/Article/CDMD-10507-1012252976.htm (accessed 8 August 2015) 2011.

\section{Li 2012a \{published data only\}}

Li D. Efficacy observation on treating swallow dysfunction after stroke by acupuncture combined with deglutition training [ 针 负配合吞咽训练对脑卒中后吞咽障碍的疗效观察]. Clinical Journal of Chinese Medicine 2012;4(23):38-9.

\section{Li 2012b \{published data only\}}

Li FF. Clinical effect of early rehabilitation combined with acupuncture therapy on stroke patients with dysphagia [早期 康复结合针刺治疗脑卒中吞咽障碍临床疗效观察]. Journal of New Chinese Medicine 2012;44(6):147-8.

\section{Li 2012c \{published data only\}}

Li F, Tang JY, Cheng HL, Hong W, Yang J. Rehabilitation effect evaluation of tri-tongue-acus and cold stimulus add tongue muscle training for stroke patients with swallowing disorder [针刺加冷刺激配合舌肌训练对脑卒中吞咽障碍患者的康复 疗效评价] . China Journal of Traditional Chinese Medicine and Pharmacy 2012;27(9):2471-4.

\section{Li 2012d \{published data only\}}

Li G, Zhang Y, Luo HQ. Clinical observation on the curative effect of acupuncture combined with estazolam for postapoplectic insomnia [针刺联合艾司唑仑治疗脑卒中后失眠的疗效观察]. Medical Journal of National Defending Forces in Southwest China 2012;22(6):641-2.

\section{Li 2012e \{published data only\}}

Li J. Clinical observation of acupuncture combined with rehabilitation for 35 patients with sequela of apoplexy [针刺 结合康复治疗中风后遗症35例临床观察]. Chinese Journal of Integrative Medicine On Cardio-/Cerebrovascular Disease 2012;10(6):697-8. 


\section{Li $2012 f$ \{published data only\}}

Li Q. Clinical research of treating dysphagia after stroke by acupuncture [针刺治疗脑卒中后吞咽障碍的临床研究] . Clinical Journal of Chinese Medicine 2012;4(12):37-8.

\section{Li 2012g \{published data only\}}

Li SG, Zhou QS. Clinical research of acupuncture combined with massage for hemiplegia after stroke [针刺配合推拿治疗中风 后偏瘫的临床研究]. Modern Journal of Integrated Traditional Chinese and Western Medicine 2012;21(23):2554-5.

\section{Li 2013b \{published data only\}}

Li F, Cai RL, Zhai L. Impacts of acupuncture at Jing-well points on the differentiated meridians and temple-three-needle therapy on P300 of patients with early vascular cognitive impairment [辨经刺井配合题三针对早期血管性认知障 碍患者P300的影响]. Chinese Acupuncture \& Moxibustion 2013;33(9):784-8.

\section{Li 2013c \{published data only\}}

Li LH. Clinical observation on Quanjing acupuncture therapy combined with rehabilitation training treatment of convalescent the stroke hemiplegia movement dysfunction [全 经针刺法结合康复训练治疗恢复期中风偏瘫运动功能障碍 的疗效观察]. Available at: http://cdmd.cnki.com.cn/Article/ CDMD-10541-1013183196.htm (accessed 8 August 2015) 2013.

\section{Li 2014 \{published data only\}}

Li YG, Liu Q. Effect of acupuncture combined with neuromuscular electrical stimulation for postapoplectic dysphagia [针刺配合神经肌肉电刺激治疗对脑卒中后吞 咽功能障碍的影响]. Journal of Ningxia Medical University 2014;36(4):450-2.

\section{Li 2015 \{published data only\}}

Li J, Hu KM, Yang L, Qu Y, Luo L, Li DH. Clinical observation on 90 cases of dysarthria after stroke treated with acupuncture and speech rehabilitation [针刺结合言语康复治疗脑卒中后构音 障碍90例临床观察]. Journal of Traditional Chinese Medicine 2015;56(4):300-3, 310.

\section{Liang 1993 \{published data only\}}

Liang R. Clinical observation and experimental studies on the treatment of sequelae of stroke by needling temporal points. International Journal of Clinical Acupuncture 1993;4(1):19-26.

\section{Liang 2010 \{published data only\}}

Liang JL. Acupuncture combined with pulse electric acupuncture for 60 patients with aphasia after apoplexy [ 针 刺加脉冲电针治疗中风后失语60例]. Guangxi Journal of Traditional Chinese Medicine 2010;33(2):30-1.

\section{Liang 2012 \{published data only\}}

Liang K. Clinical research on the effects of acupuncture in the treatment of pseudobulbar palsy due to cerebral infarction [ 针 刺治疗脑梗死后假性延髓麻痹的临床疗效研究]. Available at: http://cdmd.cnki.com.cn/Article/CDMD-10228-1012467877.htm (accessed 8 August 2015) 2012

\section{Liao 2006a \{published data only\}}

Liao HW. Clinical observations on the efficacy of occupational therapy plus acupuncture for treating reflex sympathetic dystrophy [作业疗法合针炎治疗肩手综合征45例疗效 观察]. Shanghai Journal of Acupuncture and Moxibustion 2006;25(3):9-10.

Liao 2006b \{published data only\}

Liao HW. Application of scalp acupuncture combined with language training in treatment of aphasia following stroke [头 针结合语言治疗在卒中后失语症中的应用]. Chinese Journal of Rehabilitation Medicine 2006;10(11):115-6

\section{Liao 2013 \{published data only\}}

Liao XD. Clinical observation of fire-needle therapy combined with Bobath therapy on spastic hemiplegia after stroke [火针点刺结合Bobath疗法治疗中风痉挛性偏瘫临床疗 效观察] . Available at: http://cdmd.cnki.com.cn/Article/ CDMD-10572-1013225433.htm (accessed 8 August 2015) 2013.

\section{Liao 2014 \{published data only\}}

Liao SQ, Jiang Z, Zhuo LP, Huang SE. Clinical research on the effects of acupuncture at "Quchi" and "Waiguan" acupoints on hand function recovery after stroke [针刺"曲池" "外关”穴 位促进脑卒中手功能恢复临床研究]. Asia-Pacific Traditional Medicine 2014;10(22):60-2.

Lim 2014 \{published data only\}

Lim CS, Park SK, Sun SH, Lee KH. Research on Korean Pharmacopuncture in South Korea since 2007. Journal of Pharmacopuncture 2014;17(4):15-21.

\section{Lin 2010a \{published data only\}}

Lin H, Ding XJ, Fu B. Effect of acupuncture combined with medications on postapoplectic cognitive impairment [ 针 炎配合药物治疗对脑卒中后认知障碍的影响]. Modern Journal of Integrated Traditional Chinese and Western Medicine 2010;19(1):36-7.

\section{Lin 2010b \{published data only\}}

Lin ZL, Zhen J, Li FQ. Effects of acupuncture on recovery of depression after stroke [针刺对脑卒中后抑有康复疗效的影 响] . China Prac Med 2010;5(8):59-60.

\section{Lin 2012 \{published data only\}}

Lin JW. A clinical research on the effects of acupunture at the Sun 13 ghost-points for 60 cases with post-stroke depression [针刺孙氏十三鬼穴治疗卒中后抑有疗效观察]. Available at: http://cdmd.cnki.com.cn/Article/CDMD-10572-1012396179.htm (accessed 8 August 2015) 2012.

\section{Lin 2013 \{published data only\}}

Lin ZX. Effectiveness of acupuncture for the treatment of poststroke dysphagia: a pragmatic trial comparing real acupuncture treatment with waiting list. ChiCTR Chinese Clinical Trial Register (http://www.chictr.org/) (ChiCTR-TRC-12002621) (accessed 8 August 2015) 2013.

\section{Liu 1998 \{published data only\}}

Liu J, Peng XH, Lin DD, Li CD, Jiang ZY, Zeng L, et al. Clinical study of electrical scalp acupuncture in the treatment of 
vascular dementia. Chinese Acupuncture and Moxibustion 1998;4:197-200.

\section{Liu 2004a \{published data only\}}

Liu GF, Zhou ZX. Effect of neuromuscular electrical stimulation in various modes on the rehabilitation of upper limb function in patients with hemiplegia. Chinese Journal of Clinical Rehabillitation 2004;8(22):4424-5.

\section{Liu 2004b \{published data only\}}

Liu HG, Huang SJ, Zhang HL. Effect of Jiawei simiao yongan tang combined with electroacupuncture in the recovery of motor function in patients with post-stroke sequelae. Chinese Journal of Clinical Rehabilitation 2004;8(10):1916-7.

\section{Liu 2006 \{published data only\}}

Liu LA, Guo RY, Pang SM, Li XZ, Dai SQ, Li XY. Clinical research of acupuncture combined with speech training for early phase of aphasia after stroke [针刺结合语言训练治疗中风早期失语症 的临床研究]. Chinese Archives of Traditional Chinese Medicine 2006;24(12):2256-9.

\section{Liu 2008a \{published data only\}}

Liu J. Clinical observation on treatment of spasticity poststroke by electric acupuncture with motion point and yang meridian [电针治疗中风后痉孪状态的临床研究]. Available at: http:// cdmd.cnki.com.cn/article/cdmd-87801-2008138509.htm (accessed 8 August 2015) 2008.

\section{Liu 2008b $\{$ published data only\}}

Liu W, Mukherjee M, Sun C, Liu H, McPeak LK.

Electroacupuncture may help motor recovery in chronic stroke survivors: a pilot study. Journal of rehabilitation research and development 2008;45(4):587-95

\section{Liu 2009 \{published data only\}}

Liu CS. Clinical research of acupuncture combined with neuromuscular facilitation treatment for dysphagia after stroke [针刺复合易化技术治疗脑卒中后吞咽障碍的临 床研究] . Available at: http://cdmd.cnki.com.cn/Article/ CDMD-10633-2010077373.htm (accessed 8 August 2015) 2009.

\section{Liu 2010a \{published data only\}}

Liu G, Lv CS, Yuan LX. Study on electroacupuncture improving the single-foot supporting phase rate of stroke patients [电针 改善中风患者单足支撑相比例的研究]. Chinese Acupuncture \& Moxibustion 2010;30(6):446-8.

\section{Liu 2010b $\{$ published data only\}}

Liu WA, Wu QM, Li XR, Li DD, Fu L, Yi XC. Observation on the efficacy of combined treatment of stroke hemiplegia with scalp electroacupuncture and stroke unit [头电针配合卒中单元 综合疗法治疗脑卒中偏瘫疗效观察]. Shanghai Journal of Acupuncture and Moxibustion 2010;29(3):149-51.

Liu 2011a \{published data only\}

Liu FC. Clinical observation on the effects of scalp acupuncture plus motor therapy in the treatment of post-stroke depression [头针配合运动疗法治疗脑卒中后抑有疗效观察]. Shanghai Journal of Acupuncture and Moxibustion 2011;30(11):733-4.

\section{Liu 2011b \{published data only\}}

Liu Y. Observation on the treatment of hemiplegia due to stroke in 37 patients by Buyang Huanwu soup and acupuncture [补阳还五汤结合针刺治疗中风偏瘫37例临床观察] Guiding Journal of Traditional Chinese Medicine and Pharmacy 2011;17(12):57-9.

\section{Liu 2012a \{published data only\}}

Liu HR, Li YF, Wu HQ, Xu LM, Xin JW, Jiang YN. Observation on the effects of acupuncture combined with swallowing \& speech therapeutic instrument for dysphagia in patients after stroke [针炎结合吞咽言语诊治仪治疗脑卒中后吞咽障碍]. China Pratical Medicine 2012;7(24):49-50.

\section{Liu 2012b \{published data only\}}

Liu SD. Curative effect analysis of speech training and acupuncture therapy for dysarthria caused by stroke [言语训练 结合针刺治疗脑卒中构音障碍的临床研究]. Internal Medicine of China 2012;7(4):336-8.

\section{Liu 2012c \{published data only\}}

Liu Y, Xue Z, Wu L. Clinical observation on 60 cases of hemiplegia treated with acupuncture. International Journal of Clinical Acupuncture 2012;21:16-8.

\section{Liu 2013c \{published data only\}}

Liu X, Wang PQ. Random parallel control study on the effects of acupuncture and rehabilitation combined with western medicine in the treatment of QDBS [ 针刺与康复训练联 合西药治疗气虚血癖型中风恢复期随机平行对照研究] Journal of Practical Traditional Chinese Internal Medicine 2013;27(12):68-70.

\section{Liu 2013d \{published data only\}}

Liu XP. A random parallel control study on the effects of acupuncture combined with western medicine in the treatment of stroke [针炎联合西药治疗中风随机平行对照研究] Journal of Practical Traditional Chinese Internal Medicine 2013;27(9):71-2.

\section{Liu 2013e \{published data only\}}

Liu Y, Liu L, Wang XM. Electroacupuncture at points Baliao and Huiyang (BL35) for post-stroke detrusor overactivity. Neural Regeneration Research 2013;8(18):1663-72.

\section{Liu $2013 f$ fpublished data only\}}

Liu ZF, Zhang JQ, Shao SJ, Wang SF. Therapeutic evaluation of post-stroke depression treated by acupuncture [针刺治疗卒中 后抑郁的疗效评价]. Journal of Sichuan of Traditional Chinese Medicine 2013;31(2):111-3.

\section{Liu 2014b \{published data only\}}

Liu L. Effect of elongated needling therapy combined with deglutition training/rehabilitation training in treatment of poststroke dysphagia [芒针针刺配合康复训练治疗脑卒中吞咽障 碍疗效观察]. Liaoning Journal of Traditional Chinese Medicine 2014;41(11):2442-4.

\section{Liu 2015 \{published data only\}}

Liu LQ, Li HL, Xu JM. Clinical study of electroacupuncture on memory dysfunction after stroke [电针治疗脑卒中后记忆功 
能障碍临床研究]. Journal of Emergency in Traditional Chinese Medicine 2015;24(5):775-7.

\section{Long 2013 \{published data only\}}

Long AG. Observation of clinical curative effect of acupuncture in patients with cerebral infarction [脑梗死患者针炎治 疗的临床疗效观察]. Chinese Journal of Medicine Guide 2013;15(10):1725-6.

\section{Lu 2010 \{published data only\}}

Lu M, Meng L, Peng J. Therapeutic effects of neuromuscular electrical stimulation and electroacupuncture for dysphagia post stroke [神经肌肉电刺激疗法与电针治疗脑卒中后吞咽障 碍的疗效对比研究]. Chinese Journal of Rehabilitation Medicine 2010;25(2):135-8.

\section{Lu 2011a \{published data only\}}

Lu FJ. Clinical observation on the effects of the combination of acupuncture at tendon junction and Bobath therapy for spastic paralysis after stroke [针刺经筋结点结合Bobath疗 法治疗中风后痉挛性瘫瘾的临床疗效观察]. Available at: http://cdmd.cnki.com.cn/Article/CDMD-10228-1011222551.htm (accessed 8 August 2015) 2011.

\section{Lu 2011b \{published data only\}}

Lu XF. Clinical observation on acupuncture at the eightconfluent acupoints for hemiplegia after cerebral infarction [针 刺八脉交会穴为主治疗脑梗死后偏瘫临床观察]. Shanghai Journal of Acupuncture and Moxibustion 2011;30(12):828-9.

\section{Luo 2007 \{published data only\}}

Luo WP. Clinical research of acupuncture combined with speech training on Broca aphasia following ischemic apoplexy [针刺配合语言训练治疗脑梗塞致运动性失语的临床 研究] . Availabale at: http://cdmd.cnki.com.cn/Article/ CDMD-10572-2007130686.htm (accessed 8 August 2015) 2007.

\section{Luo 2008 \{published data only\}}

Luo WP, Tan JL, Huang HY. Clinical observation on treatment of cerebral infarction-induced Broca aphasia by Tiaoshen Fuyin acupuncture therapy combined with language training [调神 复音针刺配合语言训练治疗脑梗死致运动性失语疗效观察] . Chinese Acupuncture \& Moxibustion 2008;28(3):171-5.

\section{Luo 2012 \{published data only\}}

Luo YH. Effect of acupuncture treatment on neurological deficit scores of the hemiplegic stroke patients [针炎治疗对脑卒中偏 瘫患者神经功能缺损评分的影响]. Chinese Community Doctors 2012;14(36):184-5.

\section{Lv 2009 \{published data only\}}

Lv H, Liu H, Ni JN. Electroacupuncture in treatment of postapoplectic swallowing dysfunction: a randomized controlled study [电针治疗卒中后吞咽困难的随机对照研究]. Journal of China-Japan Friendship Hospital 2009;23(4):228-9.

\section{Lv 2014 \{published data only\}}

Lv ST. Observation on the effects of acupuncture combined with rehabilitation therapy for spasticity after stroke [ 针刺配 合康复治疗中风后肌张力增高的临床观察]. Available at:
http://cdmd.cnki.com.cn/Article/CDMD-10162-1015546410.htm (accessed 8 August 2015) 2014.

Ma 2011a \{published data only\}

Ma JQ, Zheng J, Zhu LW, Yang XL, Zhang XH. Effects of acupuncture combined with rehabilitation training on swallow dysfunction after stroke [针刺结合康复训练对脑卒中后吞 咽功能障碍的影响] . Journal of Clinical Acupuncture and Moxibustion 2011;27(2):15-7.

Ma 2011b \{published data only\}

Ma XM, Li SZ, Cai NS, Yu HB, Zhang ZL. Research on the effects of quality of life in patients with stroke by tiaorentongdu acupuncture [调任通督针刺法改善脑卒中患者生存质量 的研究]. Shandong Journal of Traditional Chinese Medicine 2011;30(6):396-8.

\section{Ma 2013 \{published data only\}}

$\mathrm{Ma} \mathrm{JL}$. Acupuncture treatment of post-stroke hemiplegic shoulder pain: a random parallel control study [针炎治疗 中风后偏痽肩痛随机平行对照研究]. Journal of Practical Traditional Chinese Internal Medicine 2013;27(6):122-3.

\section{Mou 2010 \{published data only\}}

Mou J, Fu LX, Lu YM, Ren YL, He JY, Qi YZ. Clinical observation on the Xinnao Kaiqiao acupuncture plus language rehabilitation training for motor aphasia caused by cerebral infarction: a report of 30 cases [醒脑开空针刺法配合语言康复治疗脑梗死 致运动性失语30例临床观察]. Journal of Traditional Chinese Medicine 2010;51(5):428-31.

\section{Mu 2007 \{published data only\}}

Mu JP, Zhu ZM, Cheng JM, Zhao DG, Yang DR, Ao JB. The clinical observation on the acupuncture therapy enlivening brain, dredging orifices cooperating with promoting treatment for hemiplegia after stroke [醒脑开空针刺法配合促通技术治疗 脑卒中偏瘫临床观察]. Journal of Emergency in Traditional Chinese Medicine 2007;16(5):520-1.

\section{Mukherjee 2006 \{published data only\}}

Mukherjee M, McPeak L, Redford J, Sun C, Liu W. The effect of electro-acupuncture on upper limb spasticity in chronic stroke survivors. Stroke 2006;37:631.

\section{Muo 2001 \{published data only\}}

Muo FZ, Li JQ, Chu L, Lai XS, Zhang JX, Liu SH. The influence of electroacupuncture on intelligence structure in patients with vascular dementia. Shanghai Journal of Acupuncture and Moxibustion 2001;20(6):6-8.

Ni 2011 \{published data only\}

Ni HH, Hu YS, Cui X, Wu Y, Huang DQ, Qu PY. Clinical observation on acupuncture combined with rehabilitation training for 20 patients with postapoplectic upper extremity spasticity [针刺结 合康复训练治疗脑卒中后上肢痉挛20例临床观察]. Journal of New Chinese Medicine 2011;43(1):99-101.

\section{Nie 2011 \{published data only\}}

Nie WB. Clinical observation on the treatment of motor aphasia following stroke by Yinao Tiaoshen acupuncture [针炎益脑 
调神法治疗脑卒中运动性失语疗效观察]. Beijing Journal of Traditional Chinese Medicine 2011;30(12):938-9.

Nie 2013 \{published data only\}

Nie RR, Huang CH. Post-stroke depression treated with acupuncture and moxibustion: an evaluation of therapeutic effect and safety [针炎治疗脑卒中后抑郁症疗效与安全性评 价 ]. Chinese Acupuncture \& Moxibustion 2013;33(6):490-4.

Pan 2013 \{published data only\}

Pan MZ. Clinical observation of acupuncture therapy on vascular dementia after stroke [针刺头穴为主治疗脑 卒中后血管性痴呆临床疗效研究]. Available at: http:// cdmd.cnki.com.cn/Article/CDMD-10315-1014128145.htm (accessed 8 August 2015) 2013.

Pang 2010 \{published data only\}

Pang P, Lai X, Huang Y, Wang S, Wu J. The thoughts on treating post stroke limb spasticity with the four seas acupoints. International Journal of Clinical Acupuncture 2010;19(2):45-6.

\section{Peng 2007a \{published data only\}}

Peng XJ. Clinic observation of acupuncture combined with rehabilitation training for 30 cases with hemiplegia after stroke [针炎结合康复训练治疗中风偏痽30例]. China Naturopathy 2007;15(5):53-4

\section{Peng 2009 \{published data only\}}

Peng HY, Tan JL, Wang BG, Zhao MH. A clinical study of therapy of electroacupuncture at the temple-three-needle on poststroke depression. New Journal of Traditional Chinese Medicine 2009;10:89-90.

\section{Peng 2015 \{published data only\}}

Peng HY. Clinical study on acupuncture combined with recovery massaging for patients with ischemic stroke [针刺结合康复 按摩治疗缺血性中风的临床研究]. Lishizhen Medicine and Materia Medica Research 2015;26(3):664-5.

\section{Qi 2000 \{published data only\}}

Qi GS, Zhao XJ. Clinical observation on the treatment of stroke in rehabilitative stage with "Qing Nao YI Shui" acupuncture therapy. Journal of Tianjin College of Traditional Chinese Medicine 2000;19(2):23-5.

\section{Qi 2013 \{published data only\}}

Qi M. Clinical research on the effects of acupuncture in treating 128 patients with dysphagia after stroke [针炎治 疗128例卒中后吞咽障碍的临床研究]. Available at: http:// cdmd.cnki.com.cn/Article/CDMD-10026-1013203840.htm (accessed 8 August 2015) 2013.

\section{Qi 2013a \{published data only\}}

Qi M, Zhang GM. Efficacy study of acupuncture and moxibustion on dysphagia after stroke [针炎治疗卒中后吞咽障碍疗 效研究]. Beijing Journal of Traditional Chinese Medicine 2013;32(7):512-4.

\section{Qiao 2012 \{published data only\}}

Qiao HF, Zhang QJ, Yuan HF, Zhang N, Wu ZH. Efficacy

observation of acupuncture combined with paroxetine in the treatment of depression after stroke. Available at: http:// cpfd.cnki.com.cn/Article/CPFDTOTAL-ZGKF201207001119.htm (accessed 8 August 2015). 2012.

Qiu 2011 \{published data only\}

Qiu TT. A clinical study of acupuncture combined with therapeutic exercise in the treatment of shoulder-hand syndrome after stroke [针刺结合运动疗法治疗脑卒中后肩手 综合征的临床研究] . Available at: http://cdmd.cnki.com.cn/ Article/CDMD-10228-1011222549.htm (accessed 8 August 2015) 2011.

\section{Qu 1991 \{published data only\}}

Qu RM, Qu XM. Observation on the treatment of sequelae of apoplexy in 105 patients with needling Du Mai points. Jiang XI Traditional Chinese Medicine 1991;22(5):32-4.

\section{Ran 2013 \{published data only\}}

Ran XQ, Wu S, Ye DP, Min J. Effects of acupuncture combined with rehabilitation training on lower extremity blood flow on limb function with spastic paralysis after stroke [针刺结合康 复训练对中风痉挛性偏瘫患者肢体功能及下肢血流的影响] . Hubei Journal of Traditional Chinese Medicine 2013;35(10):20-1.

\section{Ren 2009 \{published data only\}}

Ren YF. Clinical research on acupuncture in combination with rehabilitation for postapoplectic spasm [针刺结合康复疗法 治疗中风后痉挛的临床研究]. Guangming Journal of Chinese Medicine 2009;24(7):1313-5.

\section{Ren 2010 \{published data only\}}

Ren XM, Wang T, Wang CM, Yang GF. Clinical study on cerebral infarction treated with Danhong Tongjing Huoluo decoction combined acupuncture [丹红通经活络汤联合针刺治疗脑梗死 临床研究]. World Journal of Integrated Traditional and Western Medicine 2010;5(10):886-8.

Ren 2012 \{published data only\}

Ren Z, Li XR, Li DD, Yan J, Tan T, Ye HM. Randomized controlled clinical study of the treatment of ischemic stroke (convalescence) with stroke unit combined with the acupuncture [针刺结合卒中单元治疗缺血性脑卒中 (恢复期) 随机对照临床研究] . Journal of Practical Traditional Chinese Internal Medicine 2012;26(7):4-6.

Sallstrom 1996 \{published data only\}

Sallstrom S, Kjendahl A, Osten PE, Stanghelle JH, Borchgrevink CF. Acupuncture in the treatment of stroke patients in the subacute stage: a randomized, controlled study. Complementary Therapies in Medicine 1996;4:193-7.

\section{Salom-Moreno 2014 \{published data only\}}

Salom-Moreno J, Sánchez-Mila Z, Ortega-Santiago R, PalaciosCeña M, Truyol-Domínguez S, Fernández-de-las-Peñas C. Changes in spasticity, widespread pressure pain sensitivity, and baropodometry after the application of dry needling in patients who have had a stroke: a randomised controlled trial. Journal of Manipulative and Physiological Therapeutics 2014;37(8):569-79. 
Schaechter 2007 \{published data only\}

Schaechter JD, Connell BD, Stason WB, Kaptchuk J, Krebs DE, Macklin EA, et al. Correlated change in upper limb function and motor cortex activation after verum and sham acupuncture in patients with chronic stroke. Journal of Alternative and Complementary Medicine 2007;13(5):527-32.

\section{Seo 2013 \{published data only\}}

Seo YR, Jung WS, Park SU, Moon SK, Park JM, Park JY. The effect of ouhyul herbal acupuncture point injections on shoulder pain after stroke. Evidence-Based Complementary and Alternative Medicine 2013;2013(2):1-5.

\section{Shang 2008 \{published data only\}}

Shang YJ, Ma CC, Cai YY, Wang DS, Kong LL. Clinical study on acupuncture combined with rehabilitation therapy for treatment of poststroke shoulder-hand syndrome [针刺结 合康复治疗中风后肩-手综合征]. Chinese Acupuncture \& Moxibustion 2008;28(5):331-3.

\section{Shao 2012 \{published data only\}}

Shao B. Clinical research on acupuncture in root and end and appearance and substance of kidney meridian associated with language training for Broca aphasia following the stroke [ 针 刺"肾经标本根结"结合语言训练治疗中风后运动性失语的 临床研究] . Available at: http://cdmd.cnki.com.cn/Article/ CDMD-10393-1012510352.htm (accessed 8 August 2015) 2012.

\section{Shen 2008 \{published data only\}}

Shen HJ, Kang XB, Xie YC, Yang H. Clinical observation of electroacupuncture for 40 cases with dysphagia after stroke [神 经肌肉电刺激治疗脑卒中后吞咽困难40例]. Shanxi Journal of Traditional Chinese Medicine 2008;29(6):709-10.

\section{Shen 2009 \{published data only\}}

Shen SJ. Observation on the effects of acupuncture combined with rehabilitation training for sequela of apoplexy [针炎结 合康复训练治疗中风后遗症的疗效观察]. Chinese Journal of Ethnomedicine and Ethnopharmacy 2009;18(20):147-8.

\section{Sheng 2011 \{published data only\}}

Sheng GB, Lu FJ, Liu CY, Wang W. The combination of acupuncture at meridian sinew nodal point and rehabilitation for spastic paralysis after stroke [针刺经筋结点结合康复疗法 治疗中风后痉挛性瘫疾]. Journal of Clinical Acupuncture and Moxibustion 2011;27(5):25-6.

\section{Sheng 2013 \{published data only\}}

Sheng GB, Gao C, Yu JK, Gao Y, Liu G. Clinical observation on the effects of electrical scalp acupuncture in the treatment of depression due to stroke [头部电针疗法治疗中风后抑有的 临床疗效观察] . Information on Traditional Chinese Medicine 2013;30(3):125-6.

\section{Shi 2007 \{published data only\}}

Shi HF, Zheng XH. Effect of scalp acupuncture drawing method on motor function in hemiplegic patients following cerebral thrombosis at convalescent period [头皮针抽提法对脑血栓 形成后恢复期偏瘫患者运动功能的影响]. Chinese Journal of Integrated Traditional and Western Medicine 2007;27(4):361-3.

\section{Shi 2007a \{published data only\}}

Shi X. Research on the specific effects and the key influential factors of acupoints: research based on the treatment of brain resuscitating acupuncture for cerebral infarction. ChiCTR Chinese Clinical Trial Register (http://www.chictr.org/) (ChiCTRTRC-07000036) (accessed 8 August 2015) 2007.

\section{Song 2010 \{published data only\}}

Song QM. Clinical research on post-stroke vascular cognitive impairment treatment with needling therapy [针刺治 疗中风血管性认知障的临床观察]. Available at: http:// cdmd.cnki.com.cn/Article/CDMD-10572-2010125609.htm (accessed 8 August 2015) 2010.

Sui 2001 \{published data only\}

Sui MH. Clinical observation on the therapeutic effect of acupuncture of hand-Shaoyang Meridian acupoints for treatment of upper-limb spasm in stroke patients. Acupuncture Research 2001;26(2):131-3.

Sun 2008 \{published data only\}

Sun J, Mi Z, Wang H, Xu D, Chen H. Study on therapeutic effect of acupuncture on dysphagia after stroke. Journal of Rehabilitation Medicine. 2008:169.

\section{Sun 2010 \{published data only\}}

Sun QR. Clinical research on plum-blossom needle and scalp acupuncture combined with language rehabilitation training for treatment of ischemic aphasia from apoplexy [头针梅花针口刺结合语言康复训练治疗缺血性中风失语 临床研究] . Available at: http://cdmd.cnki.com.cn/Article/ CDMD-11919-2010248108.htm (accessed 8 August 2015) 2010.

Sun 2011 \{published data only\}

Sun RL. Clinical observation of acupuncture combined with function training for 26 cases with dysphagia after stroke [针刺结合功能训练治疗脑卒中后吞咽困难26例临床观 察] . Journal of Shanxi College of Traditional Chinese Medicine 2011;12(3):39-40.

\section{Sun 2013b \{published data only\}}

Sun YG. Acupuncture combined with rehabilitation training for 50 patients with postapoplectic swallowing dysfunction [针刺配合康复训练治疗脑卒中后吞咽障碍50 例]. Henan Traditional Chinese Medicine 2013;33(7):1135-6.

\section{Sun 2014 \{published data only\}}

Sun JW. Research of acupuncture treatment technique of post-stroke dysphagia [针炎治疗中风后吞咽障碍技术 的研究]. Available at: http://cdmd.cnki.com.cn/Article/ CDMD-10026-1014242212.htm (accessed 8 August 2015) 2014.

Suo 2008 \{published data only\}

Suo DM, Yu T, Liu L, Shi JW, Ding XR, Fan XN. Therapeutic effect of acupuncture for dysphagia after stroke [针刺对中 风后吞咽障碍的影响]. Henan Traditional Chinese Medicine 2008;28(5):57-8.

Tang 2005 \{published data only\}

Tang XJ, She QQ, Wang YH, Zhang ZL. Efficacy analysis on prognosis of small amounts of thalamic hemorrhage by 
acupuncture at early phase [早期针刺治疗对小量丘脑出血预 后的影响]. Sichuan Medical Journal 2005;26(11):51-2.

\section{Tang 2012 \{published data only\}}

Tang X, Tang CL, Xu FM, Xie HW, Li LM, Song YE. Effect of scalp acupuncture combined with body acupuncture on limb function in subacute stroke patients [头针联合体针对亚急 性期脑卒中患者肢体功能的影响]. Acupuncture research 2012;37(6):488-92

\section{Tang 2013 \{published data only\}}

Tang X, Huang L, Xie HW, Xu FM, Li LM, Song YE. Clinical observation on the effects of yin and yang acupuncture on subacute stroke [阴阳经联合针刺治疗亚急性脑卒中的临床疗 效] . Chinese Journal of Gerontology 2013;33(10):4668-70.

\section{Tang 2013a \{published data only\}}

Tang Yao. A random parallel control study on the effects of acupuncture combined with western medicine for early ischemic stroke hemiplegia [针炎联合西药治疗缺血性中风 早期偏瘫随机平行对照研究]. Journal of Practical Traditional Chinese Internal Medicine 2013;27(4):140-1.

\section{Tian 2014 \{published data only\}}

Tian FL, Li Q, Liu GR, Zheng DS, Chen JM. Effects of yin-yang meridians acupuncture with respiratory reinforcing and reducing manipulation on lower limbs balance function in stroke patients [阴阳对刺呼吸补泻法对脑中风患者下 肢平衡功能的影响]. Chinese Acupuncture \& Moxibustion 2014;34(11):1047-50.

\section{Tong 1997 \{published data only\}}

Tong LG, Li ZG, Ren YX, Yang J, Meng XY, Ma WM, et al. Body quick-needling plus scalp acupuncture in treating apoplexy and its sequelae. International Journal of Clinical Acupuncture 1997;9(2):133-9.

\section{Tong 2013 \{published data only\}}

Tong S, Su L, Lu HB, Liu JQ. Observation on the efficacy of acupuncture at key acupoints combined with rehabilitation therapy for spasmodic hemiplegia after cerebral infarction [关 键点针刺法配合康复治疗脑梗死后痉挛期偏㿈疗效观察]. Chinese Acupuncture \& Moxibustion 2013;33(5):399-402.

\section{Tong 2014 \{published data only\}}

Tong S, Lv HB, Liu JQ. Clinical observation on the curative effect of acupuncture in combination with deglutition training for postapoplectic (pharynx period) swallowing dysfunction [针刺结合吞咽功能训练治疗脑卒中后(咽期)吞咽障碍 临床疗效观察] . Acta Chinese Medicine and Pharmacology 2014;42(2):129-31.

\section{Wan 2013 \{published data only\}}

Wan WR, Wang TL, Cheng SL, Zhao YL, Zhang W, Wu QY, et al. Post-stroke shoulder-hand syndrome treated with acupuncture and rehabilitation: a randomized controlled trial [针刺结 合康复治疗中风后肩手综合征：随机对照研究]. Chinese Acupuncture \& Moxibustion 2013;33(11):970-4.
Wang 2004 \{published data only\}

Wang MH, Liang B, Wang M, Chen LQ, Wang YS, Li ZY, et al. Clinical study on the treatment of apoplectic hemiplegia by acupuncture plus rehabilitation training. Shanghai Journal of Acupuncture and Moxibustion 2004;23(4):7-9.

Wang 2006 \{published data only\}

Wang YH, Ying SG. Observations on the curative effects of acupuncture in the treatment of postapoplectic pseudobulbar paralysis [针刺治疗中风后假性球麻痹疗效观察]. Shanghai Journal of Acupuncture and Moxibustion 2006;25(6):15-6.

\section{Wang 2007 \{published data only\}}

Wang XY. Effects of the improved acupoints and rehabilitation exercise on locomotor ability of the upper limbs and ability of daily life in the patient of cerebral infarction [改良穴位配合康 复训练对脑梗死患者上肢活动能力及日常生活能力的影响]. Chinese Acupuncture \& Moxibustion 2007;27(3):179-81.

\section{Wang 2008 \{published data only\}}

Wang YJ. Clinical research on "Yiqi huoxue, only strengthen the pain" acupuncture combined with rehabilitation training treating shoulder-hand syndrome caused by stroke ["益气活 血, 通络止痛"针法联合康复疗法治疗脑卒中后肩手综合征 的临床研究]. Available at: http://cdmd.cnki.com.cn/Article/ CDMD-10162-2009031775.htm (accessed 8 August 2015) 2008.

\section{Wang 2008a \{published data only\}}

Wang FY, Wang YQ, Li SH, Jv YB. Clinical observation on the treatment of post-stroke hiccup by acupuncture cooperated with compound of xuanfudaizhe soup [ 针炎配合旋覆代赫汤 治疗中风后呃逆的临床观察]. Chinese Archives of Traditional Chinese Medicine 2008;26(6):1340-1.

Wang 2008b \{published data only\}

Wang B. Effect of acupuncture combined with cognitive therapy on cerebral-apoplexy-induced function impairment [针刺结合认知训练对老年脑卒中患者认知障碍及残疾状 况的影响] . Available at: http://cdmd.cnki.com.cn/article/ cdmd-10507-2008118250.htm (accessed 8 August 2015) 2008.

\section{Wang 2009 \{published data only\}}

Wang JJ, Li YX. Clinical effect observation of ice stimulation combined with acupuncture for dysphagia after stroke [冷刺激 联合干扰电治疗脑卒中后吞咽困难的效果观察]. Nursing and Rehabilitation 2009;8(11):940-1.

\section{Wang 2010a \{published data only\}}

Wang LC, Wang ZY, Li BD, Ge JY. Study on electro-acupuncture on points combined with rehabilitation training for treatment of balance function disorder in cerebral infarction [电针背 俞穴联合康复训练治疗脑梗死病人平衡功能障碍的对照 研究] . Chinese Journal of Integrative Medicine On Cardio-/ Cerebrovascular Disease 2010;8(11):1322-3.

Wang 2010b \{published data only\}

Wang TL. Effects of acupuncture combined with rehabilitation therapy on shoulder-hand syndrome after apoplexy [针刺结 合康复治疗中风后肩_手综合征的疗效观察]. Available at: http://cdmd.cnki.com.cn/Article/CDMD-10393-2010251306.htm (accessed 8 August 2015) 2010. 
Wang 2011b \{published data only\}

Wang HQ, Gao XY, Zhou YL. Clinical research on electroacupuncture of ren ying for dysphagia due to stroke [ 电 针人迎穴治疗中风吞咽困难的临床研究]. China Journal of Chinese Medicine 2011;26(4):501-2.

Wang 2011c \{published data only\}

Wang JH. Effect on the motor function of stroke patients by combination of needling at back-shu point and trunk exercise [针刺背俞穴结合躯干训练对中风偏瘫患者运动功能的影响]. Chinese Journal of Integrated Traditional and Western Medicine 2011;31(6):745-6.

\section{Wang 2011d \{published data only\}}

Wang L, Liu SM, Liu M, Li BJ, Hui ZL. Research on the effects of acupuncture, psychological intervention and speech rehabilitation training for postapoplectic aphasia and depression/anxiety [针炎及心理干预配合语言康复训练治 疗脑卒中后语言障碍伴抑郁/焦虑的研究]. Journal of New Chinese Medicine 2011;43(12):90-2.

\section{Wang 2011e \{published data only\}}

Wang L, Liu SM, Liu M, Li BJ, Hui ZL, Gao X. Post-stroke speech disorder treated with acupuncture and psychological intervention combined with rehabilitation training: a randomized controlled trial [针刺及心理干预配合康复训练治 疗卒中后言语障碍: 随机对照研究]. Chinese Acupuncture \& Moxibustion 2011;31(6):481-6.

\section{Wang 2011 \{published data only\}}

Wang LC, Liu HY, Wang QH, Yang YG. Clinical research on acupuncture at Neiguan point combined with rehabilitation training for treatment of postapoplectic hand cramps [ 针刺内 关穴联合康复训练治疗中风后手部痉挛临床研究]. Chinese Journal of Integrative Medicine On Cardio-/Cerebrovascular Disease 2011;9(6):689-90.

\section{Wang 2011g \{published data only\}}

Wang M, Wang JH, Hua QH. Clinical observation on anandia after stroke which was treated by acupuncture [针刺治疗中风 后运动性失语的临床观察]. Journal of Sichuan of Traditional Chinese Medicine 2011;29(7):116-8.

\section{Wang 2011h \{published data only\}}

Wang S. Clinical study of scalp acupuncture and body acupuncture combined with language rehabilitation training for aphasia after stroke [头针体针配合语言康复训练治疗中风后 失语症的临床研究]. Available at: http://cdmd.cnki.com.cn/ Article/CDMD-10199-1011224431.htm (accessed 8 August 2015) 2011.

\section{Wang 2011i \{published data only\}}

Wang T. Clinical observation of Xinnao Shutong pill combined with acupuncture for dysphagia after stroke [心脑舒通联合针 炎治疗缺血性中风后吞咽困难]. Chinese Journal of Integrative Medicine on Cardio/Cerebrovascular Disease 2011;9(7):809-10.

\section{Wang 2011j \{published data only\}}

Wang YK. Clinical observation on the effects of acupuncture combined with Chinese medicine in the treatment of ischemic stroke with Qi deficiency and blood stasis [ 针刺联合中药治
疗缺血性中风恢复期气虚血瘀证的临床观察]. Available at: http://cdmd.cnki.com.cn/Article/CDMD-10162-1011202597.htm (accessed 8 August 2015) 2011.

\section{Wang 2013 \{published data only\}}

Wang WF. Clinical experience on acupuncture in the treatment of stroke [针炎治疗脑卒中的临床体会]. Modern Diagnosis and Treatment 2013;24(4):795, 814

\section{Wang 2014a \{published data only\}}

Wang YJ, He J, Sun CC, Zhang YM, Du JG, Zhao JG. Clinical study on transcutaneous acupoint electrical stimulation and acupuncture on postapoplectic depression [ 经皮穴位电刺激 与针刺治疗脑卒中后抑郁的临床研究]. Clinical Journal of Rehabilitation Medicine 2014;29(8):751-3.

Wang 2014b \{published data only\}

Wang ZY, Ye W, Yang LZ, Ma DY, Xu Q. Effects of acupuncture on recovery of neurological function in patients with hypertensive cerebral hemorrhage [针刺对高血压脑出血患者神经功能恢 复情况的作用]. Information on Traditional Chinese Medicine 2014;31(4):142-3.

Wei 2005 \{published data only\}

Wei LL. Effect of Shuitu acupoint injection with stellate ganglion block on swallow dysfunction after stroke. Chinese Journal of Clinical Rehabilitation 2005;9(9):106-7.

\section{Wei 2009 \{published data only\}}

Wei CL. Clinical observation on the effects of acupuncture combined with Buyanghuanwu decoction treatment on Qi deficiency and blood stasis hemiplegia after ischemic stroke [针刺结合补阳还五汤治疗缺血性中风气虚血瘀型的临床 疗效观察] . Available at: http://cdmd.cnki.com.cn/Article/ CDMD-10315-2009252060.htm (accessed 8 August 2015) 2009.

\section{Wenli 2007 \{published data only\}}

Zhang WL, Feng LH, Jia XH, Feng JP, Xu Y. Clinical observation on therapeutic effects of the point-penetrating method in acupuncture treatment of spastic hemiparalysis due to cerebrovascular disorders. Journal of Traditional Chinese Medicine 2007; Vol. 27, issue 3:170-2.

\section{Wong 2013 \{published data only\}}

Wong GK. Can acupuncture benefit putaminal hemorrhagic stroke patients? A randomized controlled clinical trial. Stroke 2013;44:AWP319.

\section{Wu 1999 \{published data only\}}

Wu D. Needling eye points combined with electrical scalp points in the treatment of urinary incontinence due to cerebrovascular accident in 40 patients. Journal of Clinical Acupuncture and Moxibustion 1999;15(9):33-4.

Wu 2009a \{published data only\}

Wu P, Liang FR, Hu KM, Tian WW, Yuan XL, Huang YL. Clinical research of acupuncture combined with facilitation technique for limb spasm after apoplexy hemiplegia - a report of 160 cases [针刺复合易化技术治疗脑卒中后偏痽肢体痉䤣的临床研究]. Journal of Chengdu University of TCM 2009;32(1):11-3. 
Wu 2009b \{published data only\}

Wu XM, Yu YM. Clinical research on the effects of acupuncture of backshu point and jiaji point in the treatment of spastic paralysis due to stroke [针刺背俞穴、夹脊穴治疗脑卒中后痉 挛性瘫瘾的临床研究]. Beijing Journal of Traditional Chinese Medicine 2009;28(7):494-6.

\section{Wu 2010 \{published data only\}}

Wu XL, An ZH, Li YQ, Liu AG, Li XD. Effects of acupuncture on the rehabilitation of neurological function in the 157 hemiplegia patients due to cerebral infarction [针刺对 157 例不同分 型脑梗死偏瘫患者神经运动功能康复的影响]. Journal of Traditional Chinese Medicine 2010;51(10):909-11.

\section{Wu 2011 \{published data only\}}

Wu P, Liang RF, Li Y, Yang L, Huang YL, Li AH. Clinical observation on acupuncture plus rehabilitation training for dysphagia after stroke: a multicenter randomizd controlled trial [针刺联合康 复训练治疗脑卒中后吞咽障碍多中心随机对照临床观察]. Journal of Traditional Chinese Medicine 2011;52(1):45-8.

Wu 2012 \{published data only\}

Wu JY, Huang RD, Ge LB. Clinical study on acupuncture for ischemic stroke sequelae [针刺治疗缺血性中风后遗症临 床研究] . Shanghai Journal of Acupuncture and Moxibustion 2012;31(2):85-7.

\section{Wu 2012a $\{$ published data only\}}

Wu HK, Tan F, Wan SY, Wang JL, Huang T, Ding DQ. Clinical study of curative effect of electro-acupuncture combined with functional electric stimulation on the treatment of spastic dysarthria in acute cerebral infarction [电针联合功能性电刺激 早期干预对脑梗死后痉挛型构音障碍的疗效研究]. Chinese Journal of Rehabilitation Medicine 2012;27(12):1116-9.

\section{Wu 2013b \{published data only\}}

Wu XL, Lu BQ, Li YQ, Xu JH, Wang LY, Liu AG. Effects of acupuncture on disease severity score and activity of daily living scales in patients with partial anterior circulation infarction [针刺对部分前循环脑梗死患者疾病严重程度及日常生 活能力的影响]. Journal of Traditional Chinese Medicine 2013;54(7):1210-3

\section{Wu 2014a $\{$ published data only\}}

Wu XL, Lu BQ, Li YQ, Xu JH, Zhang YH. Effects of acupuncture on motor function in patients with partial anterior circulation infarction [针刺对部分前循环老年脑梗死患者运动功能的康 复效果]. Chinese Journal of Gerontology 2014;34(3):1463-5.

\section{Wu 2014b \{published data only\}}

Wu ZJ, Hu KM, Guo YG, Tu YM, Zhang HY, Wang Y. Acupuncture combined with speech rehabilitation training for post-stroke spasmodic dysphonia: a multicenter randomized controlled trial [针刺结合言语康复训练治疗脑卒中后疼挛性构音障 碍: 多中心随机对照研究]. World Journal of AcupunctureMoxibustion 2014;24(4):12-6.

\section{Xia 2008 \{published data only\}}

Xia K, Yang SR, Dang DH, Sun Q. Ear acupuncture combined with Xinnaokaiqiao recipe for dysphagia caused by cerebral hemorrhage [耳针配合醒脑开空治疗脑出血脑外伤术后吞咽
困难的临床研究]. Chinese Journal of Integrative Medicine on Cardio/Cerebrovascular Diseases 2008;6(8):994-5.

Xia 2010 \{published data only\}

Xia WG, Zhu CJ, Zhu SQ, Tang ZP, Wang Y, Hua Q. Combination of feeding-swallowing training and acupuncture: an effective rehabilitation method for dysphagia after stroke [脑卒中后 吞咽障碍综合康复治疗的评价]. Acta Medicinae Universitatis Scientiae et Technologiae Huazhong 2010;39(5):614-9.

Xiao 1996 \{published data only\}

Xiao F, Liu W. Observation on treatment of dysphasia due to cerebrovascular accident with electroacupuncture at shegen point. Journal of Chinese Medicine 1996;50:27-9.

Xiao 2006 \{published data only\}

Xiao QY. Clinical observation on the effects of acupuncture combined with catgut-embedding for hemiplegic shoulder pain after stroke [针刺配合埋线治疗中风后偏瘫肩痛的临床疗效 观察]. Chinese Medicine Modern Distance Education of China 2006;4(12):31-3.

\section{Xiao 2008 \{published data only\}}

Xiao AH, Liu YP, Huang SJ, Liu B. Influence of meridian exercises and activating collaterals oil knocking stimulation acupoints on rehabilitation effect of cerebral apoplexy patients [经络操 加活络油叨击刺激穴位对脑卒中康复疗效的影响]. Chinese Nursing Research 2008;22(4):888-9.

Xiao 2011 \{published data only\}

Xiao D. Clinical study of bowels-unblocking and toxin-purging therapy combined with acupuncture for patients of post-stroke consciousness disturbance with phlegm-heat stagnation in Fuorgans [通腑泄毒法加针刺治疗痰热腑实型脑卒中意识障碍的 临床研究] . Journal of New Chinese Medicine 2011;43(5):14-6.

\section{Xie 2010 \{published data only\}}

Xie Q. A clinical study of acupuncture combined with rehabilitation training in the treatment of shoulder-hand syndrome after stroke [针刺结合康复训练治疗脑卒中肩手 综合征的临床研究] . Available at: http://cdmd.cnki.com.cn/ Article/CDMD-10572-2010125364.htm (accessed 8 August 2015) 2010.

\section{Xie 2012 \{published data only\}}

Xie XM, An JM, Huang LN, Yang YK. Effects of acupuncture on motor dysfunction of patients caused by ischemic brain stroke: a randomized and controlled study [针刺对缺血性中风患 者运动功能障碍影响的随机对照研究]. Journal of Clinical Acupuncture and Moxibustion 2012;28(12):15-8.

\section{Xie 2013 \{published data only\}}

Xie HY, Lin HX, Lin GH. Clinical research of fire-needle combined with Huoluo Guben decoction for 44 patients with hemiplegia caused by stroke [火针配合活络固本汤治疗中风后偏瘫 44 例] . World Science and Technology/Modernization of Traditional Chinese Medicine and Materia Medica 2013;15(2):281-5.

Xing 2007 \{published data only\}

Xing J, Wang YJ, Li YR. Clinical study on acupuncture combined with hyperbaric oxygenation for improving balance function of 
cerebral infarction [针刺并高压氧改善脑梗死平衡功能的临床 观察]. Chinese Acupuncture \& Moxibustion 2007;27(1):12-4.

\section{Xu 2009a \{published data only\}}

Xu HY, Zhang H. Clinical observation on the effects of acupuncture combined with pelvic floor muscle training for uracratia after stroke [针炎配合盆底肌锻炼治疗脑卒中尿失 禁临床观察] . Lishizhen Medicine and Materia Medica Research 2009;20(1):225-6.

\section{Xu 2009b \{published data only\}}

Xu Z. Clinical study on the treatment of sequela of apoplexy by acupuncture [针炎治疗中风后遗症临床疗效观察]. Clinese Journal of Modern Drug Application 2009;3(24):132-3.

\section{Xu 2010 \{published data only\}}

Xu SF, Zhuang LX, Jia C, Chen XH, Wu SP, Jiang GM, et al. Effect of "Jin three-needle therapy" on motor function in patients of hemiplegia after stroke: a multi-center randomized controlled study ["靳三针"疗法与康复治疗改善脑卒中偏瘫患者肢体功 能的疗效对比观察: 多中心随机对照]. Chinese Acupuncture \& Moxibustion 2009;29(9):689-94.

\section{Xu 2013a $\{$ published data only\}}

Xu RQ. Clinical study of acupuncture treatment for cerebral infarction in terms of heart-gall bladder theory [从心胆 论治针炎治疗脑梗死的临床研究] . Available at: http:// cdmd.cnki.com.cn/Article/CDMD-10572-1013226466.htm (accessed 8 August 2015) 2013.

\section{Xu 2014 \{published data only\}}

Xu G. A random parallel control study of acupuncture combined fluoxetine treatment for post-stroke depression [针刺联合氟西 汀治疗中风后抑有症随机平行对照研究]. Journal of Practical Traditional Chinese Internal Medicine 2014;28(11):158-60.

\section{Yan 2010 \{published data only\}}

Yan J, Zhong XQ, Wang QZ, Meng J, Jiang SY, Wen XQ. Clinical observation on the effects of acupuncture combined with rehabilitation training for dysphagia after apoplexy [针刺 结合康复训练治疗脑卒中后吞咽困难疗效观察]. Modern Journal of Integrated Traditional Chinese and Western Medicine 2010;19(31):3368-9.

\section{Yan 2011 \{published data only\}}

Yan XR. Different acupuncture and moxibustion methods in the treatment of post-stroke hiccup [不同针炎方法治疗中 风后呃逆的临床观察]. Journal of Clinical Acupuncture and Moxibustion 2011;27(11):43-5.

\section{Yang 2006 \{published data only\}}

Yang SL. Effects of needling combined with cognitive function training on the cognitive function of stroke patients [针刺结合 认知功能训练对脑卒中患者认知功能的影响]. Available at: http://cdmd.cnki.com.cn/Article/CDMD-10393-2006162984.htm (accessed 8 August 2015) 2006.

\section{Yang 2007a \{published data only\}}

Yang D, Xu L, Zhang XR. Clinic observation of integrated acupuncture and Chinese medicine for 50 cases with hemiplegia after stroke [针药结合治疗脑卒中偏瘫
50例] . Shanxi Journal of Traditional Chinese Medicine 2007;28(8):1060-1.

Yang 2007b \{published data only\}

Yang DF, Lin XD, Yu ZM, Wu ZB, Wu XF, Lin JF. Effect of acupuncture combined with Bobath therapy on spasticity and motor function suffered from postapoplectic hemiplegia [组 合针刺结合Bobath疗法对脑卒中偏瘫痉挛状态及运动功 能的影响] . Liaoning Journal of Traditional Chinese Medicine 2007;34(2):215-6

\section{Yang 2007c \{published data only\}}

Yang Y. Clinical observation on the effects of spastic paralysis after apoplexy with electric acupuncture combined with rehabilitation training [电针配合康复训练治疗脑梗死 偏瘫肢体痉挛状态的临床观察] . Available at: http:// cdmd.cnki.com.cn/Article/CDMD-10228-2007120088.htm (accessed 8 August 2015) 2007.

\section{Yang 2008 \{published data only\}}

Yang SM. Acupuncture combined with low frequency impulse electrotherapy for 36 cases with dysphagia after stroke [针刺配 合低频脉冲电治疗脑卒中后吞咽困难36例]. Zhejiang Journal of Traditional Chinese Medicine 2008;43(6):348.

Yang 2009 \{published data only\}

Yang ZH, Yu K, Li CY, Hou QF, Liu XQ. Application value of acupuncture in the rehabilitative treatment of patients with cerebral infarction [针炎在脑梗死康复治疗中的应用价 值观察]. Journal of Military Surgeon in Southwest China 2009;11(3):434-5

\section{Yang 2010 \{published data only\}}

Yang $\mathrm{H}$, Wang J. Clinical observation on the effects of acupuncture treatment for 29 cases with dysphagia after stroke [针刺治疗中风后吞咽障碍29例]. Journal of Practical Traditional Chinese Internal Medicine 2010;24(2):93-4.

Yang 2011a \{published data only\}

Yang HF, Li XX, Wang T. The videofluoroscopic study on electroacupuncture in combination with rehabilitation in treatment of postapoplectic swallowing dysfunction [电针联 合康复训练治疗脑卒中后吞咽障碍的电视荧光透视研究]. Journal of Guangzhou University of TCM 2011;28(3):239-42.

Yang 2011b \{published data only\}

Yang J. The clinical study on cognitive impairment after stroke by using the treatment of electroacupuncture given at DU20 and GB20 [电针百会、风池干预脑卒中后认知功能障碍的 临床研究] . Available at: http://cdmd.cnki.com.cn/Article/ CDMD-10393-1011220797.htm (accessed 8 August 2015) 2011.

\section{Yang 2011c \{published data only\}}

Yang J. Study on acupuncture therapy of dredging governor vessel for regulating mentality in post ischemic stroke hemiplegic patients [通督调神针刺法治疗缺血性中风偏痽 的临床研究]. Available at: http://cdmd.cnki.com.cn/Article/ CDMD-10572-1011132621.htm (accessed 8 August 2015) 2011. 
Yang 2012 \{published data only\}

Yang CD, Yang ZJ, Li JJ. Clinical observation of a combination of multiple acupuncture technique for hemiplegia after stroke [多 种针炎手法联合治疗中风偏痽的疗效观察]. China Practical Medicine 2012;7(33):239-40.

Yang 2014 \{published data only\}

Yang XH, Liu B, Ouyang BS. Effect of acupuncture combined with rehabilitative training on neural functional recovery of stroke patients during recovery phase: A randomized controlled trial [针剌治疗结合康复训练对恢复期脑卒中患者神经功能 恢复的影响: 随机对照研究]. World Journal of Acupuncture Moxibustion. 2014;24(4):17-23.

Yang 2014a \{published data only\}

Yang XH, Liu B, Ouyang BS. Effect of acupuncture combined with rehabilitative training on neural functional recovery of stroke patients during recovery phase: a randomized controlled trial. World Journal of Acupuncture-Moxibustion 2014;24(4):17-23.

\section{Yang 2015 \{published data only\}}

Yang HL, Zhang B, Liu T, Zheng JG. Efficacy of acupuncture in combination with medicine for mild cognitive impairment after cerebral infarction: a randomized controlled trial. World Journal of Acupuncture-Moxibustion 2015;25(1):7-12.

\section{Yao 2006 \{published data only\}}

Yao FD. Observation on the effects of acupuncture combined with language rehabilitation training for 22 patients with aphasia after stroke [针炎配合语言康复训练治疗脑卒中失 语22 例效果观察]. Journal of Guangdong Medical College 2006;24(3):290-1.

\section{Yao 2013a \{published data only\}}

Yao QF. Clinical observation on upper limb spastic hemiplegia following cerebral infarction treated by antagonistic acupuncture combined with rehabilitation [拮抗针法配合康复 治疗脑梗死后上肢痉挛性偏痽的临床疗效观察]. Available at: http://cdmd.cnki.com.cn/Article/CDMD-10228-1013249894.htm (accessed 8 August 2015). 黑龙江中医药大学, 2013.

\section{Yao 2013b $\{$ published data only\}}

Yao YF, Gao X, Jing R, Li SQ, Ba HZ. Efficacy observation on the treatment of poststroke hemiplegia in 30 patients by consciousness restoring obstruction clearing needing technique [醒脑开空针刺法结合康复疗法治疗脑卒中偏㿈 患者30例]. Shanxi Journal of Traditional Chinese Medicine 2013;34(8):1047-8.

\section{Yin 2013a \{published data only\}}

Yin LL. A clinical study on acupuncture combined with rehabilitation therapy for 57 cases of swallowing disorders after stroke [针刺配合康复疗法治疗中风后吞咽障碍57例临床研 究] . Journal of Traditional Chinese Medicine 2013;54(9):766-8.

\section{Yin 2013b \{published data only\}}

Yin ZK. The clinical observation on treatment of dysphagia caused by pseudobulbar palsy after stroke with acupuncture Fengchi Fengfu mainly acupuncture point [针刺风池、 风府为主穴治疗脑卒中后假性延髓麻痹吞咽困难临床
观察] . Available at: http://cdmd.cnki.com.cn/Article/ CDMD-10228-1013249935.htm (accessed 8 August 2015) 2013.

Yin 2014 \{published data only\}

Yin JC. Clinical observation on Quanjing acupuncture therapy combined with rehabilitation training for the treatment of shoulder hand syndrome after stroke [全经针刺结合康复训 练治疗中风后肩手综合征的临床观察]. Available at: http:// cdmd.cnki.com.cn/Article/CDMD-10541-1014241244.htm (accessed 8 August 2015) 2014.

\section{You 2011 \{published data only\}}

You Y. A clinical study of electroacupuncture combined with rehabilitation training in the treatment of shoulder-hand syndrome of post-stroke [电针配合康复训练治疗脑卒中后肩 手综合征的临床研究] . Available at: http://cdmd.cnki.com.cn/ Article/CDMD-10441-1011204989.htm (accessed 8 August 2015) 2011.

\section{You 2014 \{published data only\}}

You Y. Efficacy observation of disperse-dense wave electrical acupuncture combined with occupational therapy in the treatment of shoulder-hand syndrome due to stroke [电针疏 密波配合作业疗法治疗脑卒中后肩手综合征的疗效观察]. Chinese Journal of Convalescent Medicine 2014;23(6):509-11.

\section{Yu 2002 \{published data only\}}

Yu MZ, Yang GZ, Zhan KR, Fan YY, Peng MF. Clinical observation on the effects of electrical stimulation at nervous trunk points in the treatment of sequelae of stroke. Chinese Journal of Basic Medicine in Traditional Chinese Medicine 2002;8(3):55-6.

\section{Yu 2007 \{published data only\}}

Yu XG, Sun SL, Cheng YH. Clinical observation on treatment of mild cognitive impairment after cerebral infarction with acupuncture dumaijingxue mainly point [以针刺督脉经穴为主 治疗缺血性脑卒中后轻度认知功能障碍的临床观察]. Chinese Journal of Integrative Medicine On Cardio-/Cerebrovascular Disease 2007;5(12):1171-3.

\section{Yu 2009 \{published data only\}}

Yu JY, Guo XF. Observation on the effects of acupuncture in combination with rehabilitation in the treatment of spasticity following stroke [电针结合康复训练治疗脑卒中痉挛状态的疗 效观察]. Journal of External Therapy of TCM 2009;18(4):42-3.

\section{Yu 2011 \{published data only\}}

Yu XM. Clinical observation on electric acupuncture combined with rehabilitation training for 50 patients with neurogenic bladder following stroke [电针结合康复训练治疗卒中 后神经源性膀胱50例临床观察] . Available at: http:// cpfd.cnki.com.cn/Article/CPFDTOTAL-ZGKF201108001153.htm (accessed 8 August 2015). 2011:176.

\section{Yuan 2010 \{published data only\}}

Yuan LX. The research on acupuncture treatment technology of dysphagia after stroke. ChiCTR Chinese Clinical Trial Register (http://www.chictr.org/) (ChiCTR-TRC-12002695) (accessed 8 August 2015) 2010. 
Zeng 2010 \{published data only\}

Zeng XQ, Teng DS, Lin X, Yang T, Wang XF. Observations on the efficacy of acupuncture as main treatment for poststroke dysphagia [针刺为主治疗中风后吞咽障碍疗效 观察]. Shanghai Journal of Acupuncture and Moxibustion 2010;29(7):431-2.

\section{Zhang 1988 \{published data only\}}

Zhang ZJ. Observation on the effects of acupuncture in the treatment of post stroke aphasia. Journal of Traditional Chinese Medicine 1988;5:33-4.

\section{Zhang 1997 \{published data only\}}

Zhang SF, Ye XR, Dan QH, Zhang WF, Cui Y. The influence of acupuncture on SOD, CAT and serum intraproteinal fluorescence in stroke patients. Chinese Acupuncture and Moxibustion 1997;9:517-9.

\section{Zhang 2002a \{published data only\}}

Zhang L, Sheng L. Clinical observation on the effects of magnetic acupuncture in the treatment of sequelae of stroke. Chinese Journal of Information in Traditional Chinese Medicine 2002;9(1):63.

\section{Zhang 2002b \{published data only\}}

Zhang ZZ, Ma FJ, Ma Y. Observation on the effects of acupuncture in the treatment of urinary retention due to cerebral infarction in 36 patients [针刺对脑梗塞所致尿㵔 留36例疗效观察] . Hei Long Jiang Medicine and Pharmacy 2002;25(3):71.

\section{Zhang 2007a \{published data only\}}

Zhang HM. Clinical research of treatment of apoplectic aphemia with multi-needle puncture of scalp-points in combination with visual-listening-speech training [头穴丛刺结合言语康 复治疗脑卒中运动性失语临床研究]. Acupuncture research 2007;32(3):190-4.

\section{Zhang 2007b \{published data only\}}

Zhang XT, Fan RX. Clinical observation on the effects of acupuncture combined with buyang huanwu decoction in the treatment of sequela of cerebral infarction [补阳还五汤配合 针炎治疗脑梗塞后遗症疗效观察] . Jilin Journal of Traditional Chinese Medicine 2007;27(1):31-2.

\section{Zhang 2008 \{published data only\}}

Zhang WM, Zhen P. Acupuncture combined with swallowing therapy instrument for 82 cases with dysphagia after stroke [针刺结合吞咽言语诊治仪治疗中风后吞咽障碍82例]. Jilin Journal of Traditional Chinese Medicine 2008;28(11):819-20, 825.

\section{Zhang 2009b \{published data only\}}

Zhang NX, Huang TQ, Liu GZ, Hou YQ, Liu SQ, Luo JQ, et al. Effect of acupuncture and rehabilitation training on Barthel index in early-stage of stroke cases. Journal of Acupuncture and Tuina Science 2009;7(3):143-6.

\section{Zhang 2009c \{published data only\}}

Zhang W. Clinical research of acupuncture for deglutition handicap caused by supranuclear paralysis after cerebral infarction [针刺治疗脑梗死后假性延髓麻痹所致吞咽障碍
的临床研究] . Available at: http://cdmd.cnki.com.cn/Article/ CDMD-10162-2009261860.htm (accessed 8 August 2015) 2009.

Zhang 2010a \{published data only\}

Zhang $\mathrm{CH}$. Clinical research of spastic paralysis after stroke by acupuncture. ChiCTR Chinese Clinical Trial Register (http:// www.chictr.org/) (ChiCTR-TCH-11001547) (accessed 8 August 2015) 2010.

Zhang 2010b \{published data only\}

Zhang N. Clinical research of acupuncture combined with rehabilitation training for dysphagia recovery [针刺联用 康复训练治疗中风病（血疮证）恢复期吞咽障碍的临 床研究]. Available at: http://cdmd.cnki.com.cn/Article/ CDMD-10199-2010255182.htm (accessed 8 August 2015) 2010.

Zhang 2010c \{published data only\}

Zhang NX, Liu GZ, Yao QH, Li WJ, Huang Y, Wang AM, et al. Effects of warming-reinforcing acupuncture combined with rehabilitation training on the early motor function of hemiparalysis patients caused by ischemic brain stroke: a randomized controlled study [热补针法结合康复训练对缺 血性脑卒中偏瘫患者早期运动功能的影响: 随机对照研究] Chinese Acupuncture \& Moxibustion 2010;30(6):441-5.

\section{Zhang 2010d \{published data only\}}

Zhang NX, Liu GZ, Yao QH, Li WJ, Huang Y, Wang AM. Effects of warming-reinforcing acupuncture combined with rehabilitation training on the early motor function of hemiparalysis patients caused by ischemic brain stroke: a randomized and controlled study. Chinese Acupuncture \& Moxibustion 2010;30(6):441-5.

Zhang 2010e \{published data only\}

Zhang SH. Acupuncture combined with Jieyudan recipe for 33 cases with dysphagia after stroke [针炎配合解语丹加减治疗 中风后吞咽困难33例]. Zhejiang Journal of Traditional Chinese Medicine 2010;45(8):509.

\section{Zhang 2010 f $\{$ published data only\}}

Zhang ZG. Acupuncture for postoperative intracranial hematoma after hypertensive intracerebral hemorrhage [ 针 刺对高血压脑出血术后患者的临床疗效研究]. Available at: http://cdmd.cnki.com.cn/article/cdmd-10441-1011205188.htm (accessed 8 August 2015) 2010.

Zhang 2011a \{published data only\}

Zhang HM, Tang Q. Rehabilitation evaluation on post-stroke abnormal movement pattern prevented and treated with acupuncture and rehabilitation [针刺加康复防治脑卒中异常 运动模式的康复学评定]. Chinese acupuncture \& moxibustion 2011;31(6):487-92.

\section{Zhang 2011b \{published data only\}}

Zhang JH, Li JY, Zhao Y, Fan GQ, Wang JQ. Clinical observation of dysphagia after stroke by Tongnao Huoluo acupuncture therapy with swallowing training [通脑活络针刺法配合吞咽 训练治疗脑卒中后吞咽障碍临床观察] . Journal of Liaoning University of TCM 2011;13(12):188-9. 
Zhang 2011c \{published data only\}

Zhang WM. Post-apoplexy spasm treated by acupuncture on antagonistic muscles combined with modern rehabilitation training therapy [拮抗肌侧取穴针刺结合现代康复训练疗法 治疗中风后痉挛]. World Journal of Integrated Traditional and Western Medicine 2011;6(4):291-3, 301.

\section{Zhang 2011d \{published data only\}}

Zhang XH, Feng GX, Wen N. Clinical study of warm-needling therapy on stroke patients with urinary retention [温针炎治 疗中风后尿㵔留患者的临床观察]. Journal of TCM Univ. of Human 2011;31(3):72-4.

\section{Zhang 2011e \{published data only\}}

Zhang XW. Clinical research on the effects of electroacupuncture and exercise therapy in the treatment of SHS [电针结合康复训练治疗中风后肩手综合征的疗 效观察] . Available at: http://cdmd.cnki.com.cn/Article/ CDMD-10572-1011135406.htm (accessed 8 August 2015) 2011.

\section{Zhang 2012b \{published data only\}}

Zhang F. Study on acupuncture therapy of dredging governor vessel for regulating mentality in post ischemic stroke aphasia patients [通督调神针刺法治疗缺血性中风失语症 临床研究]. Available at: http://cdmd.cnki.com.cn/Article/ CDMD-10572-1012397626.htm (accessed 8 August 2015) 2012.

\section{Zhang 2012c \{published data only\}}

Zhang JW, Hu JD, MPOVA, LOLA. Clinical study on acupuncture for stroke in Congo [针刺在刚果金治疗脑中风的临床研究]. World Journal of Acupuncture-Moxibustion 2012;22(1):35-8.

\section{Zhang 2012d \{published data only\}}

Zhang YS, Yu ZP, Zhang YL, Zhao XH, Lin CR. Therapeutic observation on acupuncture and rehabilitation in treating motor aphasia after cerebral apoplexy [针刺配合康复训练 治疗脑卒中后运动性失语疗效观察]. Shanghai Journal of Acupuncture and Moxibustion 2012;31(11):781-3.

\section{Zhang 2012e \{published data only\}}

Zhang ZS, Qin YM, Li YH. Clinical observation of warmingpromotion method of acupuncture combined with Buyanghuanwu decoction on ischemic stroke with qi-deficiency and blood-stasis syndrome [温通针法联合补阳还五汤治疗气 虚血疬型缺血性卒中临床观察]. Hebei Journal of Traditional Chinese Medicine 2012;34(11):1609-11.

\section{Zhang 2013b \{published data only\}}

Zhang W. Early intervention and prevention with acupuncture therapy on the post stroke depression: A randomized controlled clinical trial. ChiCTR Chinese Clinical Trial Register (http:// www.chictr.org/) (ChiCTR-TRC-120034890) (accessed 8 August 2015) 2013.

\section{Zhang 2014b \{published data only\}}

Zhang $\mathrm{H}$. Impact on rehabilitation effect of post-stroke abnormal movement pattern prevented and treated with multineedle puncture of scalp-points. Journal of alternative and complementary medicine 2014;20(5):A47-8.

\section{Zhang 2014c \{published data only\}}

Zhang Y. A random parallel control study on the effects of acupuncture combined with fluoxetine tablet for depression after stroke [针炎联合氟西汀分散片治疗脑卒中后抑有症随机 平行对照研究]. Journal of Practical Traditional Chinese Internal Medicine 2014;28(2):123-4.

\section{Zhang 2014d \{published data only\}}

Zhang Y, Chen WP, Wang CY, Xie T, Wang M, Xia YJ. Modified acupuncture combined with rehabilitation therapy in treatment of limb spasticity in stroke patients [针炎解痉调气法结合 康复治疗脑卒中痉竬期患者临床评价]. Zhejiang Journal of Integrated Traditional and Western Medicine 2014;24(4):290-2.

Zhao 2008 \{published data only\}

Zhao YY. Acupuncture for 82 cases with dysphagia after stroke ["醒脑开空"针刺法治疗假球麻痹82例] . Journal of Liaonin University of Traditional Chinese Medicine 2008;10(7):91.

\section{Zhao 2009 \{published data only\}}

Zhao Y, Wang Q. Clinical observation of acupuncture for 60 cases of dysphagia after ischemic stroke [深刺治疗缺血性 脑卒中后吞咽困难60例] . Jilin Journal of Traditional Chinese Medicine 2009;29(6):503-4.

\section{Zhao 2010 \{published data only\}}

Zhao GP, Sun J. Observation on the effects of acupuncture combined with language rehabilitation training for 174 patients with aphasia following stroke [针炎配合语言康复训练治疗 脑卒中失语174 例效果观察]. Chinese Journal of Trauma and Disability Medicine 2010;18(1):87-8.

\section{Zhao 2011a \{published data only\}}

Zhao NN. Clinical research of fire-needle combined with rehabilitation training on spastic hemiplegia after stroke [火针配合康复训练对脑卒中后痉挛性偏㿈的临床 观察] . Available at: http://cdmd.cnki.com.cn/article/ cdmd-10572-1011135337.htm (accessed 8 August 2015) 2011.

Zhao 2011b \{published data only\}

Zhao SJ. Clinical research on the effects of acupuncture therapy for the ischemic stroke [针刺治疗缺血性脑卒中的 临床研究] . Available at: http://cdmd.cnki.com.cn/Article/ CDMD-10162-1011201326.htm (accessed 8 August 2015) 2011.

Zhao 2014a \{published data only\}

Zhao YH, Sun ZR, Zhang DQ, Li HN, Zhong JB, Liu J. Clinical observation on the electrical acupuncture with intermediate frequency combined with rehabilitation treating ischemic stroke [电针中频配合康复治疗缺血性脑卒中的临床观 察] . Chinese Journal of Integrative Medicine On Cardio/ Cerebrovascular Disease 2014;12(5):581-3.

\section{Zhao 2014b \{published data only\}}

Zhao XW, Chen XW, Wei CF, Tian QT, Yuan W. The effects of early intervention of rehabilitation training and acupuncture on stroke patients with neurological impairment and activities of daily living [康复训练结合针刺早期干预对脑卒中患者神经 功能缺损及日常生活活动能力的作用]. Medical Journal of Industrial Enterprise 2014;27(1):541-3. 
Zheng 1996 \{published data only\}

Zheng ZC. Needling scalp and lumbo-sacral points in the treatment of sequelae of stroke in 634 patients. Shanghai Journal of Acupuncture and Moxibustion 1996;15(5):15-6.

\section{Zheng 2000 \{published data only\}}

Zheng L, Zhuang LX, Li YH. Observations on the curative effect of acupuncture and herbs on vascular dementia. Shanghai Journal of Acupuncture and Moxibustion 2000;19(3):8-10.

\section{Zheng 2011b \{published data only\}}

Zheng QH, Yu B, Li Y, Yang ZQ, Yu SY. Clinical study of acupuncture with language training for aphasia after stroke [ 针 刺配合语言训练治疗脑卒中后失语症临床研究]. Journal of Liaoning University of TCM 2011;13(1):105-7.

Zheng 2011c \{published data only\}

Zheng WX. Clinical Research of Poststroke Anxiety Disorder Treated by Acupuncture Combined with Deanxit [针炎配合 黛力新治疗脑卒中后焦虑症的临床研究]. Clinical Journal of Chinese Medicine 2011;26(4):468-70.

\section{Zhong 2014 \{published data only\}}

Zhong CX. The clinical research of feasibility of "Xingnao Kaiqiao" acupuncture therapy on preventing depression after stroke ["醒脑开空"针法预防中风后抑有的临床 观察] . Available at: http://cdmd.cnki.com.cn/Article/ CDMD-10315-1014409916.htm (accessed 8 August 2015) 2014.

\section{Zhou 1995 \{published data only\}}

Zhou JZ, Zhang CS, LI L, Zhou SW, Shi XM. Clinical study in the treatment of sequelae of apoplexy with "Xing Nao Kai Qiao" acupuncture therapy. Chinese Acupuncture and Moxibustion. 1995;3:6-8.

\section{Zhou 2008 \{published data only\}}

Zhou GY. Observation on the effects of electroacupuncture and rehabilitation for 83 cases with stroke [电针和康复治疗脑卒中 83例疗效观察]. Chinese Journal of Information on Traditional Chinese Medicine 2008;15(5):77.

\section{Zhu 2010a \{published data only\}}

Zhu T. Clinical research on the treatment of dysphagia after stroke by traditional Chinese medicine combined with acupuncture [中药加针刺治疗中风后吞咽障碍的临床研究]. Guangming Journal of Chinese Medicine 2010;25(11):2074-5.

\section{Zhu 2010b \{published data only\}}

Zhu T. Clinical observation of acupuncture in the treatment of dysphagia after stroke [针刺治疗卒中后吞咽功能障碍临 床疗效观察]. Chinese Journal of Practical Nervous Diseases 2010;13(17):65-6.

\section{Zhu 2011 \{published data only\}}

Zhu F, Zhao J, Ding Y. Clinical observation on treating poststroke depression with both acupuncture and medicine. International Journal of Clinical Acupuncture 2011;20:101-3.

\section{Zhu 2012a \{published data only\}}

Zhu ST. Clinical research on electro-acupuncture at swallow hole for dysphagia induced by true bulbar paralysis after stroke [电针吞咽穴治疗脑梗死后真性延髓麻痹吞咽障碍 的临床观察] . Available at: http://cdmd.cnki.com.cn/Article/ CDMD-10228-1012467791.htm (accessed 8 August 2015) 2012.

Zhu 2012b \{published data only\}

Zhu ZQ, Xu GG, Guo YL, Ma B. Efficacy of stroke unit combined with acupuncture therapy on dysphagia in stroke patients [ 卒 中单元模式下联合针刺治疗脑卒中吞咽障碍疗效观察]. Chinese Medical Journal 2012;23(2):144-6,149.

Zhuang 2012 \{published data only\}

Zhuang LX, Xu SF, D'Amado CR, Jia C, He J, Han DX, et al. An effectiveness study comparing acupuncture, physiotherapy, and their combination in poststroke rehabilitation: a multicentered, randomized, controlled clinical trial. Alternative Therapies in Health and Medicine 2012;18(3):8-14.

\section{References to ongoing studies}

Fu 2011 \{published data only\}

Fu Q. Randomised, controlled Phase III Trial to evaluate the efficacy and safety of comprehensive acupuncture treatment programs for poststroke motor rehabilitation. ChiCTR Chinese Clinical Trial Register (http://www.chictr.org/) (ChiCTRTRC-11001347) (accessed 8 August 2015) 2011.

\section{Liu 2013b \{published data only\}}

Liu T. Acupuncture based on five elements body characteristics in the treatment of patients with post-stroke depression. ChiCTR Chinese Clinical Trial Register (http://www.chictr.org/) (ChiCTR-TRC-13003434) (accessed 8 August 2015) 2013.

Xie 2006 \{published data only\}

Xie Y. Randomized controlled study on the acupuncture for dysphagia in convalescence phase of apoplexy. ChiCTR Chinese Clinical Trial Register (http://www.chictr.org/) (ChiCTRTRC-07000010) (accessed 8 August 2015) 2006.

\section{Zhong 2010 \{published data only\}}

Zhong $\mathrm{H}$. The research of linguistic functional recovery mechanism based on $\mathrm{FMRI}$ after electroacupuncture at acupoints Tongli (HT5) and Xuanzhong (GB39) curing basal ganglia aphasia after stroke. ChiCTR Chinese Clinical Trial Register (http://www.chictr.org/) (ChiCTR-TRC-11001410) (accessed 8 August 2015) 2010.

\section{Additional references}

\section{Asplund 1988}

Asplund K, Tuomilehto J, Stegmayr B, Wester PO, TunstallPedoe $\mathrm{H}$. Diagnostic criteria and quality control of the registration of stroke events in the MONICA project. Acta Medica Scandinavica Supplementum 1988;728:26-39.

\section{Cheng 2008}

Cheng $\mathrm{H}$, Yu J, Jiang Z. Acupuncture improves cognitive deficits and regulates the brain cell proliferation of SAMP8 mice. Neuroscience Letters 2008;432:111-6. 


\section{Deeks 2001}

Deeks JJ, Altman DG, Bradburn MJ. Statistical methods for examining heterogeneity and combining results from several studies in meta analysis. In: Egger M, Davey Smith G, Altman DG editor(s). Systematic Reviews in Health Care: Meta-analysis in Context. 2nd Edition. London: BMJ Publication Group, 2001.

\section{Dickersin 1994}

Dickersin K, Scherer R, Lefebvre C. Identifying relevant studies for systematic reviews. BMJ 1994;309(6964):1286-91. [MEDLINE: 7718048]

\section{Dong 2013}

Dong QJ, Yang ZX. Systematic review of resuscitation needling technique for wind stroke. Chinese Acupuncture \& Moxibustion 2013;33(5):475-80.

\section{Ernst 1996}

Ernst E, White AR. Acupuncture as an adjuvant therapy in stroke rehabilitation?. Wien Medizinische Wochenschrift 1996;21(22):556-8.

\section{Ernst 1997}

Ernst $\mathrm{E}$, White A. Life-threatenting adverse reactions after acupuncture? A systematic review. Pain 1997;71:123-6.

\section{Feigin 2014}

Feigin VL, Forouzanfar MH, Krishnamurthi R, Mensah GA, Connor M, Bennett DA, et al. Global and regional burden of stroke during 1990-2010: findings from the Global Burden of Disease Study 2010. Lancet 2014;383:245-54.

\section{GBD2013 2015}

GBD 2013 Mortality and Causes of Death Collaborators. Global, regional, and national age-sex specific all-cause and causespecific mortality for 240 causes of death, 1990-2013: a systematic analysis for the Global Burden of Disease Study 2013. Lancet 2015;385(9963):117-71.

\section{Go 2014}

Go AS, Mozaffarian D, Roger VL, Benjamin EJ, Berry JD, Blaha MJ, et al. Heart Disease and Stroke Statistics-2014 Update. A report from the American Heart Association. Circulation 2014;128:00-00.

\section{Higgins 2003}

Higgins JP, Thompson SG, Deeks JJ, Altman DG. Measuring inconsistency in meta-analyses. BMJ 2003;327(7414):557-60. [MEDLINE: 12958120]

\section{Higgins 2011a}

Higgins JPT, Altman DG, Sterne JAC (editors). Chapter 8: Assessing risk of bias in included studies. In: Higgins JPT, Green S (editors). Cochrane Handbook for Systematic Reviews of Interventions Version 5.1.0 (updated March 2011). The Cochrane Collaboration, 2011. Available from www.cochranehandbook.org (accessed 10 August 2015).

\section{Hopwood 1996}

Hopwood V. Acupuncture in stroke recovery: a literature review. Complementary Therapies in Medicine 1996;4:258-63.

\section{Hu 1993}

$\mathrm{Hu} \mathrm{HH}$, Chung C, Liu TJ, Chen RC, Chen $\mathrm{CH}$, Chou P, et al. $A$ randomized controlled trial on the treatment for acute partial ischemic stroke with acupuncture. Neuroepidemiology 1993;12:106-13.

\section{Hugh 2010}

MacPherson H, Altman DG, Hammerschlag R, Youping L, Taixiang W, White A, et al. Revised STandards for Reporting Interventions in Clinical Trials of Acupuncture (STRICTA): extending the CONSORT Statement. Journal of Evidence-Based Medicine 2010;3:140-55.

\section{Jansen 1989}

Jansen G, Lundeberg T, Kjartansson S, Samuelson UE. Acupuncture and sensory neuropeptides increase cutaneous blood flow in rats. Neuroscience Letters 1989;97:305-9.

\section{Johansson 1993}

Johansson K, Lindgren I, Widner H, Wiklund I, Johansson BB, Johansson $\mathrm{K}$, et al. Can sensory stimulation improve the functional outcome in stroke patients?. Neurology 1993;43:2189-92.

\section{Johansson 2001}

Johansson BB, Haker E, Arbin MV. Acupuncture and transcutaneous nerve stimulation in stroke rehabilitation: a randomized, controlled trial. Stroke 2001;32:707-13.

\section{$\operatorname{Kim} 2010$}

Kim MK, Choi TY, Lee MS, Lee H, Han CH. Contralateral acupuncture versus ipsilateral acupuncture in the rehabilitation of post-stroke hemiplegic patients: a systematic review. BMC Complementary and Alternative Medicine 2010;10(10):41-2.

\section{Kong 2010}

Kong JC, Lee MS, Shin BC, Song YS, Ernst E. Acupuncture for functional recovery after stroke: a systematic review of sham-controlled randomized clinical trials. Canadian Medical Assocation Journal 2010;182(16):1723-29.

\section{Lefebvre 1996}

Lefebvre C, McDonald S. Development of a sensitive search strategy for reports of randomized controlled trials in EMBASE. Fourth International Cochrane Colloquium; 1996 Oct 20-24; Adelaide (Australia). 1996.

\section{Li 2014}

Li L, Zhang H, Meng SQ, Qian HZ. An updated meta-analysis of the efficacy and safety of acupuncture treatment for cerebral infarction. PLOS ONE 2014;9(12):e114057.

\section{Lim 2015}

Lim SM, Yoo JH, Lee EJ, Kim HJ, Shin SW, Han GJ, et al. Acupuncture for spasticity after stroke: a systematic review and meta-analysis of randomized controlled trials. Evidence-Based Complementary and Alternative Medicine 2015;2015:870398. [DOI: 10.1155/2015/870398] 


\section{Liu 2005}

Zhang SH, Liu M, Asplund K, Li L. Acupuncture for acute stroke. Cochrane Database of Systematic Reviews 2005, Issue 2. [DOI: 10.1002/14651858.CD003317.pub2]

\section{Liu 2009a}

Liu Z, Fang JQ, Zeng C. Development of studies on the underlying mechanism of acupuncture intervention in reducing post-ischemic inflammatory reaction and the related new research thought. Zhen Ci Yan Jiu 2009;34:61-6.

\section{Liu 2014a}

Liu F, Li ZM, Jiang YJ, Chen LD. A meta-analysis of acupuncture use in the treatment of cognitive impairment after stroke. Journal of Alternative and Complementary Medicine 2014;20(7):535-44.

\section{Long 2012}

Long YB, Wu XP. A meta-analysis of the efficacy of acupuncture in treating dysphagia in patients with a stroke. Acupuncture in Medicine 2012;30:291-7.

\section{Magnusson 1994}

Magnusson M, Johansson K, Johansson BB. Sensory stimulation promotes normalization of postural control after stroke. Stroke 1994;25:1176-80.

\section{NIH 1998}

$\mathrm{NIH}$ Consensus Conference. Acupuncture. JAMA 1998;280:1518-24.

\section{Park 2001}

Park J, Hopwood V, White AR, Ernst E. Effectiveness of acupuncture for stroke: a systematic review. Journal of Neurology 2001;248:558-63.

\section{Park 2014}

Park SW, Yi SH, Lee JA, Hwang PW, Yoo HC, Kang KS, et al. Acupuncture for the treatment of spasticity after stroke: a metaanalysis of randomized controlled trials. Journal of Alternative and Complementary Medicine 2014;20(9):672-82.

\section{Qi 2009}

Qi YZ, Fu LX, Xiong J, Wang ZL, Mou J, Lu YM. Systematic evaluation of acupuncture for treatment of post-stroke spastic paralysis. Chinese Acupuncture \& Moxibustion 2009;129(8):683-8.

\section{Ren 2008}

Ren L, Zhang WA, Fang NY. The influence of electro-acupuncture on neural plasticity in acute cerebral infarction. Neurological Research 2008;30:985-9.

\section{Schulz 2010}

Schulz KF, Altman DG, Moher D, for the CONSORT Group. CONSORT 2010 Statement: updated guidelines for reporting parallel group randomised trials. BMJ 2010;340:c332.

\section{SCSSS 1999}

Swedish Collaboration on Sensory Stimulation in Stroke. Sensory stimulation after stroke: a randomized controlled trial. Cerebrovascular Diseases 1999;9 Suppl 1:28.

\section{Smith 2002}

Smith LA, Moore OA, McQuay HJ, Moore A. Assessing the evidence of effectiveness of acupuncture for stroke rehabilitation: stepped assessment of likelihood of bias. Available at: www.jr2.ox.ac.uk/bandolier/booth/alternat/ ACstroke.html. (accessed 10 August 2015) 2002.

\section{Sterne 2011}

Sterne JAC, Egger M, Moher D (editors). Chapter 10: Addressing reporting biases. In: Higgins JPT, Green S (editors). Cochrane Handbook for Systematic Reviews of Intervention. Version 5.1.0 (updated March 2011). The Cochrane Collaboration, 2011. Available from www.cochrane-handbook.org. (accessed 10 August 2015).

\section{Sulter 1999}

Sulter G, Steen C, Keyser JD. Use of the Barthel Index and Modified Rankin Scale in acute stroke trials. Stroke 1999;30:1538-41.

\section{Sun 2001}

Sun HL, Li XM. Clinical study on treatment of cerebral apoplexy with penetration needling of scalp acupoints. Chinese Acupuncuture and Moxibustion 2001;21(5):275-8.

\section{Sze 2002}

Sze FK, Wong E, Or KKH, Lau J, Woo J. Does acupuncture have additional value to standard poststroke motor rehabilitation?. Stroke 2002;33:186-94.

\section{Van Tulder 2000}

Van Tulder MW, Cherkin DC, Berman B, Lao L, Koes BW. Acupuncture for low back pain. Cochrane Database of Systematic Reviews 2002, Issue 2. [DOI: 10.1002/14651858.CD001351]

\section{Wang 2012a}

Wang Y, Shen JG, Wang XM, Fu DL, Chen CY, Lu LY, et al. Scalp acupuncture for acute ischemic stroke: a meta-analysis of randomized controlled trials. Evidence-Based Complementary and Alternative Medicine 2012;2012(6):1325.

\section{Wayne 2005}

Wayne PM, Krebs DE, Eric A, Macklin EA, Schnyer R, Kaptchuk TJ, et al. Acupuncture for upper-extremity rehabilitation in chronic stroke: a randomized sham-controlled study. Archves of Physical Medicine and Rehabilitation 2005;86(12):2248-55.

\section{Wong 2012}

Wong ISY, Ng KF, Tsang HWH. Acupuncture for dysphagia following stroke: a systematic review. European Journal of Integrative Medicine 2012;4:e141-e150.

\section{Wu 1996}

Wu JN. A short history of acupuncture. Journal of Alternative Complementary Medicine 1996;2:19-21.

\section{Wu 2006}

Wu HM, Tang JL, Lin XP, Lau J, Leung PC, Woo J, et al. Acupuncture for stroke rehabilitation. Cochrane 
Database of Systematic Reviews 2006, Issue 3. [DOI: 10.1002/14651858.CD004131.pub2]

\section{Wu 2010a}

Wu P, Mills E, Moher D, Seely D. Acupuncture in poststroke rehabilitation: a systematic review and meta-analysis of randomized trials. Stroke 2010;41:e171-e179.

\section{Zhang 1996}

Zhang X, Yuan Y, Kuang P. The changes of vasoactive intestinal peptide, somato-statin and pancreatic polypeptide in blood and CSF of acute cerebral infarction patients and the effect of acupuncture on them. Chen Tzu Yen Chiu 1996;21(4):10-6.

\section{Zhang 2008a}

Zhang HZ, Zhang LX, She YF. Effect of electroacupuncture on apoptosis of hippocampus tissue in mice with vascular dementia. Zhen Ci Yan Jiu 2008;33:377-81.

\section{Zhang 2009a}

Zhang JB, Ren L, Sun Y. Meta-analysis on acupuncture for treatment of depression in patients of poststroke. Chinese Acupuncture \& Moxibustion 2009;29(7):599-602.

\section{CHARACTERISTICS OF STUDIES}

Characteristics of included studies [ordered by study ID]

\section{Zhang 2012a}

Zhang GC, Fu WB, Liu JH, Zhu XP, Liang ZH, Huang YF, et al. Meta analysis of the curative effect of acupuncture on post-stroke depression. Traditional Chinese Medicine 2012;32(1):6-11.

\section{Zhang 2014a}

Zhang JP, Chen J, Chen JQ, Li XH, Lai XY, Zhang SQ, et al. Early filiform needle acupuncture for poststroke depression: a metaanalysis of 17 randomized controlled clinical trials. Neural Regeneration Research 2014;9(7):773-84.

\section{Zheng 2011a}

Zheng GQ, Zhao ZM, Wang Y, Gu Y, Li Y, Chen XM, et al. Meta-analysis of scalp acupuncture for acute hypertensive intracerebral hemorrhage. Journal of Alternative and Complementary Medicine 2011;17(4):293-9.

\section{Zhou 2013}

Zhou JW, Li J, Zhao JJ, Xie HJ, Wang M. Meta analysis on ischemic stroke treated with scalp acupuncture. World Journal of Acupuncture-Moxibustion 2013;23(2):41-7.

\section{Zhu 2011a}

Zhu LL, Wang WX, Guo XG. Acupuncture for hiccups after stroke: a systematic review. Chinese Journal of Evidence-based Medicine 2011;11(3):325-8.

Bao 2012

\begin{tabular}{ll}
\hline Methods & RCT \\
Method of randomisation: random number table \\
Blinding: not stated \\
Adverse effects: not stated \\
ITT analysis: not stated \\
Losses to FU: not stated \\
Country: China \\
Number of participants included: 60 (30/30) \\
Demographics: aged 50-73 years, $67 \%$ male \\
Type of stroke: ischaemic only \\
Diagnosis: WHO definition and all confirmed by CT \\
Severity on entry: not stated \\
Time from stroke onset: 3 -12 months \\
Setting: inpatient and outpatient \\
Comparability: no significant difference in age or time post onset
\end{tabular}

Interventions Comparison: acupuncture + WM versus WM

Acupuncture treatment

- Acupuncture rationale: not stated 
Bao 2012 (Continued)

- Needling details

- Points used: both body and scalp acupoints. Numbers of points used: 4 scalp acupoints and 3 body acupoints

- Depths of insertion: not stated

- Deqi elicited: yes

- Needle stimulation: manual

- Needle retention time: 50 minutes

- Needle type: hua tuo brand

- Treatment regimen

- Number of treatment sessions: 56 sessions

- Frequency of treatment: 7 sessions/week

- Total course: 8 weeks

- Practitioner background: not stated

- Co-intervention: WM

Control interventions: WM

\begin{tabular}{ll}
\hline Outcomes & - Improvement of cognitive function (MMSE, MoCA) \\
- Improvement of independence (Barthel index) \\
- FU: 8 weeks
\end{tabular}

\section{Notes}

\section{Risk of bias}

\begin{tabular}{|c|c|c|}
\hline Bias & Authors' judgement & Support for judgement \\
\hline $\begin{array}{l}\text { Random sequence genera- } \\
\text { tion (selection bias) }\end{array}$ & Low risk & Randomisation by using random number table \\
\hline $\begin{array}{l}\text { Allocation concealment } \\
\text { (selection bias) }\end{array}$ & Unclear risk & Information on allocation concealment was not reported \\
\hline $\begin{array}{l}\text { Blinding (performance } \\
\text { bias and detection bias) } \\
\text { All outcomes }\end{array}$ & Unclear risk & Information on blinding was not reported \\
\hline $\begin{array}{l}\text { Blinding of participants } \\
\text { and personnel (perfor- } \\
\text { mance bias) } \\
\text { All outcomes }\end{array}$ & Unclear risk & Information on blinding was not reported \\
\hline $\begin{array}{l}\text { Blinding of outcome as- } \\
\text { sessment (detection bias) } \\
\text { All outcomes }\end{array}$ & Unclear risk & Information on blinding was not reported \\
\hline $\begin{array}{l}\text { Incomplete outcome data } \\
\text { (attrition bias) } \\
\text { All outcomes }\end{array}$ & Unclear risk & Information on attrition was not reported \\
\hline $\begin{array}{l}\text { Selective reporting (re- } \\
\text { porting bias) }\end{array}$ & Unclear risk & $\begin{array}{l}\text { Free of selective reporting bias was assessed as 'unclear' due to some clinical- } \\
\text { ly important outcomes unstated, such as quality of life, mortality and adverse } \\
\text { events }\end{array}$ \\
\hline Other bias & Unclear risk & No information provided \\
\hline
\end{tabular}


Chou 2009

$\begin{array}{ll}\text { Methods } & \text { RCT } \\ & \text { Method of randomisation: not stated } \\ & \text { Blinding: not stated } \\ & \text { Adverse effects: not stated } \\ \text { ITT analysis: not stated } \\ \text { Losses to FU: } 5\end{array}$

Interventions

Comparison: real acupuncture + PT versus sham acupuncture + PT

Acupuncture treatment

- Acupuncture rationale: stated

- Needling details

- Points used: body acupoints

- Numbers of points used: 2 acupoints

- Depths of insertion: 0.03 inch

- Deqi elicited: yes

- Needle stimulation: electrical

- Needle retention time: 20 minutes

- Needle type: the needles were 1 inch long

- Treatment regimen

- Number of treatment sessions: 16 sessions

- Frequency of treatment: 2/week

- Total course: 8 weeks

- Practitioner background: has been practicing Traditional Chinese Medicine for many years after graduating from medical school (China Medical University, Taichung, Taiwan)

- Co-intervention: PT

Control interventions: sham acupuncture + PT

\begin{tabular}{ll}
\hline Outcomes & Improvement of cognitive function (LOTCA-G) \\
- & Quality of life (SF-36, SS-QOL) \\
- FU: 8 weeks
\end{tabular}

Notes

\section{Risk of bias}

Bias

Authors' judgement Support for judgement

Random sequence genera- Unclear risk tion (selection bias) 
Chou 2009 (Continued)

\begin{tabular}{lll}
$\begin{array}{l}\text { Allocation concealment } \\
\text { (selection bias) }\end{array}$ & Unclear risk & Information on allocation concealment was not reported \\
\hline $\begin{array}{l}\text { Blinding (performance } \\
\text { bias and detection bias) }\end{array}$ & Unclear risk & Information on blinding was not reported \\
$\begin{array}{l}\text { All outcomes } \\
\text { out }\end{array}$ &
\end{tabular}

Blinding of participants Unclear risk Information on blinding was not reported
and personnel (perfor-
mance bias)
All outcomes

\begin{tabular}{|c|c|c|}
\hline $\begin{array}{l}\text { Blinding of outcome as- } \\
\text { sessment (detection bias) } \\
\text { All outcomes }\end{array}$ & Unclear risk & Information on blinding was not reported \\
\hline $\begin{array}{l}\text { Incomplete outcome data } \\
\text { (attrition bias) } \\
\text { All outcomes }\end{array}$ & Low risk & $\begin{array}{l}\text { Treatment: } 3 \text { participants could not finish the treatment protocol } \\
\text { Control: } 2 \text { participants decided not to receive rehabilitation }\end{array}$ \\
\hline $\begin{array}{l}\text { Selective reporting (re- } \\
\text { porting bias) }\end{array}$ & Unclear risk & $\begin{array}{l}\text { Free of selective reporting bias was assessed as 'unclear' due to some clinical- } \\
\text { ly important outcomes unstated, such as quality of life, mortality and adverse } \\
\text { events }\end{array}$ \\
\hline Other bias & Unclear risk & No information provided \\
\hline
\end{tabular}

\section{Dai 1997}

\begin{tabular}{|c|c|}
\hline Methods & $\begin{array}{l}\text { RCT } \\
\text { Method of randomisation: not stated } \\
\text { Blinding: not stated } \\
\text { Adverse effects: not stated } \\
\text { ITT analysis: not stated } \\
\text { Losses to FU: not stated }\end{array}$ \\
\hline Participants & $\begin{array}{l}\text { Country: China } \\
\text { Number of participants included: } 136 \text { (46/45/45) } \\
\text { Demographics: aged } 48-86 \text { years, } 75 \% \text { male } \\
\text { Type of stroke: ischaemic only } \\
\text { Diagnosis: WHO definition and all confirmed by CT } \\
\text { Severity on entry: mild to severe } \\
\text { Time from stroke onset: } 3-14 \text { months } \\
\text { Setting: unclear } \\
\text { Comparability: unclear }\end{array}$ \\
\hline Interventions & $\begin{array}{l}\text { 3 arms: } \\
\text { - acupuncture +WM } \\
\text { - acupuncture only } \\
\text { - WM only } \\
\text { Comparison eligible: acupuncture + WM versus WM only } \\
\text { Acupuncture treatment } \\
\text { - Acupuncture rationale: not stated }\end{array}$ \\
\hline
\end{tabular}


Dai 1997 (Continued)

- Needling details:

- points used: both body and scalp (three temporal points) acupoints

- Numbers of points used: 5-11 points

- Depths of insertion: 1.5-2.0 inches

- Deqi elicited: yes

- Needle stimulation: manual

- Needle retention time: 30 minutes

○ Needle type: stainless steel, gauge 26-30\#, length 2.0-2.6 inches

- Treatment regimen:

- Number of treatment sessions: 30 sessions

- Frequency of treatment: 1 session/day

- Total course: 30 days

- Practitioner background: not stated

- Co-intervention:

- aspirin $25 \mathrm{mg}$ qd orally

Control interventions: WM: aspirin 25 mg qd orally

\begin{tabular}{ll} 
Outcomes & $\begin{array}{l}\text { Number of participants with improvement in global neurological deficit (CSRS 1 score decrease > 18\%) } \\
\text { at the end of treatment } \\
\text { FU: } 30 \text { days }\end{array}$ \\
\hline Notes & - \\
\hline
\end{tabular}

\section{Risk of bias}

\begin{tabular}{lll}
\hline Bias & Authors' judgement & Support for judgement \\
\hline $\begin{array}{l}\text { Random sequence genera- } \\
\text { tion (selection bias) }\end{array}$ & Unclear risk & The method of random sequence generation was not reported \\
\hline $\begin{array}{l}\text { Allocation concealment } \\
\text { (selection bias) }\end{array}$ & Unclear risk & Information on allocation concealment was not reported \\
\hline $\begin{array}{l}\text { Blinding (performance } \\
\text { bias and detection bias) } \\
\text { All outcomes }\end{array}$ & Unclear risk & Information on blinding was not reported \\
\hline
\end{tabular}

\begin{tabular}{|c|c|c|}
\hline $\begin{array}{l}\text { Blinding of participants } \\
\text { and personnel (perfor- } \\
\text { mance bias) } \\
\text { All outcomes }\end{array}$ & Unclear risk & Information on blinding was not reported \\
\hline $\begin{array}{l}\text { Blinding of outcome as- } \\
\text { sessment (detection bias) } \\
\text { All outcomes }\end{array}$ & Unclear risk & Information on blinding was not reported \\
\hline $\begin{array}{l}\text { Incomplete outcome data } \\
\text { (attrition bias) } \\
\text { All outcomes }\end{array}$ & Unclear risk & Information on attrition was not reported \\
\hline $\begin{array}{l}\text { Selective reporting (re- } \\
\text { porting bias) }\end{array}$ & Unclear risk & $\begin{array}{l}\text { Free of selective reporting bias was assessed as 'unclear' due to some clinical- } \\
\text { ly important outcomes unstated, such as quality of life, mortality and adverse } \\
\text { events }\end{array}$ \\
\hline Other bias & Unclear risk & No information provided \\
\hline
\end{tabular}




$\begin{array}{ll}\text { Methods } & \text { RCT } \\ & \text { Method of randomisation: random number table } \\ & \text { Blinding: not stated } \\ & \text { Adverse effects: not stated } \\ \text { ITT analysis: not stated } \\ \text { Losses to FU: none }\end{array}$

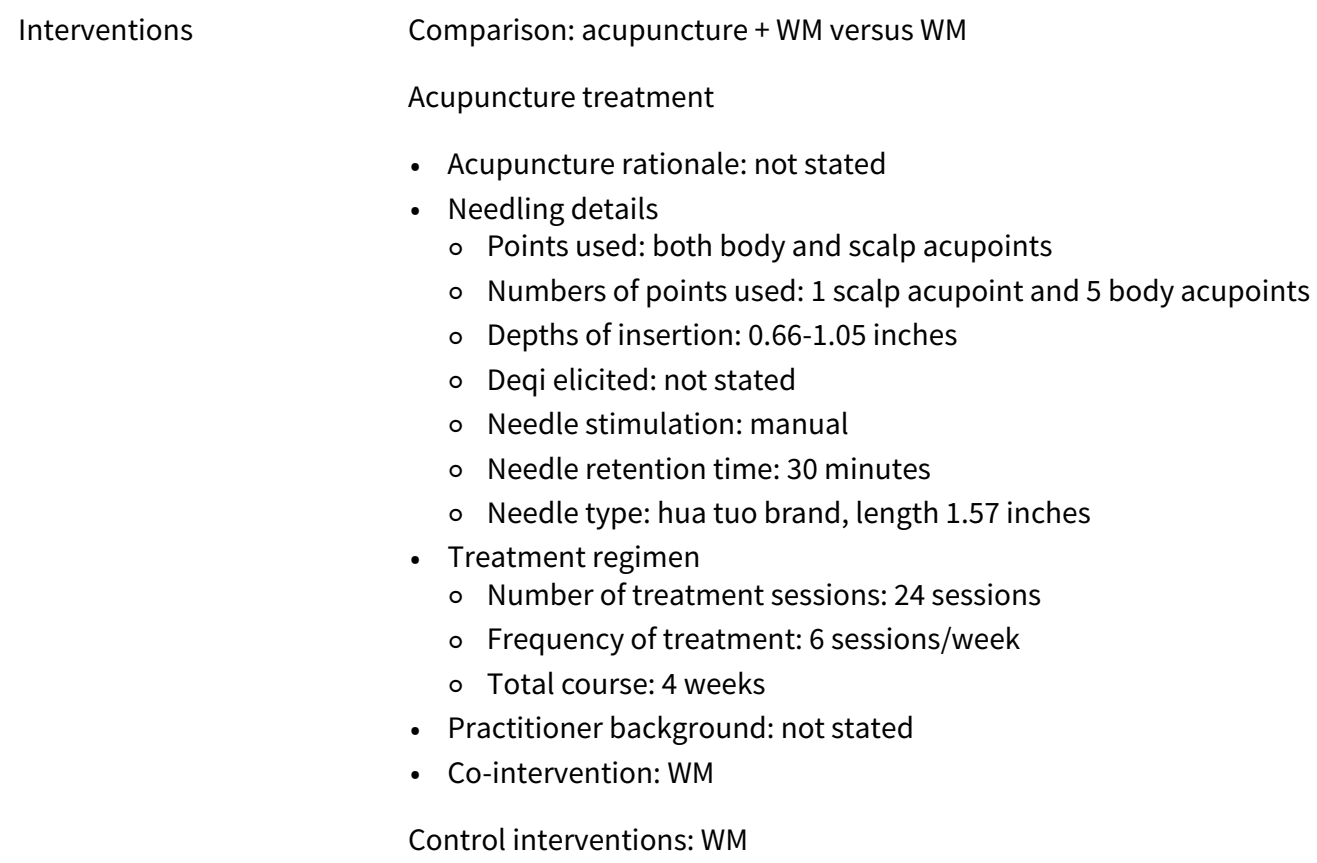

\section{Risk of bias}

\begin{tabular}{lll}
\hline Bias & Authors' judgement & Support for judgement \\
\hline $\begin{array}{l}\text { Random sequence genera- } \\
\text { tion (selection bias) }\end{array}$ & Low risk & Randomisation by using random number table \\
\hline $\begin{array}{l}\text { Allocation concealment } \\
\text { (selection bias) }\end{array}$ & Unclear risk & Information on the allocation concealment was not reported \\
\hline \hline
\end{tabular}




\section{Gao 2014a (Continued)}

Blinding (performance Unclear risk Information on blinding was not reported bias and detection bias)

All outcomes

Blinding of participants Unclear risk Information on blinding was not reported
and personnel (perfor-
mance bias)
All outcomes

\begin{tabular}{lll}
\hline $\begin{array}{l}\text { Blinding of outcome as- } \\
\text { sessment (detection bias) } \\
\text { All outcomes }\end{array}$ & Unclear risk & Information on blinding was not reported \\
\hline $\begin{array}{l}\text { Incomplete outcome data } \\
\text { (attrition bias) } \\
\text { All outcomes }\end{array}$ & Low risk & No participants lost to follow-up \\
\hline $\begin{array}{l}\text { Selective reporting (re- } \\
\text { porting bias) }\end{array}$ & Unclear risk & $\begin{array}{l}\text { Free of selective reporting bias was assessed as 'unclear' due to some clinical- } \\
\text { ly important outcomes unstated, such as quality of life, mortality and adverse } \\
\text { events }\end{array}$ \\
\hline Other bias & Unclear risk & No information provided \\
\hline
\end{tabular}

\section{Guo 2011}

$\begin{array}{ll}\text { Methods } & \text { RCT } \\ & \text { Method of randomisation: not stated } \\ & \text { Blinding: not stated } \\ & \text { Adverse effects: not stated } \\ \text { ITT analysis: not stated } \\ \text { Losses to FU: not stated }\end{array}$

\begin{tabular}{ll}
\hline Participants & Country: China \\
& Number of participants included: 95 (32/31/32) \\
& Demographics: aged $40-65$ years, $61 \%$ male \\
& Type of stroke: both ischaemic and haemorrhagic strokes \\
& Diagnosis: CT/MRI \\
Severity on entry: not stated \\
Time from stroke onset: 1-6 months \\
Setting: inpatient \\
Comparability: no significant difference in age or time post onset
\end{tabular}

\begin{tabular}{ll}
\hline Interventions & - arms: \\
- WM only \\
- acupuncture + WM \\
Comparison eligible: acupuncture + WM versus WM only \\
Acupuncture treatment \\
- Acupuncture rationale: not stated
\end{tabular}


Guo 2011 (Continued)

- Needling details

- Points used: both body and scalp acupoints

- Numbers of points used: 4 scalp acupoints and 2 body acupoints

- Depths of insertion: not stated

- Deqi elicited: not stated

- Needle stimulation: manual and electrical

- Needle retention time: 30 minutes

- Needle type: not stated

- Treatment regimen

- Number of treatment sessions: 30 sessions

- Frequency of treatment: 5 sessions/week

- Total course: 6 weeks

- Practitioner background: not stated

- Co-intervention: WM

Control interventions: WM

\begin{tabular}{ll}
\hline Outcomes & Improvement of depression (HAMD) \\
& - Improvement of neurological function (Clinical Neurological Function Defect Scale) \\
& - FU: 6 weeks
\end{tabular}

Notes

\section{Risk of bias}

\begin{tabular}{|c|c|c|}
\hline Bias & Authors' judgement & Support for judgement \\
\hline $\begin{array}{l}\text { Random sequence genera- } \\
\text { tion (selection bias) }\end{array}$ & Unclear risk & The method of random sequence generation was not reported \\
\hline $\begin{array}{l}\text { Allocation concealment } \\
\text { (selection bias) }\end{array}$ & Unclear risk & Information on allocation concealment was not reported \\
\hline $\begin{array}{l}\text { Blinding (performance } \\
\text { bias and detection bias) } \\
\text { All outcomes }\end{array}$ & Unclear risk & Information on blinding was not reported \\
\hline $\begin{array}{l}\text { Blinding of participants } \\
\text { and personnel (perfor- } \\
\text { mance bias) } \\
\text { All outcomes }\end{array}$ & Unclear risk & Information on blinding was not reported \\
\hline $\begin{array}{l}\text { Blinding of outcome as- } \\
\text { sessment (detection bias) } \\
\text { All outcomes }\end{array}$ & Unclear risk & Information on blinding was not reported \\
\hline $\begin{array}{l}\text { Incomplete outcome data } \\
\text { (attrition bias) } \\
\text { All outcomes }\end{array}$ & Unclear risk & Information on attrition was not reported \\
\hline $\begin{array}{l}\text { Selective reporting (re- } \\
\text { porting bias) }\end{array}$ & Unclear risk & $\begin{array}{l}\text { Free of selective reporting bias was assessed as 'unclear' due to some clinical- } \\
\text { ly important outcomes unstated, such as quality of life, mortality and adverse } \\
\text { events }\end{array}$ \\
\hline Other bias & Unclear risk & No information provided \\
\hline
\end{tabular}




\begin{tabular}{ll}
\hline Methods & RCT \\
Method of randomisation: not stated \\
Blinding: not stated \\
Adverse effects: not stated \\
ITT analysis: not stated \\
Losses to FU: not stated \\
\hline Country: China \\
Number of participants included: 60 (30/30) \\
Demographics: aged 38 to 73 years, $68 \%$ male \\
Type of stroke: unclear \\
Diagnosis: unclear \\
Severity on entry: not stated \\
Time from stroke onset: 3 months to 5 years \\
Setting: inpatient \\
Comparability: comorbidity and past history similar
\end{tabular}

\begin{tabular}{|c|c|}
\hline Interventions & $\begin{array}{l}\text { Comparison: acupuncture + OT versus OT } \\
\text { Acupuncture treatment } \\
\text { - Acupuncture rationale: not stated } \\
\text { - Needling details } \\
\circ \text { Points used: body acupoints } \\
\circ \text { Numbers of points used: } 1 \text { acupoint } \\
\circ \text { Depths of insertion: } 0.28-0.55 \text { inch } \\
\circ \text { Deqi elicited: not stated } \\
\circ \text { Needle stimulation: manual } \\
\circ \text { Needle retention time: not stated } \\
\circ \text { Needle type: the needles were } 1.57 \text { inches long } \\
\text { - Treatment regimen } \\
\circ \quad \text { Number of treatment sessions: } 6-12 \text { sessions } \\
\circ \text { Frequency of treatment: } 6 / \text { week } \\
\circ \text { Total course: } 1-2 \text { weeks } \\
\text { - Practitioner background: not stated } \\
\text { - Co-intervention: OT } \\
\text { Control interventions: OT }\end{array}$ \\
\hline Outcomes & Number of participants with improvement in swallowing function (water drinking test) \\
\hline
\end{tabular}

\section{Risk of bias}

\begin{tabular}{lll}
\hline Bias & Authors' judgement & Support for judgement \\
\hline $\begin{array}{l}\text { Random sequence genera- } \\
\text { tion (selection bias) }\end{array}$ & Unclear risk & The method of random sequence generation was not reported \\
\hline $\begin{array}{l}\text { Allocation concealment } \\
\text { (selection bias) }\end{array}$ & Unclear risk & Information on allocation concealment was not reported \\
\hline $\begin{array}{l}\text { Blinding (performance } \\
\text { bias and detection bias) }\end{array}$ & Unclear risk & Information on blinding was not reported \\
\hline
\end{tabular}


Guo 2012 (Continued)

All outcomes

Blinding of participants Unclear risk Information on blinding was not reported
and personnel (perfor-
mance bias)
All outcomes

Blinding of outcome as- Unclear risk Information on blinding was not reported sessment (detection bias)

All outcomes

\begin{tabular}{lll}
\hline $\begin{array}{l}\text { Incomplete outcome data } \\
\text { (attrition bias) } \\
\text { All outcomes }\end{array}$ & Unclear risk & Information on attrition was not reported \\
\hline $\begin{array}{l}\text { Selective reporting (re- } \\
\text { porting bias) }\end{array}$ & Unclear risk & $\begin{array}{l}\text { Free of selective reporting bias was assessed as 'unclear' due to some clinical- } \\
\text { ly important outcomes unstated, such as quality of life, mortality and adverse } \\
\text { events }\end{array}$ \\
\hline Other bias & Unclear risk & No information provided \\
\hline
\end{tabular}

Huang 2008a

\begin{tabular}{ll}
\hline Methods & RCT \\
& Method of randomisation: random number table \\
& Blinding: not stated \\
& Adverse effects: not stated \\
ITT analysis: not stated \\
Losses to FU: not stated
\end{tabular}

Participants Country: China

Number of participants included: $90(30 / 30 / 30)$

Demographics: $67 \%$ male

Type of stroke: ischaemic only

Diagnosis: CT/MRI

Severity on entry: not stated

Time from stroke onset: 1-3 months

Setting: inpatient

Comparability: no significant difference in age or time post onset

3 arms:
Interventions $\quad$ acupuncture only
- PT only
- acupuncture + PT
Comparison eligible: acupuncture + PT versus PT only
Acupuncture treatment
- Acupuncture rationale: not stated


Huang 2008a (Continued)

- Needling details

- Points used: scalp acupoints

- Numbers of points used: 3 points

- Depths of insertion: $0.98-1.38$ inches

- Deqi elicited: not stated

- Needle stimulation: manual

- Needle retention time: 30 minutes

- Needle type: the needles were 1.57 inches long

- Treatment regimen

- Number of treatment sessions: 24 sessions

- Frequency of treatment: 6 sessions/week

- Total course: 4 weeks

- Practitioner background: not stated

- Co-intervention: PT

Control interventions: PT

\begin{tabular}{ll}
\hline Outcomes & Neurological function (MESS and SSS) \\
- Independence (Barthel Index)
\end{tabular}

- Independence (Barthel Index)

Notes -

\section{Risk of bias}

\begin{tabular}{lll}
\hline Bias & Authors' judgement & Support for judgement \\
\hline $\begin{array}{l}\text { Random sequence genera- } \\
\text { tion (selection bias) }\end{array}$ & Low risk & Randomisation by using random number table \\
\hline $\begin{array}{l}\text { Allocation concealment } \\
\text { (selection bias) }\end{array}$ & Unclear risk & Information on allocation concealment was not reported \\
\hline $\begin{array}{l}\text { Blinding (performance } \\
\text { bias and detection bias) } \\
\text { All outcomes }\end{array}$ & Unclear risk & Information on blinding was not reported \\
\hline
\end{tabular}

Blinding of participants Unclear risk Information on blinding was not reported
and personnel (perfor-

and personnel (perfor-

mance bias)

All outcomes

\begin{tabular}{lll}
\hline $\begin{array}{l}\text { Blinding of outcome as- } \\
\text { sessment (detection bias) } \\
\text { All outcomes }\end{array}$ & Unclear risk & Information on blinding was not reported \\
\hline $\begin{array}{l}\text { Incomplete outcome data } \\
\text { (attrition bias) } \\
\text { All outcomes }\end{array}$ & Unclear risk & No information provided \\
\hline $\begin{array}{l}\text { Selective reporting (re- } \\
\text { porting bias) }\end{array}$ & Unclear risk & $\begin{array}{l}\text { Free of selective reporting bias was assessed as 'unclear' due to some clinical- } \\
\text { ly important outcomes unstated, such as quality of life, mortality and adverse } \\
\text { events }\end{array}$ \\
\hline \begin{tabular}{l} 
Other bias \\
\hline
\end{tabular} & Unclear risk & No information provided \\
\hline
\end{tabular}


Ke 2015

\begin{tabular}{ll}
\hline Methods & RCT \\
Method of randomisation: not stated \\
Blinding: not stated \\
Adverse effects: not stated \\
ITT analysis: not stated
\end{tabular}

Losses to FU: not stated

\begin{tabular}{|c|c|}
\hline Participants & $\begin{array}{l}\text { Country: China } \\
\text { Number of participants included: } 80 \text { (40/40) } \\
\text { Demographics: aged } 61-83 \text { years, } 55 \% \text { male } \\
\text { Type of stroke: both ischaemic and haemorrhagic strokes } \\
\text { Diagnosis: WHO definition } \\
\text { Severity on entry: not stated } \\
\text { Time from stroke onset: } 2-18 \text { months } \\
\text { Setting: inpatient } \\
\text { Comparability: no significant difference in age or time post onset }\end{array}$ \\
\hline Interventions & $\begin{array}{l}\text { Comparison: acupuncture + PT versus PT } \\
\text { Acupuncture treatment } \\
\text { - Acupuncture rationale: not stated } \\
\text { - Needling details } \\
\circ \text { Points used: body acupoints } \\
\circ \text { Numbers of points used: } 27 \text { body acupoints } \\
\circ \text { Depths of insertion: } 0.66-5.25 \text { inches } \\
\circ \text { Deqi elicited: not stated } \\
\circ \text { Needle stimulation: manual } \\
\circ \text { Needle retention time: } 30-40 \text { minutes } \\
\circ \text { Needle type: not stated } \\
\text { - Treatment regimen } \\
\circ \quad \text { Number of treatment sessions: } 30 \text { sessions } \\
\circ \text { Frequency of treatment: } 7 \text { sessions/week } \\
\text { - Total course: } 30 \text { days } \\
\text { - Practitioner background: not stated } \\
\text { - Co-intervention: PT } \\
\text { Control interventions: PT }\end{array}$ \\
\hline Outcomes & $\begin{array}{l}\text { - Improvement of syndrome (TCM syndrome scoring criteria) } \\
\text { - Improvement of independence (Barthel Index) } \\
\text { - FU: } 30 \text { days }\end{array}$ \\
\hline
\end{tabular}

\section{Notes}

\section{Risk of bias}

\begin{tabular}{lll}
\hline Bias & Authors' judgement & Support for judgement \\
\hline $\begin{array}{l}\text { Random sequence genera- } \\
\text { tion (selection bias) }\end{array}$ & Unclear risk & The method of random sequence generation was not reported \\
\hline $\begin{array}{l}\text { Allocation concealment } \\
\text { (selection bias) }\end{array}$ & Unclear risk & Information on allocation concealment was not reported \\
\hline
\end{tabular}


Ke 2015 (Continued)

Blinding (performance Unclear risk Information on blinding was not reported bias and detection bias)

All outcomes

Blinding of participants Unclear risk Information on blinding was not reported
and personnel (perfor-
mance bias)
All outcomes

\begin{tabular}{lll}
\hline $\begin{array}{l}\text { Blinding of outcome as- } \\
\text { sessment (detection bias) } \\
\text { All outcomes }\end{array}$ & Unclear risk & Information on blinding was not reported \\
\hline $\begin{array}{l}\text { Incomplete outcome data } \\
\text { (attrition bias) } \\
\text { All outcomes }\end{array}$ & Unclear risk & Information on attrition was not reported \\
\hline $\begin{array}{l}\text { Selective reporting (re- } \\
\text { porting bias) }\end{array}$ & Unclear risk & $\begin{array}{l}\text { Free of selective reporting bias was assessed as 'unclear' due to some clinical- } \\
\text { ly important outcomes unstated, such as quality of life, mortality and adverse } \\
\text { events }\end{array}$ \\
\hline Other bias & Unclear risk & No information provided \\
\hline
\end{tabular}

\section{Li 1997a}

$\begin{array}{ll}\text { Methods } & \text { RCT } \\ & \text { Method of randomisation: not stated } \\ & \text { Blinding: not stated } \\ & \text { Adverse effects: not stated } \\ \text { ITT analysis: not stated } & \text { Losses to FU: not stated }\end{array}$

$\begin{array}{ll}\text { Participants } & \text { Country: China } \\ \text { Number of participants included: } 112(42 / 20 / 50) \\ \text { Demographics: aged 24-76 years } \\ \text { Type of stroke: both ischaemic and haemorrhagic strokes } \\ \text { Diagnosis: WHO definition and all confirmed by CT or MRI } \\ \text { Severity on entry: not stated } \\ \text { Time from stroke onset: } 1 \text { month to } 8.5 \text { years } \\ \text { Setting: inpatients } \\ \text { Comparability: comorbidity and past history similar }\end{array}$

Interventions
- acupuncture + PT and OT
- acupuncture only
Comparison eligible: acupuncture + PT and OT versus PT and OT
Acupuncture treatment
- Acupuncture rationale: not stated


Li 1997a (Continued)

- Needling details

- Points used: both body and scalp acupoints

- Numbers of points used: $10-12$ points

- Depths of insertion: not stated

- Deqi elicited: unclear

- Needle stimulation: manual

- Needle retention time: 30 minutes

- Needle type: not stated

- Treatment regimen

- Number of treatment sessions: 72 sessions

- Frequency of treatment: 6 sessions/week

- Total course: 3 months

- Practitioner background: not stated

- Co-intervention: baseline medication, PT and OT

Control interventions: baseline medication plus PT and OT

\begin{tabular}{ll}
\hline Outcomes & $\begin{array}{l}\text { Number of participants with improvement in global neurological deficit (CSRS } 1 \text { score) at the end of } \\
\text { treatment } \\
\text { FU: } 3 \text { months }\end{array}$ \\
\hline Notes & -
\end{tabular}

\section{Risk of bias}

Bias Authors' judgement Support for judgement

Random sequence genera- Unclear risk The method of random sequence generation was not reported
tion (selection bias)

\begin{tabular}{|c|c|c|}
\hline $\begin{array}{l}\text { Allocation concealment } \\
\text { (selection bias) }\end{array}$ & Unclear risk & Information on allocation concealment was not reported \\
\hline $\begin{array}{l}\text { Blinding (performance } \\
\text { bias and detection bias) } \\
\text { All outcomes }\end{array}$ & Unclear risk & Information on blinding was not reported \\
\hline $\begin{array}{l}\text { Blinding of participants } \\
\text { and personnel (perfor- } \\
\text { mance bias) } \\
\text { All outcomes }\end{array}$ & Unclear risk & Information on blinding was not reported \\
\hline $\begin{array}{l}\text { Blinding of outcome as- } \\
\text { sessment (detection bias) } \\
\text { All outcomes }\end{array}$ & Unclear risk & Information on blinding was not reported \\
\hline $\begin{array}{l}\text { Incomplete outcome data } \\
\text { (attrition bias) } \\
\text { All outcomes }\end{array}$ & Unclear risk & Information on attrition was not reported \\
\hline $\begin{array}{l}\text { Selective reporting (re- } \\
\text { porting bias) }\end{array}$ & Unclear risk & $\begin{array}{l}\text { Free of selective reporting bias was assessed as 'unclear' due to some clinical- } \\
\text { ly important outcomes unstated, such as quality of life, mortality and adverse } \\
\text { events }\end{array}$ \\
\hline Other bias & Unclear risk & No information provided \\
\hline
\end{tabular}




\begin{tabular}{ll}
\hline Methods & RCT \\
& Method of randomisation: random number table \\
& Blinding: not stated \\
& Adverse effects: none \\
ITT analysis: not stated \\
Losses to FU: 4
\end{tabular}

Interventions

Comparison: acupuncture + WM versus WM

Acupuncture treatment

- Acupuncture rationale: not stated

- Needling details

- Points used: both body and scalp acupoints

- Numbers of points used: 5 scalp acupoints and 6 body acupoints

- Depths of insertion: $0.66-1.5$ inches

- Deqi elicited: yes

- Needle stimulation: manual and electrical

- Needle retention time: 30 minutes

- Needle type: gauge 30\#, length 1.97 inches

- Treatment regimen

- Number of treatment sessions: 60 sessions

- Frequency of treatment: 5 sessions/week

- Total course: 12 weeks

- Practitioner background: not stated

- Co-intervention:WM

Control interventions: WM

\begin{tabular}{ll}
\hline Outcomes & Improvement of cognitive function (MMSE HDS-R) \\
- Improvement of independence (Barthel Index) \\
- Adverse events \\
- FU: 12 weeks
\end{tabular}

\section{Notes}

\section{Risk of bias}

\section{Bias}

Authors' judgement Support for judgement

Random sequence genera- Low risk $\quad$ Randomisation by using random number table
tion (selection bias)


Li 2010a (Continued)

Allocation concealment Unclear risk Information on allocation concealment was not reported
(selection bias)

Blinding (performance Unclear risk Information on blinding was not reported

bias and detection bias)

All outcomes

Blinding of participants Unclear risk Information on blinding was not reported
and personnel (perfor-
mance bias)
All outcomes

\begin{tabular}{|c|c|c|}
\hline $\begin{array}{l}\text { Blinding of outcome as- } \\
\text { sessment (detection bias) } \\
\text { All outcomes }\end{array}$ & Unclear risk & Information on blinding was not reported \\
\hline $\begin{array}{l}\text { Incomplete outcome data } \\
\text { (attrition bias) } \\
\text { All outcomes }\end{array}$ & Low risk & $\begin{array}{l}\text { Treatment: } 1 \text { participant could not finish the treatment protocol } \\
\text { Control: } 3 \text { participants could not finish the control protocol }\end{array}$ \\
\hline $\begin{array}{l}\text { Selective reporting (re- } \\
\text { porting bias) }\end{array}$ & Unclear risk & $\begin{array}{l}\text { Some patient-related outcomes were not reported, such as information on } \\
\text { quality of life or all-cause mortality }\end{array}$ \\
\hline Other bias & Unclear risk & No information provided \\
\hline
\end{tabular}

Li 2011a

\begin{tabular}{ll} 
Methods & RCT \\
Method of randomisation: not stated \\
Blinding: not stated \\
Adverse effects: not stated \\
ITT analysis: not stated \\
Losses to FU: not stated \\
\hline Country: China \\
Number of participants included: 62 (31/31) \\
Demographics: $54 \%$ male \\
Type of stroke: unclear \\
Diagnosis: CT/MRI \\
Severity on entry: not stated \\
Time from stroke onset: 6 -20 months \\
Setting: outpatient \\
Comparability: no significant difference in age or time post onset
\end{tabular}

Interventions

Comparison: acupuncture + WM versus WM

Acupuncture treatment

- Acupuncture rationale: not stated 
Li 2011a (Continued)

- Needling details

- Points used: body acupoints

- Numbers of points used: 7 body acupoints

- Depths of insertion: 0.39-1.05 inches

- Deqi elicited: not stated

- Needle stimulation: manual

- Needle retention time: not stated

- Needle type: stainless steel needle gauge $28 \#$, length 1.31 inches

- Treatment regimen

- Number of treatment sessions: 28 sessions

- Frequency of treatment: 7 sessions/week

- Total course: 4 weeks

- Practitioner background: not stated

- Co-intervention: WM

Control interventions: WM

\begin{tabular}{ll}
\hline Outcomes & - Improvement of cognitive function (MMSE) \\
- Improvement of independence (ADL) \\
- FU: 4 weeks
\end{tabular}

Notes

Risk of bias

\begin{tabular}{|c|c|c|}
\hline Bias & Authors' judgement & Support for judgement \\
\hline $\begin{array}{l}\text { Random sequence genera- } \\
\text { tion (selection bias) }\end{array}$ & Unclear risk & The method of random sequence generation was not reported \\
\hline $\begin{array}{l}\text { Allocation concealment } \\
\text { (selection bias) }\end{array}$ & Unclear risk & Information on allocation concealment was not reported \\
\hline $\begin{array}{l}\text { Blinding (performance } \\
\text { bias and detection bias) } \\
\text { All outcomes }\end{array}$ & Unclear risk & Information on blinding was not reported \\
\hline $\begin{array}{l}\text { Blinding of participants } \\
\text { and personnel (perfor- } \\
\text { mance bias) } \\
\text { All outcomes }\end{array}$ & Unclear risk & Information on blinding was not reported \\
\hline $\begin{array}{l}\text { Blinding of outcome as- } \\
\text { sessment (detection bias) } \\
\text { All outcomes }\end{array}$ & Unclear risk & Information on blinding was not reported \\
\hline $\begin{array}{l}\text { Incomplete outcome data } \\
\text { (attrition bias) } \\
\text { All outcomes }\end{array}$ & Unclear risk & Information on attrition was not reported \\
\hline $\begin{array}{l}\text { Selective reporting (re- } \\
\text { porting bias) }\end{array}$ & Unclear risk & $\begin{array}{l}\text { Free of selective reporting bias was assessed as 'unclear' due to some clinical- } \\
\text { ly important outcomes unstated, such as quality of life, mortality and adverse } \\
\text { events }\end{array}$ \\
\hline Other bias & Unclear risk & No information provided \\
\hline
\end{tabular}




$\begin{array}{ll}\text { Methods } & \text { RCT } \\ & \text { Method of randomisation: not stated } \\ & \text { Blinding: not stated } \\ & \text { Adverse effects: not stated } \\ \text { ITT analysis: not stated } \\ \text { Losses to FU: not stated }\end{array}$

Participants

Country: China

Number of participants included: 60 (20/20/20)

Demographics: aged 40-75 years

Type of stroke: both ischaemic and haemorrhagic strokes

Diagnosis: CT/MRI

Severity on entry: not stated

Time from stroke onset: 1-3 months

Setting: inpatient

Comparability: no significant difference in age or time post onset

\begin{tabular}{|c|c|}
\hline Interventions & $\begin{array}{l}\text { 3 arms: } \\
\text { - acupuncture only } \\
\text { - PT only } \\
\text { - acupuncture + PT } \\
\text { Comparison eligible: acupuncture + PT versus PT only } \\
\text { Acupuncture treatment } \\
\text { - Acupuncture rationale: not stated } \\
\text { - Needling details } \\
\circ \text { Points used: body acupoints } \\
\circ \text { Numbers of points used: } 12 \text { points } \\
\circ \text { Depths of insertion: not stated } \\
\circ \text { Deqi elicited: not stated } \\
\circ \text { Needle stimulation: } \text { manual } \\
\circ \text { Needle retention time: } 30 \text { minute } \\
\circ \quad \text { Needle type: not stated } \\
\text { - Treatment regimen } \\
\circ \quad \text { Number of treatment sessions: not stated } \\
\circ \quad \text { Frequency of treatment: } 7 \text { sessions/week } \\
\text { - Total course: not stated } \\
\text { - Practitioner background: not stated } \\
\text { Co-intervention: PT } \\
\text { Control interventions: PT }\end{array}$ \\
\hline Outcomes & $\begin{array}{l}\text { - Improvement of motor function (Fugl-Meyer Assessment) } \\
\text { - Improvement of pain (Visual Analogue Score) } \\
\text { - Improvement of independence (ADL) } \\
\text { - FU: not stated }\end{array}$ \\
\hline Notes & - \\
\hline
\end{tabular}

\section{Risk of bias}


Li 2013a (Continued)

Bias Authors' judgement Support for judgement

\begin{tabular}{|c|c|c|}
\hline $\begin{array}{l}\text { Random sequence genera- } \\
\text { tion (selection bias) }\end{array}$ & Unclear risk & The method of random sequence generation was not reported \\
\hline $\begin{array}{l}\text { Allocation concealment } \\
\text { (selection bias) }\end{array}$ & Unclear risk & Information on allocation concealment was not reported \\
\hline $\begin{array}{l}\text { Blinding (performance } \\
\text { bias and detection bias) } \\
\text { All outcomes }\end{array}$ & Unclear risk & Information on blinding was not reported \\
\hline $\begin{array}{l}\text { Blinding of participants } \\
\text { and personnel (perfor- } \\
\text { mance bias) } \\
\text { All outcomes }\end{array}$ & Unclear risk & Information on blinding was not reported \\
\hline
\end{tabular}

\begin{tabular}{|c|c|c|}
\hline $\begin{array}{l}\text { Blinding of outcome as- } \\
\text { sessment (detection bias) } \\
\text { All outcomes }\end{array}$ & Unclear risk & Information on blinding was not reported \\
\hline $\begin{array}{l}\text { Incomplete outcome data } \\
\text { (attrition bias) } \\
\text { All outcomes }\end{array}$ & Unclear risk & Information on attrition was not reported \\
\hline $\begin{array}{l}\text { Selective reporting (re- } \\
\text { porting bias) }\end{array}$ & Unclear risk & $\begin{array}{l}\text { Free of selective reporting bias was assessed as 'unclear' due to some clinical- } \\
\text { ly important outcomes unstated, such as quality of life, mortality and adverse } \\
\text { events }\end{array}$ \\
\hline Other bias & Unclear risk & No information provided \\
\hline
\end{tabular}

Liu 2013a

\begin{tabular}{ll}
\hline Methods & RCT \\
& Method of randomisation: not stated \\
& Blinding: not stated \\
& Adverse effects: not stated \\
ITT analysis: not stated \\
Losses to FU: not stated
\end{tabular}

Participants Country: China

Number of participants included: $50(25 / 25)$

Demographics: aged $35-74$ years, $68 \%$ male

Type of stroke: both ischaemic and haemorrhagic strokes

Diagnosis: WHO definition and all confirmed by CT

Severity on entry: not stated

Time from stroke onset: 3-12 months

Setting: inpatient

Comparability: no significant difference in age, comorbidity, or time post onset

Interventions Comparison: acupuncture + daily OT versus daily OT

Acupuncture treatment

- Acupuncture rationale: not stated 
Liu 2013a (Continued)

- Needling details

- Points used: scalp acupoints

- Numbers of points used: 2 scalp acupoints

○ Depths of insertion: 1.05-1.31/0.66 inches

- Deqi elicited: yes

- Needle stimulation: manual and electrical stimulation

- Needle retention time: 90 minutes

- Needle type: hua tuo brand, length 0.98 inches

- Treatment regimen

- Number of treatment sessions: 24 sessions

- Frequency of treatment: 6 sessions/week

- Total course: 4 weeks

- Practitioner background: not stated

- Co-intervention: OT

Control interventions: OT

\begin{tabular}{ll}
\hline Outcomes & Improvement of cognitive function (MMSE) \\
& - Independence (ADL) \\
& FU: 24 days
\end{tabular}

Notes

Risk of bias

\begin{tabular}{|c|c|c|}
\hline Bias & Authors' judgement & Support for judgement \\
\hline $\begin{array}{l}\text { Random sequence genera- } \\
\text { tion (selection bias) }\end{array}$ & Unclear risk & The method of random sequence generation was not reported \\
\hline $\begin{array}{l}\text { Allocation concealment } \\
\text { (selection bias) }\end{array}$ & Unclear risk & Information on allocation concealment was not reported \\
\hline $\begin{array}{l}\text { Blinding (performance } \\
\text { bias and detection bias) } \\
\text { All outcomes }\end{array}$ & Unclear risk & Information on blinding was not reported \\
\hline $\begin{array}{l}\text { Blinding of participants } \\
\text { and personnel (perfor- } \\
\text { mance bias) } \\
\text { All outcomes }\end{array}$ & Unclear risk & Information on blinding was not reported \\
\hline $\begin{array}{l}\text { Blinding of outcome as- } \\
\text { sessment (detection bias) } \\
\text { All outcomes }\end{array}$ & Unclear risk & Information on blinding was not reported \\
\hline $\begin{array}{l}\text { Incomplete outcome data } \\
\text { (attrition bias) } \\
\text { All outcomes }\end{array}$ & Unclear risk & Information on attrition was not reported \\
\hline $\begin{array}{l}\text { Selective reporting (re- } \\
\text { porting bias) }\end{array}$ & Unclear risk & $\begin{array}{l}\text { Free of selective reporting bias was assessed as 'unclear' due to some clinical- } \\
\text { ly important outcomes unstated, such as quality of life, mortality and adverse } \\
\text { events }\end{array}$ \\
\hline Other bias & Unclear risk & No information provided \\
\hline
\end{tabular}




\begin{tabular}{ll}
\hline Methods & RCT \\
Method of randomisation: not stated \\
Blinding: not stated \\
Adverse effects: not stated \\
ITT analysis: not stated \\
Losses to FU: not stated \\
Country: China \\
Number of participants included: $109(61 / 48)$ \\
Demographics: aged 35-75 years, $60 \%$ male \\
Type of stroke: both ischaemic and haemorrhagic strokes \\
Diagnosis: WHO definition and all confirmed by CT before entry \\
Severity on entry: not stated \\
Time from stroke onset: 2 months to 5 years \\
Setting: unclear \\
Comparability: unclear
\end{tabular}

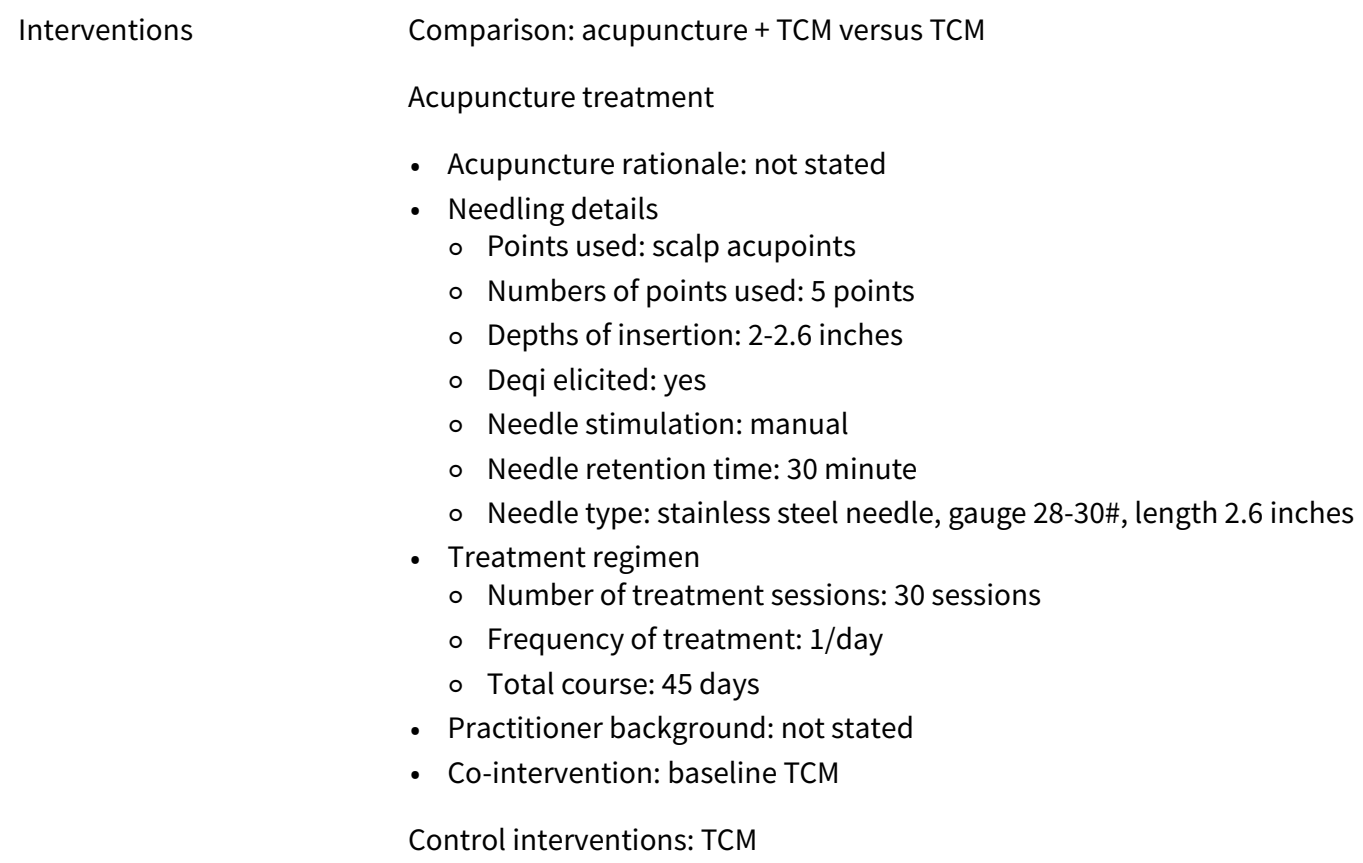

\section{Notes}

\section{Risk of bias}

\begin{tabular}{lll}
\hline Bias & Authors' judgement & Support for judgement \\
\hline $\begin{array}{l}\text { Random sequence genera- } \\
\text { tion (selection bias) }\end{array}$ & Unclear risk & The method of random sequence generation was not reported \\
\hline $\begin{array}{l}\text { Allocation concealment } \\
\text { (selection bias) }\end{array}$ & Unclear risk & Information on allocation concealment was not reported \\
\hline
\end{tabular}


Lun 1999 (Continued)
Blinding (performance
Unclear risk
Information on blinding was not reported

bias and detection bias)

All outcomes

Blinding of participants Unclear risk Information on blinding was not reported
and personnel (perfor-
mance bias)
All outcomes

\begin{tabular}{lll}
\hline $\begin{array}{l}\text { Blinding of outcome as- } \\
\text { sessment (detection bias) } \\
\text { All outcomes }\end{array}$ & Unclear risk & Information on blinding was not reported \\
\hline $\begin{array}{l}\text { Incomplete outcome data } \\
\text { (attrition bias) } \\
\text { All outcomes }\end{array}$ & Unclear risk & Information on attrition was not reported \\
\hline $\begin{array}{l}\text { Selective reporting (re- } \\
\text { porting bias) }\end{array}$ & Unclear risk & $\begin{array}{l}\text { Free of selective reporting bias was assessed as 'unclear' due to some clinical- } \\
\text { ly important outcomes unstated, such as quality of life, mortality and adverse } \\
\text { events }\end{array}$ \\
\hline Other bias & Unclear risk & No information provided \\
\hline
\end{tabular}

\section{Naeser 1992}

\begin{tabular}{ll}
\hline Methods & RCT \\
Method of randomisation: not stated \\
Blinding: participants blinded \\
Adverse effects: not stated \\
ITT analysis: not stated \\
Losses to FU: not stated
\end{tabular}

\section{Participants}

\section{Country: USA}

Number of participants included: 16 (10/6)

Demographics: aged 44-74 years

Type of stroke: ischaemic only

Diagnosis: all confirmed by CT

Severity on entry: moderate

Time from stroke onset: 1-3 months

Setting: inpatients

Comparability: no significant difference in age or time post onset

Interventions

Comparison: real acupuncture + daily PT versus sham acupuncture + daily PT

Acupuncture treatment

- Acupuncture rationale: not stated

- Needling details

- Points used: both body and scalp acupoints

- Numbers of points used: 11 body acupoints; numbers of scalp acupoints unclear

- Depths of insertion: unclear

- Deqi elicited: unclear

- Needle stimulation: electrical stimulation with frequency 1-2 $\mathrm{Hz}$ and amplitude unknown

- Needle retention time: 20 minutes

- Needle type: gauge 34\#, length and material unknown 
Naeser 1992 (Continued)

- Treatment regimen

- Number of treatment sessions: 20 sessions

- Frequency of treatment: 5 sessions/week

- Total course: 4 weeks

- Practitioner background: not stated

- Co-intervention: PT

Control interventions

- Sham

- Acupuncture + PT

Outcomes Number of participants with improvement in motor function (BMIT) within 5 days after completing treatment

FU: 35 days

Notes

\section{Risk of bias}

\begin{tabular}{|c|c|c|}
\hline Bias & Authors' judgement & Support for judgement \\
\hline $\begin{array}{l}\text { Random sequence genera- } \\
\text { tion (selection bias) }\end{array}$ & Unclear risk & The method of random sequence generation was not reported \\
\hline $\begin{array}{l}\text { Allocation concealment } \\
\text { (selection bias) }\end{array}$ & Unclear risk & Information on allocation concealment was not reported \\
\hline $\begin{array}{l}\text { Blinding (performance } \\
\text { bias and detection bias) } \\
\text { All outcomes }\end{array}$ & Unclear risk & Information on blinding was not reported \\
\hline $\begin{array}{l}\text { Blinding of participants } \\
\text { and personnel (perfor- } \\
\text { mance bias) } \\
\text { All outcomes }\end{array}$ & Low risk & $\begin{array}{l}\text { Quote: "The sham acupuncture was done only on the non-paralyzed upper ex- } \\
\text { tremity and lower extremity. The patients were told that in China acupuncture } \\
\text { is used on the non-paralysed side to treat the paralysed side. They were fur- } \\
\text { ther told that the stimulation was low level, and they would not feel anything" }\end{array}$ \\
\hline $\begin{array}{l}\text { Blinding of outcome as- } \\
\text { sessment (detection bias) } \\
\text { All outcomes }\end{array}$ & Unclear risk & Information on blinding was not reported \\
\hline $\begin{array}{l}\text { Incomplete outcome data } \\
\text { (attrition bias) } \\
\text { All outcomes }\end{array}$ & Unclear risk & Information on attrition was not reported \\
\hline $\begin{array}{l}\text { Selective reporting (re- } \\
\text { porting bias) }\end{array}$ & Unclear risk & $\begin{array}{l}\text { Free of selective reporting bias was assessed as 'unclear' due to some clinical- } \\
\text { ly important outcomes unstated, such as quality of life, mortality and adverse } \\
\text { events }\end{array}$ \\
\hline Other bias & Unclear risk & No information provided \\
\hline
\end{tabular}

Sun 2013a

$\begin{array}{ll}\text { Methods } & \text { RCT } \\ & \text { Method of randomisation: random number table } \\ & \text { Blinding: not stated }\end{array}$


Sun 2013a (Continued)

Adverse effects: 1

ITT analysis: not stated

Losses to FU: 7

\begin{tabular}{ll}
\hline Participants & Country: China \\
& Number of participants included: $71(36 / 35)$ \\
& Demographics: aged 51-72 years, 56\% male \\
& Type of stroke: both ischaemic and haemorrhagic strokes \\
& Diagnosis: WHO definition \\
Severity on entry: not stated & \\
Time from stroke onset: $3-9$ months \\
Setting: inpatient \\
Comparability: no significant difference in age or time post onset
\end{tabular}

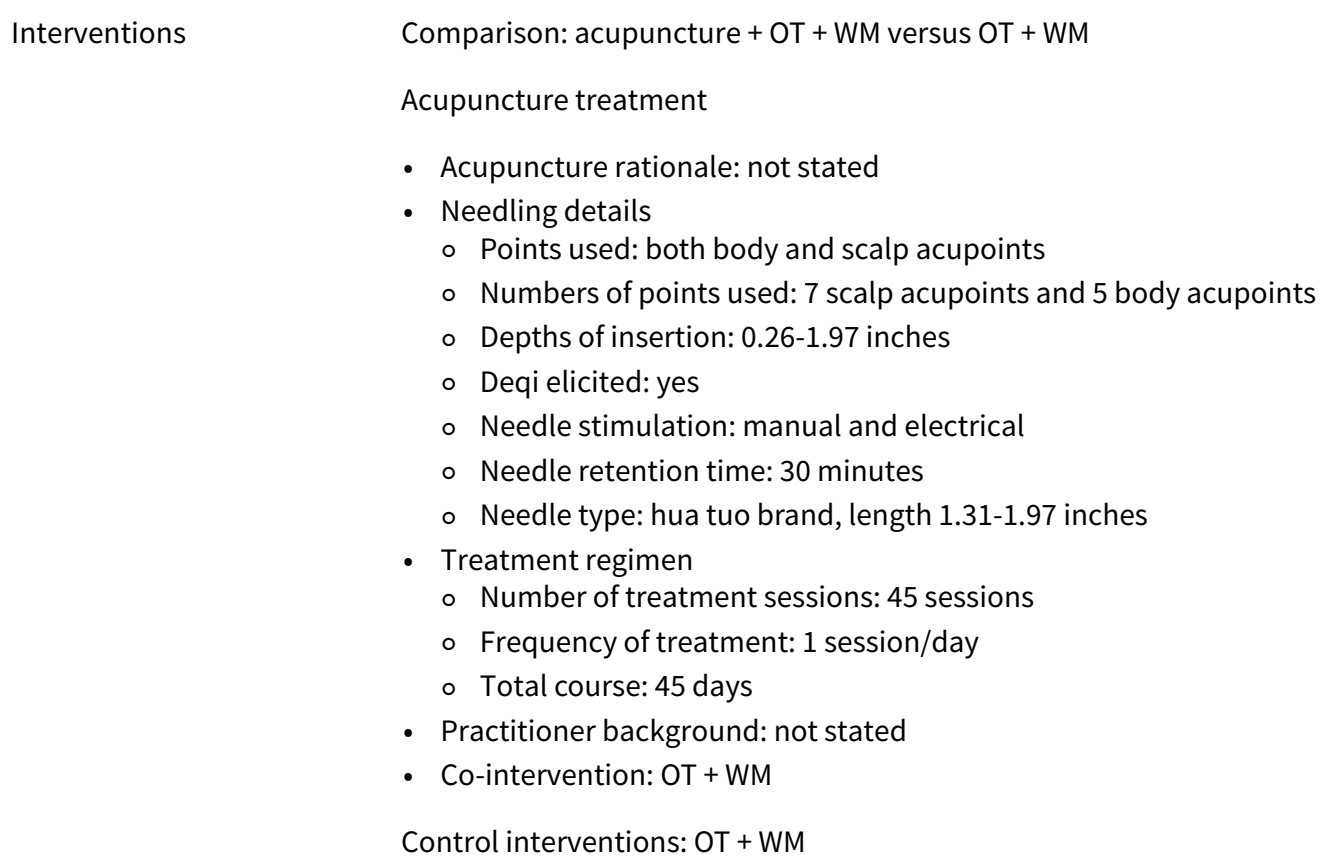

- Acupuncture rationale: not stated

- Needling details

- Points used: both body and scalp acupoints

- Numbers of points used: 7 scalp acupoints and 5 body acupoints

- Depths of insertion: $0.26-1.97$ inches

- Deqi elicited: yes

- Needle stimulation: manual and electrical

- Needle retention time: 30 minutes

- Needle type: hua tuo brand, length 1.31-1.97 inches

- Treatment regimen

- Number of treatment sessions: 45 sessions

- Frequency of treatment: 1 session/day

- Total course: 45 days

- Practitioner background: not stated

- Co-intervention: OT + WM

Control interventions: OT + WM

\begin{tabular}{ll}
\hline Outcomes & - Improvement of symptoms of turbid phlegm obstructing orifices \\
- Improvement of cognitive function (MMSE) \\
- Improvement of independence (ADL) \\
- Improvement of neurological function (NDFS) \\
- Adverse event: itchiness of the skin at the acupoint in one participant in the acupuncture group \\
- FU: 45 days
\end{tabular}

\section{Notes}

\section{Risk of bias}

\begin{tabular}{lll}
\hline Bias & Authors' judgement & Support for judgement \\
\hline $\begin{array}{l}\text { Random sequence genera- } \\
\text { tion (selection bias) }\end{array}$ & Low risk & Randomisation by using random number table \\
\hline $\begin{array}{l}\text { Allocation concealment } \\
\text { (selection bias) }\end{array}$ & Unclear risk & Information on allocation concealment was not reported \\
\hline
\end{tabular}


Sun 2013a (Continued)

Blinding (performance Unclear risk Information on blinding was not reported bias and detection bias)

All outcomes

Blinding of participants Unclear risk Information on blinding was not reported
and personnel (perfor-
mance bias)
All outcomes

\begin{tabular}{lll}
\hline $\begin{array}{l}\text { Blinding of outcome as- } \\
\text { sessment (detection bias) } \\
\text { All outcomes }\end{array}$ & Unclear risk & Information on blinding was not reported \\
\hline $\begin{array}{l}\text { Incomplete outcome data } \\
\text { (attrition bias) }\end{array}$ & Low risk & $\begin{array}{l}4 \text { participants could not finish the treatment protocol, } 3 \text { participants lost to } \\
\text { follow-up }\end{array}$ \\
\hline
\end{tabular}

\begin{tabular}{lll}
\hline $\begin{array}{l}\text { Selective reporting (re- } \\
\text { porting bias) }\end{array}$ & Unclear risk & $\begin{array}{l}\text { Some patient-related outcomes were not reported, such as information on } \\
\text { quality of life or all-cause mortality }\end{array}$ \\
\hline Other bias & Unclear risk & No information provided \\
\hline
\end{tabular}

Sun 2015

$\begin{array}{ll}\text { Rethods } & \text { RCT } \\ \text { Method of randomisation: randomisation by using envelopes } \\ \text { Blinding: not stated }\end{array}$

Blinding: not stated

Adverse effects: none

ITT analysis: not stated

Losses to FU: not stated

\section{Participants}

\section{Country: China}

Number of participants included: 93 (31/31/31)

Demographics: aged $60-95$ years, $47 \%$ male

Type of stroke: unclear

Diagnosis: WHO definition

Severity on entry: not stated

Time from stroke onset: 9-46 months

Setting: inpatient and outpatient

Comparability: no significant difference in age, comorbidity, or time post onset

$\begin{array}{ll} & 3 \text { arms: } \\ \text { Interventions } & \text { acupuncture only } \\ & \text { - WM only } \\ \text { C acupuncture + WM } & \\ \text { Comparison eligible: acupuncture + WM versus WM only } \\ \text { - Acupuncture treatment }\end{array}$


Sun 2015 (Continued)

- Needling details

- Points used: both body and scalp acupoints

- Numbers of points used: 6 body acupoints, 3 scalp acupoints

- Depths of insertion: not stated

- Deqi elicited: yes

- Needle stimulation: manual

- Needle retention time: 30 minutes

- Needle type: hua tuo brand, length 1.57 inches

- Treatment regimen

- Number of treatment sessions: 120 sessions

- Frequency of treatment: 5 sessions/week

- Total course: 24 weeks

- Practitioner background: not stated

- Co-intervention: WM

Control interventions: WM

\begin{tabular}{ll}
\hline Outcomes & - Improvement of depression (HAMD) \\
- Adverse event
\end{tabular}

- Adverse event

Notes -

\section{Risk of bias}

\begin{tabular}{lll}
\hline Bias & Authors' judgement & Support for judgement \\
\hline $\begin{array}{l}\text { Random sequence genera- } \\
\text { tion (selection bias) }\end{array}$ & Low risk & Randomisation by using envelopes assorted in a random manner \\
\hline $\begin{array}{l}\text { Allocation concealment } \\
\text { (selection bias) }\end{array}$ & Unclear risk & Information on allocation concealment was not reported \\
\hline $\begin{array}{l}\text { Blinding (performance } \\
\text { bias and detection bias) } \\
\text { All outcomes }\end{array}$ & Unclear risk & Information on blinding was not reported \\
\hline
\end{tabular}

Blinding of participants Unclear risk Information on blinding was not reported
and personnel (perfor-
and personnel (perfor-

mance bias)

All outcomes

\begin{tabular}{lll}
\hline $\begin{array}{l}\text { Blinding of outcome as- } \\
\text { sessment (detection bias) } \\
\text { All outcomes }\end{array}$ & Unclear risk & Information on blinding was not reported \\
\hline $\begin{array}{l}\text { Incomplete outcome data } \\
\text { (attrition bias) } \\
\text { All outcomes }\end{array}$ & Unclear risk & Information on attrition was not reported \\
\hline $\begin{array}{l}\text { Selective reporting (re- } \\
\text { porting bias) }\end{array}$ & Unclear risk & $\begin{array}{l}\text { Some patient-related outcomes were not reported, such as information on } \\
\text { quality of life or all-cause mortality }\end{array}$ \\
\hline Other bias & Unclear risk & No information provided \\
\hline
\end{tabular}


Wang 2001

\begin{tabular}{ll}
\hline Methods & RCT \\
& Method of randomisation: not stated \\
& Blinding: not stated \\
& Adverse effects: not stated \\
ITT analysis: not stated \\
Losses to FU: not stated
\end{tabular}

$\begin{array}{ll}\text { Participants } & \text { Country: China } \\ & \text { Number of participants included: } 90 \text { (34/30/26) } \\ & \text { Demographics: aged } 39-75 \text { years, } 56 \% \text { male } \\ & \text { Type of stroke: both ischaemic and haemorrhagic strokes } \\ & \text { Diagnosis: WHO definition and all confirmed by CT } \\ & \text { Severity on entry: not stated } \\ & \text { Time from stroke onset: } 2 \text { months to } 5 \text { years } \\ & \text { Setting: unclear } \\ & \text { Comparability: unclear }\end{array}$

\begin{tabular}{|c|c|}
\hline Interventions & 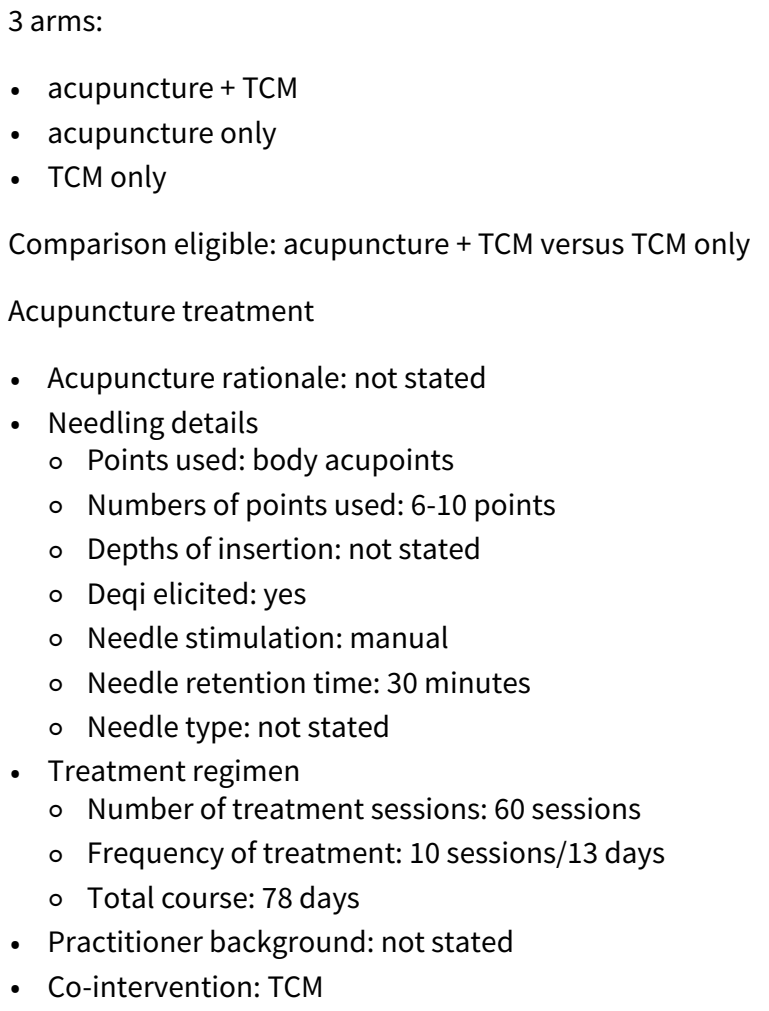 \\
\hline
\end{tabular}

Outcomes - Number of participants with improvement in global neurological deficit (CSRS 2) at the end of treatment

- FU: 78 days

\section{Notes}

\section{Risk of bias}


Wang 2001 (Continued)

Random sequence genera- Unclear risk The method of random sequence generation was not reported tion (selection bias)

Allocation concealment Unclear risk Information on allocation concealment was not reported
(selection bias)

\begin{tabular}{|c|c|c|}
\hline $\begin{array}{l}\text { Blinding (performance } \\
\text { bias and detection bias) } \\
\text { All outcomes }\end{array}$ & Unclear risk & Information on blinding was not reported \\
\hline $\begin{array}{l}\text { Blinding of participants } \\
\text { and personnel (perfor- } \\
\text { mance bias) } \\
\text { All outcomes }\end{array}$ & Unclear risk & Information on blinding was not reported \\
\hline $\begin{array}{l}\text { Blinding of outcome as- } \\
\text { sessment (detection bias) } \\
\text { All outcomes }\end{array}$ & Unclear risk & Information on blinding was not reported \\
\hline $\begin{array}{l}\text { Incomplete outcome data } \\
\text { (attrition bias) } \\
\text { All outcomes }\end{array}$ & Unclear risk & Information on attrition was not reported \\
\hline $\begin{array}{l}\text { Selective reporting (re- } \\
\text { porting bias) }\end{array}$ & Unclear risk & $\begin{array}{l}\text { Free of selective reporting bias was assessed as 'unclear' due to some clinical- } \\
\text { ly important outcomes unstated, such as quality of life, mortality and adverse } \\
\text { events }\end{array}$ \\
\hline Other bias & Unclear risk & No information provided \\
\hline
\end{tabular}

Wang 2011a

\begin{tabular}{ll}
\hline Methods & RCT \\
& Method of randomisation: random number table \\
& Blinding: not stated \\
& Adverse effects: not stated \\
ITT analysis: not stated \\
Losses to FU: not stated \\
Country: China \\
Number of participants included: 85 (43/42) \\
Demographics: aged 40-80 years, $65 \%$ male \\
Type of stroke: both ischaemic and haemorrhagic strokes \\
Diagnosis: CT/MRI \\
Severity on entry: not stated \\
Time from stroke onset: $33-192$ days \\
Setting: inpatient and outpatient \\
Comparability: no significant difference in age, comorbidity, or time post onset
\end{tabular}

Interventions

Comparison: acupuncture + PT + OT versus PT + OT

Acupuncture treatment

- Acupuncture rationale: not stated 
Wang 2011a (Continued)

- Needling details

- Points used: body acupoints

- Numbers of points used: 10 acupoints

- Depths of insertion: 0.08-0.2 inches

- Deqi elicited: not stated

- Needle stimulation: manual

- Needle retention time: not stated

- Needle type: not stated

- Treatment regimen

- Number of treatment sessions: 10 sessions

- Frequency of treatment: 3-4 sessions/week

- Total course: 3 weeks

- Practitioner background: not stated

- Co-intervention: PT + OT

Control interventions: PT + OT

\begin{tabular}{ll}
\hline Outcomes & - Improvement of motor function (Fugl-Meyer Assessment) \\
- Improvement of pain (Visual Analogue Scale) \\
- FU: 3 weeks
\end{tabular}

Notes

Risk of bias

\begin{tabular}{|c|c|c|}
\hline Bias & Authors' judgement & Support for judgement \\
\hline $\begin{array}{l}\text { Random sequence genera- } \\
\text { tion (selection bias) }\end{array}$ & Low risk & Randomisation by using random number table \\
\hline $\begin{array}{l}\text { Allocation concealment } \\
\text { (selection bias) }\end{array}$ & Unclear risk & Information on allocation concealment was not reported \\
\hline $\begin{array}{l}\text { Blinding (performance } \\
\text { bias and detection bias) } \\
\text { All outcomes }\end{array}$ & Unclear risk & Information on blinding was not reported \\
\hline $\begin{array}{l}\text { Blinding of participants } \\
\text { and personnel (perfor- } \\
\text { mance bias) } \\
\text { All outcomes }\end{array}$ & Unclear risk & Information on blinding was not reported \\
\hline $\begin{array}{l}\text { Blinding of outcome as- } \\
\text { sessment (detection bias) } \\
\text { All outcomes }\end{array}$ & Unclear risk & Information on blinding was not reported \\
\hline $\begin{array}{l}\text { Incomplete outcome data } \\
\text { (attrition bias) } \\
\text { All outcomes }\end{array}$ & Unclear risk & Information on attrition was not reported \\
\hline $\begin{array}{l}\text { Selective reporting (re- } \\
\text { porting bias) }\end{array}$ & Unclear risk & $\begin{array}{l}\text { Free of selective reporting bias was assessed as 'unclear' due to some clinical- } \\
\text { ly important outcomes unstated, such as quality of life, mortality and adverse } \\
\text { events }\end{array}$ \\
\hline Other bias & Unclear risk & No information provided \\
\hline
\end{tabular}


Wang 2012

$\begin{array}{ll}\text { Methods } & \text { RCT } \\ \text { Method of randomisation: random number table } & \text { Blinding: not stated } \\ & \text { Adverse effects: not stated } \\ \text { ITT analysis: not stated } \\ \text { Losses to FU: not stated }\end{array}$

Participants

Country: China

Number of participants included: 60 (30/30)

Demographics: aged $43-77$ years, $65 \%$ male

Type of stroke: both ischaemic and haemorrhagic strokes

Diagnosis: WHO definition and all confirmed by CT/MRI

Severity on entry: not stated

Time from stroke onset: 1-6 months

Setting: inpatient

Comparability: no significant difference in age or time post onset

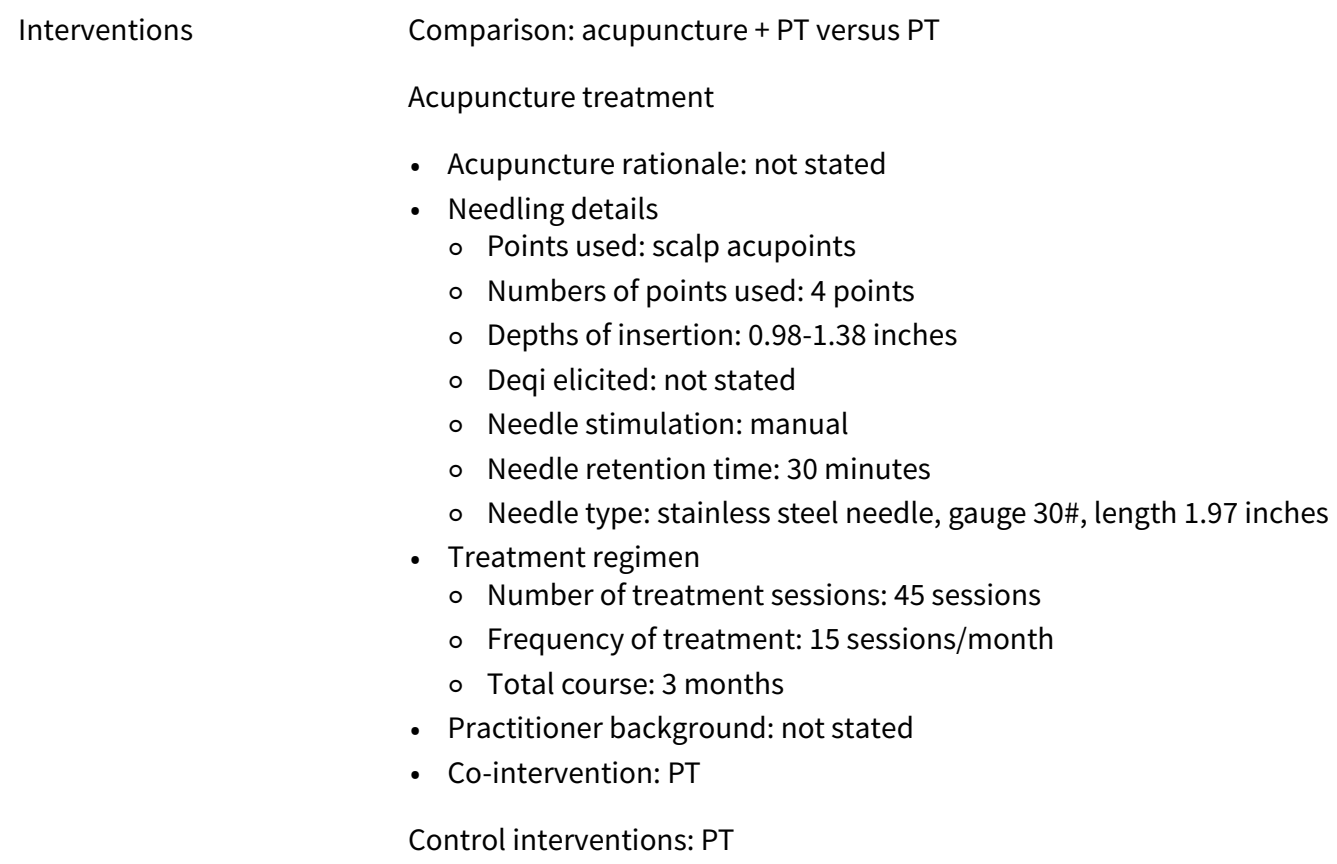

\section{Risk of bias}

\begin{tabular}{lll}
\hline Bias & Authors' judgement & Support for judgement \\
\hline $\begin{array}{l}\text { Random sequence genera- } \\
\text { tion (selection bias) }\end{array}$ & Low risk & Randomisation by using random number table \\
\hline $\begin{array}{l}\text { Allocation concealment } \\
\text { (selection bias) }\end{array}$ & Unclear risk & Information on allocation concealment was not reported \\
\hline \hline
\end{tabular}


Wang 2012 (Continued)

Blinding (performance Unclear risk Information on blinding was not reported bias and detection bias)

All outcomes

Blinding of participants Unclear risk Information on blinding was not reported
and personnel (perfor-
mance bias)
All outcomes

\begin{tabular}{lll}
\hline $\begin{array}{l}\text { Blinding of outcome as- } \\
\text { sessment (detection bias) } \\
\text { All outcomes }\end{array}$ & Unclear risk & Information on blinding was not reported \\
\hline $\begin{array}{l}\text { Incomplete outcome data } \\
\text { (attrition bias) } \\
\text { All outcomes }\end{array}$ & Unclear risk & Information on attrition was not reported \\
\hline $\begin{array}{l}\text { Selective reporting (re- } \\
\text { porting bias) }\end{array}$ & Unclear risk & $\begin{array}{l}\text { Free of selective reporting bias was assessed as 'unclear' due to some clinical- } \\
\text { ly important outcomes unstated, such as quality of life, mortality and adverse } \\
\text { events }\end{array}$ \\
\hline Other bias & Unclear risk & No information provided \\
\hline
\end{tabular}

\section{Wu 2008}

$\begin{array}{ll}\text { Methods } & \text { RCT } \\ & \text { Method of randomisation: not stated } \\ & \text { Blinding: not stated } \\ & \text { Adverse effects: not stated } \\ \text { ITT analysis: not stated } \\ \text { Losses to FU: not stated }\end{array}$

$\begin{array}{ll}\text { Participants } & \text { Country: China } \\ \text { Number of participants included: } 160(40 / 40 / 40 / 40) \\ \text { Demographics: aged 40-69 years, } 63 \% \text { male } \\ \text { Type of stroke: both ischaemic and haemorrhagic strokes } \\ \text { Diagnosis: CT/MRI } \\ \text { Severity on entry: not stated } \\ \text { Time from stroke onset: } 1-6 \text { months } \\ \text { Setting: inpatient and outpatient } \\ \text { Comparability: no significant difference in age, comorbidity, or time post onset }\end{array}$

\begin{tabular}{ll}
\hline Interventions & 4 arms: \\
& - PT + OT \\
& - acupuncture + PT + OT \\
& - acupuncture + WM + PT + OT \\
& Comparisons eligible: \\
& - acupuncture + PT + OT versus PT + OT \\
& - acupuncture + WM + PT + OT versus WM + PT + OT \\
& Acupuncture treatment
\end{tabular}


Wu 2008 (Continued)

- Acupuncture rationale: not stated

- Needling details

- Points used: both body and scalp acupoints

- Numbers of points used: 2 scalp acupoints and 2 body acupoints

- Depths of insertion: not stated

- Deqi elicited: not stated

- Needle stimulation: manual

- Needle retention time: not stated

- Needle type: not stated

- Treatment regimen

- Number of treatment sessions: 56 sessions

- Frequency of treatment: 7 sessions/week

- Total course: 8 weeks

- Practitioner background: not stated

- Co-intervention: PT + OT/WM + PT + OT

Control interventions: $\mathrm{PT}+\mathrm{OT} / \mathrm{WM}+\mathrm{PT}+\mathrm{OT}$

\begin{tabular}{ll}
\hline Outcomes & Improvement of depression (HAMD) \\
\hline
\end{tabular}

Notes -

\section{Risk of bias}

\begin{tabular}{lll}
\hline Bias & Authors' judgement & Support for judgement \\
\hline $\begin{array}{l}\text { Random sequence genera- } \\
\text { tion (selection bias) }\end{array}$ & Unclear risk & The method of random sequence generation was not reported \\
\hline $\begin{array}{l}\text { Allocation concealment } \\
\text { (selection bias) }\end{array}$ & Unclear risk & Information on allocation concealment was not reported \\
\hline $\begin{array}{l}\text { Blinding (performance } \\
\text { bias and detection bias) } \\
\text { All outcomes }\end{array}$ & Unclear risk & Information on blinding was not reported \\
\hline
\end{tabular}

Blinding of participants Unclear risk Information on blinding was not reported
and personnel (perfor-

mance bias)

All outcomes

\begin{tabular}{lll}
\hline $\begin{array}{l}\text { Blinding of outcome as- } \\
\text { sessment (detection bias) } \\
\text { All outcomes }\end{array}$ & Unclear risk & Information on blinding was not reported \\
\hline $\begin{array}{l}\text { Incomplete outcome data } \\
\text { (attrition bias) } \\
\text { All outcomes }\end{array}$ & Unclear risk & Information on attrition was not reported \\
\hline $\begin{array}{l}\text { Selective reporting (re- } \\
\text { porting bias) }\end{array}$ & Unclear risk & $\begin{array}{l}\text { Free of selective reporting bias was assessed as 'unclear' due to some clinical- } \\
\text { ly important outcomes unstated, such as quality of life, mortality and adverse } \\
\text { events }\end{array}$ \\
\hline \begin{tabular}{l} 
Other bias \\
\hline
\end{tabular} & Unclear risk & No information provided \\
\hline
\end{tabular}


Wu 2011a

\begin{tabular}{|c|c|}
\hline Methods & $\begin{array}{l}\text { RCT } \\
\text { Method of randomisation: randomisation by using random number table } \\
\text { Blinding: not stated } \\
\text { Adverse effects: not stated } \\
\text { ITT analysis: not stated } \\
\text { Losses to FU: not stated }\end{array}$ \\
\hline Participants & $\begin{array}{l}\text { Country: China } \\
\text { Number of participants included: } 60 \text { (30/30) } \\
\text { Demographics: aged } 41-76 \text { years, } 55 \% \text { male } \\
\text { Type of stroke: ischaemic only } \\
\text { Diagnosis: confirmed by CT/MRI } \\
\text { Severity on entry: not stated } \\
\text { Time from stroke onset: } 1 \text { month to } 8 \text { years } \\
\text { Setting: inpatient } \\
\text { Comparability: no significant difference in age or time post onset }\end{array}$ \\
\hline Interventions & $\begin{array}{l}\text { Comparison: acupuncture + daily PT versus daily PT } \\
\text { Acupuncture treatment } \\
\text { - Acupuncture rationale: not stated } \\
\text { - Needling details } \\
\text { ○ Points used: both body and scalp acupoints } \\
\text { ○ Numbers of points used: } 5 \text { scalp acupoints and } 16 \text { body acupoints } \\
\text { ○ Depths of insertion: not stated } \\
\text { ○ Deqi elicited: yes } \\
\text { ○ Needle stimulation: electrical } \\
\text { ○ Needle retention time: } 30 \text { minutes } \\
\text { ○ Needle type: hua tuo brand, length } 1.57 \text { inches } \\
\text { - Treatment regimen } \\
\text { ○ Number of treatment sessions: } 84 \text { sessions } \\
\text { - Frequency of treatment: } 7 \text { sessions/week } \\
\text { - Total course: } 12 \text { weeks } \\
\text { - Practitioner background: not stated } \\
\text { Co-intervention: PT } \\
\text { Control interventions: PT }\end{array}$ \\
\hline Outcomes & $\begin{array}{l}\text { - Improvement of spasticity (Ashworth) } \\
\text { - Improvement of motor function (Fugl-Meyer Assessment) } \\
\text { - Improvement of independence (Barthel Index) } \\
\text { - FU: } 12 \text { weeks }\end{array}$ \\
\hline
\end{tabular}

\section{Notes}

\section{Risk of bias}

\begin{tabular}{lll}
\hline Bias & Authors' judgement & Support for judgement \\
\hline $\begin{array}{l}\text { Random sequence genera- } \\
\text { tion (selection bias) }\end{array}$ & Low risk & Randomisation by using random number table \\
\hline $\begin{array}{l}\text { Allocation concealment } \\
\text { (selection bias) }\end{array}$ & Unclear risk & Information on allocation concealment was not reported \\
\hline \hline
\end{tabular}


Wu 2011a (Continued)

Blinding (performance Unclear risk Information on blinding was not reported bias and detection bias)

All outcomes

Blinding of participants Unclear risk Information on blinding was not reported
and personnel (perfor-
mance bias)
All outcomes

\begin{tabular}{lll}
\hline $\begin{array}{l}\text { Blinding of outcome as- } \\
\text { sessment (detection bias) } \\
\text { All outcomes }\end{array}$ & Unclear risk & Information on blinding was not reported \\
\hline $\begin{array}{l}\text { Incomplete outcome data } \\
\text { (attrition bias) } \\
\text { All outcomes }\end{array}$ & Unclear risk & Information on attrition was not reported \\
\hline $\begin{array}{l}\text { Selective reporting (re- } \\
\text { porting bias) }\end{array}$ & Unclear risk & $\begin{array}{l}\text { Free of selective reporting bias was assessed as 'unclear' due to some clinical- } \\
\text { ly important outcomes unstated, such as quality of life, mortality and adverse } \\
\text { events }\end{array}$ \\
\hline Other bias & Unclear risk & No information provided \\
\hline
\end{tabular}

Wu 2013a

$\begin{array}{ll}\text { Methods } & \text { RCT } \\ \text { Method of randomisation: random number table } \\ \text { Blinding: not stated } \\ \text { Adverse effects: not stated } \\ \text { ITT analysis: not stated } \\ \text { Losses to FU: not stated }\end{array}$

\begin{tabular}{ll}
\hline Participants & Country: China \\
& Number of participants included: $90(30 / 30 / 30)$ \\
& Demographics: $45-80$ years, $57 \%$ male \\
Type of stroke: both ischaemic and haemorrhagic strokes \\
Diagnosis: WHO definition and all confirmed by CT/MRI \\
Severity on entry: not stated \\
Time from stroke onset: $1-3$ months \\
Setting: inpatient \\
Comparability: no significant difference in age or time post onset
\end{tabular}

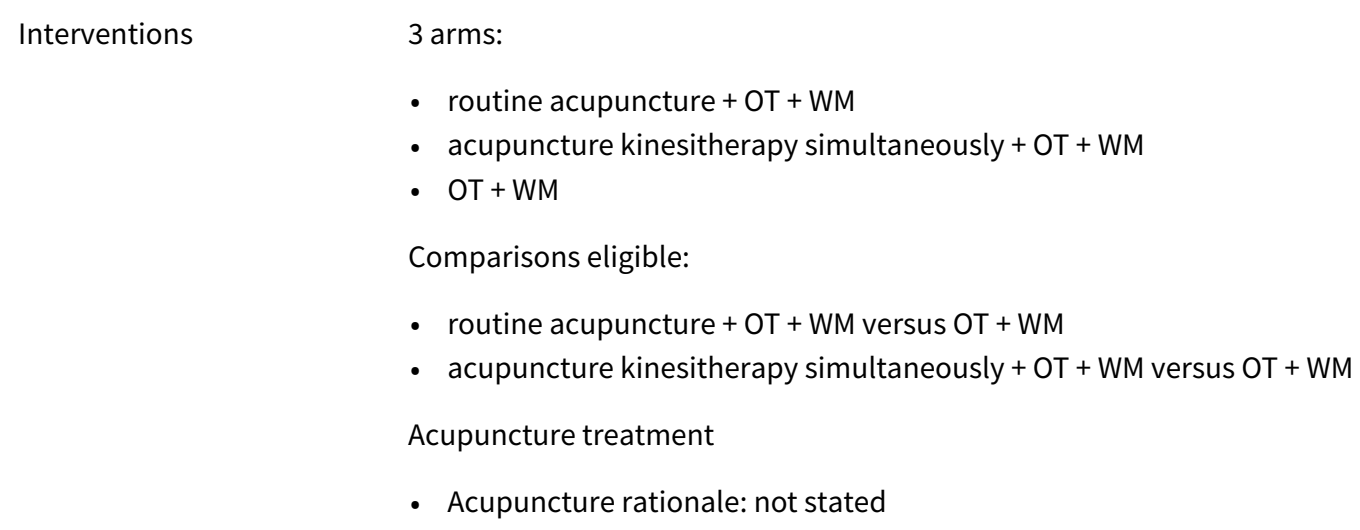


Wu 2013a (Continued)

- Needling details

- Points used: scalp acupoints

- Numbers of points used: 7 points

- Depths of insertion: 0.66-1.57 inches

- Deqi elicited: not stated

- Needle stimulation: manual

- Needle retention time: 30 minutes

○ Needle type: length 1.57 inches

- Treatment regimen

- Number of treatment sessions: 30 sessions

- Frequency of treatment: 5 sessions/week

- Total course: 6 weeks

- Practitioner background: not stated

- Co-intervention: OT + WM

Control interventions: OT + WM

\begin{tabular}{ll}
\hline Outcomes & - Improvement of swallowing function (Water drinking test) \\
& FU: 6 weeks
\end{tabular}

- FU: 6 weeks

Notes -

\section{Risk of bias}

\begin{tabular}{|c|c|c|}
\hline Bias & Authors' judgement & Support for judgement \\
\hline $\begin{array}{l}\text { Random sequence genera- } \\
\text { tion (selection bias) }\end{array}$ & Low risk & Randomisation by using random number table \\
\hline $\begin{array}{l}\text { Allocation concealment } \\
\text { (selection bias) }\end{array}$ & Unclear risk & Information on allocation concealment was not reported \\
\hline $\begin{array}{l}\text { Blinding (performance } \\
\text { bias and detection bias) } \\
\text { All outcomes }\end{array}$ & Unclear risk & Information on blinding was not reported \\
\hline $\begin{array}{l}\text { Blinding of participants } \\
\text { and personnel (perfor- } \\
\text { mance bias) } \\
\text { All outcomes }\end{array}$ & Unclear risk & Information on blinding was not reported \\
\hline $\begin{array}{l}\text { Blinding of outcome as- } \\
\text { sessment (detection bias) } \\
\text { All outcomes }\end{array}$ & Unclear risk & Information on blinding was not reported \\
\hline $\begin{array}{l}\text { Incomplete outcome data } \\
\text { (attrition bias) } \\
\text { All outcomes }\end{array}$ & Unclear risk & Information on attrition was not reported \\
\hline $\begin{array}{l}\text { Selective reporting (re- } \\
\text { porting bias) }\end{array}$ & Unclear risk & $\begin{array}{l}\text { Free of selective reporting bias was assessed as 'unclear' due to some clinical- } \\
\text { ly important outcomes unstated, such as quality of life, mortality and adverse } \\
\text { events }\end{array}$ \\
\hline Other bias & Unclear risk & No information provided \\
\hline
\end{tabular}




\begin{tabular}{ll}
\hline Methods & RCT \\
& Method of randomisation: not stated \\
& Blinding: not stated \\
& Adverse effects: not stated \\
ITT analysis: not stated & Losses to FU: not stated \\
\hline Participants & Country: China \\
& Number of participants included: $140(70 / 70)$ \\
& Demographics: $45-75$ years, $47 \%$ male \\
& Type of stroke: unclear \\
& Diagnosis: WHO definition and all confirmed by CT/MRI \\
& Severity on entry: not stated \\
& Time from stroke onset: 1 -12 months \\
& Setting: inpatient \\
Comparability: no significant difference in age or time post onset
\end{tabular}

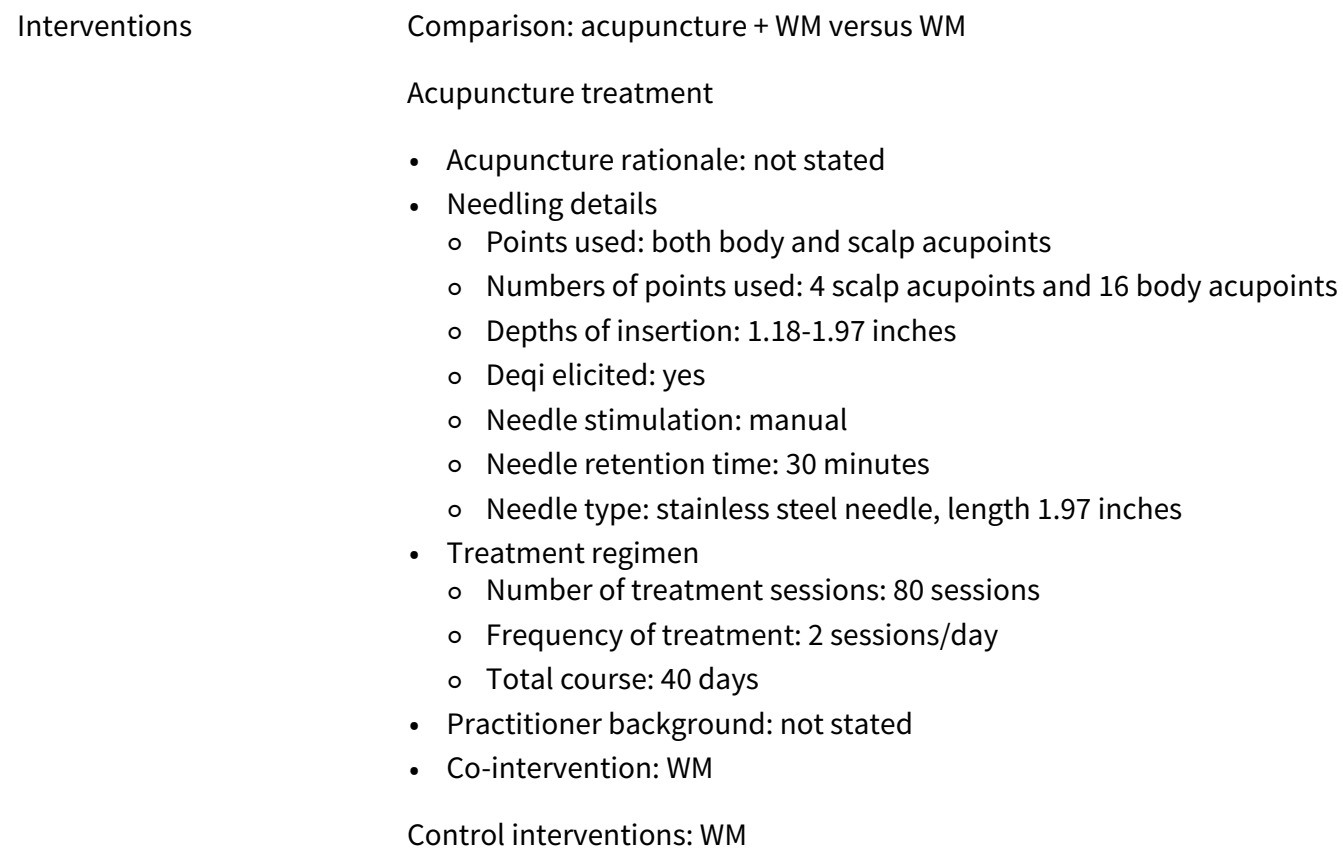

\begin{tabular}{ll}
\hline Outcomes & - Improvement of swallowing function (Water drinking test) \\
& - FU: 40 days
\end{tabular}

- FU: 40 days

\section{Notes}

\section{Risk of bias}

\section{Bias \\ Authors' judgement Support for judgement}

\begin{tabular}{lll}
$\begin{array}{l}\text { Random sequence genera- } \\
\text { tion (selection bias) }\end{array}$ & Unclear risk & The method of random sequence generation was not reported \\
\hline $\begin{array}{l}\text { Allocation concealment } \\
\text { (selection bias) }\end{array}$ & Unclear risk & Information on allocation concealment was not reported \\
\hline
\end{tabular}


Xu 2013 (Continued)
Blinding (performance
Unclear risk
Information on blinding was not reported
bias and detection bias)

All outcomes

Blinding of participants Unclear risk Information on blinding was not reported
and personnel (perfor-
mance bias)
All outcomes

\begin{tabular}{lll}
\hline $\begin{array}{l}\text { Blinding of outcome as- } \\
\text { sessment (detection bias) } \\
\text { All outcomes }\end{array}$ & Unclear risk & Information on blinding was not reported \\
\hline $\begin{array}{l}\text { Incomplete outcome data } \\
\text { (attrition bias) } \\
\text { All outcomes }\end{array}$ & Unclear risk & Information on attrition was not reported \\
\hline $\begin{array}{l}\text { Selective reporting (re- } \\
\text { porting bias) }\end{array}$ & Unclear risk & $\begin{array}{l}\text { Free of selective reporting bias was assessed as 'unclear' due to some clinical- } \\
\text { ly important outcomes unstated, such as quality of life, mortality and adverse } \\
\text { events }\end{array}$ \\
\hline Other bias & Unclear risk & No information provided \\
\hline
\end{tabular}

\section{Yao 2014}

$\begin{array}{ll}\text { Methods } & \text { RCT } \\ \text { Method of randomisation: random number table } \\ \text { Blinding: not stated } \\ \text { Adverse effects: not stated } \\ \text { ITT analysis: not stated } \\ \text { Losses to FU: not stated }\end{array}$

\begin{tabular}{ll}
\hline Participants & Country: China \\
& Number of participants included: 90 (30/30/30) \\
& Demographics: $54 \%$ male \\
& Type of stroke: both ischaemic and haemorrhagic strokes \\
& Diagnosis: WHO definition and all confirmed by CT/MRI \\
& Severity on entry: not stated \\
& Time from stroke onset: $1-12$ months \\
Setting: inpatient & Comparability: no significant difference in age or time post onset
\end{tabular}

$\begin{array}{ll}\text { Interventions } & \text { Comparison eligible: } \\ \text { - } & \text { routine acupuncture + PT versus PT only } \\ \text { Acupuncture treatment } \\ \text { - Acupuncture rationale: not stated }\end{array}$


Yao 2014 (Continued)

- Needling details

- Points used: both body and scalp acupoints

- Numbers of points used: 15 points

- Depths of insertion: not stated

- Deqi elicited: yes

- Needle stimulation: manual and electrical

- Needle retention time: 30 minutes

- Needle type: stainless steel needle, length 1.57 inches

- Treatment regimen

- Number of treatment sessions: 24 sessions

- Frequency of treatment: 3 sessions/week

- Total course: 8 weeks

- Practitioner background: not stated

- Co-intervention: PT

Control interventions: PT

\begin{tabular}{ll}
\hline Outcomes & - Improvement of motor function (Fugl-Meyer Motor Assessment) \\
& - Improvement of neurological function (Neurological Deficit Score) \\
& - Improvement of independence (Barthel Index) \\
& - FU: 8 weeks \\
\hline Notes & - \\
\hline
\end{tabular}

\section{Risk of bias}

\begin{tabular}{|c|c|c|}
\hline Bias & Authors' judgement & Support for judgement \\
\hline $\begin{array}{l}\text { Random sequence genera- } \\
\text { tion (selection bias) }\end{array}$ & Low risk & Randomisation by using random number table \\
\hline $\begin{array}{l}\text { Allocation concealment } \\
\text { (selection bias) }\end{array}$ & Unclear risk & Information on allocation concealment was not reported \\
\hline $\begin{array}{l}\text { Blinding (performance } \\
\text { bias and detection bias) } \\
\text { All outcomes }\end{array}$ & Unclear risk & Information on blinding was not reported \\
\hline $\begin{array}{l}\text { Blinding of participants } \\
\text { and personnel (perfor- } \\
\text { mance bias) } \\
\text { All outcomes }\end{array}$ & Unclear risk & Information on blinding was not reported \\
\hline $\begin{array}{l}\text { Blinding of outcome as- } \\
\text { sessment (detection bias) } \\
\text { All outcomes }\end{array}$ & Unclear risk & Information on blinding was not reported \\
\hline $\begin{array}{l}\text { Incomplete outcome data } \\
\text { (attrition bias) } \\
\text { All outcomes }\end{array}$ & Unclear risk & Information on attrition was not reported \\
\hline $\begin{array}{l}\text { Selective reporting (re- } \\
\text { porting bias) }\end{array}$ & Unclear risk & $\begin{array}{l}\text { Free of selective reporting bias was assessed as 'unclear' due to some clinical- } \\
\text { ly important outcomes unstated, such as quality of life, mortality and adverse } \\
\text { events }\end{array}$ \\
\hline
\end{tabular}


Yao 2014 (Continued)
Other bias
Unclear risk
No information provided

Zhan 2014

$\begin{array}{ll}\text { Methods } & \text { RCT } \\ \text { Method of randomisation: random number table } \\ \text { Blinding: not stated } \\ \text { Adverse effects: not stated } \\ \text { ITT analysis: not stated } \\ \text { Losses to FU: none } \\ \text { Country: China } \\ \text { Number of participants included: } 130(65 / 65) \\ \text { Demographics: aged 45-75 years, } 59 \% \text { male } \\ \text { Type of stroke: unclear } \\ \text { Diagnosis: WHO definition } \\ \text { Severity on entry: not stated } \\ \text { Time from stroke onset: } 2 \text {-11 months } \\ \text { Setting: inpatient and outpatient } \\ \text { Comparability: no significant difference in age or time post onset }\end{array}$

Comparison: acupuncture + PT versus PT
Acupuncture treatment
- Acupuncture rationale: not stated
- Needling details
$\circ$ Points used: body acupoints
$\circ$ Numbers of points used: 8 points
$\circ$ Depths of insertion: not stated
$\circ$ Deqi elicited: not stated
$\circ$ Needle stimulation: manual
$\circ$ Needle retention time: $15-20$ minutes
$\circ$ Needle type: not stated
Treatment regimen
$\circ$ Number of treatment sessions: 6 sessions
$\circ$ Frequency of treatment: 6 sessions/week
$\circ$ Total course: 1 week
- Practitioner background: not stated
Co-intervention: PT

Control interventions: PT

Outcomes $\quad$ - Improvement of independence (Barthel Index)

- FU: 1 week

\section{Notes}

\section{Risk of bias}

\begin{tabular}{lll}
\hline Bias & Authors' judgement & Support for judgement \\
\hline $\begin{array}{l}\text { Random sequence genera- } \\
\text { tion (selection bias) }\end{array}$ & Low risk & Randomisation by using random number table \\
\hline \hline
\end{tabular}


Zhan 2014 (Continued)

\begin{tabular}{l}
$\begin{array}{l}\text { Allocation concealment } \\
\text { (selection bias) }\end{array}$ \\
\hline
\end{tabular}

Blinding (performance $\quad$ Unclear risk Information on blinding was not reported
bias and detection bias)
All outcomes

Blinding of participants Unclear risk Information on blinding was not reported
and personnel (perfor-
mance bias)
All outcomes

\begin{tabular}{|c|c|c|}
\hline $\begin{array}{l}\text { Blinding of outcome as- } \\
\text { sessment (detection bias) } \\
\text { All outcomes }\end{array}$ & Unclear risk & Information on blinding was not reported \\
\hline $\begin{array}{l}\text { Incomplete outcome data } \\
\text { (attrition bias) } \\
\text { All outcomes }\end{array}$ & Low risk & No participants withdrew or were lost to follow-up \\
\hline $\begin{array}{l}\text { Selective reporting (re- } \\
\text { porting bias) }\end{array}$ & Unclear risk & $\begin{array}{l}\text { Free of selective reporting bias was assessed as 'unclear' due to some clinical- } \\
\text { ly important outcomes unstated, such as quality of life, mortality and adverse } \\
\text { events }\end{array}$ \\
\hline Other bias & Unclear risk & No information provided \\
\hline
\end{tabular}

\section{Zhang 2013a}

$\begin{array}{ll}\text { Methods } & \text { RCT } \\ \text { Method of randomisation: closed envelopes } \\ \text { Blinding: Investigators, participants, not blinded } \\ \text { Adverse effects: not stated } \\ \text { ITT analysis: none } \\ \text { Losses to FU: not stated }\end{array}$

\begin{tabular}{ll}
\hline Participants & Country: China \\
& Number of participants included: $90(30 / 30 / 30)$ \\
& Demographics: $43-75$ years, $54 \%$ male \\
& Type of stroke: both ischaemic and haemorrhagic strokes \\
& Diagnosis: WHO definition and all confirmed by CT/MRI \\
& Severity on entry: not stated \\
& Time from stroke onset: 6 -19 months \\
Setting: inpatient & Comparability: no significant difference in age or time post onset
\end{tabular}

\begin{tabular}{ll}
\hline Interventions & - acupuncture only \\
- WM only \\
- acupuncture + WM \\
Comparison eligible: acupuncture + WM versus WM \\
Acupuncture treatment \\
- Acupuncture rationale: not stated
\end{tabular}


Zhang 2013a (Continued)

- Needling details

- Points used: scalp acupoints

- Numbers of points used: 4 acupoints

- Depths of insertion: 0.66-1.05 inches

- Deqi elicited: yes

- Needle stimulation: manual and electrical

- Needle retention time: 30 minutes

- Needle type: hua tuo brand, length 0.98 inches

- Treatment regimen

- Number of treatment sessions: 30 sessions

- Frequency of treatment: 5 sessions/week

- Total course: 6 weeks

- Practitioner background: not stated

- Co-intervention: WM

Control interventions: WM

\begin{tabular}{ll}
\hline Outcomes & - Improvement of depression (Hamilton Depression Scale) \\
& - Improvement of sleep (Rhone Planck Sleepiness Scale) \\
& - Adverse event \\
\hline Notes 6 weeks \\
\hline
\end{tabular}

\section{Risk of bias}

\begin{tabular}{|c|c|c|}
\hline Bias & Authors' judgement & Support for judgement \\
\hline $\begin{array}{l}\text { Random sequence genera- } \\
\text { tion (selection bias) }\end{array}$ & Low risk & Randomisation by using closed envelopes \\
\hline $\begin{array}{l}\text { Allocation concealment } \\
\text { (selection bias) }\end{array}$ & Low risk & Randomisation by using closed envelopes \\
\hline $\begin{array}{l}\text { Blinding (performance } \\
\text { bias and detection bias) } \\
\text { All outcomes }\end{array}$ & High risk & Quote: "unable to blind to participants and operators" \\
\hline $\begin{array}{l}\text { Blinding of participants } \\
\text { and personnel (perfor- } \\
\text { mance bias) } \\
\text { All outcomes }\end{array}$ & High risk & Quote: "unable to blind to participants and operators" \\
\hline $\begin{array}{l}\text { Blinding of outcome as- } \\
\text { sessment (detection bias) } \\
\text { All outcomes }\end{array}$ & Unclear risk & Details not given \\
\hline $\begin{array}{l}\text { Incomplete outcome data } \\
\text { (attrition bias) } \\
\text { All outcomes }\end{array}$ & Unclear risk & Information on attrition was not reported \\
\hline $\begin{array}{l}\text { Selective reporting (re- } \\
\text { porting bias) }\end{array}$ & Unclear risk & $\begin{array}{l}\text { Some patient-related outcomes were not reported, such as information on } \\
\text { quality of life or all-cause mortality }\end{array}$ \\
\hline Other bias & Unclear risk & No information provided \\
\hline
\end{tabular}




\begin{tabular}{ll}
\hline Methods & RCT \\
Method of randomisation: random number table & Blinding: not stated \\
& Adverse effects: not stated \\
ITT analysis: not stated \\
Losses to FU: not stated \\
\hline Country: China \\
Number of participants included: $90(30 / 30 / 30)$ \\
Demographics: $66 \%$ male \\
Type of stroke: ischaemic only \\
Diagnosis: CT/MRI \\
Severity on entry: not stated \\
Time from stroke onset: $2-6$ months \\
Setting: inpatient \\
Comparability: no significant difference in age or time post onset
\end{tabular}

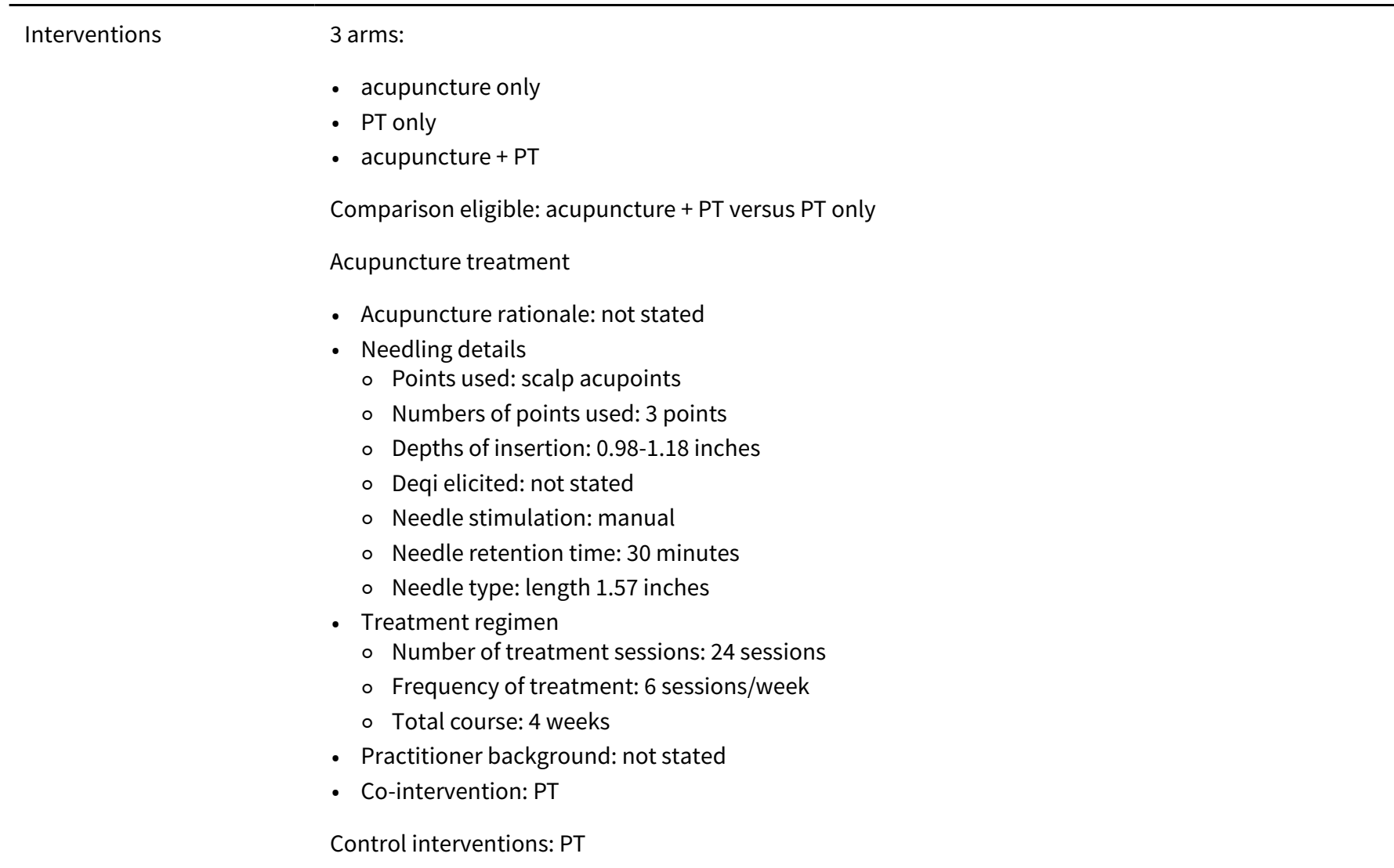

\footnotetext{
Outcomes

- Improvement of neurological function (Modified Edinburgh And Scandinavia Stroke Scale)

- Improvement of independence (Barthel Index)

- FU: 4 weeks
}

Notes

\section{Risk of bias}


Zhang 2015 (Continued)

Random sequence genera- Low risk Randomisation by using random number table tion (selection bias)

Allocation concealment
(selection bias)

(selection bias)

Blinding (performance Unclear risk Information on blinding was not reported
bias and detection bias)

All outcomes

Blinding of participants Unclear risk Information on blinding was not reported
and personnel (perfor-
mance bias)
All outcomes

\begin{tabular}{|c|c|c|}
\hline $\begin{array}{l}\text { Blinding of outcome as- } \\
\text { sessment (detection bias) } \\
\text { All outcomes }\end{array}$ & Unclear risk & Information on blinding was not reported \\
\hline $\begin{array}{l}\text { Incomplete outcome data } \\
\text { (attrition bias) } \\
\text { All outcomes }\end{array}$ & Unclear risk & Information on attrition was not reported \\
\hline $\begin{array}{l}\text { Selective reporting (re- } \\
\text { porting bias) }\end{array}$ & Unclear risk & $\begin{array}{l}\text { Free of selective reporting bias was assessed as 'unclear' due to some clinical- } \\
\text { ly important outcomes unstated, such as quality of life, mortality and adverse } \\
\text { events }\end{array}$ \\
\hline Other bias & Unclear risk & No information provided \\
\hline
\end{tabular}

Zheng 2014

$\begin{array}{ll}\text { Methods } & \text { RCT } \\ \text { Method of randomisation: randomisation by using random number table } \\ \text { Blinding: not stated } \\ \text { Adverse effects: not stated } \\ \text { ITT analysis: not stated } \\ \text { Losses to FU: none } \\ \text { Country: China } \\ \text { Number of participants included: } 60(30 / 30) \\ \text { Demographics: aged 51-79 years, } 60 \% \text { male } \\ \text { Type of stroke: both ischaemic and haemorrhagic strokes } \\ \text { Diagnosis: WHO definition } \\ \text { Severity on entry: not stated } \\ \text { Time from stroke onset: } 1-6 \text { months } \\ \text { Setting: inpatient } \\ \text { Comparability: no significant difference in age or time post onset }\end{array}$

Interventions

Comparison: acupuncture + WM versus WM

Acupuncture treatment

- Acupuncture rationale: not stated 
Zheng 2014 (Continued)

- Needling details

- Points used: both body and scalp acupoints

- Numbers of points used: 2 scalp acupoints and 5 body acupoints

- Depths of insertion: 0.39-1.97 inches

- Deqi elicited: yes

- Needle stimulation: manual

- Needle retention time: 30 minutes

- Needle type: hua tuo brand, length 1.57 inches

- Treatment regimen

- Number of treatment sessions: 48 sessions

- Frequency of treatment: 6 sessions/week

- Total course: 8 weeks

- Practitioner background: not stated

- Co-intervention: WM

Control interventions: WM

\begin{tabular}{ll}
\hline Outcomes & - Improvement of cognitive function (MMSE, MoCA) \\
- Improvement of independence (Barthel Index) \\
- FU: 8 weeks
\end{tabular}

Notes

\section{Risk of bias}

\begin{tabular}{|c|c|c|}
\hline Bias & Authors' judgement & Support for judgement \\
\hline $\begin{array}{l}\text { Random sequence genera- } \\
\text { tion (selection bias) }\end{array}$ & Low risk & Randomisation by using random number table \\
\hline $\begin{array}{l}\text { Allocation concealment } \\
\text { (selection bias) }\end{array}$ & Unclear risk & Information on allocation concealment was not reported \\
\hline $\begin{array}{l}\text { Blinding (performance } \\
\text { bias and detection bias) } \\
\text { All outcomes }\end{array}$ & Unclear risk & Information on blinding was not reported \\
\hline $\begin{array}{l}\text { Blinding of participants } \\
\text { and personnel (perfor- } \\
\text { mance bias) } \\
\text { All outcomes }\end{array}$ & Unclear risk & Information on blinding was not reported \\
\hline $\begin{array}{l}\text { Blinding of outcome as- } \\
\text { sessment (detection bias) } \\
\text { All outcomes }\end{array}$ & Unclear risk & Information on blinding was not reported \\
\hline $\begin{array}{l}\text { Incomplete outcome data } \\
\text { (attrition bias) } \\
\text { All outcomes }\end{array}$ & Low risk & Quote: "No participants lost to follow-up" \\
\hline $\begin{array}{l}\text { Selective reporting (re- } \\
\text { porting bias) }\end{array}$ & Unclear risk & $\begin{array}{l}\text { Free of selective reporting bias was assessed as 'unclear' due to some clinical- } \\
\text { ly important outcomes unstated, such as quality of life, mortality and adverse } \\
\text { events }\end{array}$ \\
\hline Other bias & Unclear risk & No information provided \\
\hline
\end{tabular}




$\begin{array}{ll}\text { Methods } & \text { RCT } \\ & \text { Method of randomisation: closed envelopes } \\ & \text { Blinding: Investigators but not participants blinded } \\ & \text { Adverse effects: } 20 \\ & \text { ITT analysis: not stated } \\ \text { Losses to FU: none }\end{array}$

\begin{tabular}{|c|c|}
\hline Participants & $\begin{array}{l}\text { Country: China } \\
\text { Number of participants included: } 147 \text { (75/72) } \\
\text { Demographics: aged } 35-80 \text { years, } 54 \% \text { male } \\
\text { Type of stroke: ischaemic only } \\
\text { Diagnosis: WHO definition and all confirmed by CT/MRI } \\
\text { Severity on entry: not stated } \\
\text { Time from stroke onset: } 1-3 \text { months } \\
\text { Setting: inpatient } \\
\text { Comparability: no significant difference in age or time post onset }\end{array}$ \\
\hline \multirow[t]{2}{*}{ Interventions } & $\begin{array}{l}\text { Comparison: acupuncture + daily PT versus daily PT } \\
\text { Acupuncture treatment } \\
\text { - Acupuncture rationale: not stated } \\
\text { - Needling details } \\
\circ \text { Points used: both body and scalp acupoints } \\
\text { ○ Numbers of points used: } 8 \text { scalp acupoints and } 9 \text { body acupoints } \\
\circ \text { Depths of insertion: } 1.18-1.38 \text { inches } \\
\circ \text { Deqi elicited: not stated } \\
\circ \text { Needle stimulation: manual and electrical } \\
\circ \text { Needle retention time: } 6-8 \text { hours/30 minutes } \\
\circ \text { Needle type: hua tuo brand, length } 1.57 \text { inches } \\
\text { - Treatment regimen } \\
\circ \text { Number of treatment sessions: } 40 \text { sessions } \\
\circ \text { Frequency of treatment: } 5 \text { sessions/week } \\
\text { - Total course: } 8 \text { weeks } \\
\text { - Practitioner background: not stated } \\
\text { Co-intervention: PT }\end{array}$ \\
\hline & Control interventions: PT \\
\hline
\end{tabular}

\begin{tabular}{ll}
\hline Outcomes & - Improvement of depression (HAMD) \\
- Improvement of neurological function (NIHSS) \\
- Improvement of independence (Barthel Index) \\
- Adverse event: bleeding, haematoma, and pain
\end{tabular}

Notes

\section{Risk of bias}

\section{Bias}

Authors' judgement Support for judgement

Random sequence genera- Low risk Randomisation by using closed envelopes tion (selection bias) 
Zhou 2014 (Continued)

\begin{tabular}{lll}
$\begin{array}{l}\text { Allocation concealment } \\
\text { (selection bias) }\end{array}$ & Low risk & Randomisation by using closed envelopes \\
\hline $\begin{array}{l}\text { Blinding (performance } \\
\text { bias and detection bias) } \\
\text { All outcomes }\end{array}$ & Low risk & Investigators blinded \\
\hline
\end{tabular}

\begin{tabular}{l}
\hline Blinding of participants $\quad$ Unclear risk Details not given \\
and personnel (perfor- \\
mance bias)
\end{tabular}

Blinding of outcome as- Low risk Outcome assessors blinded

sessment (detection bias)

All outcomes

\begin{tabular}{lll}
\hline $\begin{array}{l}\text { Incomplete outcome data } \\
\text { (attrition bias) } \\
\text { All outcomes }\end{array}$ & Low risk & Treatment: no participants lost to follow-up \\
\hline $\begin{array}{l}\text { Selective reporting (re- } \\
\text { porting bias) }\end{array}$ & Unclear risk & $\begin{array}{l}\text { Some patient-related outcomes were not reported, such as information on } \\
\text { quality of life or all-cause mortality }\end{array}$ \\
\hline Other bias & Unclear risk & No information provided \\
\hline
\end{tabular}

Zhu 2007

\begin{tabular}{|c|c|}
\hline Methods & $\begin{array}{l}\text { RCT } \\
\text { Method of randomisation: not stated } \\
\text { Blinding: not stated } \\
\text { ITT analysis: not stated } \\
\text { Losses to FU: not stated }\end{array}$ \\
\hline Participants & $\begin{array}{l}\text { Country: China } \\
\text { Number of participants included: } 60(30 / 30) \\
\text { Demographics: aged } 45-69 \text { years, } 53 \% \text { male } \\
\text { Type of stroke: both ischaemic and haemorrhagic strokes } \\
\text { Diagnosis: WHO definition } \\
\text { Severity on entry: not stated } \\
\text { Time from stroke onset: } 1-6 \text { months } \\
\text { Setting: inpatient } \\
\text { Comparability: no significant difference in age, comorbidity, or time post onset }\end{array}$ \\
\hline Interventions & $\begin{array}{l}\text { Comparison: acupuncture + PT versus PT } \\
\text { Acupuncture treatment } \\
\text { - Acupuncture rationale: not stated } \\
\text { - Needling details } \\
\text { ○ Points used: both body and scalp acupoints } \\
\text { ○ Numbers of points used: } 2 \text { scalp acupoints and } 4 \text { body acupoints } \\
\text { - Depths of insertion: } 1.57 \text { inches } \\
\circ \text { Deqi elicited: yes } \\
\circ \text { Needle stimulation: manual and electrical stimulation } \\
\circ \text { Needle retention time: } 30 \text { minutes } \\
\circ \text { Needle type: length } 1.57 \text { inches }\end{array}$ \\
\hline
\end{tabular}


Zhu 2007 (Continued)

- Treatment regimen

- Number of treatment sessions: 24 sessions

- Frequency of treatment: 6 sessions/week

- Total course: 4 weeks

- Practitioner background: not stated

- Co-intervention: PT

Control interventions: PT

\begin{tabular}{ll}
\hline Outcomes & $\begin{array}{l}\text { Improvement of neurological function (Modified Edinburgh Stroke Scale and Scandinavian Stroke } \\
\text { Scale) }\end{array}$ \\
\hline Notes & -
\end{tabular}

\section{Risk of bias}

\begin{tabular}{|c|c|c|}
\hline Bias & Authors' judgement & Support for judgement \\
\hline $\begin{array}{l}\text { Random sequence genera- } \\
\text { tion (selection bias) }\end{array}$ & Unclear risk & The method of random sequence generation was not reported \\
\hline $\begin{array}{l}\text { Allocation concealment } \\
\text { (selection bias) }\end{array}$ & Unclear risk & Information on allocation concealment was not reported \\
\hline $\begin{array}{l}\text { Blinding (performance } \\
\text { bias and detection bias) } \\
\text { All outcomes }\end{array}$ & Unclear risk & Information on blinding was not reported \\
\hline $\begin{array}{l}\text { Blinding of participants } \\
\text { and personnel (perfor- } \\
\text { mance bias) } \\
\text { All outcomes }\end{array}$ & Unclear risk & Information on blinding was not reported \\
\hline $\begin{array}{l}\text { Blinding of outcome as- } \\
\text { sessment (detection bias) } \\
\text { All outcomes }\end{array}$ & Unclear risk & Information on blinding was not reported \\
\hline $\begin{array}{l}\text { Incomplete outcome data } \\
\text { (attrition bias) } \\
\text { All outcomes }\end{array}$ & Unclear risk & Information on attrition was not reported \\
\hline $\begin{array}{l}\text { Selective reporting (re- } \\
\text { porting bias) }\end{array}$ & Unclear risk & $\begin{array}{l}\text { Free of selective reporting bias was assessed as 'unclear' due to some clinical- } \\
\text { ly important outcomes unstated, such as quality of life, mortality and adverse } \\
\text { events }\end{array}$ \\
\hline Other bias & Unclear risk & No information provided \\
\hline
\end{tabular}

BMIT: Boston Motor Inventory Test

CSRS 1: Chinese Stroke Recovery Scale based on the revised diagnostic criteria of acute cerebral infarction formulated by the second National Academic Symposium on Cerebrovascular Diseases of the Chinese Medical Association in 1986, which is similar to the Revised Scandinavian Stroke Scale (RSSS)

CSRS 2: Chinese Stroke Recovery Scale based on principles of traditional Chinese medicine

$\mathrm{CT}$ : computerised tomography

FU: follow-up

HAMD: Hamilton Depression Scale

ITT: intention-to-treat

LOTCA: Loewenstein Occupational Therapy Cognitive Assessment

MESS: modified Edinburgh Stroke Scale 
MMSE: Mini Mental State Examination

MoCA: Montreal Cognitive Assessment Scale

MRI: magnetic resonance imaging

OT: occupational therapy

PT: physical therapy

qd: once per day

$\mathrm{RCT}$ : randomised controlled trial

SF-36: 36-Item Short Form Health Survey

SS-QOL: Stroke Specific Quality of Life Scale

SSS: Scandinavian Stroke Scale

TCM: Traditional Chinese Medicine

WHO: World Health Organization

WM: Western medicine

Characteristics of excluded studies [ordered by study ID]

\begin{tabular}{|c|c|}
\hline Study & Reason for exclusion \\
\hline Bai 2007 & The trial included people with stroke less than 1 month since onset \\
\hline Bai 2011 & The trial included people with stroke less than 1 month since onset \\
\hline Bai 2013 & $\begin{array}{l}\text { The trial included people with stroke less than } 1 \text { month since onset although the median time to } \\
\text { post-stroke was more than } 1 \text { month }\end{array}$ \\
\hline Bao 2008 & The duration of stroke since onset was not stated in the trial \\
\hline Bao 2010 & The duration of stroke since onset was not clear \\
\hline Bao 2012a & The trial included people with stroke less than 1 month since onset \\
\hline Cai 2010 & The trial included people with stroke less than 1 month since onset \\
\hline Calabro 2011 & Abstract only; clarification of randomisation and intervention sought but not obtained \\
\hline Cao 2010a & The trial included people with stroke less than 1 month since onset \\
\hline Cao 2010b & Not RCT \\
\hline Chang 2010 & The trial included people with stroke less than 1 month since onset \\
\hline Chao 2009 & The trial included people with stroke less than one month since onset \\
\hline Chau 2009 & $\begin{array}{l}\text { It was not possible to include data from this trial in the analysis. The trial aimed to assess effects of } \\
2 \text { methods of acupuncture on subacute or chronic stroke. Acupoints were different between the } 2 \\
\text { groups }\end{array}$ \\
\hline Che 2002 & $\begin{array}{l}\text { The trial aimed to assess effects of } 2 \text { methods of acupuncture on subacute or chronic stroke. Acu- } \\
\text { points were different between the } 2 \text { groups }\end{array}$ \\
\hline Chen 2000 & $\begin{array}{l}\text { Confounded; the trial aimed to assess effects of acupuncture only compared with drug therapy } \\
\text { (such as WM or TCM) }\end{array}$ \\
\hline Chen 2007 & The trial included people with stroke less than 1 month since onset \\
\hline Chen 2008a & The duration of stroke since onset was not clear \\
\hline
\end{tabular}




\begin{tabular}{|c|c|}
\hline Study & Reason for exclusion \\
\hline Chen 2008b & $\begin{array}{l}\text { Stroke population not randomised to treatment: quasi-randomisation of particpants (based on ad- } \\
\text { ministrative procedure) to } 1 \text { of } 2 \text { groups }\end{array}$ \\
\hline Chen 2009 & The trial included people with stroke less than 1 month since onset \\
\hline Chen 2010a & The trial included people with stroke less than 1 month since onset \\
\hline Chen 2010b & The duration of stroke since onset was not clear \\
\hline Chen 2012a & The trial included people with stroke less than 1 month since onset \\
\hline Chen 2012b & The trial included people with stroke less than 1 month since onset \\
\hline Chen 2013 & The trial included people with acute stroke (less than 1 month since onset) \\
\hline Chen 2014 & The trial included people with stroke less than 1 month since onset \\
\hline Cheng 2006 & The duration of stroke since onset was not stated in the trial \\
\hline Cheng 2007 & The duration of stroke since onset was not stated in the trial \\
\hline Cheng 2011 & $\begin{array}{l}\text { It was not possible to include data from this trial in the analysis. Stroke population not randomised } \\
\text { to treatment: quasi-randomisation of particpants (based on administrative procedure) to } 1 \text { of } 2 \\
\text { groups }\end{array}$ \\
\hline
\end{tabular}

\begin{tabular}{|c|c|}
\hline Chow 2006 & Abstract only; clarification of randomisation and intervention sought but not obtained \\
\hline Chu 2007 & The trial included people with stroke less than 1 month since onset \\
\hline Chu 2009 & The trial included people with stroke less than 1 month since onset \\
\hline Cui 1992 & $\begin{array}{l}\text { It was not possible to include data from this trial in the analysis; this confounded trial aimed to as- } \\
\text { sess effects of acupuncture only compared with drug therapy (such as WM or TCM) }\end{array}$ \\
\hline Ding 2000 & $\begin{array}{l}\text { It was not possible to include data from this trial in the analysis. The trial aimed to assess effects of } \\
2 \text { methods of acupuncture on subacute or chronic stroke. Acupoints were different between the } 2 \\
\text { groups }\end{array}$ \\
\hline Dong 2007a & The trial included people with acute stroke (less than 1 month since onset) \\
\hline Dong 2007b & The duration of stroke since onset was not clear \\
\hline Dong 2008a & The trial included people with acute stroke (less than 1 month since onset) \\
\hline Dong 2008b & The trial included people with acute stroke (less than 1 month since onset) \\
\hline Dong 2009 & The trial included people with stroke less than 1 month since onset \\
\hline Du 2013 & The duration of stroke since onset was not stated in the trial \\
\hline Duan 2010 & The trial included people with stroke less than 1 month since onset \\
\hline Duan 2014 & The duration of stroke since onset was not clear \\
\hline Fang 2009 & The duration of stroke since onset was not stated in the trial \\
\hline
\end{tabular}




\begin{tabular}{|c|c|}
\hline Study & Reason for exclusion \\
\hline Feng 1996a & $\begin{array}{l}\text { It was not possible to include data from this trial in the analysis. The trial aimed to assess effects of } \\
2 \text { methods of acupuncture on subacute or chronic stroke. Acupoints were different between the } 2 \\
\text { groups }\end{array}$ \\
\hline Feng 1996b & $\begin{array}{l}\text { It was not possible to include data from this trial in the analysis. The trial aimed to assess effects of } \\
2 \text { methods of acupuncture on subacute or chronic stroke. Acupoints were different between the } 2 \\
\text { groups }\end{array}$ \\
\hline Feng 2011 & The trial included people with stroke less than 1 month since onset \\
\hline Fink 2004 & $\begin{array}{l}\text { It was not possible to include data from this trial in the analysis. MAS scores (as a clinical measure } \\
\text { of spasticity) were assessed before and after the treatment period but mean change of neurologi- } \\
\text { cal score after the treatment period was not available }\end{array}$ \\
\hline Fu 2010 & The trial included people with stroke less than 1 month since onset \\
\hline Fu 2013 & The trial included people with stroke less than 1 month since onset \\
\hline Fu 2014 & The trial included people with stroke less than 1 month since onset \\
\hline Gao 2001 & $\begin{array}{l}\text { It was not possible to include data from this trial in the analysis. This confounded trial aimed to as- } \\
\text { sess effects of acupuncture only compared with drug therapy (such as WM or TCM) }\end{array}$ \\
\hline Gao 2008 & The duration of stroke since onset was not stated in the trial \\
\hline Gao 2011 & The duration of stroke since onset was not clear \\
\hline Gao 2014b & The trial included people with stroke less than 1 month since onset \\
\hline Gong 2008 & The trial included people with stroke less than 1 month since onset \\
\hline Gu 2007 & The trial included people with acute stroke (less than 1 month since onset) \\
\hline Gu 2009 & The trial included people with stroke less than 1 month since onset \\
\hline Guan 2009a & $\begin{array}{l}\text { It was not possible to include data from this trial in the analysis. Stroke population not randomised } \\
\text { to treatment: quasi-randomisation of particpants (based on administrative procedure) to } 1 \text { of } 2 \\
\text { groups }\end{array}$ \\
\hline Guan 2009b & Quasi-randomised study \\
\hline Guan 2013 & The trial included people with stroke less than 1 month since onset \\
\hline Guo 1999 & The trial aimed to assess effects of acupuncture only compared with PT and OT \\
\hline Guo 2006a & The trial included people with stroke less than 1 month since onset \\
\hline Guo 2006b & The trial included people with stroke less than 1 month since onset \\
\hline Guo 2013 & The trial included people with stroke less than 1 month since onset \\
\hline Han 2008 & The trial included people with stroke less than 1 month since onset \\
\hline Han 2010 & The trial included people with stroke less than 1 month since onset \\
\hline
\end{tabular}




\begin{tabular}{|c|c|}
\hline Study & Reason for exclusion \\
\hline Han 2011 & The trial included people with stroke less than 1 month since onset \\
\hline Han 2012 & The duration of stroke since onset was not stated in the trial \\
\hline Han 2014 & Quasi-randomised study \\
\hline Hang 2014 & The trial included people with stroke less than 1 month since onset \\
\hline He 2008 & The trial included people with stroke less than 1 month since onset \\
\hline Hegyi 2012 & The trial included people with stroke less than 1 month since onset \\
\hline Hong 2013 & The duration of stroke since onset was not clear \\
\hline Hou 1998 & $\begin{array}{l}\text { The trial aimed to assess the effects of the combination of acupuncture, oxygen and herbs com- } \\
\text { pared with acupuncture or oxygen respectively }\end{array}$ \\
\hline Hsing 2012 & The trial aimed to assess effects of electrical acupuncture compared with routine acupuncture \\
\hline Hu 2011 & The duration of stroke since onset was not stated in the trial \\
\hline Hu 2012 & The trial included people with stroke less than 1 month since onset \\
\hline Huang 2002 & $\begin{array}{l}\text { It was not possible to include data from this trial in the analysis; this confounded trial aimed to as- } \\
\text { sess effects of acupuncture only compared with drug therapy (such as WM or TCM) }\end{array}$ \\
\hline Huang 2008b & The duration of stroke since onset was not clear \\
\hline Huang $2008 \mathrm{c}$ & The duration of stroke since onset was not clear \\
\hline Huang 2011 & The trial included people with stroke less than 1 month since onset \\
\hline Huang 2012 & The trial included people with stroke less than 1 month since onset \\
\hline Huang 2014 & The duration of stroke since onset was not clear \\
\hline Jia 2012 & The trial included people with stroke less than 1 month since onset \\
\hline Jiang 1998 & $\begin{array}{l}\text { It was not possible to include data from this trial in the analysis. The trial aimed to assess effects of } \\
2 \text { methods of acupuncture on subacute or chronic stroke. Acupoints were different between the } 2 \\
\text { groups }\end{array}$ \\
\hline Jiang 2000 & $\begin{array}{l}\text { It was not possible to include data from this trial in the analysis; this confounded trial aimed to as- } \\
\text { sess effects of acupuncture only compared with drug therapy (such as WM or TCM) }\end{array}$ \\
\hline Jiang 2006 & The trial included people with stroke less than 1 month since onset \\
\hline Jiang 2009 & The trial included people with stroke less than 1 month since onset \\
\hline Jiang 2010 & The duration of stroke since onset was not stated in the trial \\
\hline Jiang 2011a & The duration of stroke since onset was not clear \\
\hline Jiang 2011b & The trial included people with stroke less than 1 month since onset \\
\hline
\end{tabular}




\begin{tabular}{|c|c|}
\hline Study & Reason for exclusion \\
\hline Jiang 2012 & The trial included people with stroke less than 1 month since onset \\
\hline Jiang 2013 & The trial included people with stroke less than 1 month since onset \\
\hline Jin 1993 & $\begin{array}{l}\text { It was not possible to include data from this trial in the analysis. The trial aimed to assess effects of } \\
2 \text { methods of acupuncture on subacute or chronic stroke. Acupoints were different between the } 2 \\
\text { groups }\end{array}$ \\
\hline $\operatorname{Jin} 2010 a$ & Quasi-randomised study \\
\hline Jin $2010 b$ & The duration of stroke since onset was not stated in the trial \\
\hline Kang 2011 & The trial included people with stroke less than 1 month since onset \\
\hline Kang 2013 & The trial included people with stroke less than 1 month since onset \\
\hline Kjendahl 1997 & $\begin{array}{l}\text { The trial included people with stroke less than } 1 \text { month since onset although the median time to } \\
\text { post-stroke was more than } 1 \text { month }\end{array}$ \\
\hline Lai 1997a & $\begin{array}{l}\text { It was not possible to include data from this trial in the analysis; this confounded trial aimed to as- } \\
\text { sess effects of acupuncture only compared with drug therapy (such as WM or TCM) }\end{array}$ \\
\hline Lai 1997b & $\begin{array}{l}\text { The trial aimed to assess the effects of electrical acupuncture compared with manual acupuncture. } \\
\text { Acupoints were the same between the } 2 \text { groups }\end{array}$ \\
\hline Lai 1998 & $\begin{array}{l}\text { The trial aimed to assess the effects of electrical acupuncture compared with manual acupuncture. } \\
\text { Acupoints were the same between } 2 \text { groups }\end{array}$ \\
\hline Lai 2004 & $\begin{array}{l}\text { It was not possible to include data from this trial in the analysis. The trial aimed to assess effects of } \\
2 \text { methods of acupuncture on subacute or chronic stroke. Acupoints were different between the } 2 \\
\text { groups }\end{array}$ \\
\hline Lai 2011 & The duration of stroke since onset was not clear \\
\hline Lang 2013 & The trial included people with stroke less than 1 month since onset \\
\hline Lao 2013 & The trial included people with stroke less than 1 month since onset \\
\hline Lee 2007 & The full-text with English or Chinese language was not available \\
\hline Lee 2009 & The duration of stroke since onset was not stated in the trial \\
\hline Lei 2013 & The trial included people with stroke less than 1 month since onset \\
\hline Li 1993 & $\begin{array}{l}\text { It was not possible to include data from this trial in the analysis. The trial aimed to assess effects of } \\
2 \text { methods of acupuncture on subacute or chronic stroke. Acupoints were different between the } 2 \\
\text { groups }\end{array}$ \\
\hline Li 1994a & $\begin{array}{l}\text { It was not possible to include data from this trial in the analysis. The trial aimed to assess effects of } \\
2 \text { methods of acupuncture on subacute or chronic stroke. Acupoints were different between the } 2 \\
\text { groups }\end{array}$ \\
\hline Li 1994b & $\begin{array}{l}\text { It was not possible to include data from this trial in the analysis. The trial aimed to assess effects of } \\
2 \text { methods of acupuncture on subacute or chronic stroke. Acupoints were different between the } 2 \\
\text { groups }\end{array}$ \\
\hline
\end{tabular}




\begin{tabular}{ll}
\hline Study & Reason for exclusion \\
\hline Li 1997b & $\begin{array}{l}\text { No outcome measures of interest were available in the trial, which aimed to assess the effects of } \\
\text { acupuncture on the change of intellectual disturbance in people with vascular dementia caused by } \\
\text { cerebrovascular disease }\end{array}$ \\
\hline
\end{tabular}

\begin{tabular}{|c|c|}
\hline Li $2006 a$ & The trial included people with stroke less than 1 month since onset \\
\hline Li 2006b & The trial included people with stroke less than 1 month since onset \\
\hline Li $2006 c$ & The trial included people with stroke less than 1 month since onset \\
\hline Li $2006 d$ & The trial included people with stroke less than 1 month since onset \\
\hline Li 2006 e & The trial included people with stroke less than 1 month since onset \\
\hline Li 2008a & The trial included people with acute stroke (less than 1 month since onset) \\
\hline Li 2008b & The duration of stroke since onset was not clear \\
\hline Li $2008 c$ & The trial included people with stroke less than 1 month since onset \\
\hline Li 2008d & The trial included people with stroke less than 1 month since onset \\
\hline Li 2009a & The trial included people with stroke less than 1 month since onset \\
\hline Li 2009b & The trial included people with stroke less than 1 month since onset \\
\hline Li 2010b & The trial included people with stroke less than 1 month since onset \\
\hline Li 2010c & $\begin{array}{l}\text { The trial aimed to assess the effects of the combination of acupuncture and PT compared with PT. } \\
\text { The duration of stroke since onset was not stated in the trial }\end{array}$ \\
\hline Li 2011b & The trial included people with stroke less than 1 month since onset \\
\hline Li 2011c & The trial included people with stroke less than 1 month since onset \\
\hline Li $2011 d$ & The trial included people with acute stroke (less than 1 month since onset) \\
\hline Li 2012a & The duration of stroke since onset was not stated in the trial \\
\hline Li $2012 b$ & The duration of stroke since onset was not stated in the trial \\
\hline Li 2012c & The trial included people with stroke less than 1 month since onset \\
\hline Li 2012d & Quasi-randomised study \\
\hline Li $2012 e$ & The duration of stroke since onset was not clear \\
\hline Li $2012 f$ & $\begin{array}{l}\text { The trial included people with stroke less than } 1 \text { month since onset although the median time to } \\
\text { post-stroke was more than } 1 \text { month }\end{array}$ \\
\hline Li $2012 \mathrm{~g}$ & The duration of stroke since onset was not stated in the trial \\
\hline Li 2013b & $\begin{array}{l}\text { The trial included people with stroke less than } 1 \text { month since onset. Stroke population not ran- } \\
\text { domised to treatment: quasi-randomisation of particpants (based on administrative procedure) to } \\
1 \text { of } 2 \text { groups }\end{array}$ \\
\hline
\end{tabular}




\begin{tabular}{|c|c|}
\hline Study & Reason for exclusion \\
\hline Li 2013c & The trial included people with stroke less than 1 month since onset \\
\hline Li 2014 & The trial included people with stroke less than 1 month since onset \\
\hline Li 2015 & The trial included people with stroke less than 1 month since onset \\
\hline Liang 1993 & $\begin{array}{l}\text { It was not possible to include data from this trial in the analysis. The trial aimed to assess effects of } \\
2 \text { methods of acupuncture on subacute or chronic stroke. Acupoints were different between the } 2 \\
\text { groups }\end{array}$ \\
\hline Liang 2010 & Quasi-randomised study \\
\hline Liang 2012 & The trial included people with stroke less than 1 month since onset \\
\hline Liao 2006a & The duration of stroke since onset was not clear \\
\hline Liao 2006b & The duration of stroke since onset was not stated in the trial \\
\hline Liao 2013 & The trial included people with stroke less than 1 month since onset \\
\hline Liao 2014 & The duration of stroke since onset was not clear \\
\hline Lim 2014 & Review \\
\hline Lin 2010a & The trial included people with stroke less than 1 month since onset \\
\hline Lin 2010b & The duration of stroke since onset was not stated in the trial \\
\hline Lin 2012 & The duration of stroke since onset was not clear \\
\hline Lin 2013 & The trial included people with stroke less than 1 month since onset \\
\hline Liu 1998 & $\begin{array}{l}\text { It was not possible to include data from this trial in the analysis. ADL was assessed before and af- } \\
\text { ter the treatment period but the number of participants who were independent after the treatment } \\
\text { period was not available. The trial primarily aimed to assess the effects of acupuncture on the intel- } \\
\text { lectual disturbance in people with vascular dementia due to stroke }\end{array}$ \\
\hline Liu 2004a & The trial included people with stroke less than 1 month since onset (that is, acute stroke) \\
\hline Liu 2004b & Confounded (acupuncture plus 1 type of Chinese herbs versus another type of Chinese herbs \\
\hline Liu 2006 & The trial included people with acute stroke (less than 1 month since onset) \\
\hline Liu 2008a & The trial included people with stroke less than 1 month since onset \\
\hline Liu 2008b & Non-randomised controlled study \\
\hline Liu 2009 & The trial included people with stroke less than 1 month since onset \\
\hline Liu 2010a & The trial included people with stroke less than 1 month since onset \\
\hline Liu 2010b & The trial included people with stroke less than 1 month since onset \\
\hline Liu 2011a & The duration of stroke since onset was not stated in the trial \\
\hline
\end{tabular}




\begin{tabular}{|c|c|}
\hline Study & Reason for exclusion \\
\hline Liu 2011b & The trial included people with stroke less than 1 month since onset \\
\hline Liu 2012a & The trial included people with stroke less than 1 month since onset \\
\hline Liu $2012 b$ & The duration of stroke since onset was not clear \\
\hline Liu 2012c & The trial included people with stroke less than 1 month since onset \\
\hline Liu $2013 c$ & The trial included people with stroke less than 1 month since onset \\
\hline Liu 2013d & The duration of stroke since onset was not clear \\
\hline Liu $2013 e$ & The duration of stroke since onset was not stated in the trial \\
\hline Liu $2013 f$ & The duration of stroke since onset was not stated in the trial \\
\hline Liu 2014b & The trial included people with stroke less than 1 month since onset \\
\hline Liu 2015 & The duration of stroke since onset was not clear \\
\hline Long 2013 & The duration of stroke since onset was not stated in the trial \\
\hline Lu 2010 & The trial included people with stroke less than 1 month since onset \\
\hline Lu 2011a & The trial included people with stroke less than 1 month since onset \\
\hline Lu 2011b & The duration of stroke since onset was not stated in the trial \\
\hline Luo 2007 & The trial included people with stroke less than 1 month since onset \\
\hline Luo 2008 & The trial included people with stroke less than 1 month since onset \\
\hline Luo 2012 & The duration of stroke since onset was not stated in the trial \\
\hline Lv 2009 & The trial included people with stroke less than 1 month since onset \\
\hline Lv 2014 & The trial included people with stroke less than 1 month since onset \\
\hline Ma 2011a & The trial included people with acute stroke (less than 1 month since onset) \\
\hline Ma 2011b & The trial included people with stroke less than 1 month since onset \\
\hline Ma 2013 & The trial included people with stroke less than 1 month since onset \\
\hline Mou 2010 & The trial included people with stroke less than 1 month since onset \\
\hline Mu 2007 & The duration of stroke since onset was not stated in the trial \\
\hline Mukherjee 2006 & Abstract only; clarification of randomisation and intervention sought but not obtained \\
\hline Muo 2001 & $\begin{array}{l}\text { It was not possible to include data from this trial in the analysis. This confounded trial aimed to as- } \\
\text { sess effects of acupuncture only compared with drug therapy (such as WM or TCM) }\end{array}$ \\
\hline Ni 2011 & The trial included people with stroke less than 1 month since onset \\
\hline
\end{tabular}




\begin{tabular}{|c|c|}
\hline Study & Reason for exclusion \\
\hline Nie 2011 & The trial included people with stroke less than 1 month since onset \\
\hline Nie 2013 & The duration of stroke since onset was not stated in the trial \\
\hline Pan 2013 & The duration of stroke since onset was not stated in the trial \\
\hline Pang 2010 & Not RCT \\
\hline Peng 2007a & $\begin{array}{l}\text { The trial aimed to assess the effects of the combination of acupuncture, PT and WM compared with } \\
\text { WM. The duration of stroke since onset was not stated in the trial }\end{array}$ \\
\hline Peng 2009 & The trial included people with stroke less than 1 month since onset \\
\hline Peng 2015 & The duration of stroke since onset was not stated in the trial \\
\hline Qi 2000 & $\begin{array}{l}\text { It was not possible to include data from this trial in the analysis. The trial aimed to assess effects of } \\
2 \text { methods of acupuncture on subacute or chronic stroke. Acupoints were different between the } 2 \\
\text { groups }\end{array}$ \\
\hline Qi 2013 & The trial included people with stroke less than 1 month since onset \\
\hline Qi 2013a & The trial included people with stroke less than 1 month since onset \\
\hline Qiao 2012 & Abstract only; clarification of randomisation and intervention sought but not obtained \\
\hline Qiu 2011 & Quasi-randomised study \\
\hline Qu 1991 & $\begin{array}{l}\text { It was not possible to include data from this trial in the analysis. The trial aimed to assess effects of } \\
2 \text { methods of acupuncture on subacute or chronic stroke. Acupoints were different between the } 2 \\
\text { groups }\end{array}$ \\
\hline Ran 2013 & The trial included people with stroke less than 1 month since onset \\
\hline Ren 2009 & The duration of stroke since onset was not stated in the trial \\
\hline Ren 2010 & The trial included people with acute stroke (less than 1 month since onset) \\
\hline Ren 2012 & The trial included people with stroke less than 1 month since onset \\
\hline Sallstrom 1996 & $\begin{array}{l}\text { The median time to post-stroke was more than } 1 \text { month, but the trial included people with acute } \\
\text { stroke (that is, less than } 1 \text { month) }\end{array}$ \\
\hline Salom-Moreno 2014 & The duration of stroke since onset was not stated in the trial \\
\hline Schaechter 2007 & The duration of stroke since onset was not stated in the trial \\
\hline Seo 2013 & $\begin{array}{l}\text { The trial aimed to assess the effects of ouhyul herbal acupuncture point injection compared with } \\
\text { normal saline acupuncture point injection }\end{array}$ \\
\hline Shang 2008 & Quasi-randomised study \\
\hline Shao 2012 & The duration of stroke since onset was not clear \\
\hline Shen 2008 & The trial included people with stroke less than 1 month since onset \\
\hline
\end{tabular}




\begin{tabular}{|c|c|}
\hline Study & Reason for exclusion \\
\hline Shen 2009 & The trial included people with stroke less than 1 month since onset \\
\hline Sheng 2011 & The trial included people with stroke less than 1 month since onset \\
\hline Sheng 2013 & The duration of stroke since onset was not clear \\
\hline Shi 2007 & The trial aimed to assess the effects of combination of acupuncture, PT and WM compared with WM \\
\hline Shi 2007a & The trial included people with stroke less than 1 month since onset \\
\hline Song 2010 & Not stroke \\
\hline Sui 2001 & $\begin{array}{l}\text { It was not possible to include data from this trial in the analysis. The trial aimed to assess effects of } \\
2 \text { methods of acupuncture on subacute or chronic stroke. Acupoints were different between the } 2 \\
\text { groups }\end{array}$ \\
\hline Sun 2008 & Abstract only; clarification of randomisation and intervention sought but not obtained \\
\hline Sun 2010 & The duration of stroke since onset was not clear \\
\hline Sun 2011 & Not RCT \\
\hline Sun $2013 b$ & The duration of stroke since onset was not stated in the trial \\
\hline Sun 2014 & The trial included people with stroke less than 1 month since onset \\
\hline Suo 2008 & $\begin{array}{l}\text { The trial aimed to assess the effects of combination of sham acupuncture and PT compared with } \\
\text { acupuncture only }\end{array}$ \\
\hline Tang 2005 & The trial included people with stroke less than 1 month since onset \\
\hline Tang 2012 & The trial included people with stroke less than 1 month since onset \\
\hline Tang 2013 & The trial included people with stroke less than 1 month since onset \\
\hline Tang 2013a & $\begin{array}{l}\text { The trial aimed to assess the effects of combination of acupuncture and WM compared with combi- } \\
\text { nation of WM and PT }\end{array}$ \\
\hline Tian 2014 & The trial included people with stroke less than 1 month since onset \\
\hline Tong 1997 & $\begin{array}{l}\text { It was not possible to include data from this trial in the analysis. The trial aimed to assess effects of } \\
2 \text { methods of acupuncture on subacute or chronic stroke. Acupoints were different between the } 2 \\
\text { groups }\end{array}$ \\
\hline Tong 2013 & The trial included people with stroke less than 1 month since onset \\
\hline Tong 2014 & The trial included people with stroke less than 1 month since onset \\
\hline Wan 2013 & The duration of stroke since onset was not clear in the trial \\
\hline Wang 2004 & $\begin{array}{l}\text { Randomisation was not stated; the trial included people with acute stroke (less than } 1 \text { month since } \\
\text { onset) }\end{array}$ \\
\hline Wang 2006 & The trial included people with stroke less than 1 month since onset \\
\hline
\end{tabular}




\begin{tabular}{|c|c|}
\hline Study & Reason for exclusion \\
\hline Wang 2007 & The trial included people with stroke less than 1 month since onset \\
\hline Wang 2008 & The trial included people with stroke less than 1 month since onset \\
\hline Wang 2008a & The trial included people with stroke less than 1 month since onset \\
\hline Wang 2008b & The trial included people with acute stroke (less than 1 month since onset) \\
\hline Wang 2009 & Quasi-randomised study \\
\hline Wang 2010a & The duration of stroke since onset was not clear \\
\hline Wang 2010b & The duration of stroke since onset was not clear \\
\hline Wang 2011b & The trial included people with stroke less than 1 month since onset \\
\hline Wang 2011c & The trial included people with stroke less than 1 month since onset \\
\hline Wang 2011d & The duration of stroke since onset was not clear \\
\hline Wang 2011e & The trial included people with stroke less than 1 month since onset \\
\hline Wang $2011 \mathrm{f}$ & The duration of stroke since onset was not clear \\
\hline Wang 2011g & The trial included people with stroke less than 1 month since onset \\
\hline Wang 2011h & The trial included people with stroke less than 1 month since onset \\
\hline Wang 2011i & The trial included people with stroke less than 1 month since onset \\
\hline Wang $2011 \mathrm{j}$ & The trial included people with stroke less than 1 month since onset \\
\hline
\end{tabular}

\begin{tabular}{ll}
\hline Wang 2014a & $\begin{array}{l}\text { The trial aimed to assess the effects of acupuncture compared with transcutaneous electrical acu- } \\
\text { point stimulation }\end{array}$ \\
\hline Wang 2014b & The duration of stroke since onset was not stated in the trial \\
\hline Wei 2005 & $\begin{array}{l}\text { The trial included people with ischaemic stroke less than } 1 \text { month since onset (that is, acute } \\
\text { stroke). Data for participants with haemorraghic stroke more than } 150 \text { days were not separated } \\
\text { from data for participants with ischaemic stroke }\end{array}$ \\
\hline Wei 2009 & The trial included people with stroke less than 1 month since onset \\
\hline Wenli 2007 & The trial included people with stroke less than 1 month since onset \\
\hline Wong 2013 & Abstract only; clarification of randomisation and intervention sought but not obtained \\
\hline Wu 1999 & $\begin{array}{l}\text { Data on pre-planned outcome measures of interest were not available from the trial, which aimed } \\
\text { to assess the effects of acupuncture on urinary incontinence in people with stroke }\end{array}$ \\
\hline Wu 2009a & The trial included people with stroke less than 1 month since onset \\
\hline Wu 2009b & The trial aimed to assess the effects of three different forms of acupuncture
\end{tabular}




\begin{tabular}{|c|c|}
\hline Study & Reason for exclusion \\
\hline Wu 2010 & The trial included people with acute stroke (less than 1 month since onset) \\
\hline Wu 2011 & The trial included people with stroke less than 1 month since onset \\
\hline Wu 2012 & The duration of stroke since onset was not clear \\
\hline Wu 2012a & The trial included people with acute stroke (less than 1 month since onset) \\
\hline Wu 2013b & The trial included people with acute stroke (less than 1 month since onset) \\
\hline Wu 2014a & The trial included people with acute stroke (less than 1 month since onset) \\
\hline Wu 2014b & The duration of stroke since onset was not clear \\
\hline Xia 2008 & The trial included people with stroke less than 1 month since onset \\
\hline Xia 2010 & The trial included people with stroke less than 1 month since onset \\
\hline Xiao 1996 & $\begin{array}{l}\text { It was not possible to include data from this trial in the analysis. The trial aimed to assess effects of } \\
2 \text { methods of acupuncture on subacute or chronic stroke. Acupoints were different between the } 2 \\
\text { groups }\end{array}$ \\
\hline Xiao 2006 & The trial included people with stroke less than 1 month since onset \\
\hline Xiao 2008 & The trial included people with acute stroke (less than 1 month since onset) \\
\hline Xiao 2011 & The trial included people with acute stroke (less than 1 month since onset) \\
\hline Xie 2010 & The trial included people with stroke less than 1 month since onset \\
\hline Xie 2012 & The trial included people with stroke less than 1 month since onset \\
\hline Xie 2013 & Quasi-randomised study \\
\hline Xing 2007 & The trial included people with stroke less than 1 month since onset \\
\hline Xu 2009a & The duration of stroke since onset was not stated in the trial \\
\hline Xu 2009b & The duration of stroke since onset was not stated in the trial \\
\hline Xu 2010 & The trial included people with acute stroke (less than 1 month since onset) \\
\hline Xu 2013a & The trial included people with stroke less than 1 month since onset \\
\hline Xu 2014 & The duration of stroke since onset was not clear \\
\hline Yan 2010 & The duration of stroke since onset was not clear \\
\hline Yan 2011 & The trial included people with stroke less than 1 month since onset \\
\hline Yang 2006 & The duration of stroke since onset was not clear \\
\hline Yang 2007a & Quasi-randomised study \\
\hline Yang 2007b & The trial included people with stroke less than 1 month since onset \\
\hline
\end{tabular}




\begin{tabular}{|c|c|}
\hline Study & Reason for exclusion \\
\hline Yang 2007c & The trial included people with stroke less than 1 month since onset \\
\hline Yang 2008 & The trial aimed to assess the effects of electrical acupuncture compared with routine acupuncture \\
\hline Yang 2009 & The duration of stroke since onset was not clear \\
\hline Yang 2010 & The trial included people with stroke less than 1 month since onset \\
\hline Yang 2011a & The trial included people with stroke less than 1 month since onset \\
\hline Yang 2011b & The duration of stroke since onset was not clear \\
\hline Yang 2012 & The trial included people with stroke less than 1 month since onset \\
\hline Yang 2014 & The duration of stroke since onset was not clear \\
\hline Yang 2014a & The duration of stroke since onset was not clear \\
\hline Yang 2015 & The trial included people with stroke less than 1 month since onset \\
\hline Yao 2006 & The duration of stroke since onset was not stated in the trial \\
\hline Yao 2013a & The trial included people with stroke less than 1 month since onset \\
\hline Yin 2013a & The trial included people with acute stroke (less than 1 month since onset) \\
\hline Yin 2013b & The trial included people with stroke less than 1 month since onset \\
\hline Yin 2014 & The duration of stroke since onset was not clear \\
\hline You 2011 & The trial included people with stroke less than 1 month since onset \\
\hline You 2014 & The trial included people with stroke less than 1 month since onset \\
\hline Yu 2002 & $\begin{array}{l}\text { It was not possible to include data from this trial in the analysis. The trial aimed to assess effects } \\
\text { of } 2 \text { methods of acupuncture on subacute or chronic stroke. Acupoints were different between the } \\
2 \text { groups. The trial was also confounded; it aimed to assess effects of acupuncture only compared } \\
\text { with drug therapy (such as WM or TCM) }\end{array}$ \\
\hline
\end{tabular}

\begin{tabular}{ll}
\hline Yu 2007 & The trial included people with stroke less than 1 month since onset \\
\hline Yu 2009 & The trial included people with stroke less than 1 month since onset \\
\hline Yu 2011 & The trial included people with stroke less than 1 month since onset \\
\hline Yuan 2010 & The trial included people with stroke less than 1 month since onset \\
\hline Zeng 2010 & It was not possible to include data from this trial in the analysis. This confounded trial aimed to as- \\
\hline Shang 1988 & sess effects of acupuncture only compared with drug therapy (such as WM or TCM)
\end{tabular}




\begin{tabular}{|c|c|}
\hline Study & Reason for exclusion \\
\hline Zhang 1997 & $\begin{array}{l}\text { It was not possible to include data from this trial in the analysis. This confounded trial aimed to as- } \\
\text { sess effects of acupuncture only compared with drug therapy (such as WM or TCM) }\end{array}$ \\
\hline Zhang 2002a & $\begin{array}{l}\text { The trial aimed to assess the effects of magnetic acupuncture compared with routine acupuncture. } \\
\text { Acupoints were similar between the } 2 \text { groups }\end{array}$ \\
\hline Zhang 2002b & $\begin{array}{l}\text { The duration of stroke since onset was not stated in the trial; it was not possible to include data } \\
\text { from this trial in the analysis. This confounded trial aimed to assess effects of acupuncture only } \\
\text { compared with drug therapy (such as WM or TCM) }\end{array}$ \\
\hline Zhang 2007a & The trial included people with stroke less than 1 month since onset \\
\hline Zhang 2007b & $\begin{array}{l}\text { The trial aimed to assess the effects of the combination of acupuncture, buyang huanwu decoction } \\
\text { and routine treatment compared with routine treatment }\end{array}$ \\
\hline Zhang 2008 & The trial included people with stroke less than 1 month since onset \\
\hline Zhang 2009b & The trial included people with stroke less than 1 month since onset \\
\hline Zhang 2009 c & The duration of stroke since onset was not stated in the trial \\
\hline Zhang 2010a & $\begin{array}{l}\text { The trial aimed to assess the effects of basic therapy, rehabilitation, acupuncture, TCM, and mas- } \\
\text { sage therapy compared with basic treatment and rehabilitation treatment }\end{array}$ \\
\hline Zhang 2010b & The trial included people with acute stroke (less than 1 month since onset) \\
\hline Zhang 2010c & The trial included people with acute stroke (less than 1 month since onset) \\
\hline Zhang 2010d & The trial included people with stroke less than 1 month since onset \\
\hline Zhang 2010e & The duration of stroke since onset was not clear \\
\hline Zhang $2010 f$ & The trial included people with acute stroke (less than 1 month since onset) \\
\hline Zhang 2011a & The trial included people with stroke less than 1 month since onset \\
\hline Zhang 2011b & The duration of stroke since onset was not stated in the trial \\
\hline Zhang 2011c & The duration of stroke since onset was not stated in the trial \\
\hline Zhang 2011d & The trial included people with stroke less than 1 month since onset \\
\hline Zhang 2011e & The duration of stroke since onset was not clear \\
\hline Zhang 2012b & The trial included people with stroke less than 1 month since onset \\
\hline Zhang 2012c & The trial included people with stroke less than 1 month since onset \\
\hline Zhang 2012d & The trial included people with stroke less than 1 month since onset \\
\hline Zhang 2012e & The trial included people with stroke less than 1 month since onset \\
\hline Zhang 2013b & The trial included people with stroke less than 1 month since onset \\
\hline Zhang 2014b & Abstract only; clarification of randomisation and intervention sought but not obtained \\
\hline
\end{tabular}




\begin{tabular}{|c|c|}
\hline Study & Reason for exclusion \\
\hline Zhang 2014c & The duration of stroke since onset was not clear \\
\hline Zhang 2014d & The trial included people with stroke less than 1 month since onset \\
\hline Zhao 2008 & The duration of stroke since onset was not stated in the trial \\
\hline Zhao 2009 & $\begin{array}{l}\text { The trial aimed to assess the effects of deep acupuncture compared with routine acupuncture. } \\
\text { Acupoints were the same between } 2 \text { groups }\end{array}$ \\
\hline Zhao 2010 & The duration of stroke since onset was not stated in the trial \\
\hline Zhao 2011a & The duration of stroke since onset was not clear \\
\hline Zhao 2011b & The trial included people with acute stroke (less than 1 month since onset) \\
\hline Zhao 2014a & The trial included people with stroke less than 1 month since onset \\
\hline Zhao 2014b & The duration of stroke since onset was not stated in the trial \\
\hline Zheng 1996 & $\begin{array}{l}\text { The trial aimed to assess the effects of combination of body and scalp acupuncture compared with } \\
\text { body acupuncture only or scalp acupuncture only }\end{array}$ \\
\hline Zheng 2000 & Confounded (acupuncture plus Chinese herbs versus WM only) \\
\hline Zheng 2011b & The trial aimed to assess the effects of different forms of acupuncture \\
\hline Zheng 2011c & The trial included people with stroke less than 1 month since onset \\
\hline Zhong 2014 & The trial included people with stroke less than 1 month since onset \\
\hline Zhou 1995 & $\begin{array}{l}\text { It was not possible to include data from this trial in the analysis. The trial aimed to assess effects of } \\
2 \text { methods of acupuncture on subacute or chronic stroke. Acupoints were different between the } 2 \\
\text { groups }\end{array}$ \\
\hline Zhou 2008 & $\begin{array}{l}\text { The trial aimed to assess the effects of combination of acupuncture, PT and WM compared with } \\
\text { WM. The duration of stroke since onset was not stated in the trial }\end{array}$ \\
\hline Zhu 2010a & The duration of stroke since onset was not stated in the trial \\
\hline Zhu 2010b & The duration of stroke since onset was not stated in the trial \\
\hline Zhu 2011 & Abstract only; clarification of randomisation and intervention sought but not obtained \\
\hline Zhu 2012a & The trial included people with stroke less than 1 month since onset \\
\hline Zhu 2012b & The duration of stroke since onset was not stated in the trial \\
\hline Zhuang 2012 & The trial included people with stroke less than 1 month since onset \\
\hline
\end{tabular}

ADL: activities of daily living

MAS: Modified Ashworth Scale

OT: occupational therapy

PT: physical therapy

TCM: Traditional Chinese Medicine

WM: Western medicine 
Characteristics of ongoing studies [ordered by study ID]

Fu 2011

\begin{tabular}{ll}
\hline Trial name or title & $\begin{array}{l}\text { Randomised, controlled Phase III trial to evaluate the efficacy and safety of comprehensive } \\
\text { acupuncture treatment programmes for post-stroke motor rehabilitation }\end{array}$ \\
\hline Methods & Randomised parallel controlled trial \\
\hline Participants & People with haemorrhagic or ischaemic stroke \\
\hline Interventions & Acupuncture + rehabilitation training \\
\hline Outcomes & BOSS \\
\hline Starting date & 1 January 2011 \\
\hline Contact information & Shanghai Municipal Health Bureau \\
\hline Notes & Recruiting status : completed \\
\hline
\end{tabular}

Liu 2013b

\begin{tabular}{ll}
\hline Trial name or title & $\begin{array}{l}\text { Acupuncture based on five elements body characteristics in the treatment of people with post- } \\
\text { stroke depression }\end{array}$ \\
\hline Methods & Randomised parallel controlled trial \\
\hline Participants & People with post-stroke depression \\
\hline Interventions & - Five pedestrian body dialectical acupuncture \\
\hline Outcomes & Conventional acupuncture \\
& - HAMD \\
\hline Starting date & Neurologic function score \\
\hline Contact information & The First Affiliated Hospital of Guangxi Traditional Chinese Medicine University \\
\hline Notes & Recruiting status \\
\hline
\end{tabular}

Xie 2006

Trial name or title $\begin{aligned} & \text { Randomised controlled study on the acupuncture for dysphagia in convalescence phase of } \\ & \text { apoplexy }\end{aligned}$

\begin{tabular}{ll}
\hline Methods & Parallel RCT \\
\hline Participants & People with dysphagia in the convalescent phase of apoplexy \\
\hline
\end{tabular}


Xie 2006 (Continued)

\begin{tabular}{ll} 
Interventions & Acupuncture with swallowing training \\
\hline Outcomes & - Mortality \\
- Improvement & - Neurological function scale \\
- Length of hospitalisation & - Nutrition status \\
- Quality of life & - TCM outcomes \\
& - Rate of Lung Infection \\
& - Loss of follow-up, and withdraw \\
& Adverse events \\
\hline Starting date & Detober 2006 \\
\hline Contact information & Department of Acupuncture, Huguosi TCM Hospital attached to the Beijing University of TCM \\
\hline Notes & Dateshed: 7 February 2015
\end{tabular}

\section{Zhong 2010}

Trial name or title

The research of linguistic functional recovery mechanism based on $\mathrm{fMRI}$ after electroacupuncture at acupoints Tongli (HT5) and Xuanzhong (GB39) curing basal ganglia aphasia after stroke

\begin{tabular}{ll}
\hline Methods & Randomised parallel controlled trial \\
\hline Participants & $\begin{array}{l}\text { People who have explicit syndrome of aphasia, presenting within ischaemic stroke only in basal } \\
\text { ganglia }\end{array}$ \\
\hline Interventions & Electroacupuncture \\
\hline Outcomes & - Linguistic functional evaluation after 30 days' and 60 days' therapy \\
\hline Starting date & 1 January 2010 \\
\hline Contact information & State Administration of Traditional Chinese Medicine \\
\hline Notes & Recruiting status : completed \\
\hline
\end{tabular}

ADL: activities of daily living

BOSS: Burden of Stroke Scale

fMRI: functional magnetic resonance imaging

HAMD: Hamilton Depression Scale

TCM: traditional Chinese medicine

\section{DATA AND ANALYSES}


Comparison 1. Acupuncture plus baseline treatment versus sham acupuncture plus baseline treatment

\begin{tabular}{|c|c|c|c|c|}
\hline Outcome or subgroup title & No. of studies & $\begin{array}{l}\text { No. of partici- } \\
\text { pants }\end{array}$ & Statistical method & Effect size \\
\hline $\begin{array}{l}1 \text { Improvement of motor } \\
\text { function }\end{array}$ & 1 & & Odds Ratio (M-H, Fixed, 95\% Cl) & Totals not selected \\
\hline $\begin{array}{l}2 \text { Improvement of cognitive } \\
\text { function }\end{array}$ & 1 & & Mean Difference (IV, Fixed, 95\% CI) & Totals not selected \\
\hline 2.1 Orientation & 1 & & Mean Difference (IV, Fixed, 95\% CI) & $0.0[0.0,0.0]$ \\
\hline 2.2 Perception & 1 & & Mean Difference (IV, Fixed, 95\% CI) & $0.0[0.0,0.0]$ \\
\hline 2.3 Praxis & 1 & & Mean Difference (IV, Fixed, 95\% CI) & $0.0[0.0,0.0]$ \\
\hline 2.4 Visuomotor organisation & 1 & & Mean Difference (IV, Fixed, 95\% CI) & $0.0[0.0,0.0]$ \\
\hline 2.5 Thinking operation & 1 & & Mean Difference (IV, Fixed, 95\% CI) & $0.0[0.0,0.0]$ \\
\hline 2.6 Memory & 1 & & Mean Difference (IV, Fixed, 95\% CI) & $0.0[0.0,0.0]$ \\
\hline 2.7 Attention & 1 & & Mean Difference (IV, Fixed, 95\% CI) & $0.0[0.0,0.0]$ \\
\hline $\begin{array}{l}3 \text { Improvement of Health- } \\
\text { Related Quality of Life (MOS } \\
\text { SF-36) }\end{array}$ & 1 & & Mean Difference (IV, Fixed, 95\% CI) & Totals not selected \\
\hline $\begin{array}{l}\text { 3.1 Physical component sum- } \\
\text { mary }\end{array}$ & 1 & & Mean Difference (IV, Fixed, 95\% CI) & $0.0[0.0,0.0]$ \\
\hline $\begin{array}{l}\text { 3.2 Mental component sum- } \\
\text { mary }\end{array}$ & 1 & & Mean Difference (IV, Fixed, 95\% CI) & $0.0[0.0,0.0]$ \\
\hline $\begin{array}{l}4 \text { Improvement of Stroke- } \\
\text { Specific Quality of Life(SS } \\
\text { QOL) }\end{array}$ & 1 & & Mean Difference (IV, Fixed, 95\% CI) & Totals not selected \\
\hline 4.1 Language & 1 & & Mean Difference (IV, Fixed, 95\% CI) & $0.0[0.0,0.0]$ \\
\hline 4.2 Personality & 1 & & Mean Difference (IV, Fixed, 95\% CI) & $0.0[0.0,0.0]$ \\
\hline
\end{tabular}

Analysis 1.1. Comparison 1 Acupuncture plus baseline treatment versus sham acupuncture plus baseline treatment, Outcome 1 Improvement of motor function.

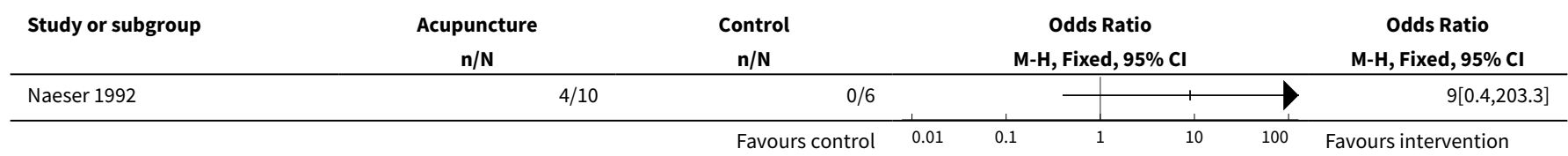


Analysis 1.2. Comparison 1 Acupuncture plus baseline treatment versus sham acupuncture plus baseline treatment, Outcome 2 Improvement of cognitive function.

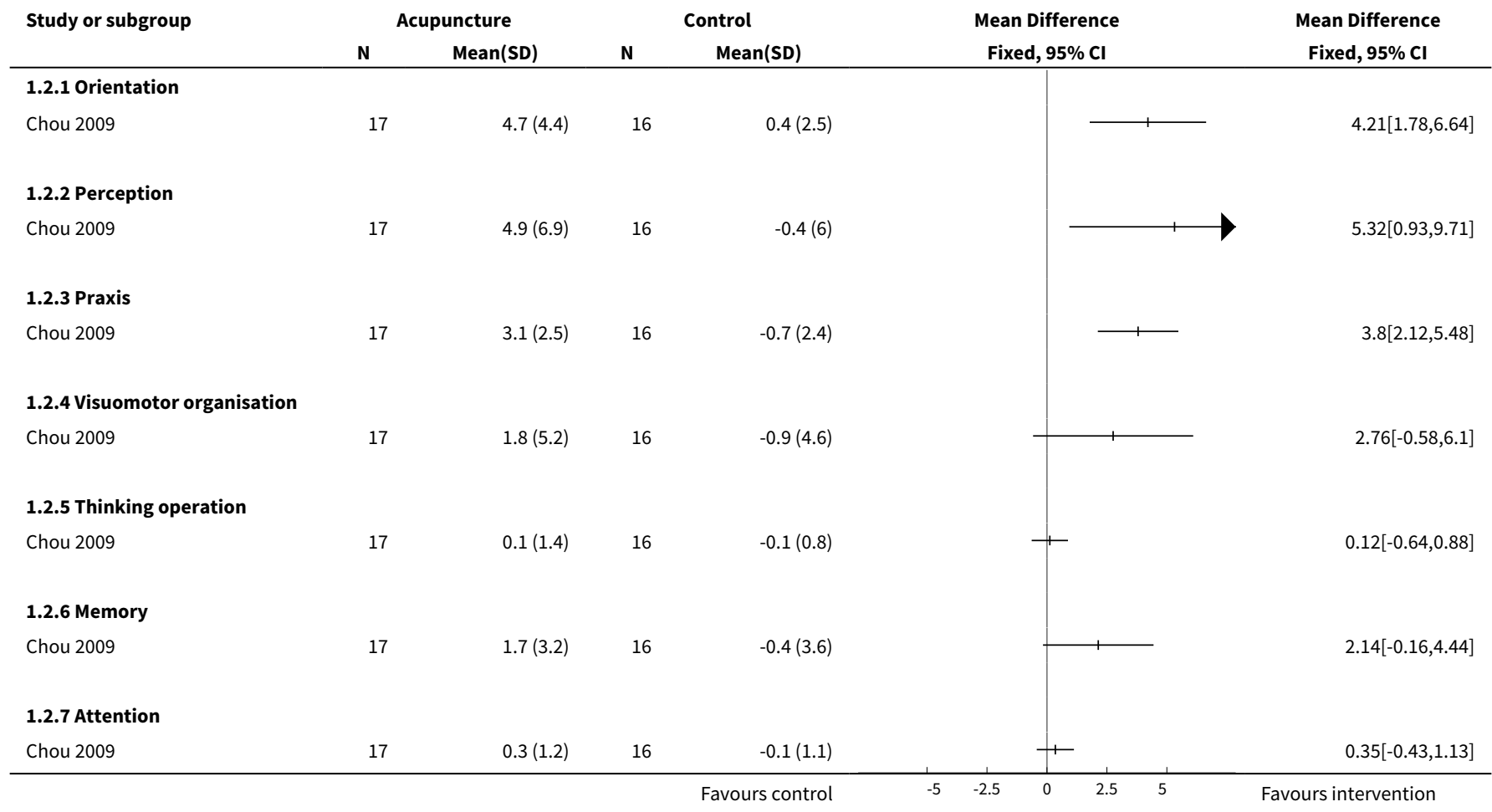

Analysis 1.3. Comparison 1 Acupuncture plus baseline treatment versus sham acupuncture plus baseline treatment, Outcome 3 Improvement of Health-Related Quality of Life (MOS SF-36).

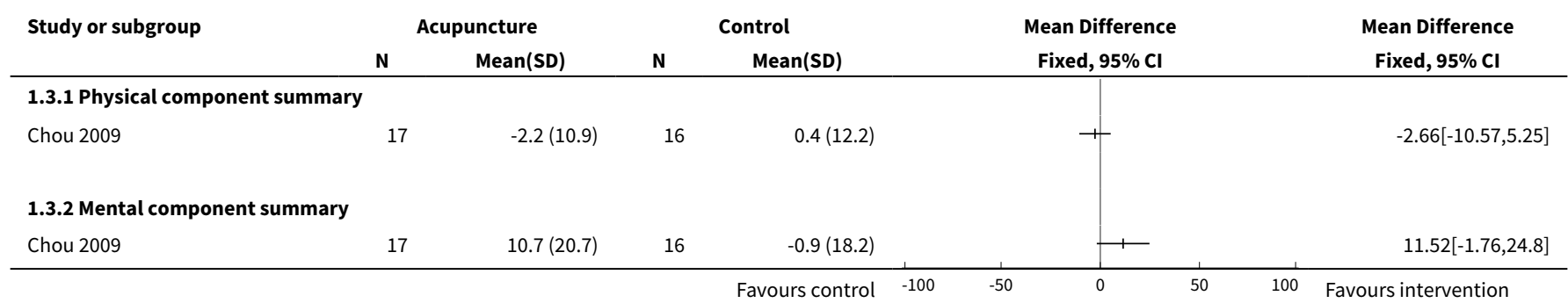

Analysis 1.4. Comparison 1 Acupuncture plus baseline treatment versus sham acupuncture plus baseline treatment, Outcome 4 Improvement of Stroke-Specific Quality of Life(SS QOL).

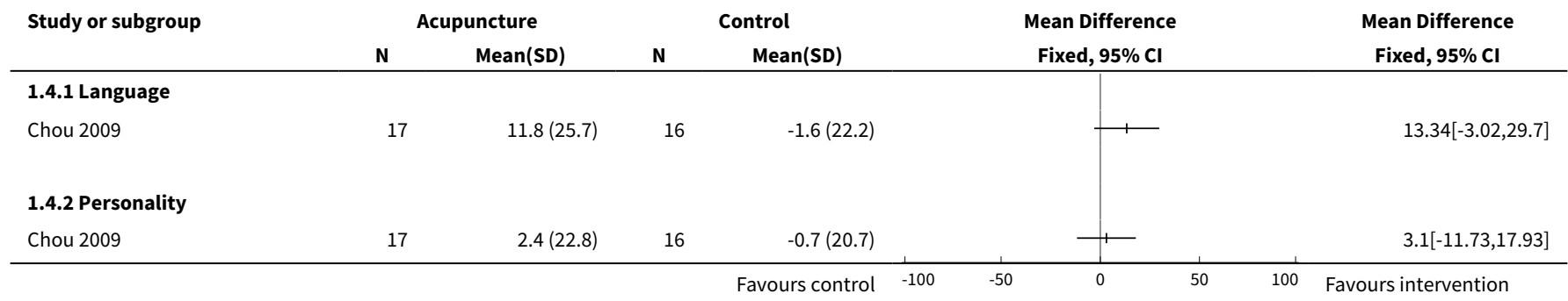


Comparison 2. Acupuncture plus baseline treatment versus baseline treatment alone

\begin{tabular}{|c|c|c|c|c|}
\hline Outcome or subgroup title & No. of studies & $\begin{array}{l}\text { No. of partici- } \\
\text { pants }\end{array}$ & Statistical method & Effect size \\
\hline $\begin{array}{l}1 \text { Improvement of dependency at the } \\
\text { end of treatment }\end{array}$ & 11 & & $\begin{array}{l}\text { Mean Difference (IV, Random, } \\
95 \% \mathrm{Cl} \text { ) }\end{array}$ & Subtotals only \\
\hline 1.1 Barthel Index & 9 & 616 & $\begin{array}{l}\text { Mean Difference (IV, Random, } \\
95 \% \mathrm{CI})\end{array}$ & $9.19[4.34,14.05]$ \\
\hline 1.2 Modified Barthel Index & 1 & 60 & $\begin{array}{l}\text { Mean Difference (IV, Random, } \\
95 \% \mathrm{CI})\end{array}$ & $3.44[0.30,6.58]$ \\
\hline 1.3 ADL & 1 & 62 & $\begin{array}{l}\text { Mean Difference (IV, Random, } \\
95 \% \mathrm{Cl})\end{array}$ & $7.80[6.04,9.56]$ \\
\hline $\begin{array}{l}2 \text { Improvement of dependency at the } \\
\text { end of follow-up }\end{array}$ & 2 & & $\begin{array}{l}\text { Mean Difference (IV, Random, } \\
95 \% \mathrm{Cl})\end{array}$ & Subtotals only \\
\hline 2.1 Barthel index & 1 & 147 & $\begin{array}{l}\text { Mean Difference (IV, Random, } \\
95 \% \mathrm{Cl} \text { ) }\end{array}$ & $7.49[1.79,13.19]$ \\
\hline $2.2 \mathrm{ADL}$ & 1 & 71 & $\begin{array}{l}\text { Mean Difference (IV, Random, } \\
95 \% \mathrm{CI})\end{array}$ & $3.83[2.67,4.99]$ \\
\hline $\begin{array}{l}3 \text { Improvement of global neurological } \\
\text { deficit at the end of treatment }\end{array}$ & 6 & & $\begin{array}{l}\text { Mean Difference (IV, Random, } \\
95 \% \mathrm{CI})\end{array}$ & Subtotals only \\
\hline $\begin{array}{l}\text { 3.1 Modified Edinburgh and Scandina- } \\
\text { vian Stroke Scale }\end{array}$ & 4 & 240 & $\begin{array}{l}\text { Mean Difference (IV, Random, } \\
95 \% \mathrm{CI})\end{array}$ & $\begin{array}{l}-2.39[-3.34 \\
-1.43]\end{array}$ \\
\hline 3.2 Neurological function deficit scale & 2 & 123 & $\begin{array}{l}\text { Mean Difference (IV, Random, } \\
95 \% \mathrm{Cl} \text { ) }\end{array}$ & $-1.02[-5.80,3.76]$ \\
\hline $\begin{array}{l}4 \text { Improvement of global neurological } \\
\text { deficit at the end of follow-up }\end{array}$ & 2 & & $\begin{array}{l}\text { Mean Difference (IV, Random, } \\
95 \% \mathrm{CI})\end{array}$ & Subtotals only \\
\hline 4.1 Neurological function deficit scale & 1 & 71 & $\begin{array}{l}\text { Mean Difference (IV, Random, } \\
95 \% \mathrm{Cl})\end{array}$ & $\begin{array}{l}-6.15[-7.09 \\
-5.21]\end{array}$ \\
\hline 4.2 NIHSS & 1 & 147 & $\begin{array}{l}\text { Mean Difference (IV, Random, } \\
95 \% \mathrm{Cl} \text { ) }\end{array}$ & $-0.83[-1.94,0.28]$ \\
\hline $\begin{array}{l}5 \text { Improvement of global neurological } \\
\text { deficit at the end of treatment }\end{array}$ & 7 & 543 & $\begin{array}{l}\text { Odds Ratio (M-H, Random, } \\
95 \% \mathrm{Cl})\end{array}$ & $3.89[1.78,8.49]$ \\
\hline $\begin{array}{l}6 \text { Improvement of motor function at } \\
\text { the end of treatment }\end{array}$ & 5 & & $\begin{array}{l}\text { Mean Difference (IV, Fixed, } \\
95 \% \mathrm{CI})\end{array}$ & Subtotals only \\
\hline $\begin{array}{l}6.1 \text { Upper and lower extremities motor } \\
\text { function(Fugl-Meyer Assessment) }\end{array}$ & 4 & 245 & $\begin{array}{l}\text { Mean Difference (IV, Fixed, } \\
95 \% \mathrm{CI})\end{array}$ & $6.16[4.20,8.11]$ \\
\hline $\begin{array}{l}\text { 6.2 General motor function (Motor as- } \\
\text { sessment scale) }\end{array}$ & 1 & 60 & $\begin{array}{l}\text { Mean Difference (IV, Fixed, } \\
95 \% \mathrm{Cl})\end{array}$ & $4.53[2.99,6.07]$ \\
\hline
\end{tabular}




\begin{tabular}{|c|c|c|c|c|}
\hline Outcome or subgroup title & No. of studies & $\begin{array}{l}\text { No. of partici- } \\
\text { pants }\end{array}$ & Statistical method & Effect size \\
\hline $\begin{array}{l}7 \text { Improvment of general motor func- } \\
\text { tion at the end of follow-up (Fugl-Mey- } \\
\text { er Assessment) }\end{array}$ & 1 & & $\begin{array}{l}\text { Mean Difference (IV, Fixed, } \\
95 \% \mathrm{Cl} \text { ) }\end{array}$ & Subtotals only \\
\hline $\begin{array}{l}8 \text { Improvement of motor function at } \\
\text { the end of treatment (Fugl-Meyer As- } \\
\text { sessment) }\end{array}$ & 2 & 125 & $\begin{array}{l}\text { Odds Ratio (M-H, Random, } \\
95 \% \mathrm{Cl})\end{array}$ & $2.41[0.98,5.96]$ \\
\hline $\begin{array}{l}9 \text { Improvement of cognitive function at } \\
\text { the end of treatment }\end{array}$ & 5 & & $\begin{array}{l}\text { Mean Difference (IV, Random, } \\
95 \% \mathrm{CI} \text { ) }\end{array}$ & Subtotals only \\
\hline 9.1 MMSE & 5 & 278 & $\begin{array}{l}\text { Mean Difference (IV, Random, } \\
95 \% \mathrm{CI} \text { ) }\end{array}$ & $2.54[0.03,5.05]$ \\
\hline $9.2 \mathrm{MoCA}$ & 2 & 120 & $\begin{array}{l}\text { Mean Difference (IV, Random, } \\
95 \% \mathrm{CI} \text { ) }\end{array}$ & $1.34[0.76,1.92]$ \\
\hline 9.3 HDS-R & 1 & 46 & $\begin{array}{l}\text { Mean Difference (IV, Random, } \\
95 \% \mathrm{CI} \text { ) }\end{array}$ & $1.26[0.29,2.23]$ \\
\hline $\begin{array}{l}10 \text { Improvment of cognitive function at } \\
\text { the end of follow-up (MMSE) }\end{array}$ & 1 & 71 & $\begin{array}{l}\text { Mean Difference (IV, Fixed, } \\
95 \% \mathrm{CI})\end{array}$ & $3.47[2.43,4.51]$ \\
\hline $\begin{array}{l}11 \text { Improvement of cognitive function } \\
\text { at the end of treatment }\end{array}$ & 3 & & $\begin{array}{l}\text { Odds Ratio (M-H, Random, } \\
95 \% \mathrm{Cl})\end{array}$ & Subtotals only \\
\hline 11.1 MMSE & 3 & 166 & $\begin{array}{l}\text { Odds Ratio (M-H, Random, } \\
95 \% \mathrm{Cl})\end{array}$ & $3.82[1.89,7.72]$ \\
\hline 11.2 HDS-R & 1 & 46 & $\begin{array}{l}\text { Odds Ratio (M-H, Random, } \\
95 \% \mathrm{Cl})\end{array}$ & $4.02[1.12,14.46]$ \\
\hline $\begin{array}{l}12 \text { Improvement of depression at the } \\
\text { end of treatment }\end{array}$ & 6 & & $\begin{array}{l}\text { Mean Difference (IV, Fixed, } \\
95 \% \mathrm{CI})\end{array}$ & Subtotals only \\
\hline 12.1 HAMD & 6 & 552 & $\begin{array}{l}\text { Mean Difference (IV, Fixed, } \\
95 \% \mathrm{Cl} \text { ) }\end{array}$ & $\begin{array}{l}-2.58[-3.28 \\
-1.87]\end{array}$ \\
\hline $\begin{array}{l}\text { 12.2 Symptoms of TCM depression } \\
\text { scale }\end{array}$ & 1 & 60 & $\begin{array}{l}\text { Mean Difference (IV, Fixed, } \\
95 \% \mathrm{Cl} \text { ) }\end{array}$ & $\begin{array}{l}-1.57[-2.96 \\
-0.18]\end{array}$ \\
\hline $\begin{array}{l}13 \text { Improvement of depression at the } \\
\text { end of treatment (HAMD) }\end{array}$ & 4 & 342 & $\begin{array}{l}\text { Odds Ratio (M-H, Random, } \\
95 \% \mathrm{Cl})\end{array}$ & $2.03[1.10,3.72]$ \\
\hline $\begin{array}{l}14 \text { Improvement of swallowing func- } \\
\text { tion at the end of treatment (Water } \\
\text { drinking test) }\end{array}$ & 2 & 200 & $\begin{array}{l}\text { Mean Difference (IV, Random, } \\
95 \% \mathrm{CI} \text { ) }\end{array}$ & $\begin{array}{l}-1.11[-2.08 \\
-0.14]\end{array}$ \\
\hline $\begin{array}{l}15 \text { Improvement of swallowing func- } \\
\text { tion at the end of treatment (Water } \\
\text { drinking test) }\end{array}$ & 1 & 60 & $\begin{array}{l}\text { Odds Ratio (M-H, Random, } \\
95 \% \mathrm{Cl})\end{array}$ & $\begin{array}{l}95.29[10.93 \\
830.86]\end{array}$ \\
\hline $\begin{array}{l}16 \text { Improvement of pain at the end of } \\
\text { treatment (Visual Analogue Scale) }\end{array}$ & 2 & 118 & $\begin{array}{l}\text { Mean Difference (IV, Fixed, } \\
95 \% \mathrm{CI} \text { ) }\end{array}$ & $\begin{array}{l}-2.88[-3.68 \\
-2.09]\end{array}$ \\
\hline
\end{tabular}




\begin{tabular}{lllll}
\hline Outcome or subgroup title & No. of studies & $\begin{array}{l}\text { No. of partici- } \\
\text { pants }\end{array}$ & Statistical method & Effect size \\
\hline $\begin{array}{l}17 \text { Improvement of sleep quality at } \\
\text { the end of treatment (Rhone Planck } \\
\text { Sleepiness Scale) }\end{array}$ & 1 & 60 & $\begin{array}{l}\text { Mean Difference (IV, Fixed, } \\
95 \% \mathrm{CI})\end{array}$ & $-1.09[-2.37,0.19]$ \\
\hline $\begin{array}{l}18 \text { Improvement of spasticity at the } \\
\text { end of treatment (Modified Ashworth } \\
\text { Spasticity Rating Scale) }\end{array}$ & 1 & 60 & $\begin{array}{l}\text { Mean Difference (IV, Fixed, } \\
95 \% \text { CI) }\end{array}$ & $-0.4[-0.64,-0.16]$ \\
\hline $\begin{array}{l}19 \text { Improvement of quality of life at the } \\
\text { end of treatment (MOS SF-36) }\end{array}$ & 1 & 71 & Mean Difference (IV, Fixed, & $2.73[-0.54,6.00]$ \\
\hline
\end{tabular}

Analysis 2.1. Comparison 2 Acupuncture plus baseline treatment versus baseline treatment alone, Outcome 1 Improvement of dependency at the end of treatment.

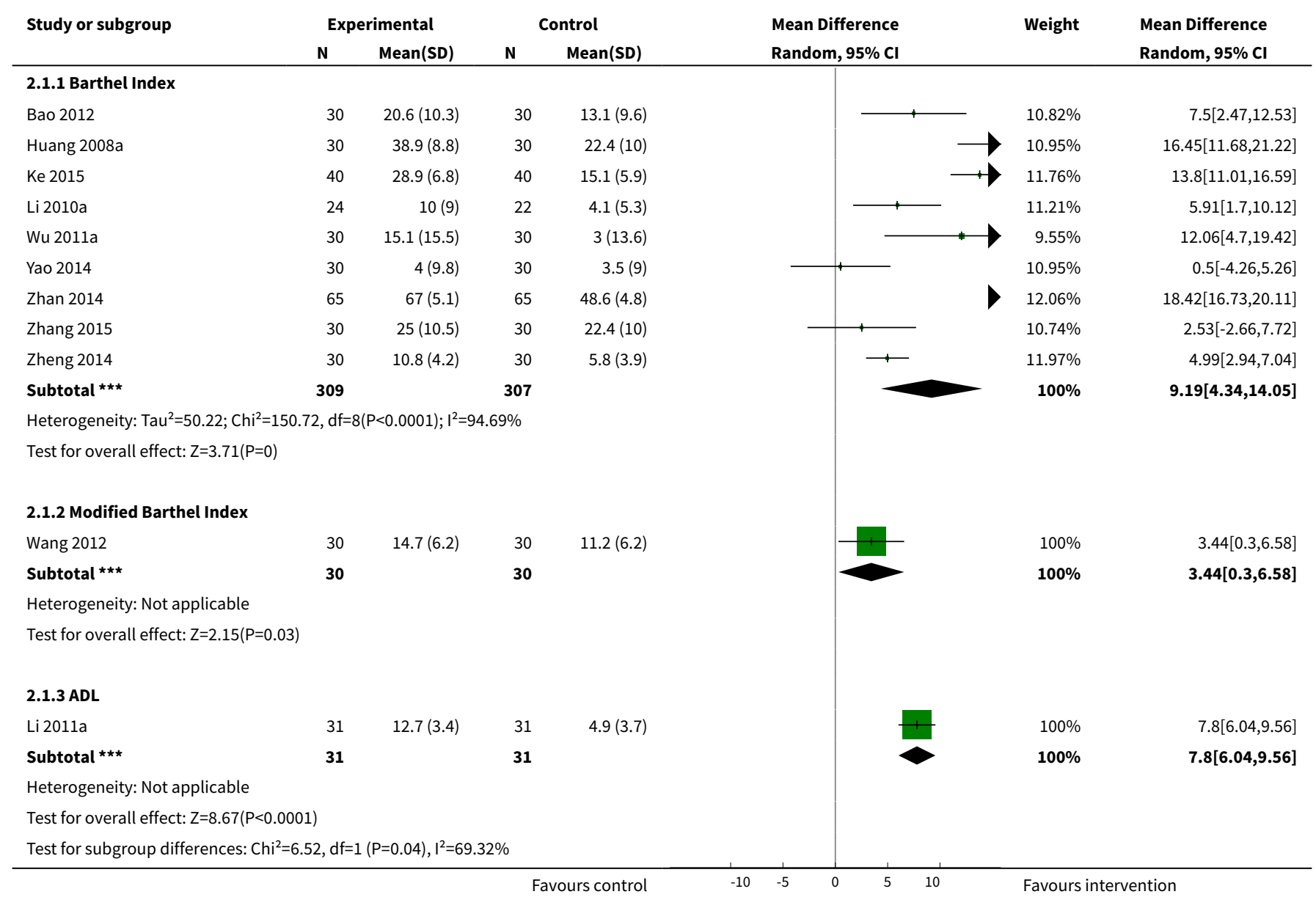


Analysis 2.2. Comparison 2 Acupuncture plus baseline treatment versus baseline treatment alone, Outcome 2 Improvement of dependency at the end of follow-up.

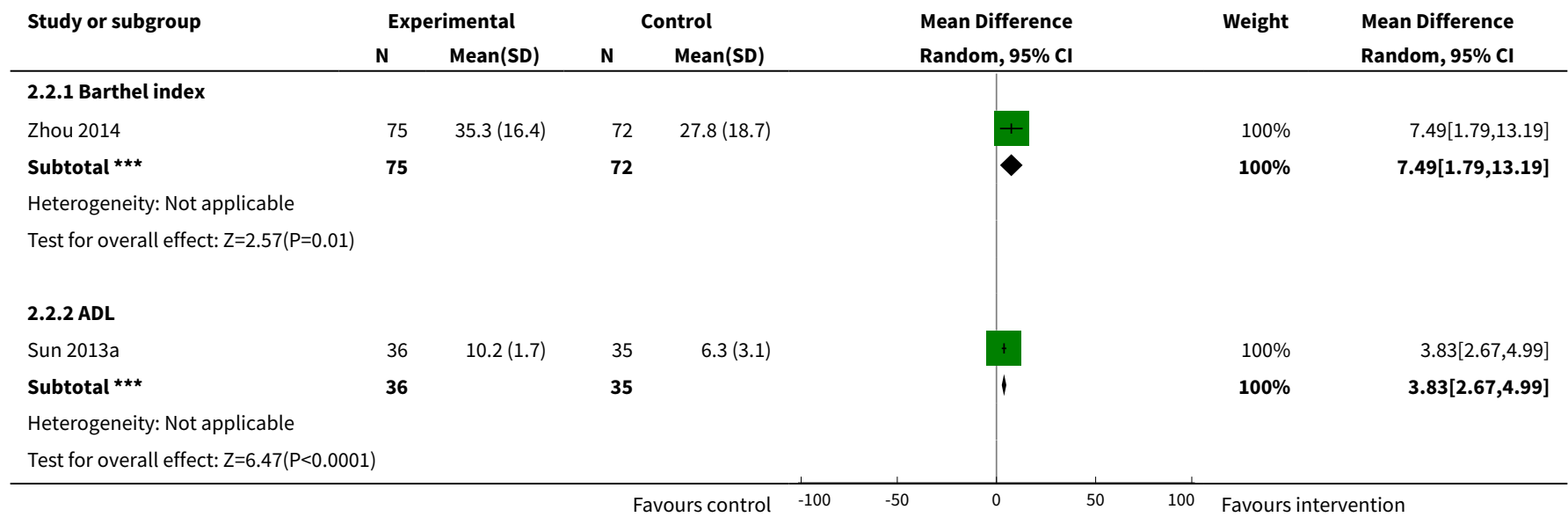

Analysis 2.3. Comparison 2 Acupuncture plus baseline treatment versus baseline treatment alone, Outcome 3 Improvement of global neurological deficit at the end of treatment.

\begin{tabular}{|c|c|c|c|c|c|c|c|}
\hline \multirow[t]{2}{*}{ Study or subgroup } & \multicolumn{2}{|c|}{ Experimental } & \multicolumn{2}{|c|}{ Control } & \multirow{2}{*}{$\begin{array}{l}\text { Mean Difference } \\
\text { Random, } 95 \% \mathrm{Cl}\end{array}$} & \multirow[t]{2}{*}{ Weight } & \multirow{2}{*}{$\begin{array}{l}\text { Mean Difference } \\
\text { Random, } 95 \% \mathrm{Cl}\end{array}$} \\
\hline & $\mathbf{N}$ & Mean(SD) & $\mathbf{N}$ & Mean(SD) & & & \\
\hline \multicolumn{8}{|c|}{ 2.3.1 Modified Edinburgh and Scandinavian Stroke Scale } \\
\hline Gao 2014a & 30 & $-10(4.6)$ & 30 & $-7.8(4.7)$ & + & $14.57 \%$ & $-2.17[-4.5,0.16]$ \\
\hline Zhang 2015 & 30 & $-4.8(3.5)$ & 30 & $-3.7(2.9)$ & $\#$ & $26.17 \%$ & $-1.1[-2.73,0.53]$ \\
\hline Zhu 2007 & 30 & $-7.8(2.6)$ & 30 & $-4.5(3.6)$ & \# & $27.19 \%$ & $-3.25[-4.84,-1.66]$ \\
\hline Huang 2008a & 30 & $-6.5(2.7)$ & 30 & $-3.7(2.9)$ & \pm & $32.07 \%$ & $-2.8[-4.22,-1.38]$ \\
\hline \multicolumn{8}{|c|}{ Heterogeneity: $\mathrm{Tau}^{2}=0.22 ; \mathrm{Chi}^{2}=3.88, \mathrm{df}=3(\mathrm{P}=0.27) ; \mathrm{I}^{2}=22.63 \%$} \\
\hline \multicolumn{8}{|c|}{ Test for overall effect: $Z=4.89(P<0.0001)$} \\
\hline \multicolumn{8}{|c|}{ 2.3.2 Neurological function deficit scale } \\
\hline Guo 2011 & 32 & $-14.9(42)$ & 31 & $-6.3(5.8)$ & & $9.48 \%$ & $-8.55[-23.25,6.15]$ \\
\hline Yao 2014 & 30 & $-1.4(1.4)$ & 30 & $-1.2(1.3)$ & & $90.52 \%$ & $-0.23[-0.92,0.46]$ \\
\hline \multicolumn{8}{|c|}{ Heterogeneity: $\mathrm{Tau}^{2}=6.44 ; \mathrm{Chi}^{2}=1.23, \mathrm{df}=1(\mathrm{P}=0.27) ; \mathrm{I}^{2}=18.61 \%$} \\
\hline \multicolumn{8}{|c|}{ Test for overall effect: $Z=0.42(P=0.68)$} \\
\hline Test for subgroup dif & $3, d f=1$ & $=0.58), I^{2}=0 \%$ & & & & & \\
\hline
\end{tabular}

Analysis 2.4. Comparison 2 Acupuncture plus baseline treatment versus baseline treatment alone, Outcome 4 Improvement of global neurological deficit at the end of follow-up.

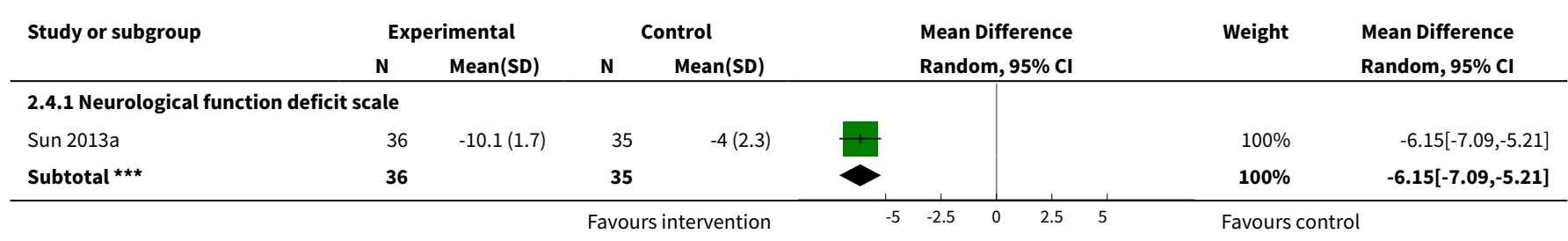




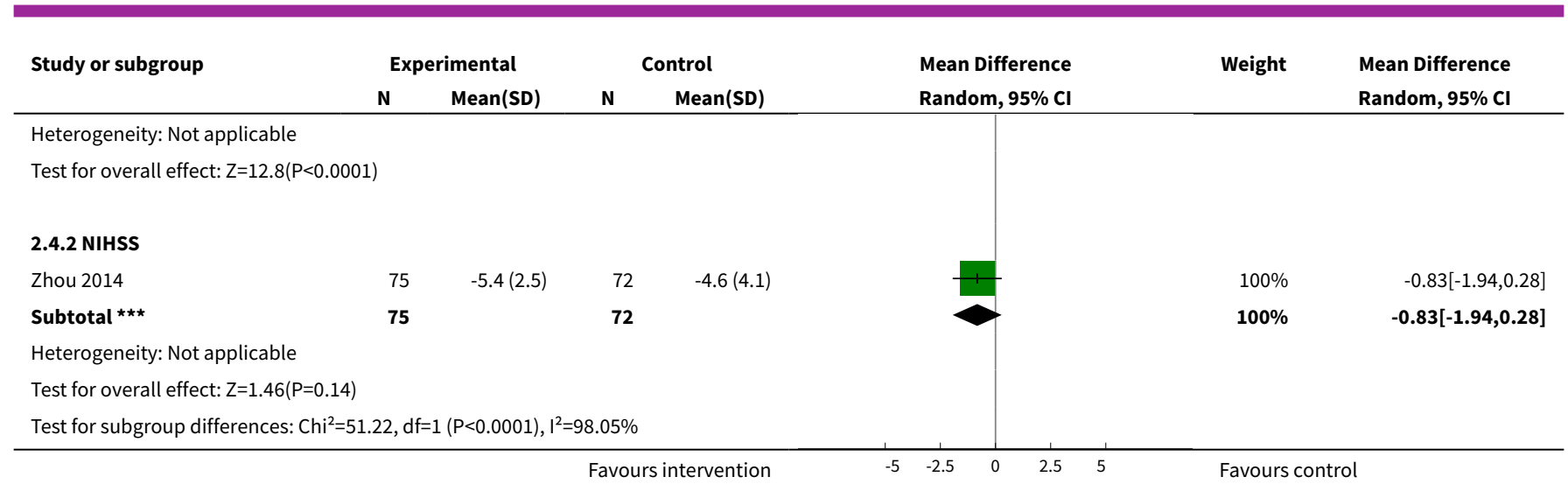

Analysis 2.5. Comparison 2 Acupuncture plus baseline treatment versus baseline treatment alone, Outcome $5 \mathrm{Improvement}$ of global neurological deficit at the end of treatment.

\begin{tabular}{|c|c|c|c|c|c|}
\hline Study or subgroup & $\begin{array}{c}\text { Experimental } \\
n / N\end{array}$ & $\begin{array}{c}\text { Control } \\
\mathrm{n} / \mathrm{N}\end{array}$ & $\begin{array}{c}\text { Odds Ratio } \\
\text { M-H, Random, } 95 \% \mathrm{Cl}\end{array}$ & Weight & $\begin{array}{c}\text { Odds Ratio } \\
\text { M-H, Random, } 95 \% \mathrm{Cl}\end{array}$ \\
\hline Dai 1997 & $44 / 46$ & $30 / 45$ & $\longrightarrow$ & $12.93 \%$ & $11[2.34,51.65]$ \\
\hline Huang 2008a & $27 / 30$ & $22 / 30$ & $\rightarrow$ & $13.86 \%$ & $3.27[0.77,13.83]$ \\
\hline Li 1997a & $38 / 42$ & $42 / 50$ & $\longrightarrow$ & $15.42 \%$ & $1.81[0.5,6.49]$ \\
\hline Lun 1999 & $59 / 61$ & $25 / 48$ & & $13.17 \%$ & $27.14[5.94,123.93]$ \\
\hline Wang 2001 & $32 / 34$ & $21 / 26$ & $\longrightarrow$ & $11.47 \%$ & $3.81[0.68,21.48]$ \\
\hline Zhang 2015 & $32 / 36$ & $27 / 35$ & $\longrightarrow$ & $15.15 \%$ & $2.37[0.64,8.74]$ \\
\hline Total $(95 \% \mathrm{Cl})$ & 279 & 264 & & $100 \%$ & $3.89[1.78,8.49]$ \\
\hline \multicolumn{6}{|c|}{ Total events: 246 (Experimental), 178 (Control) } \\
\hline \multicolumn{6}{|c|}{ Heterogeneity: $\mathrm{Tau}^{2}=0.6 ; \mathrm{Chi}^{2}=13.4, \mathrm{df}=6(\mathrm{P}=0.04) ; \mathrm{I}^{2}=55.23 \%$} \\
\hline Test for overall effect & & & & & \\
\hline
\end{tabular}

$\begin{array}{lllllll}\text { Favours control } & 0.01 & 0.1 & 1 & 10 & 100 & \text { Favours intervention }\end{array}$

Analysis 2.6. Comparison 2 Acupuncture plus baseline treatment versus baseline treatment alone, Outcome 6 Improvement of motor function at the end of treatment.

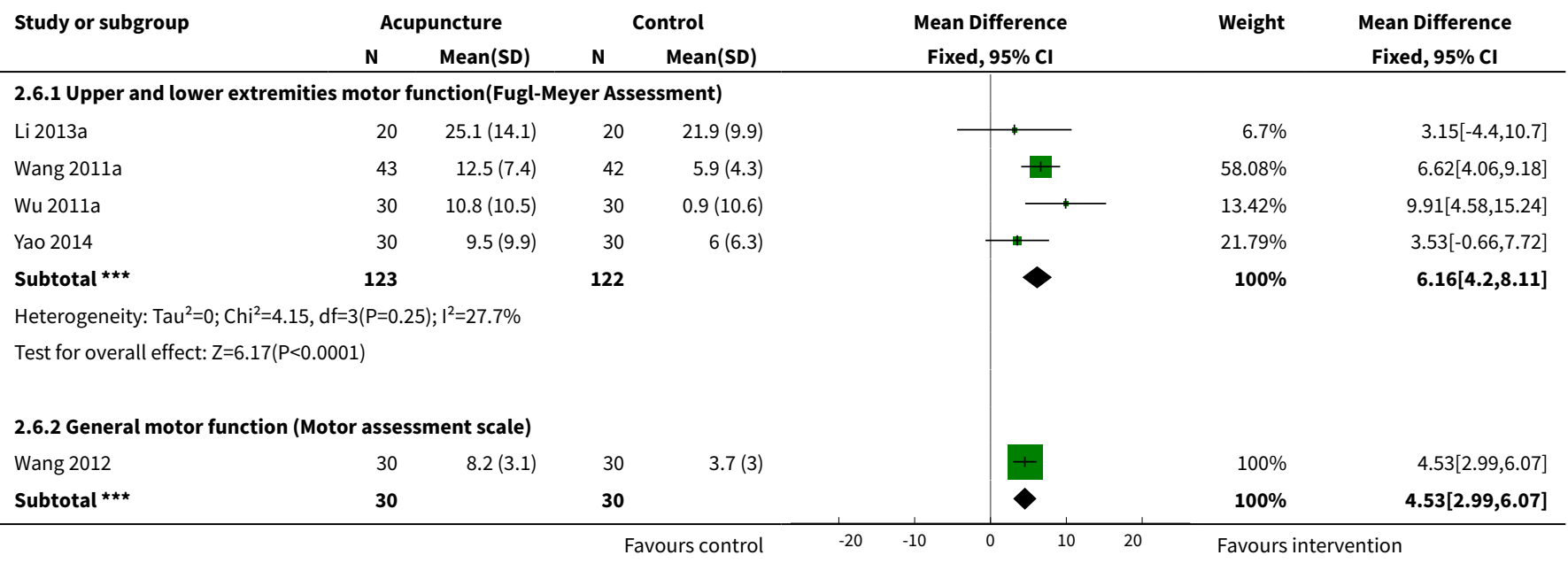




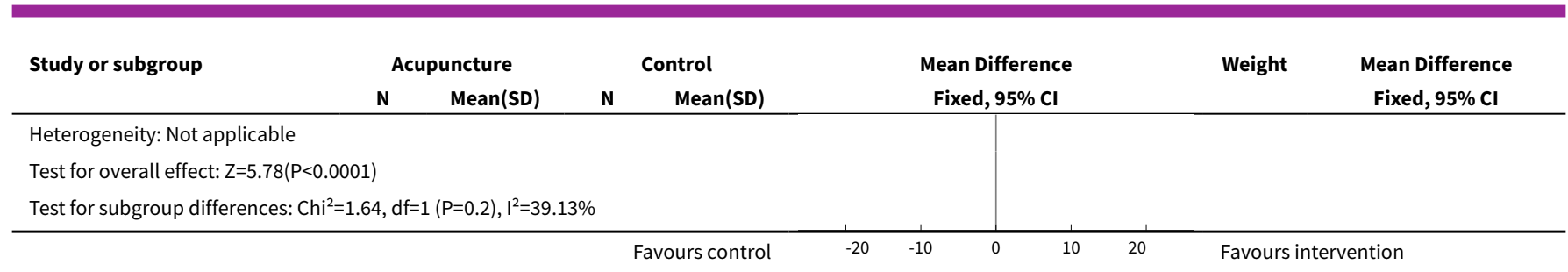

Analysis 2.7. Comparison 2 Acupuncture plus baseline treatment versus baseline treatment alone, Outcome 7 Improvment of general motor function at the end of follow-up (Fugl-Meyer Assessment).

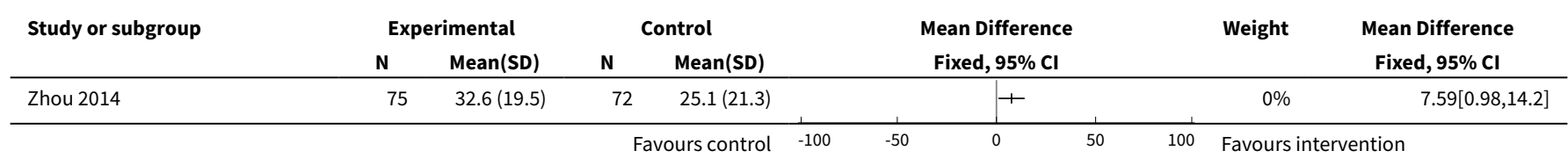

\section{Analysis 2.8. Comparison 2 Acupuncture plus baseline treatment versus baseline treatment alone, Outcome $8 \mathrm{Improvement}$ of motor function at the end of treatment (Fugl-Meyer Assessment).}

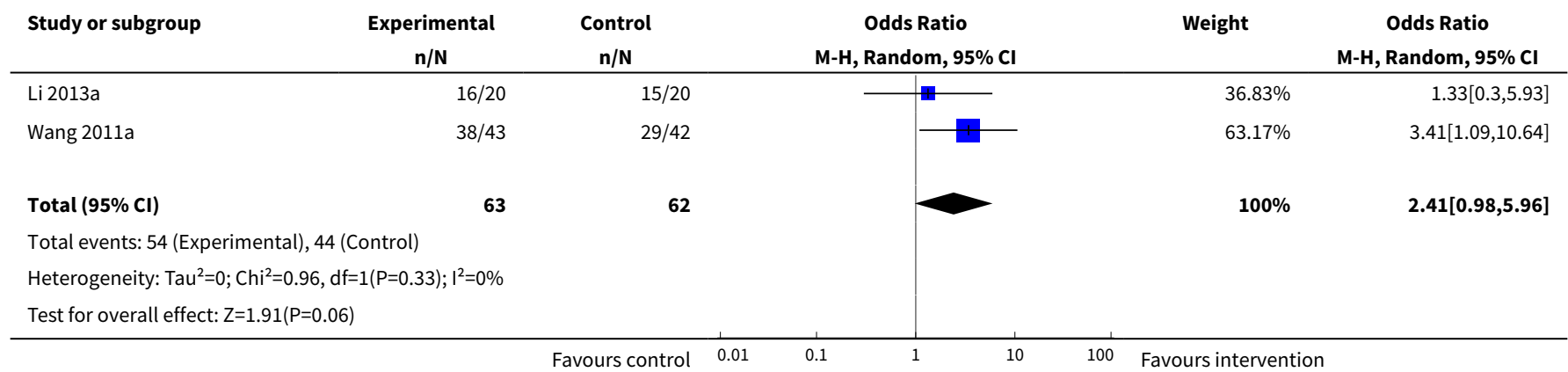

Analysis 2.9. Comparison 2 Acupuncture plus baseline treatment versus baseline treatment alone, Outcome 9 Improvement of cognitive function at the end of treatment.

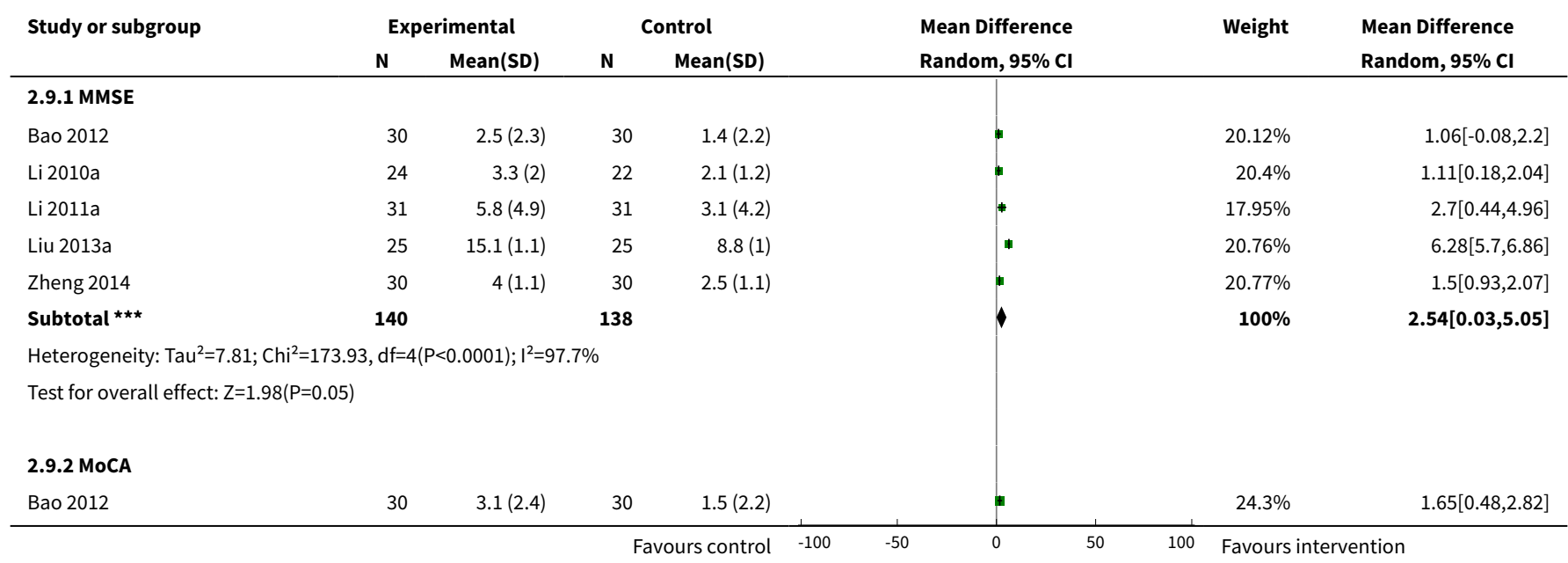




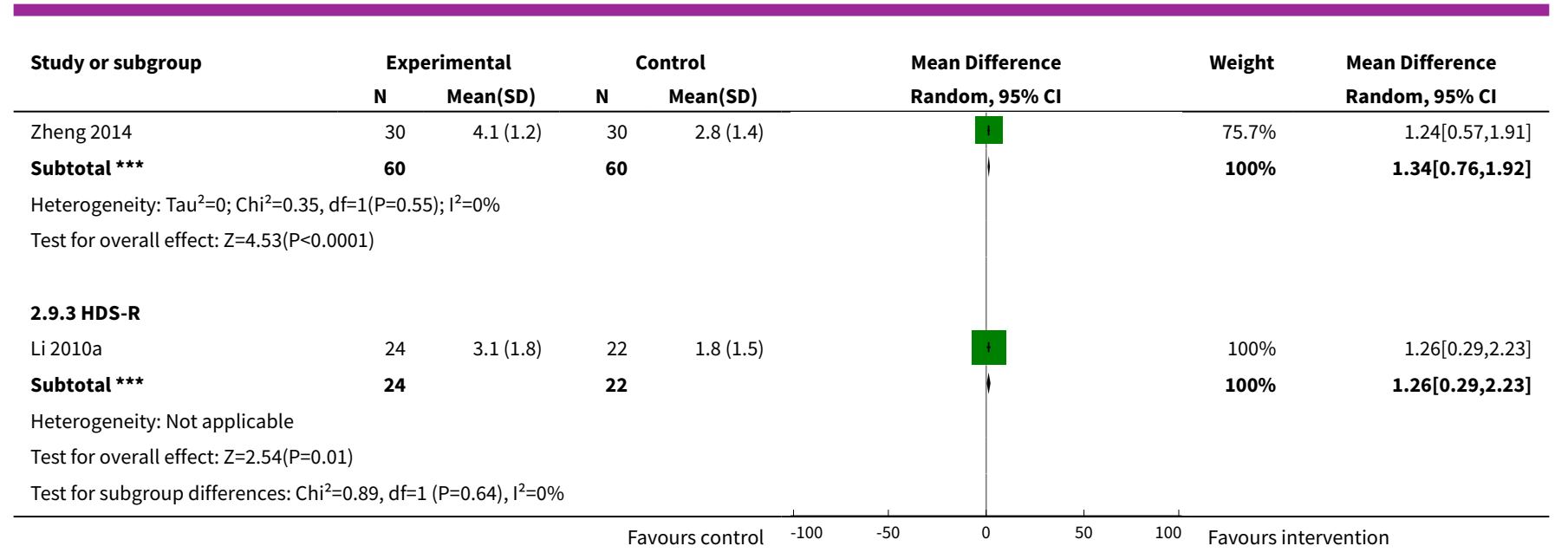

\section{Analysis 2.10. Comparison 2 Acupuncture plus baseline treatment versus baseline treatment} alone, Outcome 10 Improvment of cognitive function at the end of follow-up (MMSE).

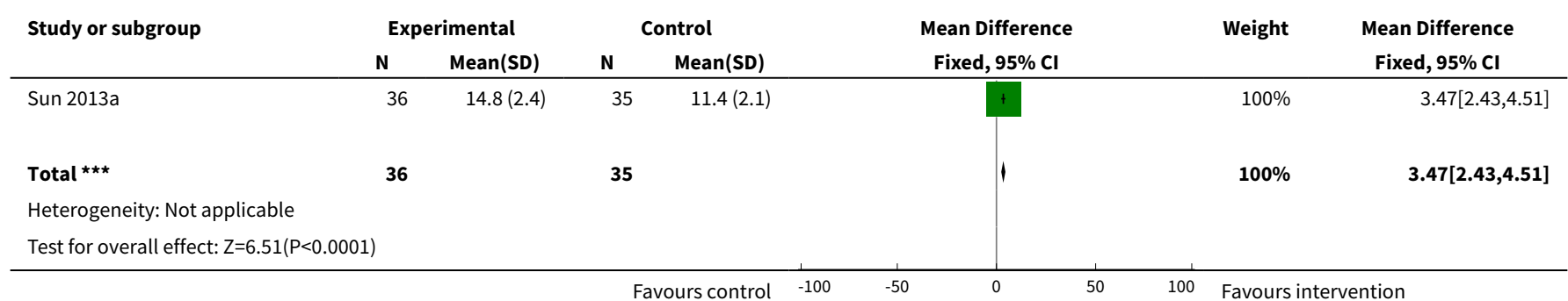

Analysis 2.11. Comparison 2 Acupuncture plus baseline treatment versus baseline treatment alone, Outcome 11 Improvement of cognitive function at the end of treatment.

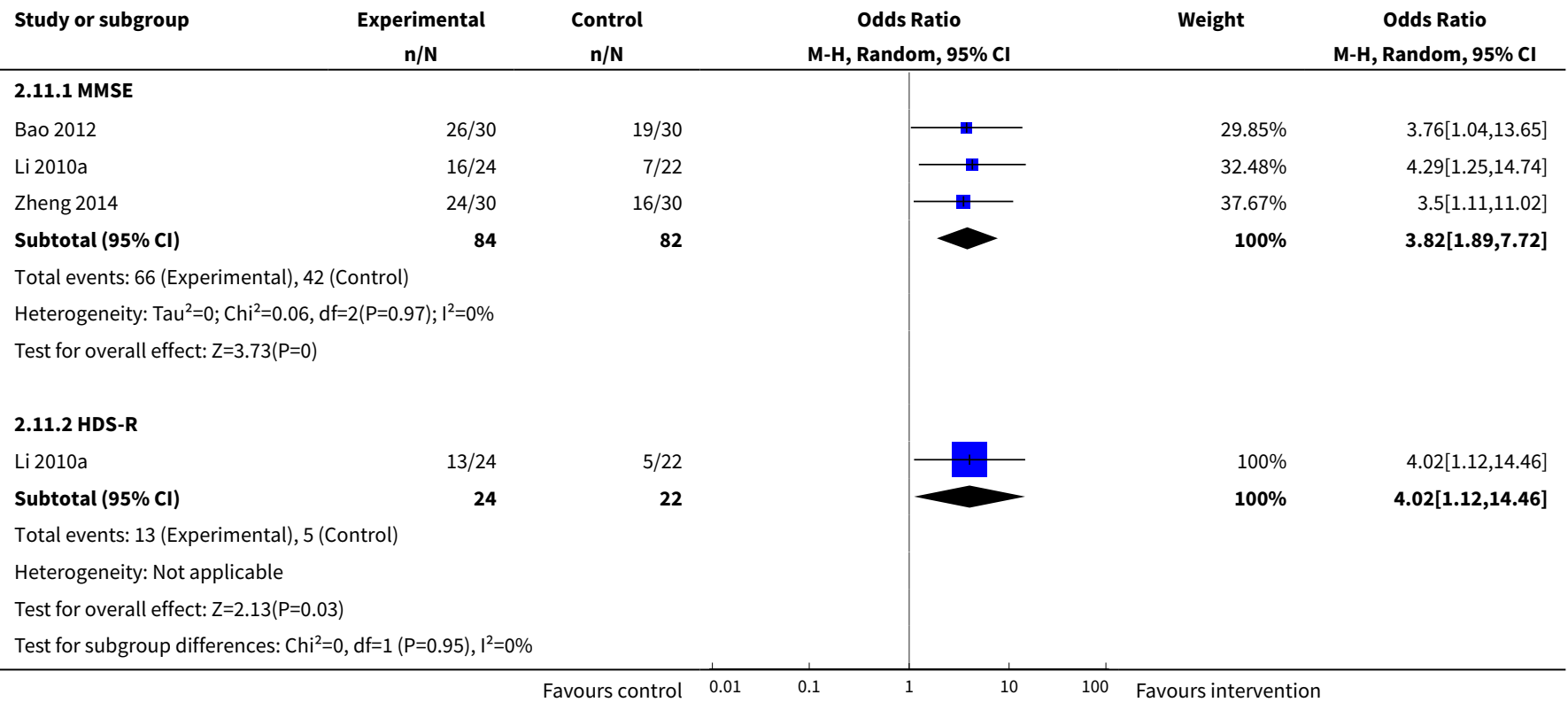


Analysis 2.12. Comparison 2 Acupuncture plus baseline treatment versus baseline treatment alone, Outcome 12 Improvement of depression at the end of treatment.

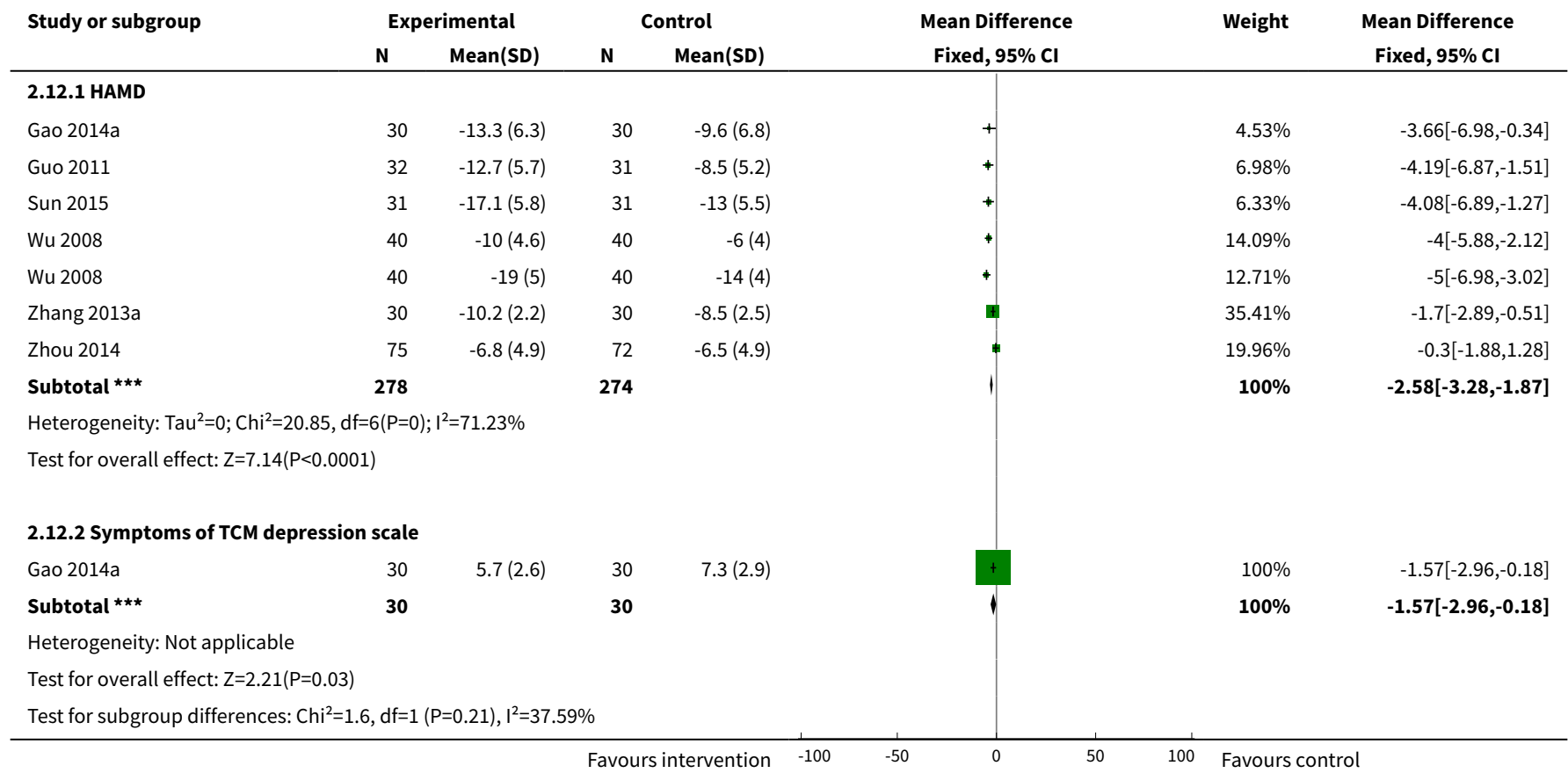

Analysis 2.13. Comparison 2 Acupuncture plus baseline treatment versus baseline treatment alone, Outcome 13 Improvement of depression at the end of treatment (HAMD).

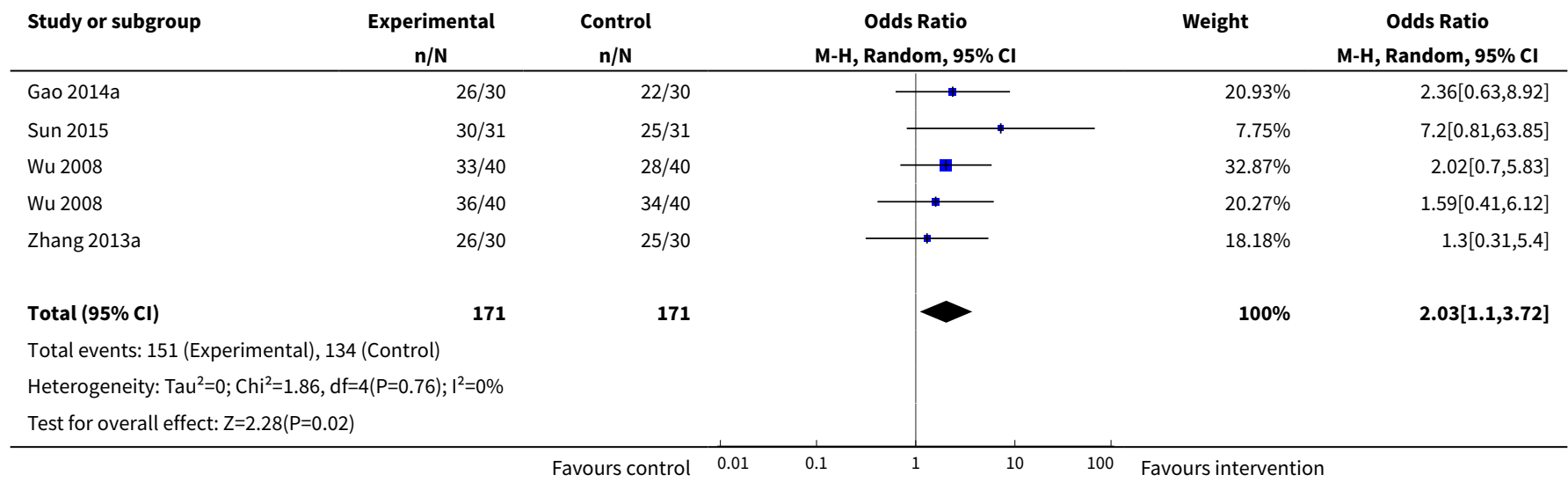


Analysis 2.14. Comparison 2 Acupuncture plus baseline treatment versus baseline treatment alone, Outcome 14 Improvement of swallowing function at the end of treatment (Water drinking test).

\begin{tabular}{|c|c|c|c|c|c|c|c|}
\hline \multirow[t]{2}{*}{ Study or subgroup } & \multicolumn{2}{|c|}{ Experimental } & \multicolumn{2}{|c|}{ Control } & \multirow{2}{*}{$\begin{array}{l}\text { Mean Difference } \\
\text { Random, } 95 \% \mathrm{Cl}\end{array}$} & \multirow[t]{2}{*}{ Weight } & \multirow{2}{*}{$\begin{array}{l}\text { Mean Difference } \\
\text { Random, } 95 \% \mathrm{Cl}\end{array}$} \\
\hline & $\mathbf{N}$ & $\operatorname{Mean}(S D)$ & $\mathbf{N}$ & Mean(SD) & & & \\
\hline Wu 2013a & 30 & $-2.2(0.7)$ & 30 & $-1.6(0.7)$ & $\frac{1}{1}$ & $48.61 \%$ & $-0.6[-0.96,-0.24]$ \\
\hline Xu 2013 & 70 & $-3(0.4)$ & 70 & $-1.5(0.6)$ & 1 & $51.39 \%$ & $-1.59[-1.75,-1.43]$ \\
\hline 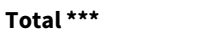 & 100 & & 100 & & 1 & $100 \%$ & $-1.11[-2.08,-0.14]$ \\
\hline \multicolumn{8}{|c|}{ Heterogeneity: $\operatorname{Tau}^{2}=0.47 ; \mathrm{Chi}^{2}=23.99, \mathrm{df}=1(\mathrm{P}<0.0001) ; \mathrm{I}^{2}=95.83 \%$} \\
\hline
\end{tabular}

Analysis 2.15. Comparison 2 Acupuncture plus baseline treatment versus baseline treatment alone, Outcome 15 Improvement of swallowing function at the end of treatment (Water drinking test).

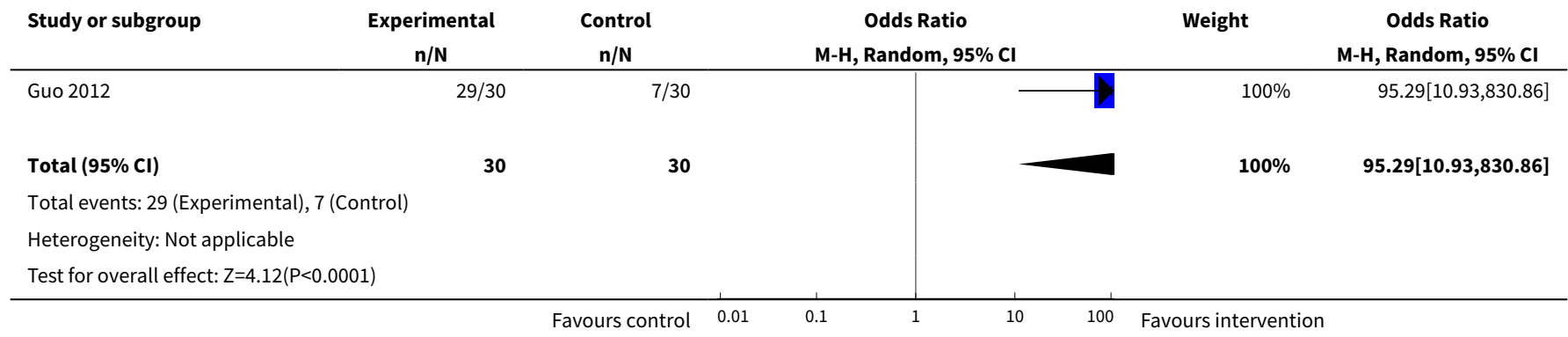

Analysis 2.16. Comparison 2 Acupuncture plus baseline treatment versus baseline treatment alone, Outcome 16 Improvement of pain at the end of treatment (Visual Analogue Scale).

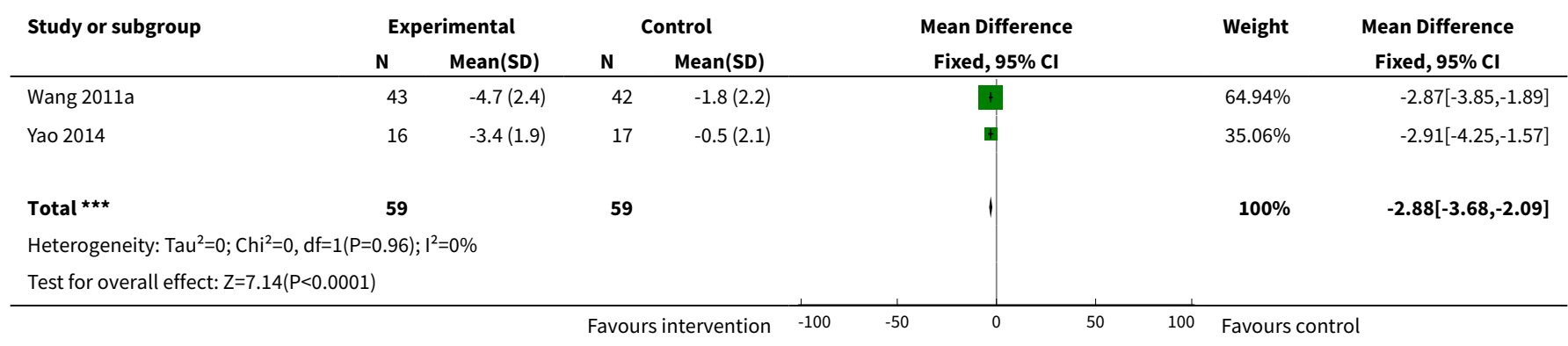

Analysis 2.17. Comparison 2 Acupuncture plus baseline treatment versus baseline treatment alone, Outcome 17 Improvement of sleep quality at the end of treatment (Rhone Planck Sleepiness Scale).

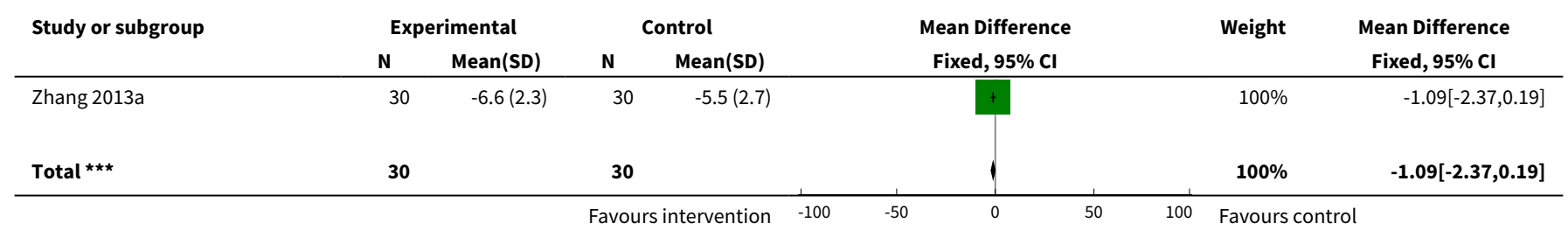




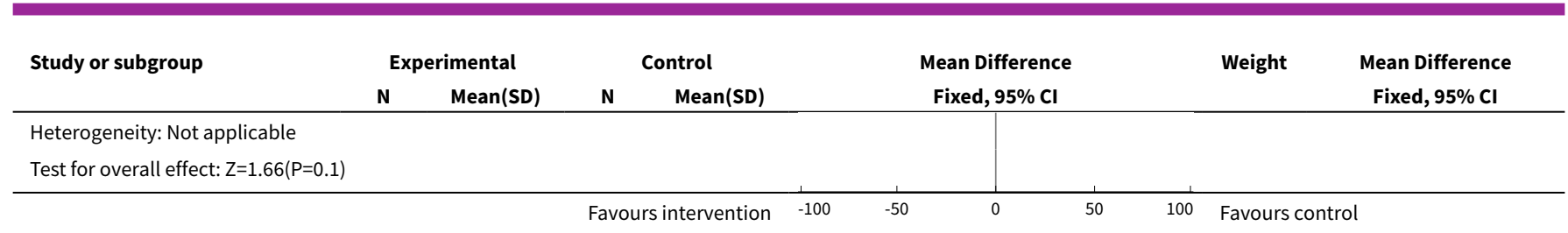

Analysis 2.18. Comparison 2 Acupuncture plus baseline treatment versus baseline treatment alone, Outcome 18 Improvement of spasticity at the end of treatment (Modified Ashworth Spasticity Rating Scale).

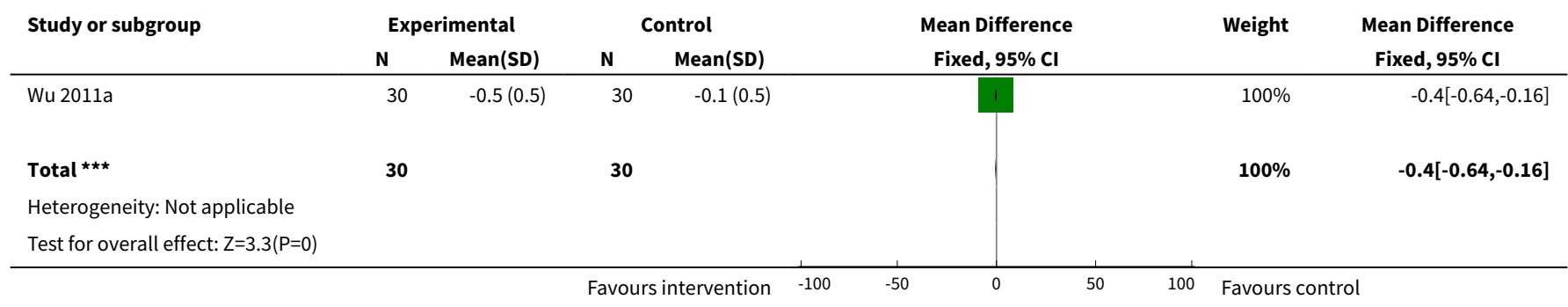

Analysis 2.19. Comparison 2 Acupuncture plus baseline treatment versus baseline treatment alone, Outcome 19 Improvement of quality of life at the end of treatment (MOS SF-36).

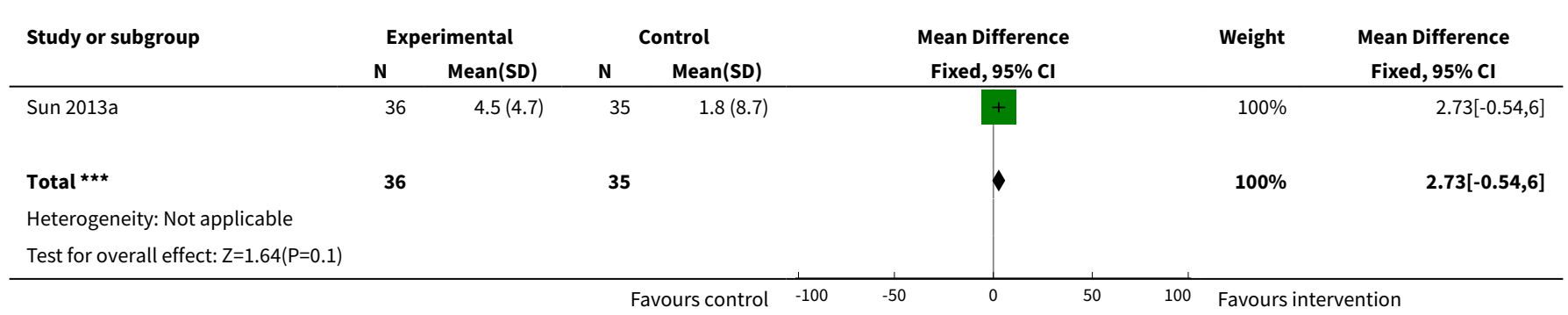

\section{AP PEN DICES}

\section{Appendix 1. Cochrane Stroke Group Trials Register search strategy}

Stage: Late treatment ( $>30$ days)

Disease: Not specified

Condition: Not specified

Intervention type: Complementary medical therapy

Intervention code: Acupuncture

\section{Appendix 2. CENTRAL search strategy}

The Cochrane Library, June 2015

\#1 [mh $\wedge^{\wedge}$ "cerebrovascular disorders"] or [mh "basal ganglia cerebrovascular disease"] or [mh "brain ischemia"] or [mh "carotid artery diseases"] or [mh "cerebral small vessel diseases"] or [mh "intracranial arterial diseases"] or [mh "intracranial embolism and thrombosis"] 
or [mh "intracranial hemorrhages"] or [mh^^stroke] or [mh "brain infarction"] or [mh^"stroke, lacunar"] or [mh^"vasospasm, intracranial"] or [mh ^"vertebral artery dissection"]

\#2 (stroke or poststroke or "post-stroke" or cerebrovasc* or brain next vasc* or cerebral next vasc* or cva* or apoplex* or SAH):ti,ab \#3 ((brain* or cerebr ${ }^{\star}$ or cerebell ${ }^{\star}$ or intracran* or intracerebral) near/5 (isch*emi* or infarct* or thrombo* or emboli* or occlus $\left.\left.{ }^{\star}\right)\right): t i, a b$ \#4 ((brain* or cerebr $^{\star}$ or cerebell ${ }^{*}$ or intracerebral or intracranial or subarachnoid) near/5 (haemorrhage* or hemorrhage $^{\star}$ or haematoma* $^{*}$ or hematoma* or bleed $\left.\left.{ }^{\star}\right)\right):$ ti,ab

\#5 [mh ^ hemiplegia] or [mh^^paresis]

\#6 (hemipleg* or hemipar* or paresis or paretic):ti,ab

\#7 [mh^"brain injuries"] or [mh^"brain injury, chronic"]

\#8 \#1 or \#2 or \#3 or \#4 or \#5 or \#6 or \#7

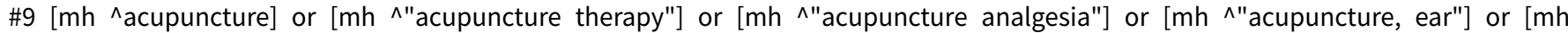
^electroacupuncture] or [mh ${ }^{\wedge}$ meridians] or [mh^"acupuncture points"] or [mh ${ }^{\wedge}$ "trigger points"]

\#10 (acupuncture* or electroacupuncture or "electro-acupuncture" or acupoint* or meridians or needling):ti,ab

\#11 ((meridian or non-meridian or trigger) near/10 point $\left.{ }^{\star}\right): t i, a b$

$\# 12 \# 9$ or \#10 or \#11

$\# 13 \# 8$ and \#12

\section{Appendix 3. MEDLINE search strategy}

MEDLINE (Ovid) November 2005 to July 2015

1. cerebrovascular disorders/ or exp basal ganglia cerebrovascular disease/ or exp brain ischemia/ or exp carotid artery diseases/ or exp cerebral small vessel diseases/ or exp intracranial arterial diseases/or exp "intracranial embolism and thrombosis"/ or exp intracranial hemorrhages/ or stroke/ or exp brain infarction/ or stroke, lacunar/ or vasospasm, intracranial/ or vertebral artery dissection/

2. (stroke or poststroke or post-stroke or cerebrovasc\$ or brain vasc\$ or cerebral vasc\$ or cva\$ or apoplex\$ or SAH).tw.

3. ((brain\$ or cerebr\$ or cerebell\$ or intracran\$ or intracerebral) adj5 (isch?emi\$ or infarct\$ or thrombo\$ or emboli\$ or occlus\$)).tw.

4. ((brain\$ or cerebr\$ or cerebell\$ or intracerebral or intracranial or subarachnoid) adj5 (haemorrhage\$ or hemorrhage\$ or haematoma\$ or hematoma\$ or bleed\$)).tw.

5. hemiplegia/ or exp paresis/

6. (hemipleg\$ or hemipar\$ or paresis or paretic).tw.

7. brain injuries/ or brain injury, chronic/

8. or/1-7

9. acupuncture/ or acupuncture therapy/ or acupuncture analgesia/ or acupuncture, ear/ or electroacupuncture/ or meridians/ or acupuncture points/ or trigger points/

10. (acupuncture\$ or electroacupuncture or electro-acupuncture or acupoint\$ or meridians or needling).tw.

11. ((meridian or non-meridian or trigger) adj10 point\$).tw.

12.9 or 10 or 11

13. 8 and 12

14. Randomized Controlled Trials as Topic/

15. random allocation/

16. Controlled Clinical Trials as Topic/ 


\section{7. control groups/}

18. clinical trials as topic/ or clinical trials, phase i as topic/ or clinical trials, phase ii as topic/ or clinical trials, phase iii as topic/ or clinical trials, phase iv as topic/

19. double-blind method/

20. single-blind method/

21. Placebos/

22. placebo effect/

23. cross-over studies/

24. randomized controlled trial.pt.

25. controlled clinical trial.pt.

26. (clinical trial or clinical trial phase i or clinical trial phase ii or clinical trial phase iii or clinical trial phase iv).pt.

27. (random\$ or RCT or RCTs).tw.

28. (controlled adj5 (trial\$ or stud\$)).tw.

29. (clinical\$ adj5 trial\$).tw.

30. ((control or treatment or experiment\$ or intervention) adj5 (group\$ or subject\$ or patient\$)).tw.

31. (quasi-random\$ or quasi random\$ or pseudo-random $\$$ or pseudo random\$).tw.

32. ((control or experiment\$ or conservative) adj5 (treatment or therapy or procedure or manage\$)).tw.

33. ((singl\$ or doubl\$ or tripl\$ or trebl\$) adj5 (blind\$ or mask\$)).tw.

34. (cross-over or cross over or crossover).tw.

35. (placebo $\$$ or sham).tw.

36. trial.ti.

37. (assign\$ or allocat\$).tw.

38. controls.tw.

39. or/14-38

40. 13 and 39

41. exp animals/ not humans/

42. 40 not 41

\section{Appendix 4. EMBASE search strategy}

EMBASE (Ovid) November 2005 to July 2015

1. cerebrovascular disease/ or exp basal ganglion hemorrhage/ or exp brain hematoma/ or exp brain hemorrhage/ or exp brain infarction/or exp brain ischemia/ or exp carotid artery disease/ or cerebral artery disease/ or exp cerebrovascular accident/ or exp intracranial aneurysm/ or exp occlusive cerebrovascular disease/ or stroke unit/ or stroke patient/

2. (stroke or poststroke or post-stroke or cerebrovasc\$ or brain vasc\$ or cerebral vasc\$ or cva $\$$ or apoplex\$ or SAH).tw.

3. ((brain\$ or cerebr\$ or cerebell\$ or intracran\$ or intracerebral) adj5 (isch?emi\$ or infarct\$ or thrombo\$ or emboli\$ or occlus\$)).tw.

4. ((brain\$ or cerebr\$ or cerebell\$ or intracerebral or intracranial or subarachnoid) adj5 (haemorrhage\$ or hemorrhage\$ or haematoma\$ or hematoma\$ or bleed\$)).tw.

5. hemiparesis/ or hemiplegia/ or paresis/ 
6. (hemipleg\$ or hemipar\$ or paresis or paretic).tw.

7. brain injury/ or acquired brain injury/

8. or/1-7

9. acupuncture/ or acupuncture analgesia/ or electroacupuncture/ or acupuncture needle/

10. (acupuncture $\$$ or electroacupuncture or electro-acupuncture or acupoint $\$$ or meridians or needling).tw.

11. ((meridian or non-meridian or trigger) adj10 point\$).tw.

12.9 or 10 or 11

13. 8 and 12

14. Randomized Controlled Trial/ or "randomized controlled trial (topic)"/

15. Randomization/

16. Controlled clinical trial/ or "controlled clinical trial (topic)"/

17. control group/ or controlled study/

18. clinical trial/ or "clinical trial (topic)"/ or phase 1 clinical trial/ or phase 2 clinical trial/ or phase 3 clinical trial/ or phase 4 clinical trial/

19. Crossover Procedure/

20. Double Blind Procedure/

21. Single Blind Procedure/ or triple blind procedure/

22. placebo/ or placebo effect/

23. (random\$ or RCT or RCTs).tw.

24. (controlled adj5 (trial\$ or stud\$)).tw.

25. (clinical\$ adj5 trial\$).tw.

26. ((control or treatment or experiment\$ or intervention) adj5 (group\$ or subject\$ or patient\$)).tw.

27. (quasi-random $\$$ or quasi random\$ or pseudo-random $\$$ or pseudo random\$).tw.

28. ((control or experiment\$ or conservative) adj5 (treatment or therapy or procedure or manage\$)).tw.

29. ((singl\$ or doubl\$ or tripl\$ or trebl\$) adj5 (blind\$ or mask\$)).tw.

30. (cross-over or cross over or crossover).tw.

31. (placebo $\$$ or sham).tw.

32. trial.ti.

33. (assign\$ or allocat\$).tw.

34. controls.tw.

35. or/14-34

36. 13 and 35

37. (exp animals/ or exp invertebrate/ or animal experiment/ or animal model/ or animal tissue/ or animal cell/ or nonhuman/) not (human/ or normal human/ or human cell/)

38. 36 not 37 


\section{Appendix 5. CINAHL search strategy}

CINAHL (EBSCO) November 2005 to July 2015

S1 -(MH "Cerebrovascular Disorders") OR (MH "Basal Ganglia Cerebrovascular Disease+") OR (MH "Carotid Artery Diseases+") OR (MH "Cerebral Ischemia+") OR (MH "Cerebral Vasospasm") OR (MH "Intracranial Arterial Diseases+") OR (MH "Intracranial Embolism and Thrombosis") OR (MH "Intracranial Hemorrhage+") OR (MH "Stroke") OR (MH "Vertebral Artery Dissections")

\section{S2 -(MH "Stroke Patients") OR (MH "Stroke Units")}

S3 - $\mathrm{TI}$ ( stroke* or poststroke or apoplex* or cerebral vasc* or brain vasc* or cerebrovasc* or cva* or SAH ) or AB ( stroke* or poststroke or apoplex* or cerebral vasc ${ }^{\star}$ or brain vasc ${ }^{\star}$ or cerebrovasc ${ }^{\star}$ or $\mathrm{Cva}^{\star}$ or $\mathrm{SAH}$ )

S4 -TI ( brain or cerebr ${ }^{\star}$ or cerebell* or intracran* or intracerebral) or AB ( brain or cerebr* or cerebell* or intracran* or intracerebral)

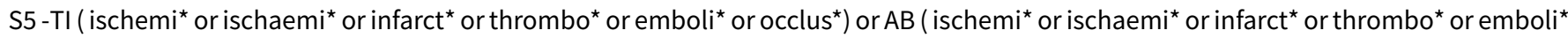
or occlus $)$

\section{S6 -S4 and S5}

$\mathrm{S} 7$ - $\mathrm{TI}$ ( brain* or cerebr* or cerebell* or intracerebral or intracran* or subarachnoid ) or AB ( brain* or cerebr* or cerebell* or intracerebral or intracran* or subarachnoid)

S8 -TI ( haemorrhage* or hemorrhage* or haematoma* or hematoma* or bleed ${ }^{\star}$ ) or AB ( haemorrhage* or hemorrhage* or haematoma* or hematoma* or bleed*)

\section{S9 -S7 and S8}

\section{S10 -(MH "Hemiplegia")}

S11 -TI ( hemipleg* or hemipar* or paresis or paretic ) or AB ( hemipleg* or hemipar* or paresis or paretic)

S12 -(MH "Brain Injuries")

\section{S13 -S1 OR S2 OR S3 OR S6 OR S9 OR S10 OR S11 OR S12}

S14 -(MH "Acupuncture") OR (MH "Acupuncture Analgesia") OR (MH "Acupuncture Anesthesia") OR (MH "Acupuncture, Ear") OR (MH "Electroacupuncture") OR (MH "Meridians") OR (MH "Acupuncture Points") OR (MH "Acupuncturists") OR (MH "Trigger Point")

S15 -TI (acupuncture* or electroacupuncture or electro-acupuncture or acupoint* or meridians or needling) OR AB (acupuncture* or electroacupuncture or electro-acupuncture or acupoint ${ }^{\star}$ or meridians or needling)

S16 -TI ((meridian or non-meridian or trigger) N10 point ${ }^{\star}$ ) or AB ((meridian or non-meridian or trigger) N10 point $\left.{ }^{\star}\right)$

\section{S17 -S14 OR S15 OR S16}

\section{S18 -S13 AND S17}

\section{Appendix 6. AMED search strategy}

AMED (Ovid) November 2005 to July 2015

1. cerebrovascular disorders/ or cerebral hemorrhage/ or cerebral infarction/ or cerebral ischemia/ or cerebrovascular accident/ or stroke/

2. (stroke or poststroke or post-stroke or cerebrovasc\$ or brain vasc\$ or cerebral vasc\$ or cva\$ or apoplex\$ or SAH).tw.

3. ((brain\$ or cerebr\$ or cerebell\$ or intracran\$ or intracerebral) adj5 (isch?emi\$ or infarct\$ or thrombo\$ or emboli\$ or occlus\$)).tw.

4. ((brain\$ or cerebr\$ or cerebell\$ or intracerebral or intracranial or subarachnoid) adj5 (haemorrhage\$ or hemorrhage\$ or haematoma\$ or hematoma\$ or bleed\$)).tw.

5. hemiplegia/

6. (hemipleg\$ or hemipar\$ or paresis or paretic).tw.

7. brain injuries/

8. or/1-7 
9. acupuncture/ or acupuncture therapy/ or acupoints/ or neiguan/ or acupuncture analgesia/ or ear acupuncture/ or electroacupuncture/ or meridians/ or needling/ or scalp acupuncture/

10. (acupuncture or electroacupuncture or electro-acupuncture or acupoint\$ or meridians or needling).tw.

11. ((meridian or non-meridian or trigger) adj10 point\$).tw.

12. 9 or 10 or 11

13. 8 and 12

\section{Appendix 7. CBM search strategy}

\#1 中风

\#2 卒中

\#3 脑血管

\#4 脑 ${ }^{*}$ 塞

\#5 脑 ${ }^{*}$ 血

\#6脑 ${ }^{*}$ 栓

$\# 7$ 蛛网膜下腔出血

\#8 主题词="中风/全部副主题/全部树"

\#9 主题词="脑血管意外/全部副主题/全部树"

\#10 主题词="垂体卒中/全部副主题"

\#11 主题词="梗塞, 大脑中动脉/全部副主题"

\#12 主题词="梗塞, 大脑前动脉/全部副主题"

\#13 主题词="梗塞, 大脑后动脉/全部副主题"

\#14 主题词= "中风后遗症/全部副主题"

\#15 主题词= "中风先兆症/全部副主题"

\#16 主题词=="蛛网膜下腔出血/全部副主题/全部树"

$\# 17 \# 1$ or \#2 or \#3 or \#4 or \#5 or \#6 or \#8 or \#9 or \#10 or \#11 or \#12 or \#13 or \#14 or \#15

\#18 随机

\#19 盲法

\#20 单盲

\#21 双盲

\#22三盲

\#23 安慰剂

\#24 主题词="随机对照试验 [文献类型]"

\#25 主题词="随机分配"

\#26 主题词="随机对照试验/全部副主题"

\#27 \#18 or \#19 or \#20 or \#21 or \#22 or \#23 or \#24 or \#25 or \#26

\#28 针 
\#29 电针

\#30 长针

\#31 芒针

\#32 皮下针

\#33 火针

\#34 头针

\#35 手捻针

\#36 巨针

\#37 头皮针

\#38 体针

\#39 温针

\#40 透刺

\#41 巨刺

\#42 针法

\#43 刺法

\#44 眼针

\#45 磁极针

\#46 毫针

\#47 谬刺

\#48 皮内针

\#49 鑱针

\#50 园针

\#51 鍉针

\#52 锋针

\#53 铍针

\#54 圆利针

\#55 大针

$\# 56 \# 28$ or \#29 or \#30 or \#31 or \#32 or \#33 or \#34 or \#35 or \#36 or \#37 or \#38 or \#39 or \#40 or \#41 or \#42 or \#43 or \#44 or \#45 or \#46 or \#47 or \#48 or \#49 or \#50 or \#51 or \#52 or \#52 or \#53 or \#54 or \#55

\section{Appendix 8. CNKI search strategy}

(主题=中风 $O R$ 主题=卒中 $O R$ 主题=脑血管 $O R$ 主题=脑梗塞 $O R$ 主题=脑梗死 $O R$ 主题=脑血栓 $O R$ 主题=脑栓塞 $O R$ 主题=脑出血 $O R$ 主 题=脑溢血 OR 主题=蛛网膜下腔出血) AND (主题=随机 OR 主题=盲法 OR 主题=单盲 OR 主题=双盲 OR 主题=三盲 OR 主题=安慰剂) AND (主题=针炎 $O R$ 主题=针刺 $O R$ 主题=电针 $O R$ 主题=芒针 $O R$ 主题=皮下针 $O R$ 主题=火针 $O R$ 主题=头针 $O R$ 主题=手捻针 $O R$ 主题=针刀 $O R$ 主题=长针 $O R$ 主题=巨针 $O R$ 主题=头皮针 $O R$ 主题=体针 $O R$ 主题=温针 $O R$ 主题=透刺 $O R$ 主题=巨刺 $O R$ 主题=针法 $O R$ 主题=刺法 $O R$ 主题=眼针 $O R$ 主题=磁极针 $O R$ 主题=毫针 $O R$ 主题=谬刺 $O R$ 主题=皮内针 $O R$ 主题=䤼针 $O R$ 主题=园针 $O R$ 主题=鍉针 $O R$ 主题=锋 针 OR 主题=铍针 OR 主题=圆利针 OR 主题=大针) 


\section{Appendix 9. VIP search strategy}

$(\mathrm{U}=$ 中风 $+\mathrm{U}=$ 卒中 $+\mathrm{U}=$ 脑血管 $+\mathrm{U}=$ 脑梗塞 $+\mathrm{U}=$ 脑梗死 $+\mathrm{U}=$ 脑血栓 $+\mathrm{U}=$ 脑栓塞 $+\mathrm{U}=$ 脑出血 $+\mathrm{U}=$ 脑溢血 $+\mathrm{U}=$ 蛛网膜下腔出血 $)$ * $(U=$ 随机 $+\mathrm{U}=$ 盲法 $+U=$ 安慰剂 $) \star(U=$ 针炎 $+U=$ 针刺 $+U=$ 电针 $+U=$ 针法 $+U=$ 刺法 $+U=$ 磁极针 $) \star$ 全部期刊 ${ }^{\star}$ 年 $=2005-2015$

\section{Appendix 10. Wanfang search strategy}

((中风 or 卒中 or 脑血管” or 脑梗 ${ }^{\star}$ or 脑“栓 or 脑栓” or 脑 ${ }^{\star}$ 血 or 蛛网膜下腔出血 $)$ and $(((($ ("随机") or ("盲法")) or ("单盲")) or ("双 盲")) or ("安慰剂" $)))$ and (((("针炎") or ("针法")) or ("针刺")) or ("电针")) and ("刺法") )

\section{Appendix 11. Risk of bias assessment tool}

\section{Potential source of bias \\ Random sequence genera- tion}

Selection bias (biased allocation to interventions) due to inadequate generation of a randomised sequence

\section{Assessment criteria}

Low risk of bias: Random number table; computer random number generator; coin tossing; shuffling cards or envelopes; throwing dice; drawing of lots; minimization (minimization may be implemented without a random element, and this is considered to be equivalent to being random).

High risk of bias: Sequence generated by odd or even date of birth; date (or day) of admission; sequence generated by hospital or clinic record number; allocation by judgement of the clinician; by preference of the participant; based on the results of a laboratory test or a series of tests; by availability of the intervention.

Unclear: Insufficient information about the sequence generation process to permit judgement.

\section{Allocation concealment}

Selection bias (biased allocation to interventions) due to inadequate concealment of allocations prior to assignment

Low risk of bias: Randomisation method described that would not allow investigator/participant to know or influence intervention group before eligible participant entered in the study (e.g. central allocation, including telephone, web-based, and pharmacy-controlled, randomisation; sequentially numbered drug containers of identical appearance; sequentially numbered, opaque, sealed envelopes).

High risk of bias: Using an open random allocation schedule (e.g. a list of random numbers); assignment envelopes were used without appropriate safeguards (e.g. if envelopes were unsealed or non-opaque or not sequentially numbered); alternation or rotation; date of birth; case record number; any other explicitly unconcealed procedure.

Unclear: Randomisation stated but no information on method used is available.

\section{Blinding of participants and personnel}

Performance bias due to knowledge of the allocated interventions by participants and personnel during the study
Low risk of bias: No blinding or incomplete blinding, but the review authors judge that the outcome is not likely to be influenced by lack of blinding; blinding of participants and key study personnel ensured, and unlikely that the blinding could have been broken.

High risk of bias: No blinding or incomplete blinding, and the outcome is likely to be influenced by lack of blinding; blinding of key study participants and personnel attempted, but likely that the blinding could have been broken, and the outcome is likely to be influenced by lack of blinding.

\section{Blinding of outcome assess- ment}

Detection bias due to knowledge of the allocated interventions by outcome assessors.
Unclear: Insufficient information to permit judgement

Low risk of bias: No blinding of outcome assessment, but the review authors judge that the outcome measurement is not likely to be influenced by lack of blinding; blinding of outcome assessment ensured, and unlikely that the blinding could have been broken.

High risk of bias: No blinding of outcome assessment, and the outcome measurement is likely to be influenced by lack of blinding; blinding of outcome assessment, but likely that the blinding could have been broken, and the outcome measurement is likely to be influenced by lack of blinding.

Unclear: Insufficient information to permit judgement 
(Continued)

\section{Incomplete outcome data}

Attrition bias due to amount, nature or handling of incomplete outcome data.
Low risk of bias: No missing outcome data; reasons for missing outcome data unlikely to be related to true outcome (for survival data, censoring unlikely to be introducing bias); missing outcome data balanced in numbers across intervention groups, with similar reasons for missing data across groups; for dichotomous outcome data, the proportion of missing outcomes compared with observed event risk not enough to have a clinically relevant impact on the intervention effect estimate; for continuous outcome data, plausible effect size (difference in means or standardized difference in means) among missing outcomes not enough to have a clinically relevant impact on observed effect size; missing data have been imputed using appropriate methods.

High risk of bias: Reason for missing outcome data likely to be related to true outcome, with either imbalance in numbers or reasons for missing data across intervention groups; for dichotomous outcome data, the proportion of missing outcomes compared with observed event risk enough to induce clinically relevant bias in intervention effect estimate; for continuous outcome data, plausible effect size (difference in means or standardized difference in means) among missing outcomes enough to induce clinically relevant bias in observed effect size; 'as-treated' analysis done with substantial departure of the intervention received from that assigned at randomisation; potentially inappropriate application of simple imputation.

Unclear: Insufficient information to permit judgement

\section{Selective reporting}

Reporting bias due to selective outcome reporting
Low risk of bias: The study protocol is available and all of the study's pre-specified (primary and secondary) outcomes that are of interest in the review have been reported in the pre-specified way; the study protocol is not available but it is clear that the published reports include all expected outcomes, including those that were pre-specified (convincing text of this nature may be uncommon).

High risk of bias: Not all of the study's pre-specified primary outcomes have been reported; one or more primary outcomes is reported using measurements, analysis methods or subsets of the data (e.g. subscales) that were not pre-specified; one or more reported primary outcomes were not prespecified (unless clear justification for their reporting is provided, such as an unexpected adverse effect); one or more outcomes of interest in the review are reported incompletely so that they cannot be entered in a meta-analysis; the study report fails to include results for a key outcome that would be expected to have been reported for such a study.

Unclear: Insufficient information to permit judgement

\section{Other bias}

Bias due to problems not covered elsewhere in the table
Low risk of bias: The study appears to be free of other sources of bias.

High risk of bias: Had a potential source of bias related to the specific study design used; stopped early due to some data-dependent process (including a formal-stopping rule); had extreme baseline imbalance; has been claimed to have been fraudulent; had some other problem.

Unclear: Insufficient information to assess whether an important risk of bias exists; insufficient rationale or evidence that an identified problem will introduce bias.

\section{WHAT'S NEW}

\begin{tabular}{lll}
\hline Date & Event & Description \\
\hline 12 January 2016 & $\begin{array}{l}\text { New citation required but conclusions } \\
\text { have not changed }\end{array}$ & $\begin{array}{l}\text { Compared with the 2006 version of this review, a substantial } \\
\text { amount of new information has been included, but there is no } \\
\text { change to the main conclusions in this updated review. }\end{array}$ \\
\hline 12 January 2016 & New search has been performed & $\begin{array}{l}\text { We have updated the searches to July 2015. We included 26 new } \\
\text { trials (1889 participants) in this version. There are now } 31 \text { trials, } \\
\text { with 2257 participants, included in this updated review. }\end{array}$ \\
\hline
\end{tabular}




\section{HISTORY}

Protocol first published: Issue 2, 2003

Review first published: Issue 3, 2006

\begin{tabular}{lll}
\hline Date & Event & Description \\
\hline 20 October 2008 & Amended & Contact details updated \\
\hline 15 July 2008 & Amended & Converted to new review format. \\
\hline
\end{tabular}

\section{CONTRIBUTIONS OFAUTHORS}

Wu HM: developing the search strategy, assessment of studies, data extraction, data entry, data analysis, writing of protocol and review. Yang A: developing the search strategy, assessment of studies, data extraction, data entry, data analysis, writing of review.

Tang JL: data analysis, resolution of disagreements, writing protocol and review.

Xu Li: assessment of studies, data extraction, data entry, suggestions and corrections.

Yang M: data extraction, suggestions and corrections.

Liu GJ: data analysis, suggestions and corrections.

\section{DECLARATIONS OF INTEREST}

Ai Yang: none known.

Hong Mei Wu: none known.

Jin-Ling Tang: none known.

Li Xu: none known.

Ming Yang: none known.

Guan J Liu: none known.

\section{SOURCES OF SUPPORT}

\section{Internal sources}

- Hong Kong Branch of Chinese Cochrane Center, China.

- Department of Community \& Family Medicine, Chinese University of Hong Kong, China.

- Chinese Cochrane Center, West China Hospital, Si Chuan University, China.

\section{External sources}

- Hong Kong Croucher Foundation, China.

\section{N DEX TERMS}

\section{Medical Subject Headings (MeSH)}

*Acupuncture Therapy; *Stroke Rehabilitation; Activities of Daily Living; Convalescence; Randomized Controlled Trials as Topic

\section{MeSH check words}

Humans 